\title{
Metaphors of Reading: Cognition and Embodiment in Contemporary Metafiction
}

Amanda L. Bailey

Follow this and additional works at: https://researchrepository.wvu.edu/etd

\section{Recommended Citation}

Bailey, Amanda L., "Metaphors of Reading: Cognition and Embodiment in Contemporary Metafiction" (2017). Graduate Theses, Dissertations, and Problem Reports. 5142.

https://researchrepository.wvu.edu/etd/5142

This Dissertation is protected by copyright and/or related rights. It has been brought to you by the The Research Repository @ WVU with permission from the rights-holder(s). You are free to use this Dissertation in any way that is permitted by the copyright and related rights legislation that applies to your use. For other uses you must obtain permission from the rights-holder(s) directly, unless additional rights are indicated by a Creative Commons license in the record and/ or on the work itself. This Dissertation has been accepted for inclusion in WVU Graduate Theses, Dissertations, and Problem Reports collection by an authorized administrator of The Research Repository @ WVU.

For more information, please contact researchrepository@mail.wvu.edu. 


\title{
Metaphors of Reading: \\ Cognition and Embodiment in Contemporary Metafiction
}

\author{
Amanda L. Bailey \\ Dissertation submitted \\ to the Eberly College of Arts and Sciences \\ at West Virginia University \\ in partial fulfillment of the requirements for the degree of \\ Doctor of Philosophy \\ in English
}

Ryan Claycomb, Ph.D., chair

Lara Farina, Ph.D.

Kirk Hazen, Ph.D.

Lisa Weihman, Ph.D.

Vera Tobin, Ph.D.

Department of English

\section{Morgantown, West Virginia \\ 2017}

Keywords: reading, conceptual metaphor theory, sensory studies, cognitive approaches to literature, metafiction

Copyright 2017 Amanda L. Bailey 


\title{
ABSTRACT \\ Metaphors of Reading: Cognition and Embodiment in Contemporary Metafiction
}

\author{
Amanda L. Bailey
}

This project brings together methodologies from sensory and cognitive approaches to literature to posit that Conceptual Metaphors of Readings mediate the experience of readers with fiction and provide an organizing framework for scholars and readers alike to consider the diverse sensory and cognitive phenomena that are used to describe the experience of reading. These conceptual metaphors are culturally and historically developed and can be used in combination with each other by authors to achieve desired effects on readers; however, there are clear patterns in metaphor blends. I demonstrate the robustness of this framework by analyzing metafictional readers, scenes of reading, and reader/writer relationships within nine metafictional novels of the modern, postmodern, and contemporary periods. In particular, I locate the figure of the metafictional reader in works of fiction as a cipher through which the actual reader presses and exerts herself and her reading practices in configuring her own experience of a text. Due to the sophisticated interplay of convention and novelty at work, the metafictional reader should be understood as an embodied metaphor of reading in which the author explores, with the actual reader in tow, an original conception of reading through a familiar configuration: the reading self. Although many metaphors of reading exist and have existed throughout literary history, in this project, I examine six that are especially relevant in contemporary works: (1) reading as an encounter with sensory bodies, (2) reading as journey, (3) reading as sexual intercourse, (4) reading as contact with the past, (5) reading as performance, and (6) reading as an encounter with nature. I organize these readings and combinations of metaphors according to four popularly touted abstract understandings of why readers read: (1) Reading as Connection, (2) Reading as Challenge, (3) Reading as Pursuit, and (4) Reading as Escape. 


\section{Contents}

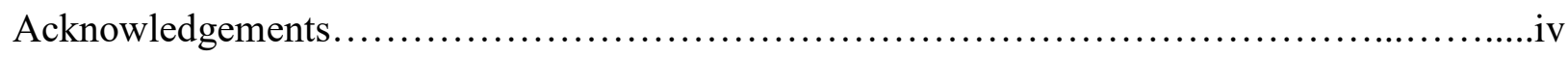

Introduction................................................................

Chapter 1: Embodied Metaphors of Reading.......................................33-72

Chapter 2: Reading as Connection............................................ $73-124$

Chapter 3: Reading as Challenge...............................................125-179

Chapter 4: Reading as Pursuit............................................... 180-230

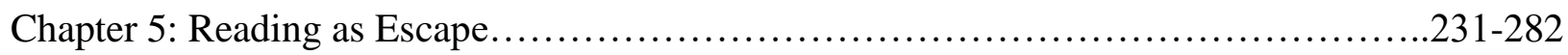

Coda: The future of embodied reading?.......................................................................283-295

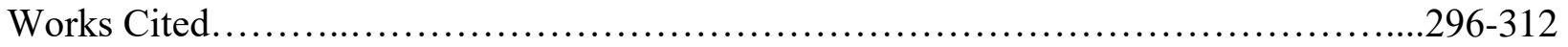

Appendix A: A sampling of contemporary experimental literature's visual aesthetics......313-315 


\section{Acknowledgements}

I would like to thank my dissertation committee and especially its director, Ryan Claycomb, for their enthusiastic support of an unorthodox project that took off in an uncertain direction but has landed, I sincerely hope, more or less on solid ground. Without their belief in my ability to sift through the massive copia that is the human experience of reading fiction, with frequent reminders to resist the urge to lose myself in the fecundity that burgeoned in and around each chapter, handing me the shears when necessary to cull and cut out some semblance of a pathway, this project would not have been possible. 


\section{INTRODUCTION}

\section{Thinking about Reading: Reading as (more than) Cognitive Activity}

If we think about the experience of reading fiction, we tend to dwell on the elements that connect it to cognitive functioning: consciousness, reason, word recognition, memory, and other cerebral exercises. This is not terribly surprising. After all, reading is a learned skill that takes time and mental energy to acquire, usually coinciding with the acquisition of other cognitive abilities developed in childhood such as sustained attentiveness, analysis of cause and effect, and Theory of Mind — that is, the recognition of mental states, intentions, desires, etc. within others. Reading is a skill that is tested repeatedly, constituting educational benchmarks, and is commonly associated with general intelligence, social acclimation, and even positive personality traits like empathy (Djikic et al. "Reading Other Minds"; Djikic et al. "On Being Moved by Art"; Kidd and Castano). All told, it is entirely rational and empirically satisfactory to conclude that reading is an activity of the mind, combining several cognitive functions and processes to create for the reader the experience of transportation—of being "lost in a good book." Further evidence of reading's cognitive nature is in the reader's necessity for limited physical interruptions and sensory stimulation while engaged in the act of reading. Absorption in fiction requires attentiveness and concentration which is easier to achieve with limitations of ambient and direct stimuli around the reading subject. Therefore, it would seem that as opposed to being a part of the act of reading, sensory experience and even awareness is arguably a hindrance to its successful achievement.

\footnotetext{
${ }^{1}$ As discussed in more detail in the following chapter, the popular use of the term "transportation" to describe the experience of reading is prevalent in both academic and lay evaluations of reading.
} 
A rejection of the body and especially its more proximate senses (touch, taste, and smell) in intellectual pursuits has a long history in Western culture, and the Cartesian mind-body split has been upheld without much disruption in our understanding of reading. This is in large part due to a continuing cultural emphasis on the greater significance of the mind in the formation and identity of the creative self — a process in which reading has long been seen to hold a crucial role. Famous quotes connecting reading with positive self-formation and self-enlargement by famous figures, who have themselves achieved greatness in connection to their valuing of reading, abound in our societal knowledge-pool: Oscar Wilde is supposed to have said, "It is what you read when you don't have to that determines what you will be when you can't help it"; attributed to Edward P. Morgan is the quote: "A book is the only place in which you can examine a fragile thought without breaking it, or explore an explosive idea without fear it will go off in your face. It is one of the few havens remaining where a man's mind can get both provocation and privacy"; and of course, Mark Twain's ever popular: "The man who does not read good books is at no advantage over the man that can't read them." Even if these and similar quotes are misattributed or reworded to better suit the modern age, the point is that they endure as tried and true proverbs about reading's importance to becoming a fully-cultured, fullyactualized individual. ${ }^{2}$ Psychologists such as Steven Pinker have even famously advocated the

\footnotetext{
${ }^{2}$ In my characterization of these quotes as "enduring" and "abounding," I refer to their ubiquity online and in physical settings (inscribed on the walls of libraries and bookstores, pinned up on offices of English grad students, etc.). A simple Google search of "quotes about reading" or "quotes about books" brings up thousands of one or two sentence axioms - many of which are repeated (more or less correctly) and reposted on blogs, websites, and social media profiles in which the writer presumably wishes to identify him or herself as someone who loves and appreciates reading. A small faction does appear concerned with the accuracy of these quotes' origins (see for example the wikiquotes discussion page for Oscar Wilde) with individuals asking for researched confirmation from others. Interestingly, misattributed quotes continue to circulate despite their being called out by other users (see for example, the "We read to know we are not alone" quote commonly but incorrectly ascribed to C.S. Lewis). The aesthetic appearance of the quote's display seems to have a great deal of impact on individuals' willingness to accept it as legitimate.
} 
idea that reading good books makes people "nicer" and capable of greater empathetic responses because, as he puts it, "reading is a technology for perspective taking," and from there it is only a short jump to altering one's convictions and feeling empathy for groups not previously identified with one's own (175). More recently, David Comer Kidd and Emanuele Castano's study linking literary fiction reading with an improved Theory of Mind (and as a result, empathy) took the internet by storm, leading to the proliferation of positive reviews, anecdotal support of their conclusions, and even shortened online versions of the "Mind in the Eyes" test utilized in the study. ${ }^{3}$

While there has been considerable critical contention regarding whether reading actually makes someone a better person (see Keen for a thorough review of the empathy-altruism hypothesis and related findings), recent studies have tentatively supported long upheld traditions correlating reading with positive social traits, such as empathy, and individuals' own self-reports of their personalities (Djikic et al. "On Being Moved by Art”; Oatley; Mar et al.). A resulting weak claim would be that even if reading does not actually make readers better people, it at least momentarily makes them think they are better people. Key to the implicit naturalness of these correlations is the assumption that personality and selfhood is mostly (if not entirely) cognitively determined, allowing its greatest influences to be equally cognitive activities. Studies and theorists of reading, including much of the Reader Response theorists prominent in the 60s and 70s, reflect this understanding with their focus on "the reader" as a brain connected to a reading eyeball-bodiless and collective. The reader's interaction with a text is a psychological one, they

\footnotetext{
${ }^{3}$ Due to the overwhelming online response, reports of this study were picked up by The Guardian (Bury), The New York Times (Belluck), Scientific American (Chiaet), and The New Yorker (Arons) among other news sources. The website Socially Mindful offered a "Mind in the Eyes" quiz link following the Kidd and Castano study (Bendycki DaSilva). Slate's Mark O'Connell responded to the hype in this way: "I felt that there was something oddly diminishing, and perhaps even absurd, in the notion of bringing literature to account in this way."
} 
claim, discursivity becoming yet another feature fixed firmly within the realm of the mind. ${ }^{4}$

Thus, a text's value is not inherent in its mere existence but in the "good" it can do when actively engaged in by the mind of a reader.

Where then is the reader's body?

Where are the hands that smooth and turn the pages, the nose that detects a special odor particular to a certain book, the eyes that dart back and forth or pause unconsciously to reread a line or gaze out a nearby window as words construct and reform themselves somewhere between the pane and eternity? For the plain truth of the matter is that readers and authors - and daresay, even cognitive psychologists - are not compelled to speak of reading in cognitive terms alone, but can and often do so in the language of the body. Stories are tasted, devoured, digested, and consumed; particularly choice words are rolled around on the reader's tongue, perhaps even mouthed quietly and intimately; readers are moved by books — moved to other worlds and other experiences, moved to new states of emotions that have corporeal effects - sweat, tears, elevated blood pressure, etc. - and touched by characters and plots as scenes play out before their eyes. It seems that reading, one of our best examples of cognitive activity and even improvement is commonly — even categorically_described in sensory terms, as if it were an activity of the body. Curiously, it is not one particular area of the body that is consistently associated with reading, such as eyes or hands, but rather a combination of sensory parts and perceptions suggesting that reading is somehow also a full-body experience as well as a full-mind experience. The question

\footnotetext{
${ }^{4}$ Wolfgang Iser's conception of the "implied reader" incorporates a pre-structuring of potential meaning by the text along with the reader's actualization of this potential through the reading process. While readers are acknowledged as taking an active part in the composition of a work's meaning, this activity is relegated to discursive and aesthetic discovery through the exercise of cognitive faculties. The $20^{\text {th }}$ century novel's focus on perception, for example, is for Iser inward-directed, encouraging the reader to discover unconscious expectations in the ultimate goal of discovering himself as a being made up of illusions and fictions in direct parallel to the book he is reading.
} 
is whether these sensory depictions of reading are merely clever turns of phrase or if a deeper impulsion lies under the surface of the language.

This question takes us to the structure and formation of language itself, and particularly to the construct of "conceptual metaphor." As discussed in detail below, conceptual metaphors are thought to structure human understandings of abstract, complex experiences and concepts by relating them to simpler, more familiar experiences. My interest in fiction-reading leads me to consider a specific type of conceptual metaphor: the embodied metaphor. In one sense, all metaphors can be thought of as "embodied"; it is, after all, the work of the metaphor to make sense of far-off information by explaining it in familiar, "close-by" terms. And what is closer than the body? It should be noted that the word "metaphor" itself is even a meta-metaphor (a metaphor to explain metaphors) with the Greek prefix $\mu \varepsilon \tau \alpha$-, denoting "sharing, action in

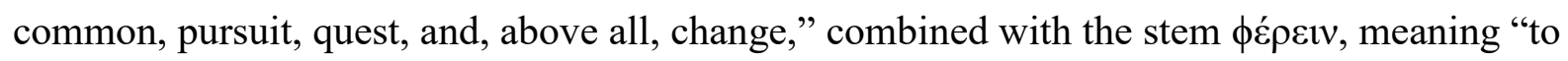
bear, carry" ("meta-"OED; “metaphor" OED). Together "metaphor" expresses a load-bearing transference, a physical swap of ideas in an effort to make sense of the world. But merely utilizing knowledge of the body (its sensations, its kinesthesia, its functions, etc.) in making sense of a non-bodily idea is not enough to classify a metaphor as an embodied metaphor. Like metaphor, the term "embodiment" brings with it notions of representation, manifestation, incarnation, and tangibility. But embodiment goes one step further in calling for previously passive recipients to become actors. As opposed to thinking about an embodiment that simply primes preexisting knowledge, we can think of embodiment as activating new and previously unknown ideas though linguistically-prescribed bodily movements and sensations. ${ }^{5}$ Thus, an

\footnotetext{
${ }^{5}$ See Leung et al. on correlations between acts of creativity/problem-solving and the physical enactment of such embodied metaphors as "thinking outside the box," "on the one hand, then on the other hand," and "putting two and two together." For a popular utilization of the positioning of bodies and mental acuity, competence, and confidence (or at least their appearance), see Amy Cuddy's TEDtalk on "Your Body Language Shapes Who You Are."
} 
embodied metaphor makes meaning through both description and action: the body within the words moving the body who encounters the words.

In this project, I side with the notion that the body_and the body's role in informing our understanding of abstract ideas and actions through metaphors-informs our experiences. I am particularly interested in how an individual's knowledge and understandings about the world, brought about from both cognitions and sensations, are harnessed by conceptual embodied metaphors to inform a reader's experience of fiction. What I frame as "metaphors of reading" function as historically-bounded but adaptive concepts that make sense of a complex experience. Metaphors of reading can and do operate on a subconscious level, mediated through a given text. As a result, not only do these constructs bring together mind and body, but also authors and readers as an author's particular understanding and desire for a reader's experience meets a reader's own understanding and desire for reading in the conciliatory space of a text. Instead of choosing between the author or the reader as the final arbiter of meaning and readerly experience, I posit that these two forces meet in the metaphorical landscape of what reading feels like. In this project, I have chosen to focus on metafictional texts containing scenes of reading and readers in my location of the figure of the metafictional reader as a cipher through which the actual reader presses and exerts herself and her practices in configuring her own experience of a text. Accordingly, in this project, identifying metaphors of reading at work in the figure of the metafictional reader is the first step to exploring an actual reader's range of potential experiences with that text.

Due to the sophisticated interplay of convention and novelty at work, the metafictional reader should be understood as an embodied metaphor of reading through which the author explores, with the actual reader in tow, a personal vision of reading through a familiar 
configuration: the reading self. Accordingly, the reader of a metafictional text is presented with recognizable features of his own actions - the bodies and minds of readers while reading, the seeing, touching, and holding of texts, readers interacting with authors, groups of readers interacting with each other, etc.- - alongside the author's new and often complex notions of the effects, practices, and significance of reading. To better evaluate these resulting configurations of reading, the figure of the metafictional reader can be mapped onto a taxonomy of cultural and historical metaphors of reading that flow beneath our social understandings of the act.

Embodied metaphors of reading take the reflexivity of the embodied metaphor to the second (or perhaps even the third) power. It looks like this: (1) a reader encounters a metaphor about reading in a text which then (2) prompts her to embody the metaphor's knowledge about reading into her current activity (i.e. reading fiction) in such a way that (3) her experience with the text undergoes a shift in connection to the primed bodily, sensory, and physical shifts invoked by the metaphor-in other words, the metaphor lives incarnate in the body of the reader; simultaneously, (4) the "body" of the text itself which already contains the body of the reading metaphor (the particulars of the effects of reading on a body) comes to (5) also contain the body of this actual reader: (5a) her experience of the work (and its metaphors) is imprinted onto the physical text in terms of physical markers (bookmarks, dog-ears, crumbs, stains, marginalia, etc.) as well as (5b) onto the reader's memory of the text, and possibly (5c) beyond these single-text memories to infiltrate her readings of other texts. ${ }^{6}$ Thus, to add fuel to an already unruly fire, we

\footnotetext{
${ }^{6}$ For fun, a mathematical formula for the effect of a metaphor on reading might look like this:
}

If reading is represented by the function, $R(T)=E$, where the input $T$ is some text, and the output $E$ is some experience,

in this situation, $\mathrm{R}_{1}$ is reading pre-metaphor, and $\mathrm{R}_{2}$ is reading post-metaphor. In other words:

$\mathrm{R}_{1}(\mathrm{~T})=\mathrm{E}_{1}$

$\mathrm{R}_{2}(\mathrm{~T})=\mathrm{E}_{2}$ 
can further connect the related concept of embodied cognition with embodied metaphors of reading in that these abstract conceptions (e.g. reading fiction is like walking through nature) can become tied to concrete, bodily sensations and movements (e.g. taking a walk in the woods) in a reversal of referent and reference; therefore, in addition to the act of reading invoking bodily sensations, bodily sensations can invoke the act of reading. However, as this project focuses on metaphors that can be identified and drawn out in fictional texts, this latter possibility will not be explored here.

While the cumulative list of available metaphors of reading, even a list confined to just those of Western civilization, is extremely vast, in this project I examine six fundamental metaphors of reading as they are expressed in various contemporary metafictional texts: (1) reading as an encounter with sensory bodies, (2) reading as journey, (3) reading as sexual intercourse, (4) reading as contact with the past, (5) reading as performance, and (6) reading as an encounter with nature. It is important to note that as opposed to relying on a single metaphor of reading to inform the formation of a metafictional reader, authors' complex visions of reading and readers generally lead them to combine metaphors. And, as my individual readings of metafictional readers in the following chapters will demonstrate, even a combination of the same metaphors of reading by different authors in different texts will result in distinct and innovative formations of metafictional readers and, by extension, the act of reading itself as imagined by the author.

$$
\begin{aligned}
& \mathrm{E}_{2}=\mathrm{E}_{1} \cdot \mathrm{m} \\
& \therefore \mathrm{R}_{1}(\mathrm{~T}) \cdot \mathrm{m}=\mathrm{R}_{2}(\mathrm{~T})=\mathrm{E}_{2}
\end{aligned}
$$

where experience is modified by metaphor, $\mathrm{m}$. 
Before exploring the theory behind Conceptual Metaphor Theory and the formulation of embodied metaphors in more detail, a brief review of previous approaches to the study of reading is worth considering. A great deal of Conceptual Metaphor Theory's appeal is in its unlimited availability of explanatory mappings; as opposed to describing a closed, universal understanding of cognition, CMT acknowledges that experiences of historical, cultural, and idiosyncratic variance will modify individuals' understandings of their world. In applying this theory to an understanding of reading, the vast range of reading experiences as articulated by centuries of readers is explained in the available variance of conceptual metaphors that are bounded by history, culture, technology, etc. As we shall see, this recognition (and explanation) of an individuated experience of fiction was not historically a part of the scientific study of reading.

\section{A Brief History of Scientific Approaches to Reading}

Although provided by authors of fiction, the examples in the previous section of "truth statements" vis-à-vis the value of reading inhabit only an optimistic middle rung in regards to the authority needed to speak on such a subject. The top rung has long been enjoyed by scientists, scholars, and researchers who utilize scientific approaches based on empirical data in their approaches to the subject. ${ }^{7}$ Unfortunately for those interested in the phenomenology of reading, cognitive science has shown a historical ambivalence toward the question of fiction-reading, in that investigations of reading have been principally grouped under larger considerations of the study of language and speech perception. This organizing conceptual framework

\footnotetext{
${ }^{7}$ As I explore below, the relationship between "lay" understandings of reading and "professional" understandings of reading is itself an interesting and not insignificant part of reading's history, study, and enactment. A large part of my argument hinges on the idea that what readers believe about reading affects their experience of reading; thus, if readers believe that fiction authors are not good authorities on the effects of reading, they may be reluctant to "buy into" their proffered narratives of what readers do, sense, feel, say, and believe.
} 
(language/speech) has in turn been predominantly associated with cognitive-flavored activities such as thought, intelligence, and memory in the world of psychology and neurology — taking researchers even further afield from the body and the body's response to reading. ${ }^{8}$ Furthermore, the act of reading itself is often merely a tool for researchers to get at findings about some other thing (e.g. reading speed used to test recognition/familiarity with certain words, recorded eyemovements while reading used to determine attention-related processes, etc.). Psychology's traditional language-related areas of interest include the following considerations (among many others): differing perceptions of written vs. spoken speech, word recognition (i.e. the process of determining whether a string of letters constitutes a word), the effects of semantic priming on comprehension and interpretation, word pronunciation and stored lexical memory, the influence of language on concept formation and other cognitive processes, early language development and acquisition, and how and where the brain processes language. Overall, many of our most basic understandings of language have come about through early behavioral studies as, true to form, psychology has largely attempted to understand normal language functioning through its study of language abnormality. (For example, we have known since the mid-nineteenth century that reading and speech perception involve somewhat different areas of the brain due to studies of brain-damaged patients who can understand spoken language but cannot read and vice versa.) ${ }^{9}$ But as far as reading is concerned, scientific interest has largely been centered around processes

\footnotetext{
${ }^{8}$ A perusal of my own Introduction to Psychology 101 textbook, Psychology (2004) by David. G Myers, contains zero chapters or even chapter sections about reading - the closest thing being a section on "Language Development."

${ }^{9}$ For a more in-depth examination of the history of psychology's investigations of language, speech, and especially reading, see Rayner, Pollatsek, Ashby, and Clifton's Psychology of Reading (2012). This thorough overview provides further evidence of psychology's disinterest in the emotional or bodily effects of reading as the reviewed studies, which make up the authors' attempt to put psychological findings concerning reading into a coherent framework, predominantly focus on word perception, discourse comprehension, and stages of reading development.
} 
of reading — "how readers go about extracting information from the printed page and comprehending the text" - as opposed to motivational or emotional issues that provoke reading or occur during or after reading (Rayner et al. vii).

However, a faction within cognitive and linguistics-focused psychology broke away from this mainstream disinterest in the reader's experience of narrative to consider the effects of stories beyond the mental processes they enlist in the mind of the reader. Following in the footsteps of the Reader Response theorists and other literary schools, this segment of psychological studies in the 70s and 80s also turned to considerations of the human processing of narrative (although they were generally limited to short selections of longer narratives). ${ }^{10}$ Relying on both older research methods and devising new ones to investigate readers' encounters with such literary devices as irony, unreliable narrators, figurative language, and encounters with "real-world" information in fiction, these studies began to appear in journals such as Psychological Science, the Journal of Memory and Language, the Journal of Personality and Social Psychology, the Journal of Experimental Psychology, and Psychological Review citing and expounding on the theories of literary criticism giants such as Wayne C. Booth, Stanley Fish, Wolfgang Iser, Jacques Derrida, Jonathan Culler, Susan Rubin Suleiman, Jane P. Tompkins, and Norman N. Holland, among others. While still a smaller subset within the field's overall (dis)interest in reading, this psychological attention to human encounters with narrative (often including references to what other disciplines have had to say on that subject) persists in a modest fashion today. ${ }^{11}$

\footnotetext{
${ }^{10}$ See, for example, the work of Richard J. Gerrig, Raymond W. Gibbs, and John R. Searle.

${ }^{11}$ See, for examples, the work of Raymond A Mar, Keith Oatley, and Maja Djikic. Mar et al.'s “'Emotion and narrative fiction: Interactive influences before, during, and after reading" (2011) provides a useful overview of empirical research to date on the interaction between emotions and literary narrative fiction.
} 
Across the field of cognitive science as a whole, the recent implementation of the functional MRI (fMRI), EEG, and other neuroimaging techniques and technology has done much to lend credence to older psychological theories which attempted to determine characteristics and patterns concerning the activities of the brain under different situations and stimuli without actually "seeing" them. ${ }^{12}$ Studies and theories of reading are no exception, although it is important to note that the imaging provided by these scans is still subject to a great deal of interpretation and bias by researchers. In an exciting turn of events for sensory- and bodyminded theorists of reading, neurological examinations as recent as the past decade have provided evidence that calls into question older theories of language-processing occurring solely within the classic "language centers" of the brain in the left frontal lobe. ${ }^{13}$ Their demonstration that language is selectively processed throughout the entire brain-particularly in areas previously thought to be involved solely in motor functioning - could provide an explanation for the reoccurring depictions of reading's bodily nature in the language we use to talk about it.

Besides their obvious expense and the difficulties in gaining access to the necessary facilities, there are some major drawbacks to these neurological studies in regards to our development of a fuller understanding of the reader's experience of narrative (which in turn echo the drawbacks of many of their behavioral psychology predecessors): the issue of duration and, along the same lines, recreation are two main concerns. While a full narrative can certainly be enclosed in a handful of words, humans commonly take the time to encounter narratives which

\footnotetext{
12 These scans are used to monitor and record changes in blood flow, blood oxygenation, and electrical energy of the brain before, during, and after exposure to variables under experimental consideration, displayed in visual terms of color and shading.

${ }^{13}$ Incidentally, this "language center" theory is a major contributor to our cultural understanding of personality as ascribed in the popular "left brain"/"right brain" differentiation of people, in which "left brain people" are more artsy and language-focused, while "right brain people" are more rational and math-oriented.
} 
require hours, days, even weeks to fully consume. Being hooked up to electrodes or stuck inside a metal tube for the length of time it takes to finish War and Peace is not practical—nor is it a satisfactory recreation of the unobserved experience of a reader with a book. Furthermore, the reading that occurs in these studies is far from the "natural" reading that occurs in a reader's everyday, unobserved life; the projection of sentences onto a screen, one at a time, replaces the experience of a book in the hands of a reader — and also prevents the reader from jumping forward or back to previously or not yet read words, phrases, or entire sentences to confirm a questionable pronoun, check a piece of information, anticipate where a sentence (or character) is going to end up, etc. — all of which are common activities in the experiences of readers of narratives. ${ }^{14}$ The assumption that a very limited snapshot of the reading experience tells us everything we need to know about the whole of that experience is flawed reasoning. But until technology advances to a state of total invasion-free monitoring, duration and recreation will continue to be problematic in any neurological investigation of reading. ${ }^{15}$

Despite these limitations, it is worthwhile to consider what some of the most diverse and significant neurological studies of reading have yielded so far with respect to an embodied experience of reading. In a much-cited study, Hauk, Johnsrude, and Pulvermüller (2004) utilized an fMRI to identify the areas of the brain activated while their participants read action words referring to face, leg, and arm actions. Not only did these researchers find activation within the brain's motor regions during passive reading, these areas were found to be directly adjacent to or overlapping with areas activated by actual movement of the tongue, feet, and fingers,

\footnotetext{
${ }^{14}$ Of the neuroimaging studies which will be reviewed in this section, Lacey et al. projected words onto a screen with readers clicking a response box to signal when they had understood the sentence; González et al. equipped readers with goggles to display words to readers; Boulenger et al. used a monitor; Hauk et al. used a screen; and Yao et al. used goggles.

${ }^{15}$ Although the observer effect of quantum physics may render this feat impossible.
} 
respectively. Hauk et al. propose their study's support for a dynamic view of word meaning in the human brain with semantic representations distributed in a systematic way throughout the brain as opposed to being contained within the brain's "classic" language centers (ex. Broca's area, Wernicke's area).

Boulenger, Roy, Paulignan, Deprez, Jeannerod, and Nazir (2006) conducted a similar study but determined this "cross-talk" between action-word language processing and motor behavior (previously thought to be conducted by separate, unrelated areas) through an analysis of movement kinematics as opposed to neuroimaging — which demonstrates that older methodologies can still yield useful results. Boulenger et al. interpret delays in participants' execution of hand-reaching movements while reading action-words (i.e. verbs) as opposed to concrete words (i.e. nouns) as evidence of the engagement of cortical regions in both language and motor tasks; in other words, they believed the delay was the result of an area of the brain trying to do two things at once, slowing down the overall processing of both activities. Implicit in this conclusion is the premise that if these two activities (reading and hand-reaching) were handled by two separate areas of the brain, there would be no delay. In this same study, Boulenger et al. also found participants' reaching movements were faster if first primed by action-words before beginning the action, suggesting that language-related activity in the cortical motor regions might contribute to the understanding of action-words that refer to parts of the human body. Overall, these findings demonstrate how reading action-words can be either a hindrance to physical action (if the words are read while an action is already taking place) or a stimulant (if the words are read prior to an action, thus engaging areas involved in programming motor action). 
Other recent neurological studies on reading have examined our encounters with sensory language in connection to areas of the brain used to handle sense perception. A study, for example, on reading odor-related words conducted by González, Barros-Loscertales, Pulvermüllerm, Meseguer, Sanjuán, Bellochm, and Avila (2006) determined that olfactory regions of the brain were activated for words relating to both positive and negative scents such as: "garlic," "cinnamon," "gunpowder," and "vomit." Conversely, words without olfactory associations or with very weak ones (e.g. "coat," "short," "dart") did not significantly activate olfactory regions. This study similarly suggests that referential meaning of olfactory words is processed by distributed cortical systems as opposed to a single language-only area of the brain. Much like the action-word oriented studies described above, this study confirms the likeliness that "semantic representations are distributed in a systematic way throughout the entire brain" (González et al. 909).

Neuroimaging has also been used to address another enduring question regarding the experience of reading: that of the readerly experience of an "inner voice" that readers "hear" while reading narratives with dialogue. Combining the utilization of fMRI with eye tracking, Yao, Belin, and Scheepers (2011) examined the activation of voice-selective areas in the auditory cortex by direct speech (i.e. dialogue) as compared to indirect speech (i.e. reported dialogue) during participants' silent reading of short stories. As they anticipated, the direct speech condition was associated with greater activity in voice-selective areas of the auditory cortex than the reading within the indirect speech condition. Their findings uphold a neurological confirmation of the long-articulated experience of hearing an "inner voice" reported by readers, especially during direct speech statements. To account for this finding, Yao et al. allude to the notion of perceptual simulation in language, the idea that if mental representations of language 
are grounded in perceptual experiences and actions, perceptual simulation is an automatic part of language comprehension (3150-3151). According to this theory, our comprehension of direct speech is grounded in our perceptual experience of past vocal demonstrations or dramatizations of a speaker's utterance. This reliance on past action and experience to understand written narrative of related experiences is a repeated theme of these studies which will be considered in greater detail in the following sections.

Finally, the activation of yet another area of the brain previously believed to be "sensation-specific" can be found in Lacey, Stilla, and Sathian's (2012) texture-based metaphor study. Using fMRI, Lacey et al. found that participants processing sentences containing textural metaphors showed activation in their parietal operculum (sensory cortical area). Interestingly, the processing of sentences with similar meaning but without the textual metaphor (e.g. "She had a bad day" vs. "She had a rough day") did not result in the activation of these textural-selective somato-sensory areas. Once again, the activation of domain-specific sensory cortical areas during the processing of language relating to a particular sense (in this case, touch) suggests that the brain understands language through simulation of related sensation. The authors of this study view their results as supporting the idea that comprehension of metaphors is perceptually grounded, specifically pointing to Lakoff and Johnson's conceptual metaphor theory (explored more thoroughly in the next section).

These studies and many like them confound older models of language processing in the brain, and indeed, of cognitive activity as a whole. As opposed to a neatly divided brain containing specific areas for specific tasks and processes, it seems that we possess an all-ornothing brain that utilizes information from regions not strictly related to the task at hand in order to provide us with as much referential information as possible when approaching a 
necessary task or novel stimulus — particularly if that task/stimulus is language-based. Furthermore, that referential information appears to come largely from our embodied cognition - that is, our experience and knowledge of what it's like to have bodies with sensations and perceptions in and of the world around us. And if what we think of as "purely" cognitive activities are actually in large part informed by the body and sensory experience, a Cartesian mind-body duality is rendered hopelessly outdated. It seems that understanding how our brains work is one long morality tale in outdated theories and models. George Zarkadakis' In Our Own Image (2015) and Anthony Chemero’s Radical Embodied Cognitive Science (2009), for example, look at the connections between historically-situated scientific models of intelligence and contemporary technological advancements including today's obsession with thinking of thinking in terms of computation. In regards to the enduring Cartesian influence on our conceptions of the human mind and life, Zarkadakis discusses how the dualistic disembodiment of the mind is taken to "a whole new level" in the age of computer technology which differentiates between hardware (physical components) and software (immaterial code) (43). In an understanding of reading that does not fall victim to deep-rooted stereotypes but neither throws the baby out with the bathwater, we must keep in mind the body by keeping the body in the mind. Fortunately, much of the groundwork has already been laid out for this task long before neuroimaging could prove or disprove the significance of sensation in cognition and vice versa.

\section{Theorizing Embodied Metaphors}

While the idea that metaphors structure experience has been around for a long time, the field now known as Conceptual Metaphor Theory_ of which embodied metaphors play a 
primary role_-was first put forth in Lakoff and Johnson's Metaphors We Live By (1980). ${ }^{16}$ Metaphors, according to Lakoff and Johnson, are a naturally occurring human phenomenon dependent on the nature of our bodies, our interactions in the physical world, and our social and cultural practices. Since the essence of metaphor is understanding and experiencing one kind of thing in terms of another, Lakoff and Johnson use language as evidence of what our underlying conceptual system is like and to gain an understanding of the metaphorical nature of human activity. In other words, they see the innate metaphorical nature of common language as indicative of an innate metaphorical nature of our conceptual system. According to this system, cultural concepts and values are metaphorically structured; the mappings and implications of widespread and foundational metaphors will turn out to structure all kinds of assumptions, beliefs, and behaviors in that culture, often in ways that are not obvious to us in the moment. It is also difficult to predict which metaphors an individual will utilize due to the influence of one's subculture and personal values. For example, at multiple points throughout their work, Lakoff and Johnson consider a major structural metaphor within Western society: "Rational Argument is War." As in all structural metaphors, a highly organized and clearly delineated concept (i.e. war/physical conflict) is used to structure another (i.e. conversation/argument). Once established, paralleling parts of each come forward: participants in conversations/arguments are now adversaries, conversational turn-taking is attacking and counter-attacking, a cooperative purpose is converted to a quest for victory, and so on. An individual who possesses the structural metaphor of "Argument is War" can be thought to conceive of an argument through knowledge and experience grounded in physical combat and antagonistic tactics such as intimidation, threat, insult, invoking authority, etc. It is a small stretch of the imagination to predict that such an

\footnotetext{
${ }^{16}$ See Paul Ricoeur's The Rule of Metaphor (1975) for a historical perspective on the understanding of metaphors' usefulness in the ancient Greek discipline of rhetoric.
} 
individual when paired with an individual with a different structural metaphor, such as

"Argument is Dance," would be fundamentally at odds — not because they presumably disagree about something, but because they disagree about the nature of the act in which they are both participating.

Both Conceptual Metaphor Theory as put forth by Lakoff and Johnson and the neurological studies described above rely on the idea of embodied cognition to explain their observations of interactions between mind and body. ${ }^{17}$ That these two distinct methodologies (i.e. language-based and neuroimaging-based) yield similar conclusions speaks to the theory's overall soundness but also suggests each approach has something to offer the other. According to Lakoff and Johnson's theory, the overlaps recently found in the brain between action/sensoryfocused language processing and actual action/sensation (both its future potential and its past memories) are indicative of the larger organizing structure they have put forth: conceptual metaphors. And, moving in the opposite direction, the large body of work that now supports and expands Conceptual Metaphor Theory can provide a useful anchor for neuroimaging studies, such as utilized in Lacey et al. As described in their 2003 Afterword to Metaphors We Live By, CMT is indeed a growing field that has expanded to encompass research from diverse fields such as literary theory, legal studies, linguistics, and the philosophy of science. Among this far-flung

\footnotetext{
${ }^{17}$ Embodied cognition, situated cognition, and grounded cognition are often used more-or-less interchangeably to describe an emphasis on cognition that is spatially located (and therefore limited and incomplete) and one in which feedback between a mind and its environment plays an essential role. However, a researcher's choice to use one term over another suggests the nuances that exist between them which further suggest the researcher's focus: for instance "situated" can be used to suggest that because the mind is located in the midst of a changing world, there is no need for representations (or simulations) of the world to plan or guide that agent's behavior (Chemero 24-25); "grounded" cognition, on the other hand, can move the focus to the role of the body in cognition and the necessity for simulation as "the reenactment of perceptual, motor, and introspective states acquired during experience with the world, body, and mind" (Barsalou 618). Hence, whether or not such simulation or reenactment exists is a contentious issue caught up in definitions of cognition. Since "embodied cognition" appears to be the most general of the three terms, it will be the one I use to refer to this idea of cognition being shaped by the body in its environment.
} 
spread of CMT's applications are theorists such as Fauconnier and Turner (proponents of conceptual blending theory) and Kövecses (who has advanced the study of metaphors of emotions), both of whom have taken Lakoff and Johnson's work and built on it to enrich our understanding of how metaphorical concepts shape our experiences and make possible the singularities (language, religion, art, science, etc.) that make us who we are. From the perspective of the history of science and computer systems, George Zarkadakis (following in the footsteps of Thomas Kuhn) emphasizes the role of metaphor in science as a tool to teach and explain natural phenomena including, especially, the human brain. Zarkadakis connects metaphors with narrative succinctly saying, "without metaphor no story is worth telling" (27).

Given the fundamental nature of metaphors as bridging both near and far, mind and body, abstract and concrete, in the following section I explain my rationale for utilizing a combination of disparate literary methodologies in order to consider the similarly bridging experience of fiction reading.

\section{Towards a Fuller Understanding of Metafictional Embodied Metaphors: Methodologies}

From Lakoff and Johnson's proposition that conceptual metaphors function as the method by which we make sense of a complex world, I turn to Fauconnier and Turner for justification of my argument that metaphors can and must be at odds with the phenomenon they attempt to place and describe. Their theory also explains why a single metaphor of reading simply will not do: such a multivariant, multisensory experience eclipses the descriptive capabilities of any one familiar activity. Fauconnier and Turner argue for the existence of an intricate type of metaphor-making, a feat they call "double-scope integration," behind humans' 
ability to conceive of and then execute the long list of singularities, including narrative. They claim the power within double-scope networks (and subsequently, the human mind) is not in blending together similar ideas and frameworks but in allowing for "rich clashes" originating from the differences between organizing frameworks which together form new emerging structures of their own:

Double-scope integration... permits us to use vocabulary and grammar for one frame or domain or conceptual assembly to say things about others. It brings a level of efficiency and generality that suddenly makes the challenging mental logistics of expression tractable. The forms of language work not because we have managed to encode in them these vast and open-opened ranges of meaning, but because they make it possible to prompt for high-level integrations over conceptual arrays we already command. (Fauconnier and Turner 182-183)

Fauconnier and Turner posit that there were no intermediate stages of language development, but that language too was a singularity, an all-or-nothing behavior whose origins (i.e. advanced integration capability) built up slowly over evolutionary time but then exploded to coincide with cultural time (i.e. human social systems). Our resulting systems of expression cover an openended number of situations and framing; new words and phrases are of course introduced and strengthened into language all the time, but the overall structure in which those new words and phrases take their place is always able to expand and adapt to bear their weight. This is especially apparent with the introduction of new concepts into a system of expression which, according to Fauconnier and Turner, automatically prompts speakers to perform conceptual integrations. Naturally, finding optimal networks is a highly valued skill that generally distinguishes the writers, poets, statesmen, and scientists from their counterparts, but complex blending is by no 
means uncommon and in fact occurs regularly with varying degrees of novelty and awareness by its practitioners.

If language is a proving-ground of complex blending with new combinations of inputs and frameworks constantly resulting in new ideas and models for understanding, fiction must stand as a super-concentrated, highly-specialized living document of our advanced integration. In one sense, fiction — all fiction — is an organic metaphor of the human experience, one that enables a never-ending supply of new inputs (from the minds, bodies, and memories of new readers) and results in a never-ending supply of outputs in the form of new frameworks for understanding the world. Evolutionary theory as applied to fiction, or the "biocultural approach to fiction" as it has been coined by "evocritic" Brian Boyd, encourages such a view of narrative given its provision of safe cognitive playing with patterns, attention, event sequences, social hierarchy, and Theory of Mind. But unlike other art forms, narrative requires our uniquely human capacity for metarepresentation - that is, to understand representation as representation in order for its effects to act. ${ }^{18}$ An evolutionary view of literature also relies on the principles of embodied cognition. According to this idea, all fiction contains "strategic information" which catches readers'/listeners' attention-information including social data on others' capacities, dispositions, intentions, actions, and reactions. Simulation is what bridges the gap: as Boyd explains it: "we think, remember, and imagine by mentally simulating or reactivating elements of

\footnotetext{
${ }^{18}$ The comedic film Galaxy Quest (1999) illustrates this well: the human protagonists of the film feel compelled to help an alien race known as the Thermians who are unable to comprehend our human "art" (in this case, episodes from an old Star Trek-esque show) as anything but an accurate depiction of Earth history. They have nothing close to fiction in their own culture and subsequently associate "lying" with deviance. As a result they fail to recognize what is all too painfully obvious to a (human) audience: that the actors whose assistance they acquire are not actually astronauts, physicists, or heroes, but people pretending to be those things in order to create "art." John Scalzi's Redshirts is a related example in that the "red-shirt" (i.e. unimportant) characters discover that their frequent deaths during away-missions really serve to heighten the intensity of the mysterious master-narrative they discover themselves to be characters in. It seems that metarepresentation is all well and good as long as you're the one reading it and not the one in it.
} 
what we have previously perceived, understood, enacted, and experienced" (156) ${ }^{19}$ Reading stories, according to this view, thus requires readers to create a mental world and keep track of it by experiencing it through semisimulation; according to some theorists these simulations are a form of "pre-reexperience" in that multimodal elements from memories of the past are recruited to aid in simulating a potential future before the event happens. This practice constitutes a strategic adaptation in allowing the individual to infer information and potential reactions to a variety of potential situations and/or the baffling behaviors of others who could make a decisive difference in the individual's fate (Boyd 158). "The boy who cried "wolf"” story, for example, is generally told and interpreted as a warning about the misuse of the power of language. While the story that "there's a wolf chasing me; run!" provokes a powerful emotional response in its audience the first time they are told it, multiple repetitions of this story begins to suggest it ought to be read by the audience as a story about the teller himself. The logical reaction is to no longer believe the young storyteller-which, as the overall story goes, results in a completely preventable tragedy. The goal of the parent or teacher who tells a young navigator of language this story is presumably to convey the message that "telling tales" may be fun, but they can come back to bite you if the tales overshadow your credibility in the eyes of others and/or if your audience misinterprets your aim as storyteller. The ideal listener-child of this story would internalize the moral not to lie_—or at least learn there may be a correct context for "lying"while also noting the (potentially contradictory) value in telling a story to convey an important message about the way the world works.

From the evolutionary/biocultural approach of Brian Boyd to the theories of mental mappings found in Fauconnier and Turner's conceptual blending theory and Lakoff and

\footnotetext{
${ }^{19}$ It should (again) be noted that not all theorists are convinced by the simulation-explanation for cognition. See Anthony Chemero's Radical Embodied Cognitive Science (2009) for a thorough rebuttal to the simulationists.
} 
Johnson's Conceptual Metaphor Theory, the diverse methodologies of "Cognitive Approaches to Literature" provide an indispensable toolset for my current project. This school of thought can be understood as an integration of the sciences with the humanities, encompassing the fields of cognitive psychology, neuroscience, linguistics, and anthropology with literary studies, and it provides exciting new ways to illuminate the integrated nature of bodily and mental experience. As examined above, recent neurological findings regarding the role of motor regions in the processing of metaphorical and action-related language confirm our need for a new understanding of the relationship between mind and body—especially in seemingly "brain-only" human activities. Corporeal information can no longer be considered as additional to cerebral information but must be understood as integral to it and to our understanding of the world around us. Thus, Cognitive Approaches to Literature, as opposed to insisting on an irreconcilable distance from the body and sensual experience, have come to insist on the presence of the body as a subject of study and as an illumination of cognition and intellectual experience, such as fiction reading.

Yet, while this approach sheds a great deal of light on the presence and effects of metafictional metaphors (to be fleshed out in the following chapter), in the construction of reading experience, a significant element is still absent from a full conceptualization of reading bodies. An alternative stance to one characterized by considerations of the mind and brain is taken up by the field of Sensory Studies, an approach that focuses attention on the body and the senses. Sensory Studies is a relatively new and growing field, combining historical and anthropological investigations of the senses and sensation in considerations of fiction, histories, biographies, memoirs, architecture, music, art, and other cultural artifacts. ${ }^{20}$ Primary concerns of

\footnotetext{
${ }^{20}$ As defined by Constance Classen in her preface to The Deepest Dense: A Cultural History of Touch, pg. xv-xvi.
} 
this field involve determining the cultural influences of societies' perception and valuing of the various bodily senses as well as the comparison of such perceptions and values among diverse societies and historical periods. In the realm of literature, Sensory Studies offers a way to recognize and evaluate authors' choices of sensory description within texts which can then be contrasted with older forms of literature as well as with literature from other cultures, revealing differing sensory values and outlooks. The experience of the reader of historical and current texts is influenced by both the authors' valuing of the senses and the reader's own personal and cultural sensory values. Furthermore, Sensory Studies provides a way to consider the individual reader as a sensorial body encountering a text through multiple senses which combine into a single experience of reading. Sensory Studies scholars have in turn found that readers do not encounter texts through sight alone, but through a variety of culturally-mediated senses and sensations. $^{21}$

Finally, Sensory Studies' focus on exploring contexts - contexts specific to cultural philosophies and performances, historical moments, occupation-, gender- and class-specific sensual practices, and sensual hierarchies_-offers a stalwart resistance to the temptation to universalize a normative notion of "the human body" — and for this project, "the reader." While conceptual blending is necessary to lay the groundwork for using embodied metaphors to describe the experience of reading fiction, sensory histories, by definition, remind us that these metaphors did not fall fully formed from the mind of Zeus: they are shaped and reinforced through repeated practice by members of a specific community of speakers/writers for which the

\footnotetext{
${ }^{21}$ Ed. David Howe's sensual culture reader, An Empire of the Senses (2005) contains sensory-focused essays, many of which trace Western society's historic mistrust of touch and touch-based knowledge-in supposed opposition to sight and sight-based knowledge — despite their frequent combination in intellectual activities. Constance Classen [The Deepest Sense (2012)] and Katharine A. Craik [Reading Sensation in Early Modern England (2007)] also consider historical acts of reading in multisensory terms with touch playing at least an equal role with sight.
} 
metaphor meets some need. Scholars working within the framework of Conceptual Metaphor Theory often remind their readers that conceptual metaphors are culturally and historically specific (besides having to do with the more universal properties of human bodies that function in similar ways in the world), but sensory studies offers an approach to the actual work of exploring those culturally and historically specific contexts. If metaphors do embed a particular experience of embodiment into their conceptual structure, then future work might be done on reading the sociocultural dimensions of certain metaphors of embodiment through other related identity structures—a path which sensory studies allows us to draw.

Models within Cognitive Approaches to Literature have pinpointed the fundamental significance of the senses and sense-driven experience in intellectual activities such as reading, but theorists from the field of Sensory Studies have laid the groundwork for a historically, culturally, and textually nuanced understanding of humanity's sensual experience and sensory theorizations. From these methodologies I utilize the concepts of embodiment, sensory hierarchies, sensory histories, simulation, blending, and embodied cognition in my investigation of embodied metaphors. A melding of these two bodies of work—-sensory and cognitive approaches - allows me to bring together theorizations of dominant metaphors; sensory histories and the cultural associations surrounding the metaphors' related senses, singly and as a sensorium; scientific observations of the areas of the brain activated during reading; and will most importantly direct attention to focal points possibly overlooked by only considering one side of the paradigm. I argue that a comprehensive examination of embodied metaphors as employed in fiction must be mindful of the mind and body as one thinking|feeling unit of meaning-making; to do otherwise would be to misapprehend the function and purpose of the 
metafictional metaphor itself, resulting in an incomplete understanding of its effects on the reader's experience with the text.

\section{Metafictional Novels and their Readers}

While the reading metaphors I examine have significant histories of their own, this project focuses on their current usage in modern, postmodern, and contemporary metafictional novels from the last century up to the present. I have set limits to the time-period and genre under scrutiny in this project for several reasons. First, I am interested in the reading experiences of a wide audience of readers - an audience that did not exist in Western society prior to the twentieth century. The novel genre, arising simultaneously in popularity with this broader reading audience, also began to encourage a particular bent towards reflexivity and selfawareness. While such inward-directed pursuits were unquestionably present in genres prior to the twentieth-century novel, they were brought to a much wider reading public through the novel genre due to both its timing and its popularity. Since metafictionality plays such a prominent role in my project - in that I begin with the metafictionality of authors and end with its translation to readers via the metafictional text - the inherent possibilities for metafiction within the novel genre itself allow me a place to start that already embeds a broad audience made up of both "lay" and "scholarly" readers as well as an authorial interest in the experience of readers.

Prior to the twentieth century, fiction-reading was rarely an activity pursued by the working classes of Western society, relegated instead to individuals who were wealthy enough to afford both the texts themselves and the leisure time necessary to enjoy such luxuries; for centuries, this meant being white, male, and of the nobility significantly improved one's chances of being a reader. This state of affairs slowly began to change in the eighteenth century. In 
conjunction with the social and economic changes brought on by the industrial revolution, increasing population size, and class shifts, eighteenth-century England saw growth in book prices and sales; however, the national literacy rates did not rise in equal measure with the proliferation of books, remaining much the same as in the Elizabethan period (Altick 30). In the late-eighteenth and nineteenth centuries, campaigns and foundations to endow and/or revamp public libraries - institutions, supposedly, set aside for the masses to receive both instruction and recreation from books - were celebrated as one of the advantages of English culture. Intellectual superiority was becoming a means by which England distinguished itself favorably from the continent, yet as Richard D. Altick traces in The English Common Reader, the defects of this Victorian voluntary library system were still extreme, being:

at the mercy of all sorts of vicissitudes - the withdrawal of financial support, dissension among the sponsors, simple evaporation of interest. Nothing could guarantee that, once the reading habit had taken hold in a town, it would continue to be nurtured. In addition, the fact that most voluntary libraries were the pet projects of religious or other partisan groups cast over them an atmosphere of controversy, latent or otherwise... Nowhere, in short, was any considerable collection of books available to all the people, without charge and completely detached from social, political, and religious prejudices. (223)

Despite the circulation of ideals of intellectual and spiritual enrichment that ought to be spread among the masses by way of reading, old classed prejudices persisted in regards to reading for entertainment (i.e. that reading "light literature" causes laziness and other unwanted attributes in the working man or woman) (Altick 231). Yet, as Altick notes, "wherever free libraries were opened, the volume of patronage bore a direct relationship to the amount of fiction available" 
(231). However decried or compromised, the provision of fiction to the public-luxury articles to induce pleasure and play, education and self-bettering - was never again to be halted. In the nineteenth century and beyond, the mass public was largely a reading public in the Western world.

Coinciding with the spread of increased literacy rates was the growing popularity of the novel as the genre of choice for readers in the late eighteenth and nineteenth centuries in both England and America. ${ }^{22}$ In parallel to the startling inclusion of working class readers in libraries, the novel bucked the literary status quo with its dubious roots in the French Romance, propensity for sensationalism and/or moral laxity, and mass appeal (further evidence of the genre's "inferiority"). Furthermore, the possession of affordable literature, the classic marker of status, was now much more accessible for lower classes looking for upward mobility: it was Shakespeare for the sitting room; novels for the bedroom. Today the novel is comfortably ensconced somewhere in between as both a symbol of respectable taste and intellectual complexity; it is a genre that has transcended class barriers to contain both "high" and "low" fiction in its various sub-genres. ${ }^{23}$

The twentieth-century marks a time of mass metafictionality in that writers and readers are both tasked with thinking about the activities they engage in through the locus of "the book" - a term which has by now largely come to denote print novels, although as discussed in

\footnotetext{
${ }^{22}$ Robert B. Winans contends that despite the American moral gatekeepers' condemnation of novels in late eighteenth and nineteenth century America, readers' private habits were quite different, with amount of printed fiction outweighing the amount of essays denouncing it when considering the large number of imported English editions that supplied the demand (268-269).

${ }^{23}$ While sharing a general form, novels of the "high" and "low" categories will often appear to be quite different in the eyes of the knowing viewer (e.g. a thick Penguin classic vs. a cheap romance) — evidence that cultural markers of literary intellectual superiority/inferiority still exist. Curiously, novels of traditionally "low" novel subgenres will rarely hide what they are: works from fantasy, science fiction, and romance genres persist in featuring covers with eye-catching illustrations of their characters in fantastic poses (often with enviably body-types and scant clothing) as opposed to the subtler, more text-focused covers of literary fiction.
} 
my Coda, this conceptualization of the recognizable form of "the book" is changing. The intersectionality of the twentieth century, with 100+ years of mass reading prior to its inception, an emphasis on the novel, and a prompting towards reflection, provides me with a place to consider conceptions of the reading experience as inscribed in metafictional embodied metaphors. The individual reading metaphors themselves span historical periods, cultures, genres, readers, and writers, and remain remarkably relevant today with every indication of adapting to outlast our own period's particular reading preferences and habits.

The following chapter lays out the six embodied metaphors of reading I use to evaluate metafictional readers and scenes of reading in chapters two through five. After establishing the identities of the metaphors employed within each work, I examine the cognitive and sensory experiences of the metafictional characters, both in their individual reading experiences and throughout the narrative. These metafictional interactions between cognitive and sensory components — dictated by the metaphors of reading in play_indicate the author's understanding of reading's purpose and effects (particularly within the specific novel examined) and come to dictate the reading experience of the actual reader of the narrative.

"Chapter 2: Reading as Connection" focuses on two metafictional novels by Virginia Woolf, Between the Acts (1941) and Orlando (1928), in which I explore Woolf's views of reading as an encounter with past readers and writers and as membership into a community of fellow readers and writers - all of whom are interested in the power of fiction to forge connections with the self and the body to other selves and bodies. The primary metaphors at work in these novels, "Reading as an Encounter with Sensory Bodies," "Reading as Contact with the Past," and "Reading as an Encounter with Nature," demonstrate Woolf's theory of "right" reading in which the reader bares vulnerable the self, body, and mind to the book-and by 
extension to the book's author and collective community of readers - in order for mutual recognition, communion, and transformation to occur. Interestingly, while maintaining her use of the same metaphors of reading across the years (1928 and 1941, respectively), these two works differ drastically in the type of metafictional readers they portray to the extent that the act of reading itself is called into question as a valid activity.

“Chapter 3: Reading as Challenge” features two modernist works: The Garden of Eden (1986) by Ernest Hemingway and Pale Fire (1962) by Vladimir Nabokov—both of which involve reading as a site of conflict in which readers resist but ultimately must relinquish control of their readings to the author. Accordingly, the primary metaphors in these texts are "Reading as Performance," "Reading as Contact with the Past," and "Reading as Sexual Intercourse." As opposed to the previous chapter's investigation of a single author across time, this chapter considers the degree of variance that two portrayals of reading and readers can take in two individual authors who nevertheless share an understanding of reading as challenge.

In “Chapter 4: Reading as Pursuit," I consider Italo Calvino's If on a winter's night a traveler (1979) and J.J. Abrams and Doug Dorst's S. (2013) in an examination of the erotic relationships between readers and writers as well as between readers and other readers which explore the conceptualization of reading as a search for completeness, closure, and consummation. The metaphors of "Reading as Sexual Intercourse," "Reading as Performance," and "Reading as Journey" are joined together within these very different novels to express the act of reading as a labor of/for love, a journey to find consummation, and an exploration for truth. That this conceptualization is commonly considered a unique feature of fiction (the ability of narrative to impose order on and make sense of the chaos of the "real world") suggests that 
these authors' portrayals of reading and readers are also attempts to cut to the heart of what it means to be human and the purpose of story in the lives of story-tellers and their readers.

My final chapter, "Reading as Escape," incorporates two works by Haruki Murakami, Kafka on the Shore (2005) and The Strange Library (2014), along with Neil Gaiman's The Ocean at the End of the Lane (2013). These authors explore "Reading as Journey" towards redemption and illumination as well as "Reading as an Encounter with Nature" which consists of both the realistic natural world and a fantastic natural world to respond to the popular conception of reading as a search for escape — especially prominent in the marked genres of fantasy and science fiction. Ultimately these authors allow for fictional worlds and truths discovered by readers to be at least as useful as the truths of "reality" - but more acceptable to the reader due to their story-forms. In these metafictional readings and readers, the idea of reading to escape is regulated by an understanding of reading as a journey, which perhaps takes readers to new worlds and realities, but nevertheless delivers them to a destination (an end) with a story in hand. Finally, my coda looks towards futures of embodied reading and metaphors of reading in response to the rise of e-books and the e-reading experience. The changes from paper to screen, page to scroll, and ink to code have dramatically altered our sensory experiences with narrative, although I argue that instead of abolishing the embodied metaphors of reading discussed here, the metaphors adapt to the social and technological trends of their day. 


\section{CHAPTER 1: EMBODIED METAPHORS OF READING}

The metafictional reader enters a narrative as a manifestation of the beyond, a haunting of currents that flow beneath the shape of the narrative in the author's mind and body. Her mere existence in a story both authenticates it — makes it more approachable and more realistic — and undoes it. She is the glitch in the Matrix, the figure in the corner silently scratching a hole in the fourth wall; she comes to preside over the reader like an attendant spirit, an unexpected, perhaps unwanted measuring-rod the actual reader either lives up to or doesn't. Or perhaps she slips by, too far out of the reader's field of vision to be detected, leaving only a vague impression of uncertainty and challenge. The metafictional reader does what other characters do not—no matter how real they seem, how well they are drawn, how close the reader feels to knowing them - in that the metafictional reader in perfect time and rhythm always exactly echoes the actual reader at the time of his reading. Whatever else she may be or do in the narrative, the metafictional reader stands in as the author's knowing nod to the actual reader: "I see you. I know you. I know what it is you're doing."

Metafictional readers are also political in nature in that they cannot help but express some part of what their authors think and know about the act of reading — good and bad. They can be idolized and celebrated by an author - their successful reading standing in as a marker or cause of a successful personality or life lived; conversely, they can be mocked, or shown to come to a bad end - their wrong reading standing in as a marker or cause of an impoverished personality or life. Metafictional readers can illustrate the consequences of reading badly or well or too much or too little or broadly or narrowly or for the wrong or right reasons. They can show the ways in which an individual's reading takes root in one's life and frames mental and sensory experiences and actions. Furthermore, they can be used to show the reader how to read by serving as either a 
positive or negative example; they can explore the dynamics of reading with which the author is most curious or concerned. Thus, the actual reader of a metafictional reader is confronted with this extra layer of reflection and inner-knowledge: plot, characters, tone, style, imagery—all of these are called into question by the cipher of the metafictional reader's very existence in a narrative.

Just as we have developed culturally specific metaphors to make sense of our experiences, emotions, situations, and abstract concepts, highly sophisticated and governing conceptual metaphors of reading shape readers' experiences with narratives, and in metafictional narratives in particular, through the figure of the metafictional reader. Since metaphors about reading are inherently metafictional in nature - in that they are expressed in language and are read by readers - these metaphors do more than describe a way to understand an activity: they come to embody the dual cognitive/sensory processes of reading itself resulting in a new metaphorical activity in the reader's experience of the narrative. This embodiment comes about through the presence of reading and readers within a work of fiction which indicates the author is drawing special attention to the processes and experiences of reading for the work's actual reader. Metafictionality signals that the text is in some part also a story about reading and readers — crafted by the author's chosen metaphor(s) of reading at work within the metafictional reader(s) within the text.

Like all embodied metaphors, metaphors of reading highlight both sensory and cognitive elements, which the reader may act out in his/her own experience with a text: cognitively making sense of the narrative world, sensorily touching and spending time with the text, and bringing together sense and kinesthetic knowledge alongside higher order functioning to engage the self in the total act of reading. These multiple inputs, directed by the text itself and the author's 
vision for the readerly experience of the text, work to form a self-encompassing closed loop with the actual reader's experience moderated by the experience of the metafictional reader as a result of the metaphor(s) in play. Just as the narrative mimics and is shaped by the particular metaphors of reading present within it, the actual reader of the narrative mimics and is shaped by the particular ways of reading conducted by the metafictional reader(s) within the narrative. It is, however, important to note that this readerly experience will still be an intensely personal one as it is influenced by the reader's reading preferences, habits, and styles as well as the reader's cognitive and sensory background of experiences from which the narrative draws. ${ }^{24}$ In any given readerly experience, there is "a particular brain in a particular body in a particular environment, and not the playing out of a neural or genetic program" (Chemero 35). ${ }^{25}$ The reader's individual experience of a text is made up of a series of personal reactions of acceptance or rejection, sympathy or incredulity, recognition or confusion — all of which are informed by the reader's sensory experiences in the real world as evoked by the language, imagery, and form of the narrative - however, a text (and its author) sets the stage for the particular variety of reading experience elicited through the particular metaphor(s) utilized.

As reading is an act of the whole body - mind and senses - there is an incredible amount of potential metaphors available to authors that express the power and effect reading has on its

\footnotetext{
${ }^{24}$ George Zarkadakis identifies self-awareness as the mind's "escape-hatch" and "route to salvation from our metaphors and delusions" - a way to break free from the prescriptions of our evolved minds and "see our limitations and do something about them" (86). I agree that self-awareness and self-reflection can serve as powerful tools for readers to resist the readerly prescriptions of authors and texts, but I would add that usually these resistances are foreseen and mediated by the author as an intentional part of the reading experience (a concept to be discussed in greater detail below).

${ }^{25}$ In this quote, Chemero is not speaking about reading per se but rather the necessary focus on the individual within the dynamical analyses utilized in Radical Embodied Cognitive Science-a methodology which posits a move away from reliance on theories of mental representations to conceive of cognition.
} 
human subjects. ${ }^{26}$ Just as our language to describe the experience of reading is drawn not from one but from all of our senses, these potential metaphors derive from a variety of sensations, perceptions, and expressions of and from the sensory world. As such, my examination of reading metaphors will of necessity be relegated to the more common ones found in Western (and Western-emulating) metafictional narratives, with more metaphors left unexamined than examined. Metaphors of reading I do not individually discuss here (but which can be traced throughout different stories and are espoused by different authors and readers) include: "reading as magic/supernatural activity," "texts as strangers," "texts as friends," "stories as "messages in a bottle,", "reading as sleeping/dreaming," "texts as axes for the frozen seas within us," and many more.

Below I present a taxonomy of six Western embodied metaphors of reading which authors of metafiction put into motion through the figure of the metafictional reader. This list is far from all-encompassing and more often than not these metaphors are used in combination. In fact, I would argue that only in the rarest of instances does an author stick to a single metaphor of reading within any given text. There is also a great deal of overlap between these metaphorical activities and mappings. For instance, "Reading as Journey" and "Reading as Contact with the Past" offer alternative, but not entirely contradictory, ways to harness the human experience of time, and especially the role of the past in the present and future, as a way of understanding reading. Bearing this in mind, however, I find it useful to first consider these metaphors separately with their own textual and cultural histories influenced by social and technological

\footnotetext{
${ }^{26}$ Peter Mendelsund helpfully posits over sixty metaphors used to describe the reading experience in his clever little book, What We See When We Read: A Phenomenology with Illustrations (2014), emphasizing especially the metaphor of reading like "floating on a river" (307; 392-393).
} 
trends of their time before considering their combinations with each other within my individual analyses of narratives.

\section{Reading as an Encounter with Sensory Bodies}

This metaphor of reading is perhaps one of the oldest of our civilization, dating at least as far back as the Biblical account of the prophet Ezekiel who in a dream is given a scroll to eat containing the word of God which, though its words are full of lament and mourning, tastes sweet as honey in his mouth (Ezekiel 3:3-4). In this example, a discrepancy between the sweetness of the words in the mouth of the reader (which speaks to where the words are coming from, i.e. God, as well as the goodness/truthfulness of the text) and the woeful contents of their message (which speaks to Ezekiel's unpleasant charge to deliver God's message to the wayward people) is emphasized in the prophet's encounter with the text as a sensory body which acts on him in certain ways. ${ }^{27}$ While the specific metaphor of "texts as food" may seem to be more applicable here, the broader category of "texts as sensory bodies" allows for greater nuance in recognizing the multiple interactions between the body of the text and the body of the reader in terms of taste as well as smell, touch, sound, and sight. The connections between sense perceptions related to "Reading as an Encounter with Sensory Bodies" are in fact remarkably varied in response to the many real world effects that bodies (dead or alive, human or inhuman, willing or reluctant) can have on other bodies.

Mary Carruthers' analysis of the medieval discipline of memoria (trained memory) positions the act of reading, particularly the contemplative reading involved in the monastic activity of meditatio, as a process whereby the reader makes the meaning of the text his own to

\footnotetext{
${ }^{27}$ As we shall see, the reference to "honey" in the taste of a text shares characteristics with the "Reading as an Encounter with Nature" metaphor, discussed below.
} 
be used "as a source of communally experienced wisdom for one's own life, gained by memorizing from it” (202). Memoria as a process of memory-training, storage, and retrieval, emphasizes the necessity of digesting and ruminating texts as opposed to simply learning their contents by rote. According to Carruthers, "the process familiarizes a text to a medieval scholar, in a way like that by which human beings may be said to familiarize their food. It is both physiological and psychological, and it changes both the food and its consumer" (205). Just as a great deal of our food comes from the sensory bodies of plants and animals, texts as food have the power to act on their eater-readers in the same way as bodies - that is, even described in the most passive terms imaginable (dead plant- or animal-matter), texts can maintain agency in the effect they are described to have on their readers once ingested. And like the bread and the fish offered to the crowds by the Christ of the gospels, the words of a text are not exhausted by the indulgence of a given reader, but spring forth whole and wholly edible for each new one.

Furthermore, texts are not always pictured as the consumed object in this relationship, but can be depicted as bodies consuming the bodies of their readers, inverting the standard power-dynamic along with the simpler "texts as food" conception. This common medieval metaphor for books and reading is also connected to the monastic custom of reading during meals: a complementary filling of both mind and body (Carruthers 208).

In medieval traditions, the metaphor of "reading as eating" is metaphysically connected to visuospatial understandings of reading and memory in which texts are understood to produce sensory experiences on and in their readers. In particular, is the ancient metaphor of memory as a seal imprinted on wax - a metaphor that was itself transferred onto understandings of reading in their shared materiality and emphasis on visual stimulation (with "seal" and "memory" mapped 
onto "written words" and "wax" and "mind" mapped onto "physical text"). ${ }^{28}$ Carruthers identifies the medieval understanding of memory as a phantasm, imprint, or copy of some sense perception that is then seen and scanned by "the eye of the mind" - a process that renders visual and non-visual memories alike as "readable" images (19-20). According to the medieval understanding of memoria, this process is necessarily an active one of organization and structuring, otherwise the mind would have no way of retrieving the information when required. It is in this idea of imprinting and manipulating sensory experience in the mind that the digestive properties of rumination and absorption are linked. The tactile imagery associated with "texts as food" is bonded to the visuospatial imagery of "texts as secondary, imprintable minds" in which the reader actively transfers what he reads to his memory through a mental re-writing, a process which recalls the Ancient Greek verb used for "to read," anagignōskō: literally "to know again" or "to recollect" (Carruthers 34).

The broader category of "texts as sensory bodies" also contains the common depiction of texts as the offspring of their authors. Mary Shelley, for example, famously referred to her most famous work as her "hideous progeny" ("Intro" to Frankenstein 173), and texts have similarly been described by their authors as "orphans," "monsters," and "children" for centuries (Craik). Not surprisingly, similarities between the labor and birthing of these textual offspring and human children are also common, in that the writer first "bears" the seed of the book, "carries" it, feels its "birthing pains," and watches as the doctor/editor/reviewer holds it up and pronounces if it were satisfactorily formed or otherwise. The metaphor of texts as the progeny of their writers invites readers to see themselves as witnesses to the intimate parent-child relationship, perhaps scanning the face of the child for signs of the parent, perhaps reflecting that, after all, the apple

\footnotetext{
${ }^{28}$ Although the earliest usage of the seal-in-wax model of cognition is in Plato's Theatetus, Plato claims that this metaphor was already implicit in Homer and hints that the description is actually very old (Carruthers 24).
} 
does not fall far from the tree. When the discovery that such and such a person wrote such and such a book leads to surprise, the reader surely had in mind something like the metaphor of the text as the natural child of the writer. In all of these cases, texts are regarded as the prolongations of the author's body, flesh of my flesh, bone of my bone, suggesting that the intimacies between text and reader also involve intimacies with the author's own body.

As illustrated above, the metaphor of "reading as an encounter with sensory bodies" is commonly inspired by and described with language drawing from the sense of touch, with physical texts literally and figuratively laying hands on readers: caressing, touching, embracing, being absorbed by and leaving impressions on readerly bodies. Like human touch, the touch of textual bodies can be described as both pleasant or unpleasant, welcomed or threatening. Touch is commonly associated with health, especially bad health, so that texts can even come to be considered infectious and dangerous as perpetrators of diseased ideas or desires. (Touch in relation to sexual intercourse will be described in a separate category due to its own impressive range of possibilities.) This turn to touch in conceptions of reading hearkens back to Aristotle's famed wariness of touch as a method of gaining knowledge and his subsequent reluctance to give it a set place at either the top or the bottom of the sensory hierarchy. Western tradition has in turn typically mistrusted touch, connecting it to sinfulness, eroticism, the lower classes, and disorder (Jütte; Howes).

Touch is indeed disorderly, even in its own representations: after all, the human hand with which touch is often depicted is only a small part of our overall touch organ — the skin — but its use also masks the other touch-related senses the human body uses for making sense of its world (e.g. proprioception: our sense of our bodily position, as well as our senses of weight, resistance, and force). But as touch scholars such as Constance Classen, Laura U. Marks, and 
Katharine A. Craik have noted, touch plays an important role in facilitating our bodily perception and interpretation of the world outside the body; touch reminds us that in our shared materiality with other sensory bodies, we are permeable and conductive, vulnerable to contact with those bodies and to our own emotional responses to that contact. ${ }^{29}$ In Haptic Modernity, Abbie Garrington refers to skin as "hypothetical, a ground on which stories unfold" (19, italics in original). Thus, this border-world of skin and touch (a border that is not ever an absolute border) becomes one of the ways in which a reader experiences a text as well as a way for him to understand and conceptualize that experience.

The lived experience of this metaphor of reading on actual readers is one as varied and paradoxical as the experiences of flesh on flesh in readers' everyday lives. Some touches are unsolicited, unwanted, unexpected — resulting in extreme reactions from the one enduring the touch. A reader may become so moved by the touch of a text that he or she chooses to put it down to finish later or maybe never. Currently in academe, teachers are encouraged to warn literature students that dramatic, sometimes painful emotions can result from contact with texts, as stories touch on the scars and wounds we already possess from our experiences in life. We have known this to be the case for a long time, and the dangers inherent in the touch of texts on their readers has a history closely tied to the discouragement and even banishment of reading. This unwanted touch may be feared, such as the touch of a diseased person, an old withered hand, or one plagued with the marks of an old illness or accident. The touch may be aggressive or combative to the point of undesirable hostility. But at other times, the touches we feel are bolstering, strengthening, tying us to others, giving us a sense of ourselves and our communities. These touches too may be painful, but a collective pain, or a collective joy: a recognition that

\footnotetext{
${ }^{29}$ See Classen's The Deepest Sense: A Cultural History of Touch (2012), Marks' The Skin of the Film: Intercultural Cinema, Embodiment, and the Senses (2000), and Craik's Reading Sensations in Early Modern England (2007).
} 
there are others who feel as we do, hope as we do, and touch as we do. Texts too can touch us in this way. There is the touch of a friend: guiding, encouraging, demonstrating affection. There is the touch of a stranger: dangerous, potentially hostile, unknown or only half-known. Altogether, the touches of the sensory bodies of texts sometimes leave traces and sometimes go unremarked on the minds and bodies of their readers. In the end, it is the reader's reaction to the touch of the story which plays the most prominent role in the effect of this metaphor of reading on his/her experience of the text. The author encourages and enables this understanding of "reading as encountering a sensory body," but it is the reader's acceptance or dismissal of that encounter which results in his or her overall impression of (and from) the text.

\section{Reading as Journey}

The common conceptual metaphor of "life as a journey" often extends to the experience of reading fiction, relying on the reader's past sensory experience of movement and mobility to function. Stories are thought of as figuratively moving readers, who become "pilgrims," "travelers," and/or "sojourners" as well as transforming readers in their movement to a new state or understanding. The journey metaphor is frequently paired with the idea of texts as offering "an escape" which readers tend to characterize as a break from reality, a refuge, and even a druginduced state of disassociation. In terms of Conceptual Metaphor Theory's widely discussed concept, "Life as a Journey," the "Reading as Journey" metaphor suggests a momentary alternate route from the meta-journey of the reader's actual life.

Historically, "Reading as Journey" relates to medieval mnemonic techniques and textual transmission practices. From ancient times well into the Middle Ages, trained clerics physically traveled to and from scholars and monasteries to orally disseminate texts from memory-a 
process that even into the mid-fourteenth century, was commonly viewed as more reliable than the medium of print as scribal copyists and secretaries were seen as more likely to erase or otherwise spoil the text (Carruthers 202). But the monastic process of memoria itself was also locational in nature, as in Augustine's archetypal metaphor of memory as "a vast cave with many inner caverns in which all experience was inventoried" (Carruthers 181$).{ }^{30}$ The ancient Herennian architectural mnemonic system, revived in the late thirteenth century by Albertus Magnus and Thomas Aquinas, prescribes the use of physical places in the real world as mental loci used to structure memoria. These loci can be natural places (such as gardens and fields) and man-made places (such as houses and churches). The loci are then filled with memorable and striking objects, connected to specific memory-images in the mind of the individual user. The placement of both the memory locations and the objects contained within them are recommended to be diagrammatic so as to be "traveled" in clear topical and/or chronological sequences, such as a grid or chessboard (Carruthers 179). As a result, the student of memoria methodically moves from place to place as he recollects and orders his memories of texts, a process that also bears an interesting connection to the medieval romance's propagation of quests and journeys as the subject of narratives.

The modern popularity of considering reading as a journey extends to scholarly considerations of the reading experience as well. ${ }^{31}$ As discussed further in Chapter 5,

\footnotetext{
${ }^{30}$ The organization of memory into a compartmentalized container will be further explored in the metaphor of "Reading as Contact with the Past."

31 "Transportation Theory" is explicitly laid out in Melanie C. Green and Timothy C. Brock's "The Role of Transportation in the Persuasiveness of Public Narratives" (2000) as: "To the extent that individuals are absorbed into a story or transported into a narrative world, they may show effects of the story on their real-world beliefs. We conceptualized transportation into a narrative world as a distinct mental process, an integrative melding of attention, imagery, and feelings" (701). This definition follows Gerrig's much earlier description of the experience of transportation during reading in parallel to actual transportation and travelers.
} 
psychologists interested in the human experience of narrative, such as Richard J. Gerrig, specifically evoke the metaphor of "transportation" to describe the experience of "being lost in a good book." Although this term is often used interchangeably with others in academic parlance, terms such as "immersion" and "absorption," the word "transportation" invokes a sense of movement from one place to another, a journey that the reader willingly undertakes, which can be seen to parallel the journey of the protagonist of the book as in Joseph Campbell's analysis of the foundational story arc of the "Hero's Journey." The readerly sense of walking in a character's shoes as both travelling companion and voyeur is the effect of the metaphor in play shaping the experience of the "transported" reader.

The language of "Reading as Journey" is also used by scholars to describe the variations in reading experiences depending on the tastes and preferences of the reader as well as the style and plot-development of the text in question. ${ }^{32}$ For example, the long, arduous quest that makes up the Lord of the Rings trilogy sends the reader on a different type of journey than a quick jaunt through The Hitchhiker's Guide to the Galaxy — even though both series have travel and movement from a familiar place to an unfamiliar one at their hearts. While it has been suggested that due to its greater cognitive involvement, literary texts are less likely to be used for escapist reasons (Mar et al.), a journey of a different type takes place in literary works that involve forays into the complexity of characters' minds. The challenge to put into practice our Theory of Mind, according to some theorists, becomes the journey of the literary work as readers work their way through layers of available mental states. According to Lisa Zunshine, the differences in readers'

\footnotetext{
${ }^{32}$ Mendelsund claims that "If texts were roads, some would be made for driving quickly... [some] would be made for walking" (96). He confesses his own preferences here: "The best book for me: I drive through it quickly but am forced to stop on occasion, to pull over and marvel. These texts are texts meant to be reread. (The first time through, I can tear along, as fast as possible, and then later, I'll enjoy a leisurely stroll—so that I can see what I've missed.)" (96).
} 
processing of stories appears in the fourth level of intentionality (as in "I think that she believes that he knows that you should do X") — not in their ability to understand or remember the content of the story, but to work through and hold in their minds the different layers of informationorigins (28-29). Zunshine suggests that literature - especially the texts that put these high demands on readers - can build on our capacity for Theory of Mind by challenging readers to go to new places, cognitively speaking. Interestingly, while the related terms of "immersion" or "absorption" might better suit her purposes, Zunshine continually relies on the language of transportation, navigation, and movement to describe her sense of readers being pulled further along and further in by the text. ${ }^{33}$ Suffice it to say that the plot of a story is by no means the only journey taking place in reading — although it is perhaps the easiest one to talk about. Readers are also taken on journeys into characters' minds and personalities all while navigating their private text-directed journey into their own minds and sense of self - a process that recalls monastic ideas of memory and reading as locational in nature. ${ }^{34}$

What this metaphor of reading looks and feels like for the reader is equally as various and idiosyncratic as the "texts as sensory bodies" metaphor. Readers come to texts with individual journey preferences and expectations; if the text does not meet these, the reader has the choice to continue on in the discovery of what this new kind of journey might mean and require — or not. The parallel between "transportation" (as it is used in academic studies of reading) and a loss of

\footnotetext{
${ }^{33}$ When it comes down to it, the difficulty in describing almost any situation or event without relying on the language/imagery of movement and travel suggests how foundational our sense of our own moving bodies is to our sense of our relation to the world - and to the ideas, theories, observations, and conclusions we come to concerning the nature of reality. If humans were more stationary, planted and treelike, how might our overarching language structures have developed to take into account that particular view of the world? It's difficult to say, not being a tree, although Daniel Chamovitz's What A Plant Knows: A Field Guide to the Senses (2012) provides an intriguing starting-point to such considerations.

${ }^{34}$ Haruki Murakami's Kafka on the Shore, discussed in Chapter 5, provides a good example of a reader journeying through the minds of others through his readings of different texts which then directly affects his own journey in the decisions he makes of where to go and who to trust.
} 
the reader's sense of time and place is an intriguing glimpse into this experience: the reader by necessity must relinquish his or her hold on the present time and place in order to be fully transported to the time and place of the text. This phenomenon occurs both literally and figuratively, if we consider time to be a human construct to make sense of the world, and one that people experience differently at different points in their lives. As a result, speed (distance divided by time) becomes more arbitrary in terms of reading, and the time experienced by the reader can be thought to pass both fast and slow in relation to the concurrent experience of time by non-readers: the reader looks up suddenly and is surprised to see from the clock and the position of the shadows on the wall that it is already well past afternoon and approaching evening - time has speed up while the reader was engrossed in her transportation to another time and place; conversely and simultaneously, this reader has lived days, years, decades in the lives of others - time has also slowed to accommodate. Similarly, place: the reader losing track of where she is and what is happening around her - a state of being that may be actively sought out by readers unhappy with the current place they are physically stuck in. The smells, sounds, tastes, sights, and touches of the world of the book are granted the power to overlap and overshadow those of the world of the reader. Altogether, this sense of total transportation shares similarities with other situations of which we sometimes say with a shock that we have "lost track of time": being totally engrossed in a deep conversation with a friend, watching a long and engaging film, becoming completely caught up in a complex and involved project, etc. The fiction-reader's experience is wonderfully hybrid: a combination of the elements of these similar experiences, bringing together the intentional loss of place/time, pleasure, intellectual stimulation, and social engagement in a journey that relates to others but also retains its own rules and existence. 
A final aspect to consider of the reader's experience as mediated by the "Reading as Journey" metaphor is that of balance and equilibrium. A large part of the general human experience is in finding and maintaining balance. While it may be, as Lao Tzu intones, that "stillness reveals the secrets of eternity," much of the balancing in which humans engage requires movement, or a balance between movement and stillness. From the very beginning of our lives to their end (at least in this world), movement is power, a sign of life and vitality, while stillness is often death, pain, and loss. The journey to find balance - or to find a sense of inner stillness - is counterintuitively expressed in such terms: traveling in order to get to a static state (which is not really static). But such is our experience of our bodies at work balancing, stretching, and finding a distribution and an equilibrium we can work with. This search, also, is a part of our experience of journey. In the reader's life, perhaps there is a need for balance (possibly time spent reading is part of the problem); perhaps the reader intentionally reads in search of something he feels will tip him back from the edge of whatever pit he has come to; perhaps the desired journey to a new place is because the old one has a destabilizing sense of unbalance. While the text and its author provide and encourage the metaphor, once again, it comes back to the reader's own sense of his journey which largely determines how the experience will unfold and which direction he will ultimately take: further in and through or back out from the way he came.

\section{Reading as Sexual Intercourse}

The "Reading as Sexual Intercourse" metaphor, a subset of the "Texts as Sensory Bodies" metaphor, holds its own in the contest for the "ultimate" metaphor of reading according to some critics. Robert Scholes, for instance, writes that "The archetype of all fiction is the 
sexual act... In the sophisticated forms of fiction, as in the sophisticated practice of sex, much of the art consists of delaying climax within the framework of desire in order to prolong the pleasurable act itself" (26). Similarly, Peter Brooks claims that "Desire as Eros, desire in its plastic and totalizing function, appears to me central to our experience of reading narrative" (132). Accordingly, the language and imagery of the "erotics" of reading flow from the language and imagery of human sex acts, that of: arousal, chase, tempting and catching, desire, pleasure, delay, intensity, and, of course, climax. When the act of reading becomes equated with sexual intercourse and intimacy, the text (and vicariously, the text's author) is placed in the position of lover in regards to the reader. Accordingly, the text becomes the site of erotic contact between the reader and the narrative, the reader and the author, and even the reader and other readers. Again the lexis of touch is employed by this metaphor, particularly vulnerable touch, as in order for physical intimacies to occur, the reader must allow himself to be vulnerable to the touch of the text and vice versa. This metaphor also alludes to the physical intimacy between the body of the a text in book-form and the body of its reader: the reader carries the text around, takes it to bed, touches it, cries on it, spills coffee on it, leaves crumbs in it, and allows it to witness emotions and expressions that few in the reader's actual life get to see. Even e-readers, although commonly considered less sensual than physical books, are operated through the medium of touch and are kept in close proximity to their readers so as to facilitate intimate moments between reader and narrative.

We may think of this metaphor as more closely tied to narratives that contain sexual scenes and intimacies, but that needn't be the case. While the genres of the mass-market romance and love letter explicitly take sex as their subject, authors can employ this metaphor even in a 
narrative void of graphic sex scenes and torrid love affairs. ${ }^{35}$ The language of love imagery draws on all of the senses, directing and paralleling our experience of love as a full-body phenomenon (as opposed to something you see or touch or smell only). This imagery, within narratives, is similarly expressed in as many ways as the human body can experience all the stages of love up to and including sexual intimacies. With new love, when the lover is still in the smitten stage and anticipating sexual consummation, the body undergoes noticeable changes: dopamine levels rise, mood swings can occur in which the "afflicted" may experience euphoria one minute, a racing heart the next, trouble sleeping, despair, raging anxiety—and everything in between. A lover may develop an obsession for his beloved and/or an emotional dependency including any or all of the unattractive qualities of jealousy, possessiveness, fear of rejection, separation anxiety, etc. Being in love changes the way we think, it changes the way we feel, what we do, where we go; it changes our priorities and our plans for the future; it makes us want more and feel dissatisfied with less. More than anything, love and sex makes us feel that we've lost some sense of control over our lives, our emotions, and our bodies. So too, can reading.

A reader takes the risk of obsession every time she picks up a text, unable to know if "this one will be the one"- the text she "can't put down," the one that even though she has to work in the morning, she'll stay up until 4 a.m. to finish. This could be the text that changes everything: the one he can't stop thinking about days and weeks after he's finished it. This may be the text that changes plans and priorities, bodies and minds. A reader cannot know when love will strike: it may be the beat-up, 75 cents paperback from last week's yard sale, it may be this year's Pulitzer Prize winner. But many readers have known this frenzy of reading-sickness—for

\footnotetext{
${ }^{35}$ Research into the mass-market romance genre suggests that the bodily/sensory satisfaction gained by the romance's female readers is linked to a corresponding social satisfaction which ultimately maintains the status quo of women in a patriarchal society (see Janice Radway's Reading the Romance).
} 
some it may be the only way they can read. The language of love, infatuation, intimacy, obsession, and surrender is also the language of this metaphor of reading.

It is crucial to note that this metaphor also functions within a gendered pseudo-history of controlling male authors dictating to passive female readers. ${ }^{36}$ While traditionally the dichotomy suggests that these subject/object roles be filled by male/female persons respectively, Susan Winnett points out that although the reader may initially be conceived as female to complete the fantasy of a pleasurable, reciprocal relationship between writer and reader, the pleasure of the reader is posited as a distinctly male one dictated by the arousal $\rightarrow$ delay $\rightarrow$ consummation trajectory of male sexual pleasure. Thus, the erotics of reading becomes a "platonized, legalized, entirely male circuit of desire" in which the reader by necessity must either be male or willing to "read in drag" (Winnett 140; 154). Winnett further considers a model and logic of narrative that conversely follows a distinctly female bodily experience - a model and logic that recognize that the female equivalent of the male orgasm (defined as a visible intensity aroused to a state of discharge) is not the female orgasm but rather the act of giving birth and breast-feeding-two activities in which female pleasure is not constituted (as it is in the male orgasm) as a desire for an end that is death-like but rather as the desire for an end that is a beginning. Winnett's counter to the inherently patriarchal (i.e. Freudian) "Masterplot" steeped in male bodily experienceparticularly male sexual experience — speaks to the variance allowed by this metaphor of reading which is dependent on both cultural sex practices (the language permissible to speak of such acts, the distinctions between acceptable and unacceptable acts, the portrayals of sex acts that circulate within a society at a given time, etc.) and individual sex practices (the author's and the reader's).

\footnotetext{
${ }^{36}$ Friedrich A. Kittler's analysis of German Romanticism within his groundbreaking work, Discourse Networks 1800/1900 (1985), highlights this gendered dichotomy in connection to literature as a consumption of discourses which begins in the Mother's mouth.
} 
As seen in "Reading as an Encounter with Sensory Bodies," the "Reading as Sexual Intercourse" metaphor ultimately leaves both text and reader vulnerable - the text to being "friend-zoned" or worse, discarded unfinished by a reader, and the reader to being wooed and then dropped abruptly by an unfavorably ending by the text. As opposed to the chance and/or casual encounters we may have with other bodies - even those of friends and family, a sexual encounter with another body leads to a deeper level of sensation, knowledge, and intimacy. Lovers come to know all aspects of each other's bodies through a willingness to be vulnerable and through repetition. Thus, this metaphor can also be utilized to consider readers' preferences for certain texts to the extent that they choose to reread previously "plundered" narratives and simultaneously relive that initial pleasure while experiencing it anew.

But unrequited love can also exist in the act of reading as, like any romantic relationship, reading is a two-way street with both text (and vicariously author) and reader providing the necessary components for love to strike. The reader may initially feel dislike or indifference towards a text, but as the relationship continues, passion may come to grow between them as something about the story or a certain character or the language strikes a chord in the reader. Physically the position of the reader towards the text may change as well: the distance of premature skepticism fades, the reader's face draws closer to the pages, the text held now in both hands instead of one. There may be ups and downs: cries and expressions of shock at the turn of a plotline or the death of a character; there may be moments where the reader feels, "I've had about all I can take of this," before the story draws him back in once more. As the pitch of the relationship rises to an extraordinary height, the reader and text will (hopefully) be drawn together as close as they can be in some unexpected but necessary climax. With all the potentials and possibilities of the experience of love and intimacy made available by this metaphor of 
reading, a given reader's experience with a text depends largely on the "fitness" between the reader's individual conceptions of the activity elicited (in this case, sexual intercourse) and the author's conceptions of it inscribed within the figure of the metafictional reader.

\section{Reading as Contact with the Past}

The metaphor of "Reading as Contact with the Past" is partially an extension of the conceptual metaphor of "Activities as Containers." According to Lakoff and Johnson, thinking of our experiences and actions as physical objects with insides and outsides allows us to impose artificial spatial boundaries on them which further allows them to be categorized, grouped, and potentially understood (25-32). In regards to texts, the container metaphor can facilitate an understanding of the text as containing the general past, past readers, past authors, and past experiences_-including the reader's own past if the text has been read by her before. This metaphor also extends to a complicated conflation of space, time, and language: the words of the text are thought to constitute the space to contain and order time(s); meanwhile the time that the reader (and author) puts into the text is held onto along with the original time-period the text was written in and for; furthermore, the reader, by reading the container-text, now has access to these different times and figures but only because of her own temporal input of past sensory memories reawakened in the present moment of reading. In effect, all three distinct times - the reader's time, the author's time, and the narrative's time_-run parallel during the reader's enactment of reading. Similarly, the "Contact with the Past" metaphor can be connected to the common readerly desire to access the past, with authors sometimes compelled to awaken their readers to the impossibility of holding onto time, even in the special time-and-space container that is the text. But the lure of reading, according to this metaphor, is in the compelling pretense that 
reading does offer the reader the possibility of making contact with a different time from her own, and furthermore, that she can connect to people from different times-even her younger self — through the act of reading. Similar to the "Reading as Journey" metaphor, the reader must be willing to lose, momentarily, a sense of herself in the present moment and surrender to a time contained within and by the text in order to make contact with it.

The container imagery inscribed in the "Reading as Contact with the Past" metaphor has a direct connection to medieval conceptions of memory as a storehouse. The material-spatial nature of the "memory-images" in medieval theories of cognition suggests the need for an equally material-spatial location for those "memory-images" to reside: a thesaurus (which translates as "storage-room," "treasury," and "strongbox"). As we've seen, in medieval tradition the connection between processes involved in making and retaining memories and acts of reading are closely related due to a fundamental understanding of reading as a process of memory-formation. Thus, the medieval metaphor of "memory as a storehouse" is easily translated to "books as storehouses" and, as Carruthers' title, The Book of Memory, suggests, memory as a book. Carruthers also notes that although the specific language used to describe these storage locations changes to reflect the most common forms of writing at the time, the general imagery remains the same. ${ }^{37}$ For instance, when texts were produced in the form of scrolls, imagery concerning the storage of memory-images took the form of cella (whose English derivative, "cellar," maintains a sense of "storeroom"). Cella could also refer to a stall or nesting-place for domesticated animals and birds as well as the compartments made by bees for

\footnotetext{
${ }^{37}$ Carruthers also suggests that this metaphor's presence in both Biblical and classical tradition enhanced its prestige as a governing archetype in the eyes of medieval scholars and thinkers (33). This observation provides a basic model for back-tracing contemporary metaphors for books and reading, that is: looking to traditional authorities, not for the origins of metaphors necessarily, but for pinpointing historical rises in popular use and general acceptance.
} 
their honey. ${ }^{38}$ Carruthers suggests that the architectural honeycombed appearance of cella used for the storage of scrolls, reminded ancient writers, such as Plato, of the appearance of "pigeonholes" and beehives, which also connected to an ancient metaphorical concept of ideas as birds, especially pigeons and doves (42-43). Presumably, when the codex-book was adopted in place of the scroll, and the storage of codices shifted from holes to shelves, the idiom fell out of use (Carruthers 43). Additionally, the terms sacculus, scrinium, male, cavus, and arca-all of which refer to compartmentalized bags, pouches, boxes, chests, or rooms for storing and/or transporting treasures, especially books - were metaphorically used at various times to refer to the mental storage of trained memory (Carruthers 45-55). Arca, in particular, as a metaphor connecting "box" with the Biblical imagery of Noah's Ark and the Ark of the Covenant (which held the chosen people of God and the record of God's commandments to the people, respectively) came to be connected to the development of a Christian's moral life, i.e. the notion of the body as a temple of the Lord (Carruthers 51-54). Arca sapientiae as both the process and product of a medieval education alluded to the mental library every scholar carried around with him, carefully organized and various in contents; the arca is both memory and book, the container and the contents, as thesaurus referred to both the treasured contents and the strongbox itself (Carruthers 41; 54-55). Reading — as a process of memory-making and retaining — is similarly both the means by which a reader makes contact with the past and an experience that becomes a memory itself, absorbed and organized so that he may forever have access to it as needed in the future.

In some ways, the "Contact with the Past" metaphor of reading can become more than a metaphor as texts and particularly texts in book-form can literally function as containers of mementos and physical traces of memories of our past. (In this conception, things come to stand

\footnotetext{
${ }^{38}$ The imagery of honey and bees, again, looks to the "Reading as an Encounter with Nature" metaphor.
} 
in for differentiated moments in time so that: things $=$ the time they come from.) These possibilities are important to consider because for many readers of novels, a text is a material book. These contained memories vary from memories of situations exterior to the book (such as where we were or what we were doing at the time when we bought the book or last read it) to memories of situations directly arising from the book (such as our emotional reactions to the story itself as retained by stains, dog-eared pages, underlining, and other marginalia). These latter contents within a book may have nothing to do with the story, but everything to do with the shape or location of the book as a physical object: its ease of access as a handy depository for some trivial item or the ease with which a secret can be hidden and found again by its concealer. ${ }^{39}$ Summer Brennan, in "On the Heartbreaking Difficulty of Getting Rid of Texts," writes that in her attempt to sift through her accumulated texts to decide which she would keep and which she would let go of:

There was a surprising amount of stuff between the pages-letters, tickets, photographs, receipts. I found my New Year's Eve resolutions for 1998; a slip of paper acknowledging my plea of GUILTY to a speeding ticket and instructing me to pay $\$ 125$ to the town of Athens, New York; a hospital bill for \$564; a Xeroxed page from Walt Whitman's Song of Myself with the stanza circled that begins I have said that the soul is not more than the body; the muted floral wrapper for fig apricot soap, still fragrant; the boarding pass for a flight from New York to Stockholm; a yellow hall pass from my California high school.

\footnotetext{
${ }^{39}$ My mother's hardback copy of Little Women has pages with flower-shaped stains from the roses I pressed in it from when I was a flower-girl in my aunt's wedding. I didn't leave them in that particular book because I was reading it at the time or because they fit the story, but rather because it was the thickest book I had in my room.
} 
Brennan concludes that despite their common categorization as object, "[books] are not impersonal units of knowledge, interchangeable and replaceable, but rather receptacles for the moments of our lives, whose pages have sopped up morning hopes and late-night sorrows, carried in honeymoon suitcases or clutched to broken hearts." Books become an extension of their readers' lives in what they come to contain of us.

Shared books - library copies, books circulated among friends, used books rescued from recycling bins - also contain traces of their previous possessors which then become a part of the current reader's experience of them. Virginia Woolf speaks at length about this "long succession of readers" who leave their marks on physical texts: “... other hands have been before us, smoothing the leather until the corners are rounded and blunt, turning the pages until they are yellow and dog's-eared. We like to summon before us the ghosts of those old readers..." (The Second Common Reader 40). ${ }^{40}$ When a reader picks up a previously-read book and begins to thumb through it for the first time, she can perhaps come to know as much about the other reader(s) as she does the book itself. In instances of heavily marked books, that other reader(s)'s experience may even come to alter that of the current reader, in that she now has to filter her experience of the text through the lens of whether she agrees or disagrees with the responses of the previous reader. At other times, the traces left by previous readers may usurp the book entirely — an old family Bible with recorded birth and death dates in faded calligraphy inside the front cover, passed down from one generation to the next, changes at some point from a book to

\footnotetext{
${ }^{40}$ My recently purchased used copy of the Everyman's Library Pocket Poems of Rilke contains an inscription which summons to mind these ghosts: “To: Clint/ Love Lauren/ Happy Valentine's Day 2006." I wonder who they werethese previous possessors of my book. Why did Lauren choose Rilke as an expression of her love? Did Clint ever read the poems inside that she wanted him to read? (There is no sign of this. There are no other marks in the book.) Did Clint see the inscription on the inside cover? Did he even receive the book? Why was it discarded to come into my possession in 2015? Did Clint love the book's giver in 2006? Does he love her still?
} 
be read to a mere record — existing only as a container of the past—and as such is no longer read as a book (especially when it is written in Old German). ${ }^{41}$

Woolf considers (in both her novels and her essays) another significant element of the "Reading as Contact with the Past" metaphor: the containment of the author in the text. For just as the reader can experience an encounter with the contained lives of fellow readers, he can also come to know indirectly something of the thoughts, opinions, desires, experiences, and observations of the author through his reading. More specifically, the reader can come to an understanding of the author's view of the world — and of reading. As discussed in greater detail in Chapter 2, Woolf considers texts to contain the unmistakable forms of their authors, "the mould of the body and mind entire," whereas it is readers who haunt the unfinished manuscript when it is still in the hands of its writer for, as Woolf says, "a writer is never alone. There is always the public with him-if not on the same seat, at least in the compartment next door... a strange travelling companion" ("Reading” 157; "Character in Fiction" 432). As such, the author's stance toward this ghostly choir of the reading public is inscribed in the text itself: her desires for her readers and expectations and intentions for their reading experience are embedded in the text at its very heart. This symbiotic relationship underlies the parallel between the experiences of readers within a text and the experience of readers of that text.

Besides readers, authors, times, and memories, texts, of course, contain stories. Because they existed prior to our encounters with them, they are necessarily stories from the pastalthough perhaps not of our own past. An evolutionary view of fiction claims that the purpose of stories, and the reason behind our unquenchable obsession with them, is that they provide us

\footnotetext{
${ }^{41}$ Texts as containers of language is another fascinating aspect of this metaphor: the modern reader, through reading, can encounter old spellings and usages of words, outdated modes of expression and references, old stereotypes and prejudices embedded in the language that have since fallen out of use, etc.
} 
with "safe" experiences to learn from so that we are better adapted for dealing with future experiences. Whether or not this explanation is entirely satisfactory, the emphasis on learning from stories (and the past informing future concerns) holds a primary position in considerations of their purpose. Texts offer at least one perspective (the author's), although probably others, for the reader to consider in terms of personal connection and applicability. ${ }^{42}$ A metafictional example of the misuse of such "fiction-sourced" information about the past comes from Jane Austen's Northanger Abbey. Towards the end of the novel, Catherine Morland's indulgence in Gothic novels featuring an imagined past from the minds of Ann Radcliffe and other writers has led her to question the activities, gestures, expressions, and very character of her host - the father of the man she is attracted to and has every motivation to think kindly towards. Fortunately, Catherine is made keenly aware of her error in judgement by Henry's cutting but honest rebuke: "If I understand you rightly, you had formed a surmise of such horror as I have hardly words to-Dear Miss Morland, consider the dreadful nature of the suspicions you have entertained. What have you been judging from? ... Consult your own understanding, your own sense of the probable, your own observation of what is passing around you... Dearest Miss Morland, what ideas have you been admitting?" (186)

In this instance, specialized information about "the past" provided by fiction led Catherine severely astray because she incorrectly applied that information to present situations in her own life: Catherine interpreted the portrait of a passionate, dangerous, and obsessive streak within

\footnotetext{
${ }^{42}$ Gerrig's findings are that there is "no psychologically privileged category "fiction," ' in that readers do not process assertions from fiction any differently from how they process assertions from nonfiction (197). He concludes that, counter to common belief, the default it to accept what we read in fiction as being "true" and then retroactively reevaluate based on its socially-assigned category as "fiction."
} 
human nature, as put forth in her Gothic novels, as universally held. She was thus primed to see evidence of this view in the actions of those around her (a self-fulfilling prophecy), and had to be reminded by an outside viewer that she ought instead to rely on an understanding of the world based on her personal observations of national, social, and religious law and ideas at work in the behavior of those around her. Henry's view of the world does not allow for the kind of passionate romance and desperate events that are described in Catherine's texts to occur in reality. His lesson is not that Catherine's texts in and of themselves are harmful or that their available contact with a fictional past was entirely divorced from reality, but that the tender reader should not allow their depiction of an imagined past to sway her view of the present world. But Catherine does grow as a result of the experience: though she now doubts the existence (in England, at any rate) of the extremes presented by Mrs. Radcliffe in which humans are angels or devils, she concludes that "among the English... in their hearts and habits, there was a general though unequal mixture of good and bad" (188). Accepting imperfections in herself and her friends, as opposed to taking them as signs of a hidden sinister nature, Catherine is returned to her earlier sense of happiness a little wiser in her understanding of divisions between herself and the Gothic view of the past in which she indulges.

The crowded container that is the text is open for the reader to peruse and ponder as desired. The presence of this reading metaphor in play within the narrative does not necessarily indicate the reader will meaningfully encounter all of the text's contents through her contact with the past, but it does provide yet another way for the author to mediate the reader's experience by drawing attention to the availability of those contents. The reader's reaction to the traces of past lives - the marks of previous readers, the shape of the author's mind in the shape of the narrative, the potential "lessons" offers by the stories, etc.-relies greatly on which elements the reader 
chooses to bestow his attention. At the other end of the spectrum, the container can always be left to sit on the shelf, its contents unknown and forgotten.

\section{Reading as Performance}

Reading as a performed activity encompasses the exertion of power by the author/text over the physical body and mind of the reader. In a sense, the reader is always compelled to act out an experience dictated by the author, regardless of what it is; the reader's only recourse is to put down the text. ${ }^{43}$ But authors focusing on "Reading as Performance" tend to press on the image of the reader as a reflexive actor of the story, both cognitively and sensorily. Thus, dictation, compulsion, power, command, and struggle are situated within the realm of this metaphor, strongly connected to conceptions of supposed "right" and "wrong" ways to read as well.

Just as the genre of travel-journal may seem to be more closely tied to the "Reading as Journey" metaphor, and the romance may seem to implicitly contain the "Reading as Sexual Intercourse" metaphor, we may initially think of drama and oral narrative as the genre closest to the "Reading as Performance" metaphor. But as seen in these earlier metaphor descriptions, the expectation that the text's genre dictates the author's choice of reading metaphor is not always borne out in practice. With that being said, drama and performance theory has much to tell us about how reading can be understood as a type of performance. Brechtian Epic Theatre, for instance, strives to continuously retain audience members' critical awareness of themselves as viewers of a drama (which ought to inspire rational self-reflection and potentially action according to this theory) by highlighting the play's representational nature. This concentration on

\footnotetext{
${ }^{43}$ Mendelsund suggests that readers "are both the conductor and the orchestra, as well as the audience" (160) and that reading a novel means the reader is "producing a private play of sorts" (216).
} 
the constructed reality of the play is intended to lead to the audience's realization of the constructed nature of their own reality. In this style of theater, the "performance" aspect is at least half conducted by the audience members themselves (in that analysis and application is just as much a part of the play's performance as what happens on stage) as opposed to the conventional model of a dichotomy between the players acting the play and the audience viewing the spectacle from their separate planes of existence. But drama history and theorizations remind us that even this "traditional" view of drama is not necessarily an accurate depiction of the reality of play-going: in Shakespearean Sensations, for instance, editors Katharine A. Craik and Tanya Pollard undermine such simplified conceptions of historical performances by emphasizing the role of the body and sensory stimulation in Early Modern experiences of performances (and readings) of literature. As such, Early Modern audiences sought out different encounters with literature in the expectation that the texts would perform on their bodies in multisensory ways such as: encounters with fear as a bodily disease (the gradual consumption by fear undergone by the title-character in MacBeth), the shocking withhold of affective release and closure (Iago's lack of confession in Othello), the role of the senses in foolish self-love (Malvolio in Twelfth Night), and the private bodily pain of devastating grief (the lovers in Venus and Adonis). ${ }^{44}$ These differing theorizations of performance remind us that, whatever the desired outcome (on the part of the director, performers, or playwright), passivity is not a part of the audience's experience. Reading shares this in common with drama performances, in that the text can be thought of as actively playing on and in the body of the reader.

\footnotetext{
44 These examples come from individual essays included in Shakespearean Sensations: "Feeling fear in MacBeth" (pg. 29-46) by Allison P. Hobgood, "Hearing Iago's withheld confession" (pg. 47-63) by Allison K. Deutermann, "Self-love, spirituality, and the senses in Twelfth Night" (pg. 64-82) by Douglas Trevor, and "Shakespearean Pain" (pg. 191-207) by Michael Schoenfeldt, respectively.
} 
Readerly performances of narrative are both cognitive and sensorial in nature. The reader walks away from the text with some idea of what he has just read: he thinks of how he could describe this book to a friend; he thinks of his favorite scenes or moments; he thinks of how he likes this book in comparison to other texts; he thinks of any gaps or disappointed expectations in his overall experience of the plot and his knowledge of characters' motivations, understandings, and actions. The reader's cognition is awakened by the opportunity to encounter other minds and other worlds that can be, to some extent, known and puzzled over; the text enlists the services of cognitive processes the like of which cognitive science thrills to unpack and pin down.

Simultaneously, the performance of reading works on the reader's body. Performance is closely related to the sense of touch (the pliable reader being moved in definite ways), but it is also aligned to the sense of sight—-both in terms of the reader "seeing" the performance of the book played out before his eyes and the author looking over the shoulder at the reader's performance of the book. In this way, the book itself becomes the eyes and hands of the author: directing, manipulating, and witnessing the reader's experience with the book. ${ }^{45}$

The performance of emotions, a performance related to both sensation and cognition in the readerly experience of fiction, is typically assumed to occur in encounters with literature-if not always with (or too much with) fiction in general (depending on the theorist). As discussed in a previous section, the question of whether that emotion leads to any meaningful or sustained change in the perspective or action of the reader remains an open debate, but the arise of an emotional response to the story is presumed to be intentionally orchestrated by the author for the

\footnotetext{
${ }^{45}$ Anna Wierzbicka's analysis in Experience, Evidence, and Sense: The Hidden Cultural Legacy of English (2010) of what she calls "the linchpins" of entire networks of meaning in the English language ("experience," "evidence," and "sense") remind us that philosophical domination and cultural knowledge (and lacks within knowledge systems) are already always embedded in the linguistic system we use to explain our mental framing of our understanding of the world around us.
} 
reader. In The Rhetoric of Fiction, Wayne C. Booth concludes that "Every literary work of any power... is in fact an elaborate system of controls over the reader's involvement and detachment along various lines of interest," adding that "The author is limited only by the range of human interest" (123). Booth goes on to analyze the readerly pleasure which can spring from a reader's contemplation of an author's skill—particularly an aesthetic achievement of distance (120). This distance, according to Booth, inspires different types of readerly interest such as: intellectual curiosity about "the facts," a desire to see the overall pattern or form completed, a practical desire for the success or failure of a certain character, or the hope for an intellectual, situational, or moral change in a character (125-133). But disruption, interruption, and disorder can provoke a strong readerly emotion to the text as well. In controverting readers' expectations or desires, the author can direct readers into performances of anger, dismay, or even outright rejection. Ian McEwan's Atonement contains such a disruption, requiring the reader, at the close of the book, to reevaluate what she previously thought to be true; this reader has a choice: to accept this unexpected turn of events (and, subsequently, McEwan's portrayal of the beauty and power of story-telling to allow for some type of redemption) or to reject the ending, permitting it to negatively skew her opinion of the book as a whole. The willingness of the reader to accept these unwanted impositions or hold out as long as possible against them will take the readerly performance of the text to different outcomes; nevertheless, the script (as laid out by the author) will always remain the impetus for the reader's attitude towards his or her experience of a particular text. ${ }^{46}$

\footnotetext{
${ }^{46}$ This brings to mind the internet's year-long span of "Jon Snow's not really dead" theories in regards to HBO's Game of Thrones. Viewers could not accept, despite all evidence to the contrary and the show's famed habit of killing off beloved characters, that their favorite, Jon Snow, could really be dead. And in a way, they got their wish when the show brought him back to life in Season 6. Since author George R.R. Martin hasn't written as far ahead as the latest TV season, fans have no way of knowing if Snow was always destined for resurrection or if the decision was due to their impassioned and often threat-laden pleas for his return.
} 
Utilizing metafictional readers, authors can choose to hit the metaphor of "Reading as Performance" on the nose. For example, the narrator of Michael Ende's The Neverending Story describes the protagonist Bastian's first encounter with "The Neverending Story" in a textshop, before pausing to speak directly to the reader:

If you have never spent whole afternoons with burning ears and rumpled hair, forgetting the world around you over a book, forgetting cold and hungerIf you have never read secretly under the bedclothes with a flashlight, because your father or mother or some other well-meaning person has switched off the lamp on the plausible ground that it was time to sleep because you had to get up so early-

If you had never wept bitter tears because a wonderful story has come to an end and you must take your leave of the characters with whom you have shared so many adventures, whom you have loved and admired, for whom you have hoped and feared, and without whose company life seems empty and meaninglessIf such things have not been part of your own existence, you probably won't understand what Bastian did next. (11)

[What Bastian did next, of course, was to steal the book.] Such an address on behalf of the narrator clearly indicates the sort of readers the author had in mind reading his book. These readers are the ones who, despite the narrator's questioning aside, will be able to identify with the protagonist in his compulsive desire to possess the book of all texts and will be more likely to cheer Bastian on, first in his reading of the book and later in his saving of it. Yet similar to the opening of Calvino's If on a winter's night a traveler, with every repetition of "If you" in this early passage, the narrator carefully crafts the performance of the actual readers of the work; 
although the text sets up an expectation for "if readers read this way," the effect transforms, for the actual reader, to "when you read this way." For if the reader does not read in this prescribed fashion, according to the narrator, the remainder of the story will be unfathomable to him. This prescription is a subtle but imperative script for "right" reading, and a "right" reader will, accordingly, be possessed of "burning ears and rumpled hair," will remain impervious to extremes in temperature and hunger, will be importuned by sleepless nights, and will surrender to emotional reactions expressed in "bitter tears" - in short, the proof of a performance of reading will be seen and known by alterations in and on the reader's body.

\section{Reading as an Encounter with Nature}

One of the great paradoxes of reading is the persistent belief that it draws us toward a closer understanding of the world and the people around us while simultaneously pulling us away for extended periods of time from their company. The "Reading as an Encounter with Nature" metaphor demonstrates how the two can be concurrently true, in that readers are allowed to feel they have a special connection to and with the world while reading which can potentially transfer to knowledge about the "real world" (knowing things about the narrative world intimately and omnisciently as guided by the author, creating predictions about probable future events, etc.) — even as they cannot be physically doing much in the real world at the time of their reading (depending on whether getting a sun-burn while lying on a blanket counts in that category). Narratives that utilize this metaphor of reading draw the reader's attention to details that would otherwise be overlooked, just as we typically think of our experiences with nature as drawing our attention to sensations we don't typically pay attention to in our usual human "habitats" - i.e. the insides of rooms, hallways, and vehicles. The story need not take place in the 
woods or contain Arcadian characters for this metaphor to be evoked; the reader may instead be pointed to consider unacknowledged or unnoticed aspects of human nature or behavior as opposed to aspects of the characters' natural world. In Gloria Naylor's Mama Day, George slowly woos the beautiful (but still tourist-minded) Ophelia by gradually showing her "his city," one neighborhood at a time. While talking through Riverside Park, Ophelia reflects on the view around her, combining both the "natural" beauty of the trees and the sky with the "human" beauty of trash on the street and old stone buildings (and more covertly, her growing feelings of love for George):

The air is more than fresh, it makes your senses come alive-so you'll remember something as unimportant as a crushed Pepsi can lying in a patch of weeds, a loose awning hitting the front of a building, the sun reflecting off the edge of a Gothic stone in Riverside Church. Yeah it was one of those days for poetry. (102) Here sensory experience is implicitly connected to an enhancement of memory and an appreciation of the normally unnoticed wonders of her world. As a city-dweller whose once yearly visits the rural island where she was born and raised, Ophelia typically keeps her livesand their connections to natural elements and manmade elements—-separate. But some works presents these worlds in an even sharper contrast: the natural world of the narrative may be unknowable, uncontrollable, or antagonistic to humans; in others, the natural world is a thing that can be known and understood, the human character(s) finding a connection to its ebbs and flows. ${ }^{47}$ Both depictions are a part of our human encounters with nature and conceptualizations of ourselves in the world.

\footnotetext{
${ }^{47}$ One of Hemingway's best-known short-stories, "Big, Two-Hearted River," is an example of this latter option.
} 
"Reading as an Encounter with Nature" is an old metaphor. In the New Testament, Paul uses the metaphor in a letter to the Romans, mimicking its much older use in the Psalms, saying that "God's invisible qualities — his eternal power and divine nature — have been clearly seen, being understood from what has been made, so that people are without excuse" (Romans 1:20, $N I V$ version, italics mine). According to Paul, encountering nature is a kind of involuntary reading in which the truth of God is the only rational interpretation; thus, the natural world and scriptural texts bear the same message regarding the power and nature of God. This metaphor is also rooted in the ancient understanding of ideas as living things, particularly symbolized as domesticated birds. Carruthers calls the related associations concerning birds, bees, reading, and memory a "texture of metaphors" beginning with the likening of "the placement of memoryimages in a trained memory to the keeping of birds (especially pigeons) and to the honey-making of bees. Trained memory is also linked metaphorically to a library. And the chain is completed by a metaphorical connection of books in a library both to memories placed in orderly cells and to birds and bees in their celled coops and hives" (42). Not only are books and the cognitive memories of reading considered living things, the reader himself is historically thought of as a bee who stores his cella (physical and mental libraries) with honey (Carruthers 45). In this configuration, books can be likened to "fields and gardens (campi and prata) full of flowers, which the reader must cull and digest in order to store the cella of his memory"; thus, the experience of reading is akin to wandering through the natural world in search of nectar that will transform into true honey (i.e. wisdom, knowledge, understanding, etc.) as well as the process of distilling that natural essence (Carruthers 45). This conception of reading is also apparent in the Latin verb lego for "to read," which literally translates to the gathering processes of "to collect" and "to cull, pluck," and in florilegium, a medieval compilation or gathering (legere) of extracts 
and maxims of great writers (flos) which literally translates to "flowers" + "to gather" (Carruthers 34; 219).

As Carruthers notes, the medieval conception of memoria signifies not just content, but a mental structure and means for information retrieval; medieval imagery for reading and memory accordingly features comparisons that incorporate individual compartments and embedded organizational schemas. To the medieval mind, memories (especially memories derived from reading) that are without structure are silva: pathless forests of chaotic material that are useless because they do not lead to memories as needed (Carruthers 39). It is an organized and coherent natural world that the medieval mind desires, a neatly tended garden and not a wilderness. Such a desire connects to several medieval mnemonic traditions in the understanding that memory is locational in nature and that the natural world (as the location) can be ordered to suit man's whims. One such mnemonic tradition is the Bestiary, considered a beginner's book of alphabetical semi-narrative descriptions of animals and birds — both real and imaginary. Carruthers argues that while useful for teaching natural history and moralized animal fables, the Bestiary was primarily intended as a method for mentally organizing material through the mental imagining of "pictures" of living things and their primary characteristics (160). Similar in use to the Bestiary was the medieval production of visual alphabets, in which letters are given the shapes of animals, birds, or tools, often according to the first letter of the thing's name, such as aquila ("eagle”) for “A," bubo (“owl”) for "B," etc. (Carruthers 160). Finally, the Herennian architectural mnemonic system, as mentioned in the "Reading as Journey" section, encouraged medieval thinkers to see their readings and memories in terms of specific locations - many of which were in the natural world. The Bradwardine system in particular recommended that users utilize ordered places that are rectangular in shape, such as small gardens or fields, as potential 
loci for memory-overlays, particularly places that can be revisited and re-inspected frequently by the user (Carruthers 164). As with the honeybee/beehive imagery, the mapping of this metaphor allows for the text to be both a disordered natural wilderness (which the reader encounters and carefully culls and prunes to suit his needs) as well as an already tended garden (which allows the reader to observe the work of someone else's labor). However, users of mnemonic systems were frequently advised not to rely on another thinker's imagery but to instead create their own, so that even the tidiest garden created by the author of a text was constantly being refashioned and reordered by each new gardener. ${ }^{48}$

"Reading as an Encounter with Nature" ultimately represents the liminal space between the human experience of nature as both something separate from us - an unhuman order, operating on a different system from us and reactive to stimuli that we are not — as well as a part of who we are and where we have come from — an earlier state of being which suggest nostalgia and longing. In modern Western society in particular, the natural world is viewed as largely divorced from our human world of human goals and human motivations. As such, our encounters with nature are encounters with an alien world: the difference between walking down a busy city street and walking down a mountain path. Yearning for nature, the like of which characterized the Romantics, is often portrayed as a yearning for a separate place from the human world: a physical and mental escape or refuge. But at the same time, it is a yearning for connection, a way for us to engage all of our senses and truly feel alive. This is because encounters with nature are thought to awaken sensory perceptions and awareness which are normally turned off or ignored in our everyday lives; thus, getting out into "the great outdoors" for many is synonymous with

\footnotetext{
${ }^{48}$ Carruthers notes that these traditional pedagogical cautions reflect Plato's warning in Phaedrus "against substituting textbooks and recipes for teachers and disciplined practice" (180).
} 
"really living," finally "breathing the fresh air," and "stirring the soul." Presumably these individuals are ordinarily not living, are breathing stale air, and as possessed with sleeping souls. The word "nature" can carry both positive and negative traits, largely due to its commodification in a culture that treats encounters with nature as extreme states of experience (rock-climbing, white-water rafting, skiing, hunting, camping, etc.) — experiences outside of and additional to "normal" modes of human life. "Nature" and particularly "natural” have largely positive connotations of a return to a desirable, lost state of being. Yet "savage," "barbaric," "untamed," and "inhumane" have negative connotations in reference to where we have come from as a species and as a society. This linguistic liminality is played out in our desire for pleasurable, natural experiences - separate from our everyday lives - in contrast to the terrifying abruptness with which we are reminded of our continued existence as a part of the natural world —usually through the destruction of hurricanes, tornadoes, typhoons, thunderstorm-caused breaks in internet connection, and every other natural disaster beyond our control. ${ }^{49}$

Humanity's strange relationship with nature is played out in the reader's experience with narrative worlds: the "reading as an encounter with nature" metaphor emphasizes the reader's desire to enter a strange, new, and exciting world alongside her parallel and often contradictory desire for familiarity, identification, and a way to orient oneself towards the story. The reader wants to feel something in reading: an arousal of all the senses—particularly the ones she doesn't use in everyday encounters, a connection to a world that is not her own but has similarities nonetheless, a way to see and feel something incredibly central to her existence but which was never before noticed or expressed. The reader wants a sense of belonging to and with a book but at the same time wants to be awakened to the previously unseen beauty and wonders of the

\footnotetext{
${ }^{49}$ As the saying goes, humanity is only two meals and twenty-four hours away from barbarism.
} 
world. Accordingly, the author must find a balance between the conflicting desires of the reader in order to tell a story somewhere between familiarity and novelty, knowledge and suspense, stability and chaos. This balance must also take into account the sensations evoked within the reader-the narrative providing a point of reference and grounding for the reader's experience as well as combinations and arrangements that give the reader the impression of memorable originality. As opposed to relying on a certain sense more than the others, this metaphor encourages a feeling of "fullness" in one's reading experience: tasting, smelling, hearing, seeing, and touching the "nature" within the fiction. Texts evoke a feeling in readers which is experienced synesthetically — the parts coming together to form a whole — in the same way we experience the world around us, drawing especial attention to the things we overlook in that world through the mediating world of the book.

In our contemplation of the significance and effects of the act of fiction reading on the minds and bodies of readers, we undeniably come to rely on the depictions of reading already embedded within our specific cultural and sociohistorical contexts. These depictions are in turn dependent on the reinforced practices and philosophies of communities of individuals who are brought together under a shared set of rules governing work, class, law, politics, sexuality, and yes, narrative. According to Conceptual Metaphor Theory, suitable metaphors will surface over time as central and seemingly foundational in their ability to make sense of an abstract or complex idea, and they will come to feel natural to the point of invisibility to members of the community. I find the lack of a single, fixed conception of the experience of fiction reading an exciting invitation for our continued inquiries into the activity's depths. The historical endurance 
of the six metaphors I discuss above suggests that these and other embodied metaphors of reading are adaptable to the social, cultural, and technological changes in their continued ability to inform our understanding of reading. This endurance tells us there is untapped potential underneath, that reading is not an activity we can dismiss as known and fully-plumbed: there is more there under the surface, and each writer must consider, as all who have gone before her, what it is she does when she writes, who it is that she writes for, and what happens when the ones she writes for encounter her words in her absent-presence. These questions are in turn passed on to readers, particularly in the medium of metafictional narrative through the figure of the metafictional reader.

Beginning with reading as expansion and connection to other minds and bodies contained within the world of the book, we will see just how personal the reader-identity questions become in the lives of writers. We turn now to Virginia Woolf - a writer famed for her focus on inwardness, her experimentation with the reading experience and with consciousness, and her portrayals of artists and writers who contemplate and recreate their experiences for others and for themselves. Woolf's own conception of the reader, and especially her "Common Reader," is transformed time and again into the metafictional readers of her written work which actual readers must encounter and absorb into their own experiences of reading. The reading metaphors which speak to Woolf — and which she speaks to her readers-work together to create an experience of reading that prioritizes community, reclamation, and connection through the sensations of the body encountering other bodies, other times, and the natural world. 


\section{CHAPTER 2: READING AS CONNECTION}

...somehow or another, the windows being open, and the book held so that it rested upon a background of escallonia hedges and distant blue, instead of being a book it seemed as if what I read was laid upon the landscape not printed, bound, or sewn up, but somehow the product of trees and fields and the hot summer sky, like the air which swam, on fine mornings, round the outlines of things.

-Virginia Woolf ("Reading” 142)

In the excerpt above from her 1919 unpublished essay, "Reading," Virginia Woolf brings together the panorama outside the reader's window (tall ladies met by gentlemen carrying racquets, flitting butterflies and bees in blossoms, thrushes hopping on sycamore branches) into a metaphysical melding with the book in her hands. The reading narrator here experiences the book in a collective inrush - the physical book and the physical world together available for sensory perception and knowledge — with the book as the product of nature and specifically of a hot summer's day. ${ }^{50}$ It's an idyllic scene, steeped in embodiments of pleasure and the leisure necessary to take in pleasure, but this view of reading is not sustained; by the end of the essay Woolf introduces three distinctly modern images of contemporary reading: (1) reading as akin to rape and attack, the reader "strip[ping] a whole page" of a book's sentences and "crush[ing] their meaning out in one grasp"; (2) reading appraised in expressions of speed and ease, the modern reader travelling now by "electric train" as opposed to "mounting only a solemn and obstinate donkey"; and finally, (3) reading described in capitalistic terms of exchange and value with "a page of print" acting "almost servile... making only the standard charge on our attention and in return for that giving us the full measure, but not an ounce over or under our due" ("Reading" 158-159). Much can be said about Woolf's vision of modern readers as opposed to their historical counterparts, but it is significant to note that in all these depictions of reading, the

\footnotetext{
${ }^{50}$ Conversely, Mary Shelley's Frankenstein can stand in as an example of a book conceived by a cold summer day.
} 
reader's sensory experience informs and provides the expression of Woolf's understanding of the act itself. To understand Woolf's metaphors of reading in this essay and, in fact, in all her writings, it is essential to think of reading as an embodied activity, with sensory language and knowledge describing and giving meaning to what is commonly perceived as a purely cognitive activity. In this case, the impression of a violent readerly body on a vulnerable textual one along with the bodily sense of proprioception (the body's unconscious perception of movement and spatial orientation) and the sense of time passing combine to form Woolf's depiction of what reading is commonly like for a twentieth-century individual. In this sensory portrayal, she is also able to convey a sense of judgment on these types of modern readers who demand their due from textual bodies without offering their own in return.

Conceiving of reading in deeply sensory terms is not a feature of this early essay alone, but is Woolf's general practice, both in her essays and in her novels' metafictional accounts of reading. Woolf's preferred metaphors of reading - the ways in which she both portrays reading within her works and shapes the experience of those works' readers — are layered and complex, resulting in a reading experience facilitated by her emphasis on reading as a search for human relation and union as well as for an unfettering release from such constraints. Reading can be idyllic and "natural," a product of nature or an activity similar to that of exploring the natural world; it can also be threatening and alien to our own private thought-lives which we generally keep hidden from the influence of others. As Woolf's writings demonstrate, reading is an activity from which we may not have the freedom to walk away unchanged, both in mind and in body. As I explore in two of Woolf's metafictionally-inclined novels, Orlando (1928) and Between the Acts (1941), and in her many essays on the topic of reading, books, and authors, three central metaphors of reading come to the fore in mediating the reader's experience of her fiction as 
indicated by the experiences of her reading characters. The first of these metaphors is "Reading as an Encounter with Sensory Bodies." As seen in many other works predicated on this metaphor of reading, Woolf's depictions of reading and books are steeped in the proximate senses of taste and touch — senses which are raised above the "intellectual" senses of sight and hearing when it comes to encountering books. As such, books are not dead or passive objects but rather emerge as sensory bodies that are tasted, ingested, and crushed by readers and in turn have strong effects on their readers' bodies - causing the reader to experience an alternate series of sensations and stimulations, some that are sought out and others that are avoided. Woolf deploys images of books being consumed by readers both in scenes of fullness (in which books provide essential nutrients for the bodies and minds of their readers) and in scenes of starvation (in which books cannot satisfy readers' demands) depending on the text, the reader, and the reader's historical, cultural, and situational positions at the time of reading. ${ }^{51}$ Similarly, the touch of books can be intimate, exhilarating, and fulfilling as well as dangerous, infectious, and/or overly stimulatingwith readers oscillating between celebrating and shunning the touch of books. As such, this metaphor of reading ultimately suggests what is articulated in Locard's exchange principle: "Every contact leaves a trace"—-whether the reader expects it, desires it, wills it, or otherwise. The contact between readers and books goes both ways as recognized in the second foundational reading metaphor utilized by Woolf: "Reading as Contact with the Past."

\footnotetext{
${ }^{51}$ Woolf's mysterious and frightening periods of "madness" consisted of both mental and physical symptoms including her unwillingness to eat and subsequent extreme weight loss. As Hermione Lee points out in her biography of Woolf, "this sounds like anorexia nervosa, a condition first defined in 1873 and associated at the turn of the century with 'morbid mental states' and hysteria in young girls. But anorexia arises from an obsession with one's body. That does not seem to be the case here. She simply could not eat" (171-172). The common treatment prescribed by the many doctors Woolf saw over her lifetime was typically a combination of food (especially milk and meat diets for weight gain), rest (physical and mental rest from her literary pursuits), and pills (veronal, adalin, chloral hydrate, paraldehyde, potassium bromine, and digitalis) intended to sedate and induce sleep (Lee 180). A similar connection between reading, a rejection of food, and a dependence on pills is forged in the character of Isa in Between the Acts.
} 
Accordingly, books are containers of their authors, their historical times of origin, and their readers - all of which are only accessible to the current reader who puts his or her own time into the book as well. Woolf seems to be especially interested in the overlay of times that run on parallel tracks within the books and are available in varying degrees to the present reader: the time of the writer, the time of past reader(s), the time of the story itself, cultural time, personal time, and the reader's own time(s). The book is not a mere passive container of these times, but an active rememberer of them — an activity which alters the reader's own present experience and memory of time. In her attention to these simultaneously contained and remembered times, Woolf reinforces that while books do contain traces of the past, the reader is never able to access the "true" past through the book; the best she can hope for is to lay claim to the records left by past readers through the physical marks left on and in the book itself. Hence, the physical properties of the book as container become more reliable than its cognitive properties (i.e. the simulation of a "real" or "true" past that the reader can experience through reading). Woolf also reminds readers that the contents of books are fragile and can be lost if books themselves are lost, forgotten, or unwanted. Her passion for obscure writers suggests that Woolf's general reading interests led her to what we would now consider to be "readerly acts of recovery" — an activity that many of her own reading characters do not themselves undertake.

Finally, Woolf's writings often feature the metaphor of "Reading as an Encounter with Nature." Through this metaphor, reading is enacted out of a desire for connection with the world (often caused by encounters with nature) as well an escape into a new world which evokes sensations that the reader's world (i.e. the "real" world) is unable to arouse. As the narrator of Orlando comments, "Nature and letters seem to have a natural antipathy; bring them together and they tear each other to pieces" (17). In the writings of Woolf, books, stories, and ultimately 
humans are shown to be both a part of the natural world and able to transcend it; the reader's senses are variously stimulated and soothed; the reader escapes from the world momentarily and yet dives further into an embrace with the deeper nature of things in his experience with narrative. To continue with the paradox, Woolf allows for nature to be both a background to art (and humanity) as well as its origin in that art comes about from human perception and interactions in the natural world — even in our destruction of it. The connections between reading and nature in Woolf - with books as a part of the natural world, nature inspiring art, nature saving art, characters writing with the natural world's unprocessed "ink," books as a way to understand the natural world, etc. - - speak to the liminality of the human reader: a figure both here and there experiencing bodily sensations engaged by ethereal phenomena. The reader in Woolf is a seeker after both familiarity and transcendence.

In her combinations of these three governing metaphors, Woolf depicts experiences of reading that celebrate the connections between texts, authors, and readers but also warn of their limitations. If reading is a search for connection and novel sensation, there is also the possibility for harmful effects on the engaged reader's body and mind, such as in the experience of the young title-character of Orlando. To read is to be vulnerable - to be open to unforeseen sensations and emotions, to the bodies of others, to realizations about one's own body and one's existence in an unkind world. Reading can put the reader in danger, causing him to reject aspects of his life he was previously insensible to or to embrace unfamiliar ideologies and discard his old familiar ones. The touch and taste of books can bring pain, unease, discomfort, and sorrow as experienced by Isa of Between the Acts. The blame for dangerous or failed readings may lie with the reader who reads incorrectly or unreflectively and thus spurns the potential offered by books. The key to understanding Woolf's sense of reading is that the engagement of the body constructs 
and parallels the engagement of the reading mind: reading is not just similar to experiences with bodies, containers, and the natural world - the book becomes those things for the fully engaged reader.

\section{A Weight on Her Mind: Virginia Woolf's Theory of Reading}

Woolf's preference for particular metaphors of reading speaks to a fully cognitive and fully sensory readerly engagement with a text - a phenomenon she fleshed out and clothed over the years in her critical writings on the subject. Thus, any attempt to understand the metafictional readers and scenes of reading in her literary works must take into account a figure she refers to as "the common reader" who predominates her theory of reading. This personage is articulated most fully in her two essay collections of the same name: The Common Reader: First Series (1925) and The Second Common Reader (1932), but Woolf also wrote frequently about reading, writing, literature, and critics throughout her career in letters, lectures, published essays, unpublished essays, and her diaries. Since Woolf famously considered herself a "common reader," these writings are equally significant as a description of her own reading experiences. As explored in later sections of this chapter, Woolf remains true to this original version of the reader even to the end of her life, and these earlier workings-out of the common reader illustrate the role of Woolf's metaphorical conceptions of the ideal reader on whom she bestowed the term "common."

Woolf's paradoxical address to the enigmatic "common reader" in her many essays on the subject has been deemed by scholars everything from a transcendence of class barriers (Katerina Koutsantoni, Melba Cuddy-Keane, Juliet Dusinberre) to the worst kind of snobbish hypocrisy only to be expected by high modernism (Jonathan Rose, John Carey). Rose is 
particularly damning of Woolf's claims about common readership in his definition of modernism as "a body of literature and art deliberately made too difficult for a general audience" that "in effect rendered the common reader illiterate once again, and preserved a body of culture as the exclusive property of a coterie" (393-394). Woolf's two Common Reader essay collections invite skepticism of this intentional inaccessibility in that Woolf is writing to a group of individuals she clearly identifies with — active readers who read for the love of it and desire nothing less than the consumption of all available ranges of human experience. However, Rose's argument is given some credence in that Woolf also stands apart from these readers as a member of the uppermiddle class of well-connected and privileged people, relating to and associating with some of the best-educated minds in England. Nevertheless, by virtue of her gender, her lack of formal education, the Victorian patriarchy in which she was brought up, but especially due to her own particular reading habits and tastes, Woolf does consider herself a part of the common readership, to and about which her many essays are written. If these readers are largely uneducated, ignorant, and self-motivated, they are also intellectually curious, engaged, and passionate - their weaknesses becoming the source of their strengths. Woolf is also clear that in her use of the word "common" to designate these particular readers, she does not mean to suggest that they are commonplace or conventional; rather, she confirms their rarity in the eyes of an author: "One writes for a very few people, who understand" (The Common Reader 63). But Woolf is not content to merely praise the notion of the uncommon common reader; instead, she places these simple, eager, hasty, inaccurate, and often superficial readers above the distained, unnatural "middlemen" of her time: the reviewers who insert themselves between the writer and the reader without the profound insight of the great critics of the previous ages of literature. As 
opposed to sustaining the connections between texts, authors, and readers, these middlemen are more interested in policing what the public reads through dissection and categorizing:

Reviewers we have but no critic; a million competent and incorruptible policemen but no judge. Men of taste and learning and ability are for ever lecturing the young and celebrating the dead. But the too frequent result of their able and industrious pens is a desiccation of the living tissues of literature into a network of little bones. (The Common Reader 233-234).

And while it might be easier, even "wiser" to "allow the critics, the gowned and furred authorities of the library, to decide the question of the book's absolute value for us," Woolf rejects this bovine passivity with her claim that not only is it the responsibility of readers to think for themselves, it is impossible to truly read and do otherwise (The Second Common Reader 268).

As Richard D. Altick and other book historians have recounted, an unprecedented appetite for print became a major social phenomenon in nineteenth century England with the formulation of the mass reading public (Altick 5-7). Writers were largely shifting from their previous dependence on patrons to a new system of sales dependency - the writer writing now to an anonymous group of readers from different classes with different readerly habits and desires including, for the first time, the working class (Koutsantoni; Collier). This emerging audience of "common readers" went hand in hand with the emergence of "professional" readers, i.e.

reviewers and self-professed critics who filled the gap of controlling and checking the uncultured appetite of average, uneducated readers. They were also responsible for guiding readers towards "worthy" books and away from the "unworthy" or potentially dangerous ones. Woolf particularly despised these middlemen reviewers as bearing the worst traits of the "Middlebrow" 
class in pursuing art for fame, money, and power as opposed to a genuine interest or connection (Rose 431-432). But it is important to note that Woolf in the twentieth century does not dismiss the value of the critic whole-cloth — after all, as many scholars have pointed out, Woolf herself began and ended her career as a critic and deeply admired many of the great critics of earlier literary ages. Rather, it was the practice of modern critics who dictated absolute rules for readers and abused their power by deifying themselves at the expense of readers' autonomy that Woolf decried. In one of her most widely-read essays, “The Leaning Tower," Woolf comes to her denouement on the narrowing gulf between the "two worlds" of England — the small, educated aristocratic class and the immense, uneducated "other class" - by locating the outcome of the future of England in the image of a used library book. The message of that book to a member of the common, "other class" is, in her words: "It is time that even you, whom I have shut out from all my universities for centuries, should learn to read your mother tongue. I will help you... If I lend you books, I expect you to make yourselves critics"” (“The Leaning Tower" 276, italics mine). In her dismissal of book reviewers who insist that readers cannot be their own critics, Woolf subverts the traditional hierarchy with writers topping the pyramid, critics and reviewers in the middle, and readers at the bottom, to an equation of readers with writers. This subversion is partially accomplished through an inversion of the traditional sensory hierarchy of Woolf's social world.

Sensory studies, largely spearheaded by the work of David Howe, Robert Jütte, and Mark M. Smith, has made great strides in identifying culture-specific sensory hierarchies which not only underlie but are often unconsciously utilized to naturalize social, cultural, and political hierarchies. Sight and vision-with hearing a close second — in the Western world, is the sense most commonly associated with knowledge, wisdom, enlightenment, and understanding. As 
such, sight-based metaphors and descriptions both signify the upper classes themselves and are used to justify their power over those beneath them. Conversely, touch, taste, and smell are the senses most closely aligned with the lower classes whose lives and experiences are characterized by their coarseness and rudeness (always one step away from violence and brutality), unable to perceive clearly or comprehend fully the finer aspects of life owing to their bodies taking the place, at least symbolically, of their minds. Thus, the proximate, close-range senses are the sphere of the untutored, earthy working class who touch, eat, and smell indiscriminately, whereas the distance senses are the realm of the upper classes who, situated above such plebian affairs, are free to set their minds to abstract thoughts of beauty, truth, knowledge, and meaning.

In Woolf's reimagined literary hierarchy, reading is counter-culturally connected to the desires and satisfactions of the body as opposed to those of the mind in expressions of consumption, appetite, skin-on-skin contact, orgy, fertility, and transgression. Melba CuddyKeane in particular traces how Woolf"s metaphor of "reader as eater" replaces the early twentieth century's cultural production of reader as "student" or "buyer" (68). In Woolf, words, pages, and texts are taken into the body and absorbed over and over; the smells and tastes and touches of books under one's fingers are erotic and irresistible. Paradoxically, the satiation of these readerly cravings is the method for achieving refinement: "as time goes on perhaps we can train our taste; perhaps we can make it submit to some control. When it has fed greedily and lavishly upon books of all sorts... we shall find that it is changing a little; it is not so greedy, it is more reflective" (The Second Common Reader 268). Physical desire and love for tangible books is consistently linked to desire and love for their intangible contents with the former a sign of the latter. The reader who reads for the love of reading is a reader after Woolf's own heart, but moreover, she is a reader who reads rightly, with and for pleasure as opposed to mere 
knowledge — or worse — the appearance of seeking knowledge. Knowledge, as every good reader knows, is a valuable outcome of reading (as is the development self-discipline, freedom, and imagination), but to read only for knowledge without feeling an emotional response and relationship to the text, the author, and one's fellow readers reveals the presence of outside authority—-society's standards and prescriptions for self-betterment or social standinginsinuated between the reader and the text. Alternatively, true readers are the ones who read in order that they may join writers in a mutual quest for delight and acceptance: "the writer has us by the hand, forces us along her road, makes us see what she sees, never leaves us for a moment or allows us to forget her" (The Common Reader 156). In "How Should One Read a Book," Woolf writes that "it is precisely because we hate and we love that our relation with the poets and novelists is so intimate that we find the presence of another person [i.e. the middleman critic] intolerable" (The Second Common Reader 268). So extreme is this intimacy between reader and writer, that "the standards we raise and the judgments we pass steal into the air and become part of the atmosphere which writers breathe as they work" (The Second Common Reader 269). Writers breathe in readerly desire and expel its stimulation: a proximate, intimate cycle repeated ad infinitum. And again: "The nerve of sensation that sends shocks through us, is our chief illumination; we learn through feeling," she writes ("How Should One," The Second Common Reader 268). In these statements, the intimacy of the supposed lower senses is elevated to the position of prominence and honor as characterizing the only right way to read in Woolf's view. This metaphorical connection between physical sensation and reading (one aspect of the "Reading as an Encounter with Sensory Bodies" metaphor) will be repeated in many of the metafictional scenes and characters of her novels as well in as her essays. 
Woolf's The Second Common Reader, published seven years after the first series, more clearly articulates the physical role of the common reader in relation to writers and texts. ${ }^{52}$ As her essays suggest, it is not simply enough to read: the common reader must fulfil his readerly duties by also evaluating, interpreting, and eventually coming to accept or reject the writer's work. Having been granted an authority superior to that of the professional critic, the common reader must now judge with sympathy and good intentions the writer who is also a friend—and yet not do so uncritically. The necessity of this second part of reading, of receiving "the book as a whole... the shape from start to finish" allows for the reader to "compare book with book as we compare building with building" (The Second Common Reader 267). Woolf recommends that we readers "be severe in our judgements; let us compare each book with the greatest of its kind. There they hang in the mind the shapes of the books we have read solidified by the judgments we have passed on them" (The Second Common Reader 267). Her recommendations for readers to read and judge responsibly includes re-reading books in order to approach the text more reflectively and judiciously ("On Re-reading Novels"). Yet even these very cognitive processes of evaluating, interpreting, comparing, and judging are also revealed to be grounded in sensory experience and impressions. As Woolf's persistent theory of "books as wholes" develops, it is

\footnotetext{
52 As evidenced from her diaries and fragments of drafts dating from 1940-1941, at the end of her life, Woolf had in mind a third Common Reader of sorts. She had spent much of her time in essay-writing over the years considering obscure writers, obscure readers, and the value of readers learning to read critically and independent of the handholding dictatorship of modern reviewers. This third volume would seem to pick up from these ideas but push further back into the past than she had yet gone to the birth of the reader with the death of "Anon." - the first singer, story-teller, and artist who also encompassed his/her audience, before the coming of the writer's permanence and separation from audience. Coinciding with the spread of print throughout Elizabethan Britain, "the reader then comes into existence some time at the end of the sixteenth century," she writes, convinced that "his life history could we discover it would be worth writing, for the effect it had upon literature"-a notion that tallies with her earlier assertions that the audience deeply affects the writer's creations ("Anon" 600). What remains of these essays is sad but hopeful: the acknowledgment that writing and reading are antithetical to warfare with the belief that literature has yet in it the power to survive the wars of man by transcending nations and their destruction of each other, as spoken of in "The Leaning Tower" (1940). Ultimately, however, there is a regret at the necessity of the death of a thing even as it leads to rebirth.
} 
clear that the memory of one's reading, the "emotion" produced in the reader by the book, is what is being compared to that of others. The reader's felt experience: feeling compelled, bored, excited, distraught, engaged, enraptured, obsessive, etc. as well as the reader's lived experience: the occasion(s) of the reading, where, when, how long, how short, in what room, etc. come together to form one's "whole" of a book. ${ }^{53}$ As Woolf claims, it is impossible to compare one book to another in any other way, and tellingly, Woolf describes this intellectual process of evaluation in terms of the physical: "the skeleton alone remains... there is something satisfactory in bone—one can grasp it” (“On Re-reading Novels” 341).

This almost mystic process of passing judgment on texts, a combination of both the cognitive and the sensory that is then somehow felt by the author through the atmosphere of his/her readership, originates for Woolf in the reader's engagement with the physical book itself. Books, in the writings of Woolf, are themselves both actual bodies while also containers of bodies - initially, the bodies of their writers. It seems to Woolf that the shapes of books and their writers will match, even as gendered entities, as explored in A Room of One's Own. Something of the writer's individual personality, habits, and appearance are preserved, a piece and a whole of him or her self lives on, and the astute reader can see the writer in the book's size, shape, and words, plain as can be. For Woolf, prose in particular (as opposed to poetry) "takes the mould of

\footnotetext{
${ }^{53}$ Perhaps surprisingly there is also no small space within Woolf's writings dedicated to the failings of literatureand of readers. In A Room of One's Own, Woolf claims that "for the most part, of course, novels do come to grief somewhere. The imagination falters under the enormous strain" (73). Failure and dullness abound in literature for: "Undoubtedly there is a dullness in great books," she writes of the masterpieces of the past ("How It Strikes" 237). The "stock complaints" against the "fat Victorian volumes" which ask so much of their readers' time and energy is that "they are so long, so dull, so badly written; and, after all, one has life enough on one's hands already without living it all over again between dinner and bedtime in prose" ("On Re-reading Novels" 337-338). Poetry, too, can be dull: "The Elizabethans bore us because they suffocate our imaginations rather than set them to work" ("Notes on an Elizabethan Play" 50). Even in writing that provides intense moments of terror and profundity, such as the works of Sir Thomas Browne, "more often by far he is, as all great men are, a little dull" ("Reading" 157). The narrator of "Reading" even goes so far as to suppose that "If one stitched together the passages in Wordsworth, Shakespeare, Milton, every great writer in short... they would make a formidable volume - the dullest book in the world" (157).
} 
the body and mind entire"; for some writers, Sir Thomas Browne among the first in Woolf's opinion, "it is difficult to be certain whether we are looking at a man or his writing" ("Reading" 157; The Common Reader 47). In A Room of One's Own, the narrator discusses the need for the book "to be adapted to the body," which, practically speaking, would mean "that women's books should be shorter, more concentrated, than those of men, and framed so that they do not need long hours of steady and uninterrupted work. For interruptions there will always be" (78). The biographer of Orlando also famously proclaims the astute reader's ability to detect not only the body, but the entire life of the writer-morally, socially, intellectually, sexually, etc., within the text. But books, while containing writers, also become their own selves, with bodies separate from those of their writers, taking on a life of their own and going where the writer cannot go. For example, "Shakespeare" can now refer to the historical man, the literary and cultural icon, the collected works of one author, a single play of an author, or even a particular textbook that becomes for a particular reader, "Shakespeare." But Woolf affirms that books also come to contain their readers — pieces of them at least — and the memories of past readers and readings (even our own) confront us in the unintended collections of crumbs, hair, coffee-rings, folded corners, marginal notes, underlinings, bookmarks, smudges, blotches, and fingerprints which books over time come to possess between their pages. ${ }^{54}$

For Woolf, one of the greatest ironies of reading is that at its heart is a desire to access the past - that books are "written to escape from the present moment" and are read for the same reason - as if simply by virtue of having come down to the present from the past, they open a

\footnotetext{
${ }^{54}$ Inspired by Woolf's delighted description of the Lewes library's copy of her first Common Reader (a twelve-yearold volume at the time) as "a book spotted with common readers," Melba Cuddy-Keane tracked the copy down and found "literal spots... thumb marks but also orange spots, brown spots, pink spots-looking like tea, marmalade, jam, and lipstick" - a physical sign, for Cuddy-Keane, of Woolf's work on readers "working for the integration of literature into our daily lives" (113-114; Oct 12, 1940: Diary vol. V.).
} 
direct portal to their original time (The Second Common Reader 40). And yet, Woolf says, the present reader is only able to access past readers and readings - the "very broken message" left by the previous generations — and not the true past itself through reading ("Reading" 143). It is all "an illusion"- the misconception that one can read a work from the past "as currently and certainly as we read our own"... and yet we do it (The Second Common Reader 9). Nevertheless for Woolf, the memories of past readers are perhaps part of the text's appeal if not its promise: "we like to feel that the present is not all; that other hands have been before us, smoothing the leather until the corners are rounded and blunt, turning the pages until they are yellow and dog'seared" (The Second Common Reader 40). Thus the book itself, passed down from one generation to the next, bears witness to "the long succession of readers" whose "ghosts" can be summoned in an instant by the simple act of opening a book (The Second Common Reader 40).

This idea of the enduring presence of past readers is strongly connected to Woolf's claim that future readers will always have to go through the spectral presence of past readers of the text (the original audience the writer wrote to and had in mind) in order to get at the text itself. "Undoubtedly all writers are immensely influenced by the people who read them," she writes, which in turn causes later audiences to "have a sense of breaking into a happy family party" when reading the words of previous centuries ("Reading" 157). As a result, Woolf believes readers will always feel more closely aligned to the work of their own time, for they are in the writer's mind and in many ways influence what the writer will write before pen is dipped to ink, so much so that if the reader does not read, the writer cannot write ("The Reader"). For modern readers, modern literature will always have "the same endearing quality of being that which we are, that which we have made, that in which we live, instead of being something, however august, alien to ourselves and beheld from the outside" (The Common Reader 236). The picture 
she presents to the contemporary common reader of him or herself is humbling and yet motivating as an honorable tradition of which any reader can share a part:

Each has read differently, with the insight and the blindness of his own generation. Our reading will be equally partial. In 1930 we shall miss a great deal that was obvious in 1655; we shall see some things that the eighteenth-century readers ignored. But let us keep up the long succession of readers; let us in our turn bring the insight and the blindness of our own generation to bear... and so pass it on to our successors. (The Second Common Reader 40)

Woolf's theory of reading is one of seeking and sharing, of being a part of a whole while still retaining one's own individuality. As illustrated in Orlando, when readers are given a chance to read freely and read widely, "by reading omnivorously, simultaneously, poems, plays, novels, histories, biographies, the old and the new," some of them might become writers themselves - fiction-writers, biographers, scholars, or critics (“The Leaning Tower" 277). For Woolf, this connection between writing and reading is inseparable, and she recommends that to better appreciate the mastery of great writers, readers ought "to write; to make your own experiment with the dangers and difficulties of words" (The Second Common Reader 259). But even if a reader never takes pen to paper, she will participate in "another kind of criticism, the opinion of people reading for the love of reading, slowly and unprofessionally, and judging with great sympathy and yet with great severity" - a criticism that gets into the air surrounding an author, raising standards and passing judgments (The Second Common Reader 270).

In my following examination of two of her more metafictional novels, these overarching sketches of how and why readers read will be shaded in; readings in and of Woolf will be shown to consist of encounters with an other, and readers' choices of how to respond to such a imposition on their selfhood is the result of books taking physical form in the minds and on the 
bodies of those readers. Like the metafictional characters of Orlando, Isa, Lucy, and Bart, reading takes place bodily as well as cognitively for readers of Woolf, informed by our material experiences of the past worked into our present experience of reading. As suggested in her essays, the central components of Woolf's theory of reading revolve around sense-evoking encounters with bodies, the concept and passage of time facilitated in books, and the natural world. Beginning with Orlando, a vulnerability to this type of reading - consisting of openness to other bodies, times, and sensations - depicts how a reader's life can be shaped by the books she reads - even to the point that she desires to shape the lives of others through her own writing.

\section{Orlando: A Primer on Reading}

The metaphor of "Books as Bodies" plays an early prominent role in Orlando as readers, writers, and books are shown to have sensorily defined bodies that act on one other and are themselves enacted upon. Much of this vigorous, ironic text explores these interactions of bodies, specifically playing with their apparent oppositions: male and female, intangible and solid, living and non-living, past and present, and active/actor and passive/receiver. The most obvious example of bodily contradiction comes in the title character's unnaturally long life and inexplicable sex change from a young boy in the Elizabethan age to a middle-aged, married woman in the twentieth century. Largely due to these bizarre plot-devices and the novel's overall wry tone (of an ardent biographer making the best of a bad job), Orlando has been called a "romp," a "high-spirited lark," a "jeu d'esprit," but also a novel with a "sense of history" (Briggs 212). Woolf herself referred to it as "all a joke; \& yet gay and quick reading I think; a writers holiday" and later, "a freak" (Diary Vol. III. 177; 180). It should be noted that chronologically, Orlando comes between the first and the second series of The Common Reader and a year before 
A Room of One's Own — at the height of Woolf's major publications of reader- and readingfocused essays.

As scholars have noted, the opening lines of Orlando immediately draw attention to the prominence of the body (and to its sex) as the title character and subject of biography, the young Orlando, is presented en medias res, "in the act of slicing at the head of a Moor which swung from the rafters" (Orlando 13). Thus begins a complex and frequently narrated division between the world of the physical and the world of the written with Orlando's biographer bemoaning the duties and challenges of the faithful scribe in chronicling the inner-workings of an individual based purely on sight alone-particularly the sight of an inactive body. But in fact the biographer "himself" (referring to himself as male) is more ghostly than fleshly in his constant shadowing of Orlando and immediate annulment of the sight-based boundary he had previously established: while the biographer begins with a description of Orlando's youthful appearance and habits, he soon "mount[s] up the spiral stairway into [Orlando's] brain —which was a roomy one" to inform readers that "all these sights, and the garden sounds too... began that riot and confusion of the passions and emotions which every good biographer detests" (Orlando 16). Such slippage between boundaries and crossing through the body and into the minds of others continues throughout the novel, especially in the biographer's — and Orlando's — questioning of the connections between the written world and the material world that inspires what is written. For Orlando, a lifelong lover of books (despite all the other changes that befall him/her), literature is made up of textual bodies that speak to their authors, ages, and readers - a phenomenon that is especially visible in the variations of his own literary work, "The Oak Tree." 55 Orlando

\footnotetext{
${ }^{55}$ For the remainder of this section I will refer to Orlando in the abstract with both pronouns (he/she); however, when I speak of Orlando at a specific point in his/her life, I will use the appropriate male or female pronoun for clarity.
} 
him/herself is both a stand-in for the history of British literature and a real person worthy of chronicling (according to the biographer): an individual writer whose personal growth, challenges, and relationships shape his/her identity and art. Thus the body of Orlando and the bodies of books are fused as a site of transformation and of study, and the cycle continues even when Orlando wanders from his/her literary habits, as passions aroused from the company of others and from the natural world alike consistently lead Orlando back to books. Here is a reader who seeks a connection to the past, who looks for waves of sensation to wash over him/her, who longs for a place in and beyond his/her own world. Here is a reader whose experience in the natural world brings him/her back time and time again to a textual one and who, at the end, leaves her published book of poems as a forgotten and meaningless tribute at the roots of the oak tree which first inspired her verse in Elizabethan England. ${ }^{56}$ In Orlando Woolf presents readers with complicated relationships between books and "real life" and mediates the two through a recognition of the materiality of books as bodies, containers, and a pathway to and from the natural world.

\section{Reading as an Encounter with Sensory Bodies}

Books in Orlando are remarkably (although matter-of-factly) first described by the biographer-narrator as the incubators of disease — an infection that begins innocently enough for Orlando with a "taste for books" in his early childhood (Orlando 73). In a story familiar to many young readers, Orlando as a young boy is often caught reading at midnight and is forced to invent new ways to feed his habit each time his elders take away his light. Orlando was,

\footnotetext{
${ }^{56}$ The biographer, for his own part, seems to enjoy mocking Orlando's efforts to describe "as all young poets are for ever describing, nature" (Orlando 16).
} 
according to the biographer, simply "a nobleman afflicted with a love of literature" (Orlando 73), a malady which is described as:

a germ said to be bred of the pollen of the asphodel and to be blown out of Greece and Italy, which was of so deadly a nature that it would shake the hand as it was raised to strike, cloud the eye as it sought its prey, and make the tongue stammer as it declared its love, It was the fatal nature of this disease to substitute a phantom for reality... (Orlando 74 ; italics mine)

Here multiple bodily senses are invoked as the reading disease is likened also to the physical symptoms of falling in love - a state traditionally associated with artistic fervor as well as madness. This hybrid "literary" disease, spread by the sensuous act of reading and encountering the infectious bodies of books, also manifests itself in the immediate surroundings of the reader. While in the throes of his youthful heartbreak and self-imposed solitude, Orlando "would read often six hours into the night; and when they came to him for orders about the slaughtering of cattle or the harvesting of wheat, he would push away his folio and look as if he did not understand what was said to him" (Orlando 74). The physical act of opening a book also had, for Orlando, physically-described consequences in its power to "turn to mist" the vast accumulation of his fortune: his property "vanished," his servants "disappeared," his horses "became invisible," and all of his other possessions "evaporated like so much sea mist under the miasma" (Orlando 74). As well as erasing from existence the things, people, animals, and world around him, Orlando's reading body also undergoes a transformation as “Orlando would sit by himself, reading, a naked man" (Orlando 74$)$.

While such sight-based imagery of reading suggests a close connection to the psychological processes of the mind in Western society, nakedness implies total extremes of both 
sight and touch — the body of the naked reader and the body of the naked book are together rendered open, knowable, and vulnerable to being read. Reading is therefore not just extreme seeing (which is usually characterized in terms of a subject acting on an object) but extreme touching (with no distinction between the actor and the acted-upon) between two exposed subjects. Proximity is required for touch, and knowledge of the other is the mutual outcome. As first suggested by the biographer, the common metaphor of "reading a person" as one would a book is also present in Orlando as, for example, Queen Elizabeth sees within the boy Orlando, “strength, grace, romance, folly, poetry, youth—she read him like a page" (Orlando 25). The metaphor suggests that something like the actual words themselves appear on the skin of the one being read in the mind of the reader. This mystery of text-on-body is taken one step further by Orlando's biographer: that readers are able to discern the body of the author in the body of the text: his position, his habits, his choices, and even the state of his clothes and the room he is in during the book's composition (Orlando 209-211). In connection to what Woolf herself suggests in her essays, superior readers, according to Orlando's biographer, are able to make up "the whole boundary and circumference of a living person" from "bare hints dropped here and there" (Orlando 72-74). In short, the limitations of words (and of the sights they are based on), a repeated trope of the biographer, cannot stop a reader who knows his business. Beth A. Boehm claims that "while the biographer seems to praise those readers who work to make meaning even when there are no words to guide them," the dictation of the biographer that the reader obviously come to certain conclusions about Orlando given his descriptions of his subject should be taken as evidence that Woolf "distains both readers whose responses are whimsical and inattentive to the words on the page and readers whose responses are unconsciously conventional" (197). Given Woolf's admonishments and advice for readers in the essays examined above, Boehm's 
reading of the biographer's direct addresses to readers has merit. Yet beyond hinting at Woolf's preferences for the types of reading literature requires, I see the biographer's assertion concerning "the reader's part" as an acknowledgement of the work that all readers must unconsciously do: in order to "see" and "hear" the bodies of written characters, readers must lose sight of the appearance and sounds of words and allow the story as a whole to take on flesh (Orlando 73). Here we are presented with further evidence of Woolf's view of reading as overlapping the material world by seeming (to the reader, in the moment) more pressing, more sensorily proximate, and far beyond the cognitive activities of being merely "lost in thought" or "absent minded."

Following the double-punch blows to his pride in two devastating encounters-first with a Russian princess and second with an Elizabethan poet who mocks his writing-Orlando decides to burn everything: "some forty-seven plays, histories, romances, poems; some in prose, some in verse; some in French, some in Italian; all romantic, and all long" (Orlando 76-77). The single work spared from Orlando's youthful literary massacre — a short poem called "The Oak Tree"- is continually written and rewritten until its publication in the twentieth century. From the reader's perspective, the manuscript itself becomes an absent presence throughout the novel in that while Orlando carries it on his/her person even to Constantinople and back, its completion, value, and even topic remains elusive. The reader of Orlando never reads "The Oak Tree." But as it nears its culmination, the manuscript becomes more and more alive-it has and is a body that acts on Orlando's own as well as a mind and personality. And it wants to be read:

The manuscript which reposed above her heart began shuffling and beating as if it were a living thing, and, what was still odder, and showed how fine a sympathy was between them, Orlando, by inclining her hear, could make out what it was 
that it was saying. It wanted to be read. It must be read. It would die in her bosom if it were not read. (Orlando 272)

The manuscript's body, in childlike fashion, conveys its needs to its parent, Orlando, even as she rushes to fulfill them. Fortunately, the literature professor and critic, Sir Nicholas Greene, concurs with the manuscript's demands concluding that "It must, of course, be published instantly," and takes it away despite Orlando's initial protests (Orlando 280). Orlando lets it part from her, understanding that "there was nothing for it but to submit to what was evidently [Sir Nicholas's] wish and the fervent desire of the poem itself," but it nevertheless leaves her with "a bare place in her breast where she had been used to carry it" (Orlando 281). The manuscript is, like a human child, an extension of Orlando's own body but also separate from her. It must leave her to find its own place out in the world.

\section{Reading as Contact with the Past}

While in the depths of despair following his betrayal by Sasha, the Russian Princess, Orlando gives himself over to a lonely life of gloom and solitude, consisting of "perambulating" the enormous and supposedly haunted family mansion where even his servants dared not follow. In his solitude, Orlando's mood becomes macabre to the point that he begins to haunt the tombs of his ancestors, obsessed with the past and with death. But what intrigues Orlando the most are the slim traces those long dead leave on the present. Taking a skeleton hand in his own, Orlando asks himself: "“Whose hand was?... The right or the left? The hand of man or woman, of age or youth? Had it urged the war horse, or plied the needle? Had it plucked the rose, or grasped cold steel?"” and concludes that "Nothing remains of all these Princes"” (Orlando 71). One night beyond the "dust and ashes" of his ancestors" names and exploits, Orlando glimpses in an 
instant — as the memory of the unknown poet suddenly returns to him — that in the act of writing, an immortality can be achieved (Orlando 81). A mere man will die, but books can allow an author to live forever; his words on the page "lie entombed, not dead, embalmed rather, so fresh is their colour, so sound their breathing" (Orlando 81). In this realization, Orlando himself comes to desire such immortality and launches into a frenzy of composition.

But Orlando's emphasis on books' ability to immortalize their authors gradually shifts to a recognition of the immortality of readers. After all, the author (and his/her words) can only truly live on if someone reads them. Throughout Orlando books function as gateways to and containers of the past that both sustain and consume their readers in a singular relationship of exchange and interdependence. As we have seen, the interaction between textual bodies and readerly bodies is especially highlighted in moments when Orlando is absorbed in literary activities of reading, writing, or thinking about reading and writing. At one key point in the novel, after her transformation into a woman and subsequent return to England, Orlando takes up "a little book bound in velvet, stitched with gold, which had been held by Mary Queen of Scots on the scaffold" (Orlando 172). This is only one of Orlando's many metafictional instances of reading, but here Woolf allows for a series of epiphanies and resolutions to occur in Orlando, originating as much out of the physical qualities of the book as the conceptual.

How Orlando has acquired Mary’s prayer-book is not specified, but the so-called Mary Stuart's Book of Hours - like Orlando herself - is a text at the center of British culture and history: juxtaposed between two queens, two religious ideologies, and ultimately, their tragic finale as Mary is beheaded allegedly without the approval of Cousin Elizabeth. The original owner of Mary's Book of Hours, the text the denounced queen may or may not have carried to her death (as accounts vary), is unknown. Inside this singular volume Orlando finds a brownish 
stain, supposedly of Royal blood, a lock of hair, a crumb of pastry, and a flake of tobacco (this last added by Orlando herself) (Orlando 172). As Orlando reads and smokes she is "moved by the humane jumble of them all — the hair, the pastry, the blood-stain, the tobacco — to such a mood of contemplation as gave her a reverent air suitable in the circumstances, though she had, it is said, no traffic with the usual God" (Orlando 172). Such reverence towards the traces of readers and the ability of the book to become the physical embodiment and vessel of humanity, would be oft-repeated by Woolf in her essays on reading, although her choice to have Orlando come to this state in the reading of such a nationally significant book in intriguing. ${ }^{57}$ The peripheries of life itself become contained within the contents of the dead queen's prayer-book: in the words themselves which instruct readers how to pray to God at various intervals of everyday life; in the national history of the book as the former possession of Mary, bearing in itself blood from her execution; and in the incidental but somehow not sacrilegious "relics" from the everyday lives of past readers. Later, Queen Mary's prayer book is used to marry Orlando and Shelmerdine, adding yet another layer of significance to the specific text (Orlando 261). This combination of tangible and intangible meanings sets up a range of connections for the reader of any book to his or her own past, the "imagined" past of a previous time, the writer of the words on the page, and in this case, more significantly, the previous royal reader of the words. After her epiphany of common humanity and the high office of the poet to shape the

\footnotetext{
${ }^{57}$ This language is closely echoed in Woolf's essay "How Should One Read a Book?" in her imagery of the "rubbish-heap of literature":

The greater part of any library is nothing but the record of such fleeting moments in the lives of men, women, and donkeys. Every literature, as it grows old, has its rubbish-heap, its record of vanished moments and forgotten lives told in faltering and feeble accents that have perished. But if you give yourself up to the delight of rubbish-reading you will be surprised, indeed you will be overcome, by the relics of human life that have been cast out to moulder. It may be one letter-but what a vision it gives! It may be a few sentences - but what vistas they suggest! (The Second Common Reader 263, italics mine)
} 
divinity of words, Orlando puts down the prayer-book and thinks, "II am growing up... I am losing some illusions... perhaps to acquire others"" (Orlando 174). And later:

"Hair, pastry, tobacco — of what odds and ends are we compounded," she said (thinking of Queen Mary's prayer book). "What a phantasmagoria the mind is and meeting-place of dissemblables. At one moment we deplore our birth and state and aspire to an ascetic exaltation; the next we are overcome by the smell of some old garden path and weep to hear the thrushes sing." (Orlando 176).

The next morning, the experience of reading having altered her mind and body, Orlando begins writing again, one literary activity leading to another, presided over by the attendant ghosts of past readers.

Reading as an Encounter with Nature

It is significant that the poem that transforms Orlando from a "dabbler" in the beginning of the novel into a published author at the end of it begins and ends with an oak tree. When he craves solitude, the boy Orlando climbs up the hill to his favorite oak tree and flings himself to the earth at its feet where he imagines it "the earth's spine beneath him... or, for image followed image, it was the back of a great horse that he was riding; or the deck of a tumbling ship — it was anything indeed, so long as it was hard, for he felt the need to something what he could attach his floating heart to" (Orlando 19). It is in these pre-compositional moments of unloosened imagination that Orlando is as close as he can be to the natural world in all of its summer abundance and fecundity and yet as far from it as possible, imagining the tree to be anything but what it is - and he himself anywhere but where he is. The oak tree is the anchor for his "floating 
heart" filled with "spiced and amorous gales" so that body and mind, Orlando is both earth and sky, everywhere and everything he wants to be (Orlando 19).

"The Oak Tree" later appears as "the only monosyllabic title" among the dozens of documents written by Orlando by the age of twenty-five (Orlando 77). It is this one poem that escapes his purge, only because it "was his boyish dream and very short" (Orlando 96-97). But though Orlando loses his ambition to become a great poet, he continues to write in "The Oak Tree," described now as "an old writing book, stitched together with silk stolen from his mother's workbox, and labelled in a round schoolboy hand" (Orlando 112-113). As readers discover, this poem, the boyish dream of his youth, comes to contain a record of the changes in tastes and habits of both Orlando and of the age itself; as such, the poem is erased, rewritten, reworked, and unwritten:

His floridity was chastened; his abundance curbed; the age of prose was congealing those warm fountains. The very landscape outside was less stuck about with garlands and the briars themselves were less thorned and intricate. Perhaps the senses were a little duller and honey and cream less seductive to the palate. All that the streets were better drained and the houses better lit had its effect upon the style, it cannot be doubted. (Orlando 113)

Posed between the old world and the new, between poetry and prose, Orlando's writing process appears often to be more a process of unwriting, with the sum of lines at the end of the year "rather less that at the beginning" (Orlando 113). Curtailing long descriptions and ramblings which attempted to contain everything the natural world offers, prose writing now attempts to find the fewest, most precise words to say exactly what is needed and no more. Orlando struggles 
with his enormous labor in concert with the labor of man on the increasingly-modern landscape to curb and restrain, holding its wild abundance in check.

While his writing is interrupted for a time by the inconveniences of becoming the Ambassador to Constantinople in order to escape the unwanted attentions of an admirer and, under mysterious and ill-documented circumstances, becoming a woman herself, Orlando continues to carry and work on "The Oak Tree" and takes to "secret[ing it]... in her bosom" (Orlando 139-140). After her miraculous transformation and escape from public life to join in with a group of gypsies, Orlando continues to carry the poem tucked into her clothes, although she leaves behind everything else. While she seems to be one of them for a time, the gypsy elders soon realize that Orlando "had contracted in England some of the customs or diseases... which cannot, it seems, be expelled": the "English disease, a love of Nature" (Orlando 142-143). This diagnosis of a love of nature as a disease echoes her early diagnosis with the disease of a love of books, and indeed, the two are connected; Orlando's inward response to the beauty of nature around her also brings with it a compulsion to share it with others. Since no one among the gypsies understands her ravings about the beauty of nature and only laugh at her outlandish statements, Orlando begins to long for pen and ink "as she had never longed before" (Orlando 145). Accordingly, she makes ink from berries and wine, fills in all the margins of "The Oak Tree" manuscript and even develops a "kind of shorthand" so as to fit more words in using her limited paper supplies. For a time she is happy even through her relations with the gypsies become increasingly strained. And then, "Nature, in whom she trusted, either played her a trick or worked a miracle"; Orlando receives a vision of the hills, grassy lawns, oak trees, and animals of "a summer's day in England" before the vision changes to show her a winter which swallows up everything she loves, leaving "only the blazing hillside which a thousand vultures seemed to 
have picked bare" (Orlando 150-151). Whether she takes this as a premonition of things to come or as a reminder of how much she loves England in the summer, Orlando immediately decides to return home. "The Oak Tree," naturally, returns home with her to the land of its birth, described now as "a roll of paper, sea-stained, blood-stained, travel-stained" with the writing so thick and overscored in the sections when she had wanted for paper that it "looked like a piece of darning most conscientiously carried out" (Orlando 236). She had been writing for close to three hundred years; "It was time to make an end" (Orlando 236, italics added).

After more delays—including marriage — the poem, finally, is done, and soon after its completion the manuscript is parted from Orlando forever. As readers are informed in a by-theway manner, by the end of the novel — which has caught up to the "present moment" of 1928"The Oak Tree" has had seven editions and Orlando herself has won a cash prize with her photograph in the evening paper for it (Orlando 312). But the fame bothers her and leads her to question the value of poetry in general. In her confusion, Orlando returns once more to the poem's namesake that remained the same through all the centuries. Climbing to the top of the hill which still commanded a wide view of much of England, she finds that "the tree had grown bigger, sturdier, and more knotted since she had known it, somewhere about the year 1588, but it was still in the prime of life" (Orlando 323-324). Once more, she lies down on its roots and thinks again of her old fantasies that she was "riding the back of the world," attached "to something hard" (Orlando 324). But Orlando realizes in that moment that her intention to bury her poem at the foot of the great oak that had first inspired it (the poem now "a little square book bound in red cloth"- a signed first edition) is but an empty gesture. She had planned a speech too: "II bury this as a tribute... a return to the land of what the land has given me,"” but the words seemed "silly" now that she was there (Orlando 324). The two now-tree and poem- 
seem to have nothing to do with one another, just as praise and fame have nothing to do with poetry. Humans are the only readers of the natural world, and the book and Orlando both long for readers. Orlando wonders:

Was not writing poetry a secret transaction, a voice answering a voice... What could have been more secret, she thought, more slow, more like the intercourse of lovers, than the stammering answer she had made all these years to the old crooning song of the woods, and the farms and the brown horses standing at the gate, neck to neck, and the smithy and the kitchen and the fields, so laboriously bearing wheat, turnips, grass, and gardens blowing irises and fritillaries? (Orlando 325)

In this moment of recognition of who she is and what she has been attempting to do all these years in her writing, Orlando lets the book lie "unburied and disheveled on the ground"; she turns her eyes instead to the view the old oak affords her and the dreams it had inspired, just as she had as a child (Orlando 325). Even in her admiration of nature, it is once again humanity that is necessary to hear the "answering voice" inspired by nature but only perceptible by her fellow human readers.

\section{Metaphorical Reading in Orlando}

Orlando — whether it is read as a whimsical love-letter, a farcical literary history, a critique of Western gender stereotypes, or as Woolf herself called it, a "writer's holiday"_pays tribute to the complexity and possibility that lies within books. But even as it celebrates the act of reading, the text's metafictionality prods readers into reflective considerations of their readerly actions and demands: for instance, the biographer craves the reader's understanding of the 
difficulty of his task to account for the life of one such as Orlando while simultaneously assuring the reader that everything should be quite clear given his efforts to convey precise detail and actual dialogue - even Orlando's rambling dialogues with herself. But it is these very details that make it clear that the biographer is not entirely to be trusted as he plays with the reader even though readers must go through him to get to Orlando. It also becomes apparent that the text must be read as the hybrid that it reveals itself to be, drawing from the genres of biography, memoir, drama, bildungsroman, and myth. The novel's meanderings from the sixteenth to the twentieth century also come with a challenge: the reader is charged with picking up on sometimes obscure historical references, understanding witty allusions to the stereotypes of the literatures and writers of each century - to say nothing of the reader's necessary acceptance of Orlando's long-life and mystical sex change halfway through the narrative. Yet the reader's struggles with the novel are undercut by its honest portrayals of literary acts: while the biographer's descriptions of Orlando's reading “disease" are arguably laugh-out-loud funny, the physical depictions of what such a "disease" looks like (sneaking books to bed, staying up all night to finish a book, ignoring the whole world to spend more time reading, etc.) are dead-on. The biographer's descriptions of Orlando's love of books are never shallow or trite, but are consistently new and invigorating. As such, the slippage between the three metaphors of reading found within Orlando-reading as an encounter with sensory bodies, as contact with the past, and as encounters with nature-should not go unremarked.

Taking Orlando's evolution from reader of books to writer as an example, all three metaphors of reading are used at various times to explain the transformation. "Reading as an Encounter with Sensory Bodies" provides the language and imagery for the reading "disease" in which a reader is first inflicted with the need to read hours into the night and ignore his usual 
interests, but "worse was to come": "For once the disease of reading has laid hold upon the system it weakens it so that it falls an easy prey to that other scourge which dwells in the ink pot and festers in the quill. The wretch takes to writing" (Orlando 75). Conversely, the metaphor of "Reading as Contact with the Past" provides the understanding of books as containing the lives of their authors and their readers— even those long dead—and, accordingly, Orlando's resolve to write is equally connected to his desire to be remembered and to leave a trace of himself behind for future readers to uncover and awe over: to be "the first poet of his race, the first writer of his age, conferring eternal immortality upon his soul and granting his body a grave among laurels and the intangible banners of a people's reverence perpetually" (Orlando 104). And finally, the "Reading as an Encounter with Nature" metaphor provides the final piece of explanation for Orlando's desire to write that has nothing to do with fame and fortune but everything to do with voice answering voice: a human response to the beauty and wonder of the world which is compelled by it and yet separate from it. Writing, readers are told, is flinging out your nets and finding sometimes "an inch of silver—six words—in the bottom of the net. But never the great fish who lives in the coral groves," the writer never able to match what nature gives her (Orlando $313)$.

Altogether, reading bodies within Orlando are rendered vulnerable by their reading: naked and known by the books they lovingly allow to see and touch them. And those books are possessed of and by bodies: containing their authors, their past readers, their contemporary time, and something more than the mere combination of these other bodies within their pages. In short, books have their own lives though they also spring from the lives and bodies of their writers. And, as Orlando discovers, books in modern times have grown to the point of no longer being luxury items for the very rich, but wondrous everyday items for the common reader to delight in 
and become a part of herself. This reading audience allows for the greater production of books as "time containers" to come to contain greater amounts of reading and readers; the communion between author and reader is now vast and varied, inspiring awe and wonder in Orlando and in the novel's reader alike. But in a search for communion, reading paradoxically reveals that readers are separate from the natural world, however much it inspires them to turn to books for more. This layering of reading's effects and purposes should not be seen as antithetical to each other, but rather as Woolf's acknowledgement of the fully-embodied mystery that is reading: drawing from our experiences with our own bodies, the bodies of others, the sense of time and memory, and our understandings of ourselves in the world. All told, Orlando brings readers to the "present" in a celebration of literature, writers, readers, and the human experience. But it is important to acknowledge that the present moment of Orlando is 1928, and the Second World War is still a decade off. The contrast between her depictions of reading within Orlando and, years later, her depictions of reading within Between the Acts, demonstrates a turning-point in Woolf's conceptions of her place as writer and the place of her reading public. While her metaphors of reading maintain their central place in informing the language and imagery surrounding acts of reading, their metafictional workings-out are a far cry from the carnival of reading in Orlando; the act of reading in Between the Acts is dangerous in its irrelevance to the present, and readers are aligned with passivity as opposed to invigoration.

\section{Between the Acts and the End of Reading}

Between the Acts, published posthumously and without final approval from its author, gives life to the most important questions the postmodern era would ask—questions which, in retrospect, it seems Woolf has always been puzzling out: those which explore the veracity of the 
"grand narratives" of history and culture and reconsider the nature of representation and mediation when it comes to the relationship between writer and reader. Woolf's work has consistently inclined towards metafictionality, but in Between the Acts, questions of the role and uses of literature in the everyday life of British citizens reaches a fevered pitch - a concentration that is also exhibited in "Anon [and] The Reader," the early draft of a book on English literature she was writing during the same time. Rampant literary allusions arise in Between the Acts in characters' attempts to make polite conversation using the cultural touchstones of Shakespeare and Byron, which takes them (sometimes unknowingly) into Keats, Eliot, and Yeats. The revisionist literary history of the pageant at the heart of the novel also provokes considerations of the troubling complicity of English literature in the crimes and violence of British imperialism. Of literature and books' effects on readers, Woolf revisits her earlier metaphors of reading, but now uses their imagery and language to reveal the deep sense of loss and lack which pervades readers. Between the Acts takes place in 1939, the year Britain would enter World War II-a war that resulted in the deaths of some 450,000 British soldiers and civilians and the destruction of two million homes — most of those in London during the Blitz. Prior to September 1939, in what is known as the "Age of Appeasement," the years-long drama of events and public opinions swinging one way to the other filled newspapers, and Britain repeatedly sought excuses to avoid another war. Finally the drama reached its climax when Britain shifted its previously tepid response to Hitler's invasions of neighboring countries to a declaration of alliance with Poland, and in September finally issued an ultimatum to the German government to cease hostilities or be declared at war with Great Britain. The events of Between the Acts take place in June just 
months before this ultimatum and its resulting declaration of war with Germany. ${ }^{58}$ While Woolf largely avoids direct allusions to the impending war, there are hints of it in the thoughts, conversations, and observations of its characters; moreover, readers in the novel are portrayed as cut off from the books that previously connected them with past readers and past times: the books are there, but "the library was empty” (BTA 17).

Pointz Hall, the English countryside setting of Between the Acts, has its fair share of books and reading materials, some located in the library, some in Mr. Oliver's private gentleman's library, as well as the books of poetry in the wall on the landing (which get damp in the winter), the twice daily mail (including the all-important newspaper), the ghostly Figgis's Guide Book (oft-quoted to guests for its mention of their "view"), and other various scraps of reading, carried and dispersed about the house. But John Whittier-Ferguson's careful study of Woolf's revisions of Between the Acts rightly highlights the books housed in the library as undergoing the most drastic alteration from earlier drafts to the final published draft. Originally, and in similar proportion to her vision for "Reading at Random," the library of Pointz Hall was to reach "extraordinary dimensions," containing a complete survey of British literature beginning with Chaucer (Whittier-Ferguson 309). While the early typescript's originally-conceived library was clearly not in possession of a scholar or book collector, "nevertheless there was the whole of literature here... what Chaucer had begun was continued with certain lapses from his day to this very morning" (Pointz Hall 48). It was a library which contained accessible memory, a place for readers to "maintain illusions of personal and cultural memory"; thus, Whittier-Ferguson views

\footnotetext{
${ }^{58}$ In her diary on September 3, 1939, the day Prime Minister Chamberlain announced to the British people they were at war with Germany, Virginia Woolf writes, "This is I suppose certainly the last hour of peace... I suppose the bombs are falling on rooms like this in Warsaw... No one knows how we're to fight. Rumours beginning... People buying stuff for windows. Little girl says If we have a chink they'll spy us out... One's too tired, emotionally, to read a page. I tried Tawney last night — cdn't concentrate... Nothing in the garden or meadows that strikes me out of the way--\& certainly I cant write" (Diary, vol. V., 233-234).
} 
Woolf's drastic alterations to the library scene as an enactment of "the advancing cultural amnesia that diminishes the consequence of printed archives and the writer's vocation in our time" $(304,305)$. The library was where once (in the earlier typescript) readers could read and believe "that they were in contact with something or other..." and could experience "a particular sensation—some in the spine, others in the thigh—others in the pit of the stomach—at the sound of certain words... a curious feeling" (Pointz Hall 49). In the published version of the novel, however, the library is a place for disconnect: characters sit and dream or look through the titles without finding what they're looking for. The books are there, but the readers are not. Thus, the act of reading and thoughts/considerations/reflections about reading and literature in general take on a very different status from their appearance in earlier works like Orlando. Under question is not only whether reading still occurs in a world on the brink of war, but whether reading is capable of producing the same kind of experience that it once did: can reading connect its readers with sensory bodies?, can it connect readers to the past?, can it call forth new and exhilarating sensations and desires like those one experiences in nature? For the readers of Pointz Hall, it seems that the answer to these questions is largely: no.

\section{Reading as an Encounter with Sensory Bodies}

Lucy Swithin, the Old Guard book-reader in Woolf's final version of the novel, is most strongly characterized by her ethereality and whimsy as she is consistently compared to swallows, thrushes, angels, and air balls [balloons] (BTA 101, 9, 24, 116). Lucy, as Between the Acts' token book-reader, lacks the physicality of an Orlando: there is no sense of the material presence of authors or past readers maintained in the book in Lucy's hands nor that she is herself leaving a sense of her presence for future readers. Her reading is spent "thinking... 
underst[an]d[ing] ... suppose[ing] ... and presum [ing] ..." lacking the "adultrat[ion] and destr[uction]," the divinity and power of Orlando's reading (BTA 8-9, italics mine; Orlando 173174). And while Lucy does experience the past in her reading, it is a past that predates history, writers, and writing altogether: "her favourite reading" is "an Outline of History"-a text which likely operates as her own coping mechanism in the face of England's impending war by taking her to a time outside of its reach (BTA 8). Lucy's book is likely a reference to H. G. Well's The Outline of History (1920), but it is also a possible nod to G. M. Trevelyan's History of England (1926) which Woolf writes about in her diary on October 26, 1940 as an "Insider" text that does "a great service like Roman roads. But they avoid the forests \& the will o the wisps" (Diary V, 333). Woolf plainly states that while she respects these men, "the glory of the $19^{\text {th }}$ century," "turned out by the University machine... I dont love them. I dont savour them" (Diary V, 333). Lucy clearly does not hold the same opinion of her "Roman road" as she continues to read and think about her Outline of History throughout the novel.

Moreover, while in Orlando the sensory bodies of readers come to shape the present reader's experience with a book, the only reader Lucy encounters in her book is herself; this lack of connection with other bodies prevents her own reading from being truly embodied. While reading has long been connected to imagination as a cognitive activity (even in Orlando the young boy watches the old poet and wonders that he can see fantastic creatures no one else can until they read what he has written), there is a more skewed balance between the cognitive and sensory elements of reading in Between the Acts given that Lucy is the only reader who still reads books and not newspapers in Pointz Hall. Her habit of "one-making," of travelling down flights of fancy at inappropriate times becomes her primary characterization as her brother, her nephew, and the servants laugh at her behind her back. Without a sense of past readers, writers, 
and a materiality in reading, the relationship between readers and books in Between the Acts has perceptibly shifted: reading is no longer an act of touching or tasting the sensory body of the book in one's hands, nor is it an encounter with the body of its writer or its past readers. At best it is, as seen in Lucy's reading, an escape from the present world into a world that predates all modern human bodies. Instead of feeling, Lucy looks only, aided in her efforts to avoid looking at the present by the book's illustrations of fantastic, pre-human creatures: "mammoths, mastodons, prehistoric birds" (BTA 217).

Lucy's niece by marriage, Isa Oliver, has a relationship with books characterized by reluctance, in part because she is emphatically a creature of the present moment and in part because she lacks a readerly appetite for textual food, preferring instead to pop textual pills that suppress any such craving. Isa is described as "book-shy... like the rest of her generation," but she still pauses in the library to contemplate what the rows of books were reflecting, sitting there, and if they had a remedy "for her at her age - the age of the century, thirty-nine... as a person with a raging tooth runs her eye in a chemist shop over green bottles with gilt scrolls on them lest one of them may contain a cure" (BTA 19). Much like the narrator of A Room of One's Own, Isa considers the books of the library in a particular order: first poetry, then books of a life, then books of a country's life, then science. She stops, concluding that "none of them stopped her toothache" (BTA 20).

Taste and eating related metaphors for reading have a long history, but here, Isa is not interested in chewing on words, devouring their goodness, consuming volume after volume, or tasting another's poetry on her tongue_-instead she wants to swallow them whole without having to chew, an immediate absorption of an immediate cure. In A Room of One's Own, Woolf notes that "novels so often provide an anodyne and not an antidote," but neither seems 
forthcoming in Isa's case (A Room 80$)$. Instead, books are threatening in their potential stimulation at a time when people are desperately trying to continue their lives as stimulant-free as possible, in the hope that the threat of war will miraculously be averted. Of course, Isa would conclude, after scanning their titles with her eyes (not her fingers), that "none of them stopped her toothache"-for how could they? (BTA 20). Instead, Isa turns to the more easily swallowed, tablet-sized stories of the newspaper where she finds the fantastic, the romantic, and the real that strikes a chord deep within her. The desire for reading is again connected to consumption, but Isa has no appetite: she chooses pills over food, numbing over invigoration.

Between Lucy's pre-history book and Isa's newspaper article, reading has lost much of its power over the sensory bodies of its readers. While it still has the power to transport the reader to another time and place, unaware of the immediate circumstances, reading's danger now lies in its very irrelevance to the present day. Lucy eagerly uses her book as a means to take herself, body and mind, far from the trials of the present: the coming war, but also her nephew's dislike and her brother's ridicule. Isa, finding no physical connection to books, must utilize the newspaper for such momentary journeys of narratives that feel relevant (due to their recent publication date of that morning) but nevertheless still serve to distract her from her own trials: her duties as wife and mother, her husband's infidelity. Gone is the eager search for authors' bodies, readers' records, and sensory stimulation from and in books. Gone is the circulation of books from one eager pair of hands to another. Readers here are separated not only from the physical bodies of books but also from each other as inter-connected individuals

But even in the book-weary world of Between the Acts, the physicality of texts as food endures in Woolf's descriptions of reading acts. After the community pageant's audience has departed but before the final dispersal of the Oliver family for bed, "the circle of the readers"- 
Bart, Lucy, and Giles — are together, lit by a reading lamp as Isa watches them (BTA 216).

"There in that hollow of the sun-baked field were congregated the grasshopper, the ant, and the beetle, rolling pebbles of sun-baked earth through the glistening stubble" (BTA 216).

Bartholomew (the grasshopper), Giles (the ant), Lucy (the beetle) "polished and nibbled and broke off crumbs" of their various reading materials (BTA 216). This final imagery of reading hearkens back to an earlier image from the book's opening page: the daylight bird—not the romantic and poetic nightingale- - "chuckling over the substance and succulence of the day, over worms, snails, grit, even in sleep" (BTA 3). These images of reading highlight a bodily conception of the act in which the readers' consumption of material is one of instinctual necessity, as compulsory as eating, but of material that is now only the reporting of recent events disconnected from the continuity of literature or history. Significantly, reading is portrayed at the novel's end as the everyday—not the ethereal or otherworldly, the present—not the past. Lucy's childlike reading in which she guiltily expects to be stopped at any moment is the only holdover of both the pre-war way of life and of Woolf's earlier typescripts of the novel in which reading is still acceptable and useful behavior. The books endure and have the potential to endure, but only so long as their human caretakers do their part in remembering and needing them.

\section{Reading as Contact with the Past}

When Grace, the maid, enters Lucy's room with tea while Lucy is reading of rhododendron forests and monsters in Piccadilly in her favorite book, Lucy is suddenly jolted to the present:

It took her five seconds in actual time, in mind time ever so much longer, to separate Grace herself, with the blue china on a tray, from the leather-covered 
grunting monster who was about, as the door opened, to demolish a whole tree in the green steaming undergrowth of the primeval forest. Naturally, she jumped, as Grace put the tray down and said: "Good morning, Ma'am." "Batty," Grace called her, as she felt on her face the divided glance that was half meant for a beast in a swamp, half for a maid in a print frock and white apron. (BTA 9)

While similar to the reading-driven disappearance of Orlando's world, Lucy's loss of present awareness is mocked and implicitly connected to mental incompetence and old age by those around her. Losing oneself in 1939 England to absorption into the unspecified time and place within the book is ultimately not a beneficial or celebrated act. Orlando likewise feared the mockery of others for his literary habits, but nevertheless, maintained a grounded sense of power and status which Lucy, even with her vague connections to the upper-class, does not possess in the eyes of the servants or her family. Her nephew, Giles, especially looks down on her flights of fancy away from the realities of the present moment. This scene with the maid is echoed later when Lucy herself enters a room and jars Isa from her reading of the Times' article about the rape of a girl by troopers at Whitehall. Isa, reading the article, thinks:

That was real; so real that on the mahogany door panels she saw the Arch in Whitehall; through the Arch the barrack room; in the barrack room the bed, and on the bed the girl was screaming and hitting him about the face, when the door (for in fact it was a door) opened and in came Mrs. Swithin carrying a hammer. (BTA 20)

Isa, like Lucy, takes a moment to extricate the reality of the present from the reality of her reading, and in that moment the two are blended as the mind and body attempt to make sense of the discordant stimuli. Conspicuously, it is not a book that takes Isa from the world around her 
but rather a news-story of sex and violence. The acceptability of such a flight of fancyconnected to the immediate present as opposed to the distant past—is questionable, but at least Isa is not mocked for it by the servants; it does not brand her as it does Lucy.

Bartholomew Oliver, as a reader, is certain that as far as determining the past and origins, books are indeed capable: "Lemprière would settle it; or the Encyclopaedia," he asserts knowingly to question of the origin of "knock wood" (BTA 25). But as far as resolving the deeper questions of life, the hearts of things and events and people in the present moment, books are incompetent. This mixed position is reflective of Bart's mediatory place as an old soldier and an old man, long past his prime and incapable of present action, but still possessed of a longing for the past action he had known and commanded. The books of poetry he reads in the earlier typescripts are taken from him in the published version; instead of Byron, he holds a newspaper, the intermediary between reading deeply and reading nothing at all. Newspapers are here today and gone tomorrow, transient things; they can be manipulated, snapped, folded, coned, bent, traded, passed around, and discarded, for their daily significance is a limited, time-dependent thing. Yet for this generation, "the newspaper was a book" which contained everything the bookshelves did and something they didn't: the immediate (BTA 20). Bart is not of the generation of the young men who must fight in England's present battles, but neither is he in Lucy's camp of going so far into the past as to ignore the present. Like the other readers of his day, Bart must "snap" up his daily paper for the most recent news on the war everyone feared was drawing closer (BTA 216). Newspapers even allow him some small action-if only in their ability to be rolled into a cone and used to scare his young grandson before being passed along to the next person. From the perspective of a Bart, newspapers didn't destroy the world of reading, but they were the harbingers of such destruction in their obliteration of contact with the past. 
Later that evening, Giles Oliver would take up the newspaper after his father had finished with it before crumpling it up and turning out the light. Reading, for this middle-aged modern man, is the opposite of action, and action is what is needed in the present time of war. Like Bart dreaming of past valor, like Isa looking for a shocking story that will drown out her own anxieties, like Lucy losing herself in a past beyond the ravishes of man, Giles too feels that the pressure of the present requires a release. Books are supposed to invigorate and inspire the mind, but Giles does not see that they can still perform such feats in the present time- - let alone do the same for the body. Such a view of reading is not by any means new-even Orlando's favoring of reading over physical activities like hunting and riding are bemoaned by his servants and biographer alike. Woolf's essays on reading also address this issue in their insistence that reading does the necessary work of expanding our thinking and improving current writing by connecting us to our present time through contemporary works as well as to the past through the prism of past readers of those works. But by the time Woolf was completing her final revisions of Between the Acts' manuscript, the devaluation of pleasure reading was well in effect, and, as Mitchell A. Leaska would write decades later by way of explanation, "she [Woolf] knew better than anyone that art was the first thing to be jettisoned from the habits of daily living in a time of stress" ("Intro," Pointz Hall 6). Reading is no longer about amusement and making contact with the past, it is not even about achieving a deeper understanding of the present; the purpose of reading in 1939 is purely for information about current events, without reflection or analysis, and for predictions of future events. As such, the body comports itself as passive receiver, with Giles's earlier reading of the newspaper on his way home recalling Woolf's description of modern reading as "going up to town by an electric train" ("Reading" 158). The inability of present action which haunts Old Bart and his son Giles reflects the attitude that reading is a 
passive, inactive activity. If the act of reading no longer functions as contact with the past or requires that readers insert their own time in order to access that lost past, than reading truly does become a mere precursor to "real" action: an experience akin to sitting on a train, simply waiting to get to where you are really trying to go.

\section{Reading as an Encounter with Nature}

As in Orlando, in the English homestead setting of Between the Acts, the beauty of the natural world is shown to persist, outlasting its human inhabitants. And it is though the language and imagery of this final metaphor of reading that Woolf offers the greatest amount of hope, even in its potential negation. According to the oft-quoted entry in the 1833 Figgis's Guide Book, nature has more or less endured at Pointz Hall and the surrounding countryside—despite the traces of human history and destruction visible on its surface (albeit only by airplane, from which one can see, according to Bart, "the scars made by the Britons; by the Romans; by the Elizabethan manor house; and by the plough, when they ploughed the hill to grow wheat in the Napoleonic wars") (BTA 4).

At the heart of the story and at the heart of Pointz Hall is the location's enigmatic "view" of the surrounding countryside: it is a sight that inspires love and admiration, but also fatigue when its repetition becomes "senseless, hideous, stupefying" after too long in its presence (BTA 67). According to Lucy, the view is "'sad"” and "'beautiful"” precisely because "'It'll be there... when we're not"' (BTA 53). But for Giles, who also "loved the view" commanded by his family home, this sentiment is naïve - the outlook of "old fogies" (BTA 53). "At any moment guns would rake that land into furrows; planes splinter Bolney Minster into smithereens and blast the Folly," he thinks (BTA 53, italics mine). While the traces on the land from past empires and wars 
might suggest that nature — and humanity—will endure yet again, Giles's anger and fear suggest that this is no longer a guarantee. In the world of 1939 England, there is no certainty that nature or anything else will endure beyond the present time. As such, enjoying the pseudo-certainty of the present is ignoring the reality of the coming future.

If suspected inconstancy is the key characteristic of nature in the world of Pointz Hall, an experience of reading that mimics an experience of nature is even more so. The best of the natural world and the best of literature could (would) at any moment be destroyed, so that, according to Giles, it was pointless to look "at views over coffee and cream when the whole of Europe — over there — was bristling... with guns, poised with planes" (BTA 53). It was just as pointless to read books that take the reader away from the present moment when the present is now all-consuming. Escapes into the embrace of the past are either impossible (Isa), isolating (Lucy), or abortive (Bart). Thus, the literary response that Orlando feels is called forth by nature is largely blunted for the characters of Between the Acts - with Isa's fragmentary (but mostly unrecorded) poetry as a possible exception.

But even while Woolf sets up this despondent depiction of loss, the hope that life and literature, nature and humanity will live on beyond the war is evident in the novel's entwined roles of nature and narrative. The town pageant, hosted by the Olivers, consists of layered enactments of six periods of British literary history: beginning with first century England (with England as a young girl), skipping ahead to Chaucerian England (England as an older girl), then Elizabethan England (where Elizabeth and her fool take the stage), eighteenth century England (with a personified "Reason"), followed by Victorian England (recognizable by the depiction of a London Policemen), and finally the present twentieth century England (portrayed by the reflected images of the audience-members themselves). While the audience is provided with 
programs to consult for scene descriptions and director's notes, it is largely the appearance of recognizable figures from British history which informs the audience of each scene's historical period. But after recognition is achieved, the period itself is portrayed by the pervading literary genre of each time period, respectively: an oral epic song (or an approximation of one that has since been lost to time), the Canterbury Tales, an Elizabethan play, a Restoration play, and a Victorian novel scene. Altogether, the play is a pastiche which attempts to revive a timely sense of the past and its literature to the audience - the success of that revival, however, is questionable. (The playwright and director, Miss La Trobe, feels that it was “"a failure"” (BTA 209).) Furthermore, the choice to perform the play outside, despite the possibility of rain, allows for nature to take a central role in the audience's (and vicariously, the readers') sense of narratives of the past—particularly the act of remembering familiar genres of British literature.

At two instances during the pageant, Miss La Trobe recognizes that her audience has become distracted and irritated to the extent that she concludes "audiences were the devil" and longs to "write a play without an audience" (BTA 180). In both times, she momentarily loses her audience but has them returned to her by the unexpected assistance of nature. In this first instance, the wind's theft of the actor's words leaves the audience "staring at the villagers, whose mouths opened, but no sound came," and Miss La Trobe feels that "her power had left her... illusion had failed" (BTA 140). But just as easily as nature had stolen her illusion, it replaces it with another: "the cows took up the burden" (BTA 140). "In the very nick of time" a cow who had lost her calf "lifted her great moon-eyed head and bellowed," encouraging the rest of the herd to do the same so that "the whole world was filled with dumb yearning. It was the primeval voice sounding loud in the ear of the present moment" (BTA 140). Nature had "annihilated the 
gap; bridged the distance; filled the emptiness and continued the emotion" where the actors, and Miss La Trobe herself, could not (BTA 140-141).

The second time that nature saves the performance is during Miss La Trobe's "experiment" of giving the audience ten minutes of "present time"-conveyed by swallows, cows, and trees before the play's final scene. But too late does she realize "'Reality too strong"” and that her audience was "slipping the noose" as her illusion failed once again (BTA 179-180). But the moment is redeemed by a sudden shower: "No one had seen the cloud coming. There it was, black, swollen, on top of them. Down it poured like all the people in the world weeping. Tears. Tears. Tears... they were all people's tears, weeping for all people... Then it stopped. From the grass rose a fresh earthy smell" (BTA 180). Miss La Trobe, relieved, concludes that "nature once more had taken her part" and that "the risk she had run acting in the open air was justified" (BTA 181).

Although her overall impression of the play's success is dismal, Miss La Trobe has already begun imagining a new play before leaving Pointz Hall as inspired by the general—not particular — sense of the natural world around her: "It was growing darker. Since there were no clouds to trouble the sky, the blue was bluer, the green greener. There was no longer a view-no Folly, no spire of Bolney Minster. It was land merely, no land in particular. She put down her case and stood looking at the land. Then something rose to the surface" (BTA 210). Even in the dark hours before the coming war, the land is still able to speak to the writer who seeks it. As she drinks and listens to the talk around her later that evening, "words of one syllable sank down into the mud... the mud became fertile. Words rose above the intolerably laden dumb oxen plodding through the mud. Words without meaning—wonderful words" (BTA 212). Finally, the smoke in the room obscures the pictures before her, and Miss La Trobe sees "the high ground at midnight; 
there the rock; and two scarcely perceptible figures. Suddenly the tree was pelted with starlings... She heard the first words" (BTA 212). These words, formed in the mud of a common language turned over by the plodding oxen, become the beginning of a new story, a new play, a new configuration of humanity and nature together veiling and revealing each other.

In the final scene of the novel as Bart, Lucy, Isa, and Giles gather around in the big room with the windows open to let in the last of the evening, it seems as if this new play has already befallen them, perhaps conveyed by the fertile mud under them all: so that an old woman like Lucy can appear "for a moment... like a tragic figure from another play," cautious Isa-who hides the very fact that she writes poetry — can see her husband and long for "a new plot, or that the author came out from the bushes," and together, a common English couple can "become enormous" and prepare to fight like foxes or like figures from a Greek tragedy while "dwellers in caves... watched from some high place among rocks" (BTA 214, 215, 219). This final imagery of words deriving from and fertilized in mud and audiences in caves suggest that even if Giles is right and the view will soon be destroyed, there will endure in the primeval wreckage some spark of life: humanity and its stories will live on.

\section{Metaphorical Reading in Between the Acts}

The reality of encountering Between the Acts as a contemporary reader is that of an inheritance of continuing to question the possibilities within literature while hoping against hope that reading and books will outlast the destructive actions of man-despite the knowledge that Woolf's final act (drowning herself in the nearby river) seem to suggest that such hope is ultimately futile. Today, closing in on a century since the war that many believed would mean the death of Western civilization, readers face new but similar fears regarding the endurance of 
our way of life, including our value of reading, and Between the Acts' metafictional portrayals of reading could very well be a prediction of what's to come: the enlargement of the present to consume all significance of the past which blocks the realization of sensory encounters through reading. ${ }^{59}$ But most readers will likely cling to the sense of promise at the end of the novel: a promise that stories, art, nature, and humanity will endure and continue to carry on the legacy of the past. It is a promise that texts will once again be the antidotes to the aches of the present time and will connect readers to a past they instinctually long to encounter. Between the Acts' portrayals of reading and of books, though largely removed from her final version of the novel, nevertheless suggest that readers must carry on; "if no human being ever came, never, never, never, the books would be mouldy, the fire out and the tortoiseshell butterfly dead on the pane" (BTA 17). Like the butterfly, something too precious to fully grasp would be lost, the books and stories themselves but also a central part of what it means to be human. In this way, Between the Acts can be read as a passing of the baton to new readers and new writers to find the words and allow them to come forth and speak new stories for a new succession of readers.

\section{The Reader at the End of the World}

Like the celebrated figure of the common reader of Woolf's essays, reading in Orlando involves a healthy balance of the cognitive and the sensual. Even while Orlando's teasing biographer-narrator ridicules the resulting stillness and lack of action in the reader, reading clearly motivates and moves the reader into activity, mental and physical alike. The "long succession of readers" is maintained through the physical handling of the text itself as well as

\footnotetext{
${ }^{59}$ With the loss of local bookstores, the resistance to reading more difficult literature in schools, the proliferation of reading-alternative activities such as TV, video games, social media, etc., and the death or hostile takeover of numerous publishing companies, many would say that reading is, to an extent, once again under attack.
} 
through the thinking and writing of each new generation of readers on the literature of the past.

The circle is completed by the incorporation of contemporary books into the fold of past works as well as by the incorporation of contemporary readers into the fold of past readers. Literary activities beget more literary activities, and books, like their readers, have bodies and minds, life and limb, shape and weight.

In Between the Acts, not only are scenes of reading and descriptions of books largely cut from the published version, the very fellowship of readers is disbanded. Gone are the earlier drafts' depictions of past readers, centered around Chaucer as the first English author. Gone is the explicit connection between embodied readers by way of poetry. Gone are the questions of how books relate differently to different readers. ${ }^{60}$ Such deletions do not indicate that Woolf has abandoned her theory of reading, only that the menacing flipside of her theory has revealed itself: readers are so essential to books and their authors that if they are not there, we lose all we have accumulated through centuries of readership. The very materiality of reading which enables the texture and pressure and presence of readers within and around works is chipped away, not by the years, but by the absence of new readers. The remnants of reading in Between the Acts indicate how it starts: a shift in reading materials away from the past (i.e. books are rejected in favor of newspapers) occurs simultaneously with a loss of enjoyment in embodied reading, that is, anticipating an encounter with past readers and writers through the physical book. The lack of sensuality in reading belies a lack of cognition in reading as the two go hand in hand.

Newspapers abound and their physical properties are certainly not ignored in the novel, but they

\footnotetext{
60 "For in the course of three centuries, several dozens of people had opened that very copy of the Canterbury Tales <in the bookcase opposite the window.>" (Pointz Hall 50); "So you've read that. And I never thought it; so we're not such fools either of us; not such simpletons..." (Pointz Hall 38); Whether "pure understanding [could] be achieved between Bartholomew and Chaucer, Giles and Chaucer, Alice Swithin and Chaucer, Haines and Chaucer, Perry and Chaucer? And then what about Bartlet [the butler] and Chaucer, and the two nurses, Amy and Mabel? All adults, all capable of reading..." (Pointz Hall 49).
} 
are folded, bent, torn, passed around, and thrown away without any indication of pleasure or the necessity of encounters with past readers. The present moment - and attempts to suppress the present moment — has become all, as reflected by the uneasy pageant put on in the yard: the present swallows up the audience as the newspaper swallows up its readers.

Just as the audience members of the pageant are presented with themselves, the current reader's approach to the work of Woolf is and will forever be mediated by Woolf's contemporary readers - both the atmosphere their pressure exerted on her writing and the result of their perceived recession from her awareness, especially apparent in her final novel. No one was more conscious of this transaction than Woolf herself, and the implications of this relationship were consistently worked and reworked in the very novels and writings her readers would then consume. The cyclical nature of these exchanges suggests that readers-common and otherwise - ought to pay attention to the metafictionality of Woolf's reading characters. Not only do they offer glimpses of Woolf's own working out of questions about reading, these fictional readers direct and encourage actual readers' experiences with the texts and their author. Their cognitive and sensory depictions are the models present readers must follow and address in their own reading; their questions are our own: what are we looking for in books? Are we finding it? Can reading save us from our present selves?

In considering these two novels by Virginia Woolf, one earlier in her career and one at the end of it, the full range of metaphorical possibilities are revealed in her inclination towards the combination of reading as (1) an Encounter with Sensory Bodies, (2) as Contact with the Past, and (3) an Encounter with Nature. As opposed to narrowing the writer's (and reader's) conception of reading, such reuse and recodification enlarges its scope and alters the texts' overall tones towards metafictional reading and literary activities. While Orlando is made 
possible by an embrace of reading that elicits the body's senses and memories as the means by which the reading individual achieves the fullest encounter with a book, Between the Acts demonstrates what a disruption of one or more aspects of Woolf's readerly triad means for the now unfortunately unstable reader (who may easily become a nonreader). Significantly, the first element to go seems to be the ability of the readership at large to value reading in the first place - a valuing that both justifies one's time spent at it and facilitates the type of self-loss (illustrated so well in Orlando) that is necessary to allow the reader to move beyond his/her present moment and self. In this conception of the unbalanced reader, interposed between reader and book is an anxiety; the need for solace, connection, and sensation persists, but the reader's state of mind rejects the vulnerabilities of body required. Thus, reading becomes mere seeingglimpses, frozen moments of the present — and no longer an embodied movement of mind and body acting in concert. 


\section{CHAPTER 3: READING AS CHALLENGE}

"I have only words to play with." - Vladimir Nabokov, Lolita, pg. 32

As seen in the previous chapter, the vulnerability and permeability of bodies encountering texts is a significant conception for writers with high stakes in the cultural dialogues between "high" and "low" readers as well as the dialogues between writers and readers. Acts of reading, for an author like Virginia Woolf, connect a reader with the author and with fellow readers by eliciting the memory of sensory encounters with others, with the past, and with nature; but these connections are predicated on the vulnerability of reading bodies. As Woolf demonstrates in the metafictional readers and scenes of reading in Between the Acts, when readers no longer permit the text full access to their bodies, the act of reading is warped into a disconnection between mind and body, and between reader and author. But what happens when the readerly vulnerability which Woolf so celebrates is itself the subject of exploration, and potentially, exploitation? That is, if readers are indeed rendered vulnerable to texts, the question is how vulnerable? Do readers maintain freewill and independence in their reading experiences? Can a reader only ever enact a reading experience already prescribed by the author, or is it possible for a reader to be anything more than "the reader"- - a rhetorically prescribed figure without autonomy?

One motivation behind reading as well as writing fiction can be described in the abstract metaphor of "Reading as Challenge" - although the two impulses need not be complementary. A desire to be challenged by one's reading materials is a very different sort of desire than say, reading to escape one's problems (an impulse explored in Chapter 5). Challenge suggests stimulation, arousal, and, perhaps, competition. Like other metaphors, it is highly specific to the 
individual in that what one reader may consider to be a challenge to her beliefs, her worldview, her reading habits, even her vocabulary, another reader may find quite tame. Likewise, time and distance may render a previously challenging text almost flavorless to a particular reader or group of readers. The metafictional use of challenging reading and reading as challenge as the subject of a narrative has produced a wide variety of works, some of which consider the antagonism of certain readers - namely, scholarly readers - towards texts, and others that focus on the struggle of the author to produce meaningful work in the antagonistic world of cutthroat publishers and fickle readers. In this chapter I explore these questions of readerly and writerly challenge in two structurally and thematically different novels, both of which present strained metafictional writer/reader relationships mediated by the frameworks of three embodied metaphors of reading: "Reading as Sexual Intercourse," "Reading as Performance," and "Reading as Contact with the Past."

Ernest Hemingway's The Garden of Eden presents a series of challenges that derive from alleged dichotomies surrounding the act of reading — good reader vs. bad reader, reader vs. writer, traditional artist vs. unconventional artist, text vs. body, and past vs. present— the results of which posit the triumph of the traditional male author (and his text) over the attempted sabotage of an unworthy reader. Conversely, Vladimir Nabokov's Pale Fire presents a seemingly antagonistic relationship between writer and reader that fractures the more the actual reader attempts to pin down these positions as antipathetic to one another. The sides and stakes developed in both novels can be read as reactions to critical movements at the time of their conceptions in which the former authority of the Author was beginning to be questioned and even replaced by a new emphasis on the experience of the reader. Both novels (and their authors) refute this "Death of the Author" ultimatum by subsuming such readings within their own 
"Death of the Reader" stories which promise resurrection to the reader who aligns or merges with the author. Actual readers are pressed into evaluations of their own readerly habits through both positive and negative identifications with metafictional readers and metafictional relationships between readers and writers. A reader may still choose to engage with the author on the field of battle, but resistance - according to these texts—is narratively preordained and predictable when the text itself is a challenge to the reader's understanding of the experience of reading and of herself as a reader.

The metaphor of "Reading as Sexual Intercourse" plays a crucial role in developing these challenge-based relationships between writer and reader, especially in invoking rapid and/or unexpected shifts from safe to dangerous intimacy with another individual. Critical to the engagement of this metaphor is its imagery of physical bodies in their closest possible proximity to each other-imagery which is then transposed onto the reader/writer relationship available to actual readers of the texts. Intimacy between writers and readers, both metafictional and actual, is necessary to the engagement of this metaphor and, as such, is encouraged by the allure of its revealing language — both in the sensory details conveyed and the emotional vulnerability those details represent. For Hemingway's The Garden of Eden, this level of intimacy with its emphasis on displaying the inner workings of the writer's mind is unusually exposed as Hemingway allows readers a glimpse of "the working problems of the artist, employing, varying, and enlarging on concepts that he had expressed in interviews or written about in his fiction" to a greater extent than in any of his other works (Fleming 145). In this warm textual embrace, the reader is encouraged to respond in kind, flattered by the intimacies the writer offers and honored in her role of secret-keeper, admirer, and ultimately, lover. Similarly, in Pale Fire, the reader is offered intimacy in the language of puzzles, secrets, codes, and obscure references with the 
promise that she too can make sense of them and work her way through the author's mind. But, as in other coupled sexual relationships, the imposition of another body — and even fear of that imposition — between the central pair leads to instability in the relationship as well as jealousy, uncertainty, and resentment. Readers, seduced by the text, are then likewise invited to experience this bewilderment (even anger) when a writer interrupts the expectations of the normative writer/reader relationship (as in Pale Fire) or when a writer rebukes or banishes a character with whom the reader has been led to admire (as in The Garden of Eden). The development of such a close, even dependent relationship on another is always with its risks, and a reader may react violently to textual portrayals of control and challenge mediated by the "Reading as Sex" metaphor. Prior experiences and beliefs regarding sexual relationships and even the role of sex in relationships will shape a reader's response to metafictional readers' vulnerabilities, jealousies, desires, and abandonments as well as to the demands readers and writers place on each other. Maintaining one's identity as a reader becomes a part of navigating alliances and protecting oneself from perceived threats due to an earlier vulnerability — be it against the metafictional writer, the actual writer, or the metafictional reader.

"Reading as Performance" is another metaphor which has close ties to literary questions of challenge and contest. On its own, performance incorporates conceptions of viewership and spectacle; when utilized as a framework for reading, the observatory role is pivoted to both writer and reader: readers may be allowed to observe their writers in the act of composing (whether metafictionally within the narrative or as actual readers "watching" actual writers write) and writers may observe their readers in the act of reading - engaged in an enactment of their words. Through the "performance" metaphor in metafictional texts, actual readers are also invited to watch themselves reading and, in their observations of themselves, to analyze this act 
in terms of authorial control as well as, potentially, its purpose in their overall lives. Beyond these sight-based, single-sense conceptions of observation, viewing, and reflection are the realities of performance on and in the entire body. Readers' responses to texts take many forms even if constrained to a mere tightening of the brow, pursing of the lips, or unconscious comforting gestures of self-touch in response to the emotional rises and falls, plot surprises, confusion, and apotheoses. Texts such as Pale Fire demand a more active participation in requiring readers to physically flip back and forth to different sections of the text in an obvious mimicry of the metafictional reader, Charles Kinbote. Or, as in The Garden of Eden, the metafictionality of one reader watching another reader and being in turn watched by the writer, all of which is observed by the actual reader, may create the illusion that the actual author (in this case, Hemingway himself) is watching the body of the reader reading his novel. As mediated through the sexual intercourse framework, performance also entails a taking of sides: is the reader a performer of the text watched by another, an observer of it, a self-observer of his performance, or all the above? As we shall see, the "Reading as Performance" and "Reading as Sexual Intercourse" metaphors fold into each other in both texts with the one used to explore and activate the other based on their authors' choice of emphasis.

"Reading as Contact with the Past" provides a final framework for metafictional readers and reader/writer relationships within these novels as actual readers are presented with the suggestion that contact with the past is one of the key purposes of the narrative. The revelation of one's past is a further sign of intimacy between individuals, particularly if the past that is related consists of moments of vulnerability, struggle, and loss. These confessions propel the reader into an empathetic response to the author, and in these acts of identification, the reader's body is moved to trace the position of the writer's past, whether that past contains painful disconnection 
from others, struggles before or after the achievement of celebrity, or the necessity of reliving a traumatic past in order to write about it. The reader is there as a co-reliver in the sensory experiences of metafictional authors that point to their actual authors. Significantly, it is contact with a particular and personally-significant past which these texts' metafictional writers offer their readers (as opposed to a "general" past), and readerly resistance to the narratives can take the form of resistance to the touch of these pasts and/or the presentation of a competing past. The language of contact with the past is also the most difficult to pin down as such contact may take place at any moment with the slightest provocation. The past may be alternatively touched, seen, smelled, tasted, heard, and felt—it is an already re-determined object, its properties forged in the contact it makes and effects it has on the present human subject. Additionally, ghosts from the past may return with the writer to the present time to haunt both writer and reader as in the ghost of David's father in The Garden of Eden and the ghost of Shade's daughter (and perhaps Shade himself) in Pale Fire.

While the metaphors of "Reading as Sex," "Reading as Performance," and "Reading as Contact with the Past" are present within the reading experiences of both works, the theme of authorial challenge of and contest with readers plays out in astonishingly different ways on the macro-scale. The Garden of Eden unfolds as a story ostensibly rewarding good, obedient readers with intimacy with the author, while punishing bad readers who attempt to control or one-up the writer; and yet, for all that, The Garden of Eden remains a story about a bad female reader who is revealed to be a worthy subject for a narrative as well as a challenger fit to stand toe-to-toe against the traditional male writer - at least for a time. Pale Fire, meanwhile, appears to antagonize all readers equally — lay and scholarly, young and old, male and female — in setting them a script of readerly performance which splinters into infinite possibilities, but which holds 
to the promise of answers for every contained puzzle; whether or not the reader succeeds in discovering what those answers might be comes down to his willingness to keep searching. Actual readers can love or hate these metafictional readers and writers; they can also resist textual invocations to perform the narrative and make contact with the characters' written pasts by skipping over sections or giving less weight to metafictional writers' or readers' commands and opinions. As a result of these freedoms, readers may come away from The Garden of Eden despising David, the writer, and celebrating his rejected reader, Catherine, as the true hero (which may or may not rouse negative feelings towards Hemingway himself). Likewise, a reader of Pale Fire may throw her hands up at the whole enterprise and decide that its riddles and puzzles are not worth her pursuing and constant page-flipping. But such actions, these texts make clear, are failures on the reader's part, not the text itself - a conclusion made especially necessary in light of the anti-Author sentiments of modern and postmodern literary theory.

\section{Authoricide, and the Combative Trends of Modernist/Postmodernist Literary Theory}

Following the chaos of World War I, literary theory, along with the rest of Western society, had to pick itself up again with an uneasy sense that the old gods had failed to prevent the worst from happening. But now that it had happened, writers and critics alike sought to fill the void opened by social disillusionment with the irrefutable authorities of yore (Religious Doctrine, the State, the Church, Western Tradition) in recognition of the harsh new reality of the present. Perhaps not surprisingly, many of the new critical (and cultural) ideologies of the midtwentieth century sought to provide a degree of comfort for their shell-shocked disciples, a trend that can be seen in schools of thought ranging from the human-centric phenomenology of Edmund Husserl, which proclaimed consciousness to constitute a knowable world, to the 
elevation of the Reader from under the reign of the Author in the School of Reception Aesthetics, to the achievable systematic control offered by a Saussurian structuralism. In so doing, the repression of actual historical context and actors became the norm in critical literary interpretation as instead "language, with its problems, mysteries and implications... bec[a]me both paradigm and obsession for twentieth century intellectual life" (Eagleton 97, italics mine). But notably, it was language stripped of its origins, histories, and general usage that caught the modernist eye (not ear). The old formalist dream of evaluating a text in total isolation from the tedious tentacles of society, author, history, and actual readers lived on in these mid-twentiethcentury approaches to texts in the name of both complete objectivity and an embrace of the unbounded multiplicities of subjectivity. Roland Barthes' 1967 treatise, "The Death of the Author," perhaps best sums up the distance such criticism had come. According to Barthes, the idea of a fixed, "immanent" meaning and reading of a text based on authorial intention had become not only unnecessary, but distasteful to the world of readers whose critical acts of reading were now seen as creative acts as well. This critical movement from stable to destabilized, fixed meaning to plurality, and product to production was the fulfillment of modernist thought. Reading was now a mirrored double to the act of writing in the metaphor of reader as writer.

Not all readers were in favor of this Barthesian elevation. Contemporary novelist Zadie Smith opens her essay "Rereading Barthes and Nabokov" with the suggestion that, instead of a mirror, novels "have an architecture" in which the reader lives while reading, even coming to "feel that you [the reader] possess it, that nobody else has ever lived there"-not even its architect (i.e. author) (42-43). The Common Law doctrine of Adverse Possession in which undetected squatters can claim ownership if they retain possession of the property is inherent in 
Smith's suggestion that the reader in reading has effectively taken up residence in the text while its creator is away and so has a claim to it. But such possession is still not the same as building and "owning" the house, and in all this talk of living in and taking possession of textual houses through reading, Smith cannot apply Barthes' "death of the Author" to an actual author - the Nabokov of her beloved Pnin - in any way but as a superficial acknowledgement that both critic and author, Barthes and Nabokov, believed in the creative act of reading. Whereas for Barthes, the indeterminacy of the text is due to the emptiness under the surface of its script, for Nabokov, there is an over-abundance of meaning, only decipherable by degrees, beneath the surface of both a text and the larger world. In light of the unachievable depths of meaning in the textual worlds Nabokov offers, Smith acknowledges that Nabokov's ideal reader is in fact Nabokov himself, and that in order to fully share in the abundance of the author's joy and struggle of creation, "it is the reader who must die so that the Author may live" (53, italics in original). The squatter may reside for a time, but "The only perfect tenant of the house that Nabokov built is Nabokov," she writes (53).

If Smith is right in thinking that Nabokov's preemptive answer to the critic's call that he silently disappear into the dust-jacket is to demand a subsumption of the reader into his unwavering authorial self, Hemingway's response — while coming to a similar end — takes an opposite tack. For Hemingway, the place for the reader is not within the writer's mind, but rather, by his side, or — if you will — on her knees before him. ${ }^{61}$ Even non-readers who have never opened a Hemingway novel in their life likely know something of his reputation - the mythos of the Great White Male Author caught up in images of indestructible masculinity with bull fights, big game hunting, fishing, soldiering, boozing, and seduction. A reader could not,

\footnotetext{
${ }^{61}$ The necessity of a female reader (or feminized reader) will be explored in greater detail in the next section.
} 
arguably, read an author like that without knowing it—or forgetting it, and Hemingway himself famously utilized the competition-based metaphors of boxing and bullfighting to describe his contests against the great writers of the past. ${ }^{62}$ Nabokov expects gratitude from his readers; Hemingway demands adoration.

Both within their works and within the readings and criticism surrounding their works, Nabokov and Hemingway fight against the threat of an imposed authoricide utilizing their unique writing styles in line with idealized views of the author/reader relationship. For Nabokov, the reader would come to the text as "something resembling a butterfly collector, with an interest both empirical and aesthetic" (Smith 51) — an individual willing and expecting to see beauty in the craft and satisfaction in the details. Significantly, the ideal reader is, and must be, a rereader, for only in rereading does the essence of the text begin to reveal itself as the reader cuts through the limitations of time and space, according to Nabokov's view. A reader must also read not with the mind, the heart, or the brain but with "the top of the tingling spine" and "with a pleasure which is both sensual and intellectual" (Nabokov, "Good Readers and Good Writers" 4, 6). Conversely, for Hemingway — and especially Hemingway at the end of his life — the reader is a younger, admiring woman, eager for stories and attention from "Papa," strange and solemn or delighted as a child with a new toy by turns in careful response to the whims of the great man himself. She is conscientious, protective, a little naïve, and obviously, beautiful. While the possibilities for actual readers to find themselves living out (or wanting to live out) these representations of ideal reader/writer relationships exists within these texts, the authors have

\footnotetext{
${ }^{62}$ Rena Sanderson in "Hemingway and Gender History" notes that even prior to Lillian Ross' published interview with Hemingway in which he lists authors he has bested in the ring and declared himself literary heavy-weight champion, Hemingway had utilized this metaphor in a letter to Charles Scribner in 1949, mentioning those authors he had beaten in the ring as well as "some guys nobody could ever beat like Mr. Shakespeare (The Champion) and Mr. Anonymous” (qtd. in Sanderson 170).
} 
readers coming and going in the insinuation that if the reader finds herself responding in a less than ideal way, the fault it not on the author, but on herself - a last laugh on the presuming critic from a prematurely dug, author-sized grave.

\section{Reading and Readers in The Garden of Eden: Body-blows and Mind Games}

In The Garden of Eden (1986), Hemingway responds to the general threat of an erasure of authorial authority and personal allegations that his best writing years were behind him in typical Hemingway fashion: he first imagines a feminized version of the threat against his status in a narrative about an author and then has that author (his avatar) defeat it soundly. To ensure that the victorious author is not left alone following the loss of the threatening female, Hemingway also provides an alternative reader relationship with the author-figure: a supportive, controllable ideal reader who is everything her competitor is not, save that they are both attractive to the author. The actual reader will reveal herself to be either friend or foe in her reaction to this narrated contest: will she too embrace the author as the true hero of the story, deserving support and adoration from his readers?, or will she continue to challenge his superiority by resisting the prescribed ending? This is the ostensive plot and readerly experience of the novel, but not the whole story. The threatening female reader who opposes the author and intrudes in the sacrosanct miracle of his writing is also an incredibly attractive character in her increasing mystery and complexity. She is not an older, domineering bully of a wife who acts as she does for social elevation or wealth; she is a young, beautiful, changeable changeling of a girl, whose depths Hemingway leaves carefully unplumbed. It is the intrigue and mystique that Hemingway grants the figure of his alleged competitor that distinguishes the novel as a rich 
proving ground for questions of authorial authority and of the conception of reading as itself a challenge.

The Garden of Eden has a spotty composition and publication history as one of Hemingway's four posthumously published works, likely begun in either 1946 or 1948 and put down for the last time in 1959 , two years before Hemingway committed suicide. ${ }^{63}$ Due to its final unauthorized status, the novel is often cautiously addressed by scholars, if not out and out ignored. Criticism that does address the text, however, tends to focus broadly on three major topics of interest: (1) the dramatic posthumous editorial decisions made to the manuscript to create the published novel, (2) the text's emphasis on writing and writers-particularly the competition between David as the traditional male author and Catherine as the nontraditional, female author/artist, and (3) autobiographical connections between the trauma experienced by the metafictional writer, David Bourne, and the young Hemingway. The first category of criticism, while continuing to supply fodder for interested critics thanks to the extreme editing of Scribner's Tom Jenks that reduced a massive manuscript to a $<250$ page novel, will not be addressed here. ${ }^{64}$ As such all references to The Garden of Eden will be to the published version unless otherwise indicated. However, the latter two categories of Garden's textual criticism remain on the fringes of my reading insofar as they speak to the actual reader's experience of the novel as a challenge encompassing the embodiment of performed sexual desire and intimacy (i.e.

\footnotetext{
63 There is some confusion over the start of composition among Hemingway biographers and critics: James R. Mellow in Hemingway: A Life without Consequences (1992) has it as 1946; other scholars, such as Marc Seals, has it as 1948; John Leonard in "The Garden of Eden: A Question of Dates" puts it as late as 1957. The general consensus, however, suggests the mid to late 1940s as the most likely period.

${ }^{64}$ This manuscript, consisting of 48 chapters to the novel's 30 and 200,000 words to the novel's 70,000, is now housed in the Hemingway Room at the JFK Library in Boston, MA. For comparisons between manuscript and novel, see Frank Scafella's “Clippings from The Garden of Eden" and Chris L Nesmith's "The Law of an Ancient God' and the Editing of Hemingway's The Garden of Eden: The Final Corrected Typescript and Galleys.”
} 
the Catherine vs. David category) and the empathetic reliving of the author's past (i.e. the David/Hemingway connection category). I will briefly review these critical categories beginning with the Catherine vs. David contest before continuing to my close reading of the novel below.

The view of Catherine as an artist capable of challenging her husband as opposed to (or in addition to) being a disturbed young woman in need of psychological care is directly related to the reader's level of admiration for her. While unable to create through language, Catherine is depicted as demonstrating an artistic vision in her desire for appearances to portray a felt reality; she pays especial attention to the hair, skin, and clothes of all three members of the ménage à trois with an intentional disregard for societal rules. "'Why do we have to go by everyone else's rules? We're us... Stupid people will think it is strange. But we must be proud. I love to be proud," she tells David after her first boyish haircut (GOE 15-16). Kathy Willingham, declaring that we absolutely must see Catherine as just as legitimate an artist as David, submits that as a struggling female artist in a phallocentric world, Catherine "compensates for her insecurities about expressing herself with language by asserting her creativity and ingenuity physically" (52). My own reading will touch on the significance of the reader's assessment of Catherine as a “true" artist or as a jealous poseur of an artist: if the actual reader champions Catherine's realization of her artistic vision over that of her husband, then her final narrative dismissal packs an even greater punch, possibly leading the reader to alter her opinion of Hemingway himself in the autobiographic David character; conversely, if the reader views Catherine as a conniving, spoiled rich girl who only fancies herself an artist (without actually creating art) her exit will result in readerly satisfaction and a reconfirmation of the supremacy of the author.

As for the third major category of Garden scholarship, the critically-noted connection between David Bourne and Ernest Hemingway reflects the similarities between character and 
creator in their obsession over writing and the reading of their writing, but it also speaks to the empathetic nostalgia in which the actual reader is invited to participate alongside both David and Hemingway. The connections between the loss of David's work at hands of his wife, Catherine, and Hemingway's own loss of his early work at the hands of his wife, Hadley, are relatively straightforward. ${ }^{65}$ Hemingway-biographer James Mellow sums up the critical impulse to connect these two series of events on an emotional level saying, "Hemingway had a tenacious memory even where long-buried events were concerned, and his depiction of David Bourne's realization of his loss has all the freshness of a recent event" (212). Marc Seals and other critics utilizing trauma theory in their approach to Hemingway's work have pointed out that this particular story of the writer's traumatic loss was reused by Hemingway in other narratives but never in ones which were published; as a result "these were narratives with no author-sanctioned readers" (Seals 64). ${ }^{66}$ Also significant in this critical category is that while the real lost Hemingway manuscripts were never rewritten—-probably because, as Ezra Pound suggested, they were not worthy of rewriting — the metafictional David is able to rewrite his lost manuscripts and write them better than they were before. As scholars of Garden frequently note, the loss of his manuscripts counterintuitively improves David's writing and allows him to recover his

\footnotetext{
${ }^{65}$ In keeping with the Hemingway mythos, accounts of the actual events of Hemingway's lost manuscripts, including Hemingway's response to the loss and whether Hemingway blamed Hadley for "intentionally accidentally" losing the manuscripts, are muddled at best: in The Moveable Feast, Hadley is so upset that she couldn't initially tell him what was wrong (suggesting it really was an accident with no malice aforethought), whereas in in his first mention of the theft by letter, Hemingway tells Ezra Pound on January 23, 1923 that he "went up to Paris last week to see what was left and found that Hadley had made the job complet by including all carbons, duplicates etc.," the phrasing suggesting at least a latent blaming of Hadley—only acceptable under the veneer of humor-for her part in the loss.

${ }^{66}$ The four texts in which an account of an author losing his stories is featured are: "The Strange Country" (a short story derived from the deleted "Miami" section of Islands in the Stream, True at First Light (although the loss of the manuscripts was cut from the final version), The Garden of Eden, and A Moveable Feast. Of these four fictionalized accounts of the loss of Hemingway's own manuscripts, The Garden of Eden is the one in which the role of the semito-fully responsible wife is treated the most harshly - the act itself becoming vindictive and cruel, and yet it is also the only account in which the author-protagonist is able to remember and rewrite the lost stories and rewrite them better than they were originally.
} 
confidence as a writer - a confidence that had been shattered by Catherine's frequent bodyblows. Hemingway, through the character of David, is able to rewrite his personal history of loss as a story with a happy ending.

My reading of Garden also sees an essential connection between David Bourne and Hemingway, but I depart from this category of scholarship in a crucial way: in focusing on connecting David to a young Hemingway, critical work drawing from trauma theory and other autobiographically-driven methodologies frequently overlooks the immediate context in which the novel was written, i.e. the end of Hemingway's life. From the beginning of his career to its end, Hemingway "became a celebrity rather than a famous writer, and if he was not only willing but complicit in the formation of that celebrity's image, he eventually found that carrying that persona around with him could be psychologically and even physically troubling" (Donaldson 12). As celebrity giveth, celebrity taketh away, and towards the end of his life, Hemingway was keenly aware of the dangers in being a washed-up has-been, his best creative years behind him. Additionally, Hemingway's well-known metaphor of writing as "duking it out" with the previous great writers meant that "a writer of a certain standing had to strive continuously to push beyond his previous limits" in order to prevent himself from becoming obsolete (Fleming 128). In combining Hemingway's late life, authorial anxieties put into relief by his legendary status with Rena Sanderson's observation that Hemingway "feminized the things that hurt his career" (191), a context for the novel's dueling female readers, heavy layering of nostalgia, final male authorial triumph, and emphasis on the sexual overtones of an ideal narrative situation begins to unfold.

A final note on the traditional critical approaches to this novel: with such sustained emphases on the writer and writing - in both the plot of the novel and in its surrounding autobiographical and editorial events, it is easy to lose sight of the fact that the writer is not 
alone. The novel equally features readers and scenes of reading which open it up to critical considerations of embodied reading — reading in which physical and psychological challenges feature heavily. Not insignificantly in a narrative that values and emphasizes bodies and bodily pairings, David's two readers are women; moreover, they are women with whom he has emotional and sexual relationships though only one, Catherine, is his legal wife. Utilizing the metaphors of "Reading as Sex," "Reading as Performance" and "Reading as Contact with the Past," the text leads readers to identify and empathize with David but to admire and adore the enigmatic Catherine; ultimately, readers are instructed to accept that of the two, David, as the author, "wins" in the end and indeed that he deserves to win. The challenge to love the woman/reader but side with the man/author - in a sense, to accept Hemingway's retelling of his relationships with his own readers and wives - is complicated by the text's invocation that the actual reader not find the author guilty in the end of rigging the game. Thus, The Garden of Eden is both a story about the challenges issued between reader and author as well as a story that challenges an actual reader's sense of justice between the conflicting positions of readerly adoration on the one hand and authorial veneration on the other-with Hemingway, presumably, keeping watch over the reading body's every secret and subtle reaction to his words.

\section{Reading as Sexual Intercourse and Performance}

If two metaphors exist to best sum up Hemingway's approach towards reading and readers, they are arguably that of "Reading as Sexual Intercourse" and "Reading as Performance." From the beginning of his career, critics made much of Hemingway's "masculine" style of writing consisting of clean, clear, forceful lines whose surfaces spoke of untouched depths - a style that supposedly mimics the ideals of courageous and true manhood in 
pursuit of manly activities. In its apparent simplicity, readers are invited to lose themselves to the exploration of those promised depths, an activity in which Hemingway's famous quest for what is "true" sets readers a prescription for a sublime readerly performance. Sex-rewritten as the revealer of truth in both one's self and one's understanding of another-and sex as performance go hand-in-hand in Hemingway's narratives. Sex as the performance of a relationship reveals the troubles, paradoxes, and hints of future failure/success in couples; sex as the performance of a reader/writer relationship likewise suggests the possibility or impossibility of an ideal, "gardenof-Eden-like" achievement. Critic Rena Sanderson points to other examples of how Hemingway views writing, writers, and readers in sexual terms: Hemingway's statements connecting a writer's ability to his sexual prowess and fertility (so that censorship equals emasculation); Hemingway's characterizations of his disapproving critics as female inhibitors of his male quest to create great art; and Hemingway's view of his stories as confirmation of his masculinity, particularly in connection to their subjects as manly topics $(183,191,182)$.

This merger of sexual intercourse with performance (or sexual intercourse as performance) plays out in The Garden of Eden in significant ways in the embodied reading experience made available to readers. For metafictional writer David Bourne, both sex and writing become sites of immense struggle for self-definition but also for the achievement of oneness with a willing other. David longs to feel that he and his wife Catherine are together to face the world, but Catherine's insistence on changing both herself and David make this merger an impossibility. The Garden of Eden also substitutes sexual partners for readers and vice versa, in that both Catherine's and Marita's performances of sex can be read as performances of reading; sex and reading so closely parallel each other that David's conception of his "wives" as readers directly follows the level of satisfaction he receives from his sexual encounters with 
them. As a result, either a lack of sex or hostile sex signals lacks of reading or hostile readings which doubly-identifies the status of David's romantic and authorial relationships with his two female readers. Another interesting feature of The Garden of Eden is its splitting of what in Hemingway's earlier novels is a single challenging female character into two people: the good woman/lover/reader characterized by every constructive attribute and the bad woman/lover/reader characterized by every feared one. Such a "wishful makeover of modern women" allows for the male figure to identify and reject negative female traits and to achieve unblemished reciprocity with the positive female figure (Sanderson 175-176). This splitting of good and bad female characters also accommodates the novel's ending in David's achievement of an ideal audience/mate in paradise without the bother of having to make accommodations for the bad female character. The actual reader may identify with one metafictional reader or the other, but all readers are made aware of which one the author prefers.

The sexual competition between Catherine and Marita as readers and wives is also reflected in the textual competition between David's two manuscripts: (1) the "narrative"- the story of the present time featuring David and Catherine's relationship (which Catherine wants David to write) and (2) David's “Africa" stories — stories taken from his past, particularly the painful memories he had repressed of his father. Initially, David does what Catherine wants and writes about their lives together in the present, allowing Catherine to be both the subject and recipient of the narrative she describes as, "my present and our project"” (GOE 188). Later, however, David abandons the narrative to focus on the Africa stories while allowing Catherine to continue believing he is writing their/her narrative as well. What gradually becomes clear to the actual reader and what Catherine fails to see is that although ostensibly refusing to follow her demands that he write "her" story, David, in another sense, is fulfilling her wishes in that his 
Africa stories contain a shared emotional current with his present life with Catherine. A similar sense of inevitability — of a bad end ultimately to come — following betrayal and regret pervades the stories of David's elephant hunts with his father and the plot of The Garden of Eden itself. For David, past and present can only be full accepted — and possibly understood — through bringing them together in writing. Unfortunately, the actual reader of the novel is the only one able to see this connection-a use of dramatic irony which entails that Catherine remain forever dissatisfied and (so she believes) un-narrated despite her best intentions.

In order for the author to stand undefeated at the novel's end, the competition between his two female readers (one combative, one supportive) and his two texts (one chosen, one rejected) can only have one outcome. But Catherine doesn't make it easy for him, both because she is so overwhelmingly attractive and so seductively tyrannical. In the knowledge that everything they do will be chronicled and explained (or at least described) fully, Catherine intentionally complicates the plot (of both David's new story and The Garden of Eden), first by making physical alternations to her clothes, hair, and skin-color, and then by bringing in the character of Marita. Catherine becomes both darker and lighter in her skin and her hair, respectively, and boyish in appearance. Such changes can be understood as outward signs of her refusal to conform to both societal standards and to David's expectations that she wait in the wings as his happy—female — wife and reader. The character of Marita also serves to highlight Catherine's sexual explorations in providing an experienced lesbian partner for her and a competing sexual interest for David so that their marriage bed becomes rife with polyamorous and androgynous comings and goings. Marita's presence reveals Catherine's unfitness as David's lover and reader in that it is Marita and not Catherine who satisfies David's sexual and authorial needs through submission to his desires and a complete veneration of his work above all else. Marita praises his 
stories, marvels at them, and even the dark ones of his childhood in Africa only serve to make her love and admire him more. In turn, David finds himself wanting to give Marita his unfinished manuscripts to read-something he had never done before with anyone else, including Catherine. Marita's reading body has become essential to David, and her physical reactions to his work are addictive. She breaks literary as well as marital boundaries in David's inability to help himself, "sharing what he had never shared and what he had believed could not and should not be shared" (GOE 203). At one point, Marita tells Catherine that "I'm also more of a woman than you are Catherine,"” and later that "'You aren't really a woman at all"”; Catherine doesn't disagree (GOE 192). Instead she admits that it's easier for them to be "'a girl and a boy both and you really are. You don't have to change and it doesn't kill you and I'm not'” (GOE 192). For this reason, Catherine acknowledges that Marita is indeed the one who can make David happy whereas she changes too much to do the job right. Thus, both Marita (as the good reader) and the Africa stories (as the better narrative) are depicted as defeating the attempted appropriation of Catherine and her desired narrative.

But Catherine does not take these attacks to herself and her narrative lying down; the text (and Hemingway) allows her to be a worthy adversary in the fight for control over David and his stories. She begins by attacking her fellow reader, first signifying Marita's alleged inability to be a good reader by emphasizing that she herself never read David's work—“"I never interfere"”; she next brings up a sore spot for David — his financial dependence on her-by reminding him that it was she who " "tried to make it economically possible... to do the best work of which he is capable""; she further goes on to insult Marita's abilities as a critical reader of David's writing in noticing that Marita has to resort to cliché French adjectives to describe her impressions of his writing (GOE 156). The remarks of the two women after reading one of David's Africa stories is 
telling: Marita's: “'It's a terrible story and it's wonderful"”; Catherine's: "'It's horrible... it's bestial,"” "'You're a monster,"” and "“I hate you"” (GOE 154, 157-158). Catherine also attacks David's texts more directly. After reading his first African story, she rips it in two in disgust. She later sneaks into David's study to read his next unfinished manuscript, all the while knowing he doesn't want her to see it. Finally, most destructively, she resorts to burning all of his Africa stories along with the clippings he had saved of reviews of his previous novel, sparing only the unfinished and discarded narrative story she wanted him to write all along. In the transference of female readers and texts, Catherine has erased the bodies of her rivals: the Africa stories that take David's attention away from her story and Marita who takes David's attention away from her. In this sense, it is surprising that directly following this ultimate act of violence on a textual body, Catherine voluntarily decides to leave the "garden" to those she had defeated.

But as the novel so intriguingly suggests, both types of readers, good and bad, antagonistic and sympathetic, are necessary for the author, with the struggle and competition serving as a tempering of his abilities. Catherine's destruction of the Africa manuscripts has the unintended consequence of creating an occasion for Marita's full value as a reader — and a reader characterized as a sexual partner - to crystalize, and it here that the actual reader is presented with the clearest depiction of what David needs in order to hold onto the persona of Great Male Artist. After this debilitating loss, David is now the one who needs careful watching over. Catherine initially attempts to help by offering to pay for the assumed loss of the stories, but David is clearly not in need of this kind of help. What he needs - commiseration, conversation, encouragement, kindness, and provision of his bodily needs-Marita provides. She bolsters him with the knowledge that his reader is faithful still—“"We'll really do it. Toi et moi,"”- and takes full control of David's schedule and his eating and drinking, making sure that he doesn't dwell 
too long in his misery (GOE 232). Marita continues to satisfy him sexually as well and uses sex to convince him of their stability as a couple which succeeds in granting him a measure of stability as a writer. Marita's presence, devoted and loyal despite their setback, encourages David to continue writing to rectify the loss. When at first he is unable to do so, she provides him with diversions so that he can try again the next day. In the end, Marita's formula of work alternated with pleasure and unwavering solidarity between reader and author results in David's successful rewriting of the lost stories. As a reader, Marita's body takes over Catherine's role in inspiring and moving David to artistic climax while also sliding appropriately out of sight so the David can relish in his final moment of glory. The reader of Garden, in the bodies of both Catherine and Marita has her marching orders: inspire a writer to greatness like Catherine, help him to achieve greatness like Marita, and at all times, never waver in devotion to the author.

In the end, Catherine's failure to sabotage both David's writing and Marita's new place as his chosen reader/wife are concluded neatly by her disappearance from both the novel's end (a narrative dismissal) and David's writings (a metafictional dismissal). Significantly, her failure is painted as a form of self-destruction by David who describes the situation in terms of war:

[Catherine] needs an enemy so badly always that she has to keep one near and she's thenearest and the easiest to attack knowing the weaknesses and strengths and all the faults of our defenses. She turns my flank so successfully then finds it is her own and the last fighting is always in a swirl and the dust that rises is our own dust. (GOE 193-194)

Catherine is pitied but ultimately seen as responsible for the final tragedy of the novel and for putting up obstacles to a happy, healthy relationship with David. By the closing of The Garden of Eden, Catherine's poison is sucked from the wound and she herself is rendered powerless-a 
failure as a wife, lover, reader, creator, and a narrative subject; as a result, the attention of the reader is refocused on the value of David's literary attempts and away from the dangerous downward spiral of a troubled young woman. The reader, along with David himself, is amazed that even Catherine's more vicious attack on his writings is not enough to destroy them. Like a phoenix, the words rise to him again out of the flames, intact, and even improved "as if he were going over proof" (GOE 247) — and the reader is expected to care more about the survival of these words than the woman who first inspired him to write them. In the battle of textual bodies, the writer has won.

All the while, the reader who has read to this idyllic but perplexing ending has been pursued and (perhaps) wooed by the language of The Garden of Eden and the fantasy invoked that, like David, Hemingway also leans over the shoulder of his reader, watching for every sensation of bodily delight and desire in response to his words. But unlike in the narrative, the reader of The Garden of Eden also has the privilege of leaning over the shoulder of the writer as he writes - a symbiotic intimacy which invites the reader to feel a physical connection to the words and vicariously to their author, suggesting that the Africa of David's memories becomes the Grau du Roi and Spain of Hemingway's, and Catherine and Marita become echoes of Hadley and Pauline as well as some splintered formulation of Hemingway's ideal audience. The Garden of Eden invites the reader to accept that narratives render the bodies of both writer and reader vulnerable and knowable just as they do for the metafictional writer and reader. The performance enacted by the reader of The Garden of Eden thus mimics its metafictional readers: leisure in the garden that gives life, or banishment outside the garden which is death.

\section{Reading as Contact with the Past}


As a writer, David has consistently chosen the past over the present to supply his material, and the reader, in turn, has no choice but to be taken into David's past and feel it alongside him. Conversely, Catherine and Marita's pasts are rendered unimportant to the reader as a result of their near complete absence in the novel. This lack of grounding restricts the reader's ability to connect empathetically with the women, especially Marita who is already flattened as a character. Instead, the reader is driven to embody David's memories of the past - a past that is recalled not for pure nostalgia but for the purposes of narrative inspiration. David is convinced that in order to write about the past he must fully relive each moment in order to truly feel its subtle and overlapping sensations in their fullness and complexity: the heat of the jungle beating down, the sound of the elephant moving through the brush, the fur of the dog under his hand, the voices of his father and the guide whispering together, the sweat dripping off his body, the exhaustion of a boy trying to keep up with men, etc. In this full-body empathetic identification, the reader becomes both Davey the boy, realizing that he hates his father, and David the man, looking back at his memories to see his father for who he truly was. Hemingway is there too in the figure of the man writing about being a boy, but he is also there in the character of David's father who haunts both his son and the novel and whose memory demands confrontation and a willingness to reconsider earlier conclusions.

But not any chance contract with the past will do for the purposes David intends them. According to David's narrated musings, a memory is only fully useful to an author if emotion was present in its original occurrence and if the author takes care in his navigation of that emotion so as to avoid rushing the feeling or having it ring out untrue. As a result of this belief, David's acts of memory and composition are given all the cautious consideration owed to a live grenade - the slightest mishandling potentially resulting in complete destruction. Part of the 
difficulty of this process is that perfect recall of sensations and emotions is not beholden to the passage of real time, and David's experience of the story world of his memories and the present world of his wife and honeymoon are typically out of sync - a fact that Catherine is quick to harass him for allowing. Another major difficulty is in aligning his memories of the past with what the reader in the future will experience. Sensory memory is key to crafting the kind of reading experience he wants readers to have: a transformative experience of self-loss through an overwhelming sensual invasion dictated by his narrative. David writes his character, himself as a boy, so that "whoever read it would find what there was there and have it always," the reader as a palimpsest awaiting the transfer of his past (GOE 129). The writing process David undergoes is also a type of self-evisceration in that it necessitates a frequently painful exorcising of his past. In the second-person language befitting a guide to fiction-writing, David convinces himself that he is doing everything right:

...you must write each day better than you possibly can and use the sorrow that you have now to make you know how the early sorrow came. And you must always remember the things you believed because if you know them they will be there in the writing and you won't betray them. (GOE 166)

Towards the end of this process, David particularly struggles to keep his present emotions in check and distinct from how he felt in the past: "The hardest to make truly was how he had felt and keep it untinctured by how he had felt later. The details of the country were sharp and clear as the morning until the foreshortening and prolongation of exhaustion and he had written that well" (GOE 174). But the careful laying out of remembered details from a personal experience of pain and loss also serves the purpose of working on the reader's sense of empathy and trust regarding the authors: David as the metafictional author who is disclosed, and Hemingway as the 
actual author doing the disclosing. Linking David to Hemingway as an autobiographical version of himself as a young man further encourages the reader's placement of empathetic identification with Hemingway as author.

The connection between David's nostalgic ruminations of the past (especially his feelings about his father) and the reader's willingness to shift to "Team David" is facilitated by several factors. First, as previously stated, David's past is the only real recollection of any character's past given in the novel, and it takes up a hefty portion of second half of the text - so much so, in fact, that the publishers at Scribner's were able to combine these sections into a ten page standalone short story, titled “An Africa Story,” published in The Complete Short Stories of Ernest Hemingway. ${ }^{67}$ As a result of this increasing narrative emphasis on David's past, Catherine, Marita, and the present time are edged out of focus. Secondly, the detailed intimacies of David's remembered past — a past that is both inherently traumatic and traumatic to relive and record—is interpreted by the reader as a meaningful disclosure of personal information. There are several concepts from social psychology and sociology used to explain the implications of such disclosure with the basic principle being that self-disclosure from one party induces the perception of intimacy which induces further self-disclosure from the receiving party. According to the "norm of reciprocity," not reciprocating with disclosure, in effect violating a social norm, will usually lead to distress in both parties, the former now characterized by the latter's silence as an over-sharer. Thus, individuals can be coerced into giving away more information than they intended in order to offset the perceived imbalance — a phenomenon well-known and taken advantage of by intelligence gathering professionals, salesmen, fiction-writers, and other persons of ill repute. Beyond setting up a social imbalance that needs to be righted, self-disclosure also

\footnotetext{
${ }^{67}$ The text for this short story was taken nearly word for word from The Garden of Eden pages 159-160, 164-166, 171-174, 179-182, 197-202.
} 
induces a general sense of trust and intimacy. According to the "social attraction-trust hypothesis," an individual tends to read into disclosure the understanding that the person doing the disclosing likes and trusts him/her, thus, the disclosed-to party will be more willing to like and trust the disclosing party. Even if a reader does not see the fictional David Bourne as a standin for the real person of Hemingway, these social norms are nevertheless triggered by the narrative's disclosure of David's past. As a reader, the proper and socially-responsible reaction to such disclosure is to disclose in turn. And since the text is not a person, the disclosure must take more nuanced forms in which the reader submits his body to the sensory experiences entailed in the text's offering. Whether such an offering is enough to convince a reader of David's innocence in the matter of his marriage, whether it justifies David's greater need for his writing than his wife, whether it clears him of the charge of infidelity (albeit, one encouraged by his own wife), whether it causes the reader to choose David in the end as the novel's rightful hero- that, of course, is an individual preference and dictated by the success of the narrated disclosure's facilitation of empathy, identification, and readerly disclosure.

One such failed reading and reader is, of course, illustrated in the person Catherine Bourne. But Catherine's failure as a reader is not the result of an out-an-out hatred of the past or experiencing the past. There is in Catherine and David alike a hunger for time and a desire to hold on to memories. The novel's insinuation that art is the one thing that can hold onto the past helps to explain the urgency in the Catherine-as-artist critical debate as well as the urgency she shows in encouraging David's writing of her story:

“The whole way here I saw wonderful things to paint and I can't paint at all and never could. But I know wonderful things to write and I can't write a letter that isn't stupid. I never wanted to be a painter nor a writer until I came to this 
country. Now it's just like being hungry all the time and there's nothing you can ever do about it." (GOE 53).

For Catherine, David's writing of her/their narrative is the only method for contact with her past that she can fathom. Her statement in response to David's ambivalent announcement to discontinue writing the narrative_—“"That was my present and our project"”—can take on the meaning that Catherine's sense of the present moment is the present she most wants from David $(G O E 188) .{ }^{68}$ As a reader, this is her greatest lack: she is unwilling to immerse herself in David's past for fear of losing her own.

As a byproduct of our empathetic identification with David (if for no other reason), the reader, like David, comes to care for Catherine. This care, concern, admiration, love (depending on the level the reader takes it to) primes the reader to recognize that Catherine's obsessive fear of loss of time is not entirely unfounded. The text provides a series of evidence that Catherine's death is in fact planned for the novel's end and even hints to a cause of death: a car accident. Her car's bad brakes are frequently mentioned as is Catherine's initial desire to drive to Carcassonne after burning the manuscripts which makes David uneasy for her safety (GOE 227). David's initial reaction to the news that the stories are gone is also likened to a car crash: "It was like coming around a curve on a mountain road and the road not being there and only a gulf ahead" (GOE 216-217). And in Catherine's only piece of writing seen by readers of the novel, a letter left for David, she compares her burning of his stories to running over a child with a car: "The thump on the fender or maybe just a small bump and then all the rest of it is happening and the

\footnotetext{
${ }^{68}$ This is the same pun that both Catherine and Marita make earlier after Catherine identifies Marita as a "present" for David. When David says that he likes his present, Catherine ask how he likes his future; Marita asks if his future is a dark one (alluding to her darker skin color) and then comments "I'd rather be a dark present than a dark future"; Catherine rounds it off by instructing David to " give her a kiss David and make her a fair present" (GOE 104). Unfortunately the whole session is dampened after Marita bursts into tears after the kiss.
} 
crowd gathering to scream. The Frenchwoman screaming ećrasseuse even if it was the child's fault" (GOE 237). ${ }^{69}$ But in the end, Catherine is spared a tragic death by a change in her decision to instead travel by train. Since the novel closes with Catherine far out of sight, the reader has no way of knowing if her premonitions of an early death come to pass. And yet, in contrast to David's intense focus on the past, for the character of Catherine, the past is gone, the present is fleeting and ungraspable as soon as it's reached for, and the future is a frightening anticipation that she will be locked away in a psychiatric ward if not worse. The moral of her story suggests that David's perspective is the wiser one — at least for an artist—and that his ability to forge contacts with his past is the true path of a writer.

Without a place in David's presence and present, Catherine has no choice but to leave The Garden of Eden narrative. After writing out a new marriage certificate to Marita in the sand, David is finally able to write again and return to his past where the stories reside (GOE 244). With Catherine finally out of the picture, his writing could now be both a journey to reexperience his childhood past and his past days of writing (before Catherine's attempted destruction of them) as "not a sentence was missing and there were many that he put down as they were returned to him without changing them" (GOE 247). For readers of The Garden of Eden, contact with a past—David's and potentially Hemingway's — is offered as the true test of a true reader as well as the key to an embodied reading of past sensations that, once lived, become the reader's own.

\footnotetext{
69 "Ećrasseuse" is roughly the female form for the French word "road-hog" (écraseur). The verb "écraser" can translate as 'crush,' 'squash,' 'run down,' 'run over,' 'overcome,' 'overwhelm,' and 'overwrite.' The use of this term to describe the violence done by Catherine on David's manuscripts is telling of her present opinion of her actions: she indeed attempted to "hog the road" when it came to David's artistic choices, forcing him to one direction (hers), and the result of his lack of obedience led to destruction. But Catherine ultimately sees it as his fault: that the violence was something she had to do.
} 
The Garden of Eden presents a paradigm of struggle — a challenge issued regarding stories, pasts, presents, readers, writers, and bodies. Doubling back onto itself, the text pairs reader against reader, reader against writer, and body against text which leaves actual readers in the somewhat contradictory position of ostensibly rooting for a writer at the expense of a reader, and celebrating the power of creative text over the creative body. While the readers/women of the novel did not necessarily " "try to make sides"” in opposition to one another, it happened nonetheless (GOE 243). Readers of The Garden of Eden are pushed into the same conundrum: to side with or against David?, to side with or against the narrator?, to be a good or a bad readerthat is, to read as the author desires (and as is depicted by Marita) allowing one's body to perform the text like a lover performing a relationship or to read counter to the author (as depicted in the reading and non-reading of Catherine)?

The acknowledgement of such readerly opposition and challenge is no mere fictional plot; Hemingway himself knew the devastation of having an unhappy and discontent readership, especially towards the end of his life. Lillian Ross, in response to criticisms of her New Yorker "Profile of Hemingway," concludes that when confronted with the "real" Hemingway (a man of playful dialogue, love of amusement, and strange mannerisms), “they didn't like Hemingway to be Hemingway. They wanted him to be somebody else-probably themselves" (15). These readers, like Catherine, seeking to control the writer, are ultimately doomed to failure in both a fictional and the real world, according to the Hemingway story. And in her opposition to the popular view of Hemingway's decline in later years, Ross identifies herself as a good reader, like Marita, in her view that: "he was heroically and uncorruptedly and uncompromisingly occupied day after day with writing as hard as he could and as well as he could until the day he died" (16, italics in original). Such a strong position in favor of Hemingway as a great artist pits all lesser 
views of the man and his work as ignoble and slanderous. And for Hemingway as well as for David, it is only these good readers who matter, not the views of the "devastation people," as he called them (Ross 15). In a world where the writer has the power to first feminize (read: weaken) and then write out bad readers according to his own standards, even after acknowledging and using them to further his fiction, the author will always maintain control over readers-good, bad, and everything in between.

\section{Reading and Readers in Pale Fire: Caressing Polluted Flesh with Strange Gratitude}

Pale Fire (1962), composed towards the end of Hemingway's composition of Garden, similarly presents reading as challenge, contest, vulnerability, and trial. This theme, as in Garden, is depicted in the metafictional reader/author relationship, but, unlike Garden, it takes hold root and branch in the actual reader's very act of reading. A famously challenging text, Pale Fire is frequently alluded to as a touchstone in scholarly conversations about metafiction, unreliable narrators, and readerly disorientation — and for good reason. From the novel's beginning, readers are made keenly aware of their inability to escape a self-awareness of themselves as readers all the while confronting the challenge of keeping up with a text that continually produces the uneasy sense that the reader is missing something important. As critics have suggested, Pale Fire perhaps ought to be read in the spirit of Nabokov's famous chess problem in which one individual (a writer) devises a challenging puzzle for another (a reader) with the goal of leading the latter to discover an elegant, multiphase solution which produces "a synthesis of poignant artistic delight" (Speak, Memory 291-292). In this process, readers physically and cognitively wrestle with the text: flipping back and forth between sections, agonizing over wordplay puzzles, hunting down obscure references outside the text, and 
evaluating and reevaluating their sense of how Pale Fire is supposed to be read. While some take this challenge to be antagonistic, even cruel, towards the reader who, after all, must work much harder to get to the story's meaning, others, such as notable Nabokovians Zadie Smith and Brian Boyd, take this invitation as a sign of generosity and abundance on the part of the writer who “invites the solver as close to creative equality as the difference in their roles allows" (Boyd 9). However, in order to discover such equality, the reader of Pale Fire must be willing to become a rereader and even a re-rereader since Nabokov only gradually cycles readers towards the answers she seeks as well as towards the readerly sophistication necessary for her to discover those answers. According to Nabokov's lectures on reading, “Curiously enough, one cannot read a book: one can only reread it. A good reader, a major reader, an active and creative reader is a rereader... In reading a book, we must have time to acquaint ourselves with it" ("Good Readers and Good Writers” 3). In its unyielding test of readerly constitution, a conscientious, curious reader, according to this Nabokovian reading theory, will be made all the better for having stuck it out through Pale Fire's insistence on physical and mental manipulations of the text, and will have transitioned from a surface-level reader to an earnest and passionate re-reader, from a shallow reader to a reader who embodies the experience of reading as a challenge to both body and mind.

The first cognitive check of a reader's experience of Pale Fire will likely occur as early as the table of contents which lists the four parts of the novel's text: (1) a Foreword, (2) a poem also titled "Pale Fire," (3) a Commentary, and (4) an Index. Such intentional genre confusion (is this a novel? is it a poem?) will likely cause the reader some unease, and the narration of the Foreword does little to relieve it. Unlike a traditional poem-reading experience in which secondary materials (glosses, introductions, footnotes, etc.) are optional reading compared to the 
text of the poem, Pale Fire's narrator, who is also the poem's editor, Charles Kinbote, argues adamantly that his comments are just as, if not more, significant than the poem itself. The sensory challenge to the actual reader takes ahold as Kinbote increasingly directs readers to flip to his commentary and away from the text of the poem; readers discover that, instead of illuminating the poem, Kinbote's notes more often than not lead to other notes, so that the reader must physically and mentally hold (in hand and in mind) the alternatives places, stories, and times referenced throughout in frantic overlap. This competition between the poem and the commentary mimics the competitive relationship between the poet and his reader: the late celebrated American poet, John Shade and his bizarre expatriate literature professor neighbor and fan-boy, Charles Kinbote. Yet, because of these sections' close ties and complicated connections to each other, readers and critics are often moved to conclude a single author wrote both pieces - in other words, that one of the characters made up the other: either the writer (Shade) invented a reader (Kinbote) or a writer (Kinbote) invented another writer (Shade) and imagined himself to be that writer's reader.

The debate between the "Kinboteans" (those in favor of Kinbote as the novel's "author") and the "Shadeans" (those in favor of Shade as the novel's "author") began immediately following the novel's publication in the 1960s with Page Stegner credited as the first "Kinbotean" and Andrew Field as the first "Shadean." 70 Over fifty years later, the critical controversy continues as new evidence and connections between the two supposedly separate

\footnotetext{
${ }^{70}$ As Brian Boyd points out, Page Stegner's Escape into Aesthetics: The Art of Vladimir Nabokov (1966) and Andrew Field's Nabokov: His Life in Art (1967) interestingly put forward their respective and oppositely-situated theories within a single year of each other.
} 
sections continue to come to light over time. ${ }^{71}$ More recently, Brian Boyd's "two author" theory attempts to transcend the discontinuities of the single-author theories (himself a previously staunch Shadean) in suggesting that the connections between the poem and the commentary are evidence of the ghosts of Shade and his daughter Hazel continuing to influence Kinbote and his interpretation of the poem from beyond the grave — a theme of "the dead having sway over the living" which Nabokov had incorporated into other fiction.

The overwhelming tendency of readers to feel they must choose a side suggests that Nabokov's wish that his readers be re-readers has been successfully granted in the reading experiences of those who take up Pale Fire and persist to its end. In order to argue a side, the reader is drawn back again and again to the text in search of clues, so that regardless of which interpretation speaks truest to any particular reader - a first-timer or a thirty-year Nabokov scholar - the novel situates its attendants as problem-solvers, puzzlers, riddle-minders, and pattern-tracers regarding everything from pinning down character identities, tracking down literary allusions across the centuries, uncovering replicated structures paired with specific colors and descriptions, and accounting for each re-reflected and/or mirrored image that results from the gradual accumulation of the novel's refractive circlings. It is exactly this spirit of probing for discovery, sifting for meaning, that Nabokov thought was humanity at its most human — not in the manner of searches for "empty" Freudian symbols, but rather in the discovery of connections

\footnotetext{
${ }^{71}$ A third hypothesis championed by Peter Rabinowitz and echoed by Brian McHale also enjoyed its heyday: that Nabokov intentionally provided just enough evidence in favor of each side of the single-author debate to keep the novel's narration forever undecidedly unreliable and unknowable. Avoiding the duality of the single-author hypothesis, other scholars have focused on Kinbote's "true" identity as Wordsmith University's Professor of Russian Literature, V. Botkin (the pseudonym's reverse capable of discovery by the careful reader); others have considered the autobiographical connections between Pale Fire and Nabokov's life; and some have maintained the novel as a humanistic moral parody. For texts which avoid or downplay the single-author hypothesis debate, see D. Barton Johnson's Worlds in Regression: Some Novels of Vladimir Nabokov (1985), Robert Alter's Partial Magic: The Novel as Self-Conscious Genre (1975), and Ellen Pifer's Nabokov and the Novel (1980).
} 
that signal a greater design at work, "not text, but texture," behind the fabric of our world. ${ }^{72,73}$ As seen in The Garden of Eden, the author has in mind a right and a wrong way of reading: for Nabokov, a right reader will press on and fall prey to the full complexity of the challenge Nabokov has set before him; a wrong reader will ignore all invocations or will simply be too blind to see them.

In the reader's experience of what reading feels like in Pale Fire, Kinbote's relationship with Shade and his poem becomes a model for the reader's relationship toward Nabokov and his novel. Understanding this relationship also becomes one of the chief mysteries for a reader to investigate, paying particular attention to Kinbote's descriptions of his interactions with Shade, Shade's reported dialogue in conversation with Kinbote, and Kinbote's jealousy towards anyone else claiming what he feels to be his rightful place of intimacy alongside the poet. The metaphors, "Reading as Sex," "Reading as Performance," and "Reading as Contact with the Past," become especially prominent in these author/reader interactions as Kinbote continues to convince readers that the poem, "Pale Fire," stands in as evidence of his great intimacy with Shade and of the presence of his history counter-pointed within the poem.

\section{Reading as Performance and Sexual Intercourse}

One similarity between the writing styles of Hemingway and Nabokov is their tendency to employ the reading metaphors of sexual intercourse and performance, although they diverge in which of these two metaphors takes the upper hand. As we've seen, Hemingway uses the

\footnotetext{
${ }^{72}$ Both Shade and Nabokov have a deep dislike for Freud and tendencies towards Freudian analysis in literature and life as a search for general symbols: see Speak, Memory (20) and Pale Fire (156).

73 "Pale Fire" lines 808-810 reads: "Just this: not text, but texture; not the dream / But topsy-turvical coincidence, / Not flimsy nonsense, but a web of sense." (Pale Fire 63)
} 
language and imagery of sex to talk about performance with wives/lovers as readers, but for Nabokov, the opposite is true. Overtly and otherwise, sexual encounters in the work of Nabokov are seldom (if ever) just what they seem. ${ }^{74}$ Manipulations of the obvious performance aspects of sex-and the assumptions these performances naturalize concerning participants' relations towards each other-allow Nabokov to lead readers by the nose in coming to certain desired conclusions. These overt manipulations become especially apparent as the reader begins to pick up on the dramatic irony that courses through Kinbote's language. But more covert manipulations of the reader's performances of reading are only revealed through second looks and re-readings. For instance, when Kinbote sardonically describes himself as a "lean wary lover," waiting for Shade to be left alone in the house by his wife, it is revealed to the reader that Kinbote himself recognizes something of the absurdity of his relationship with Shade, namely, that he has to bide his time and pounce on an opportunity in order to spend time with the poet (Pale Fire 287). When the reader later realizes that Kinbote's feelings toward Shade are not mutual, the imagery of the cuckolding lover lying in wait is flipped in the knowledge that Kinbote is the unwanted one in the "love triangle" and not Shade's wife; in Kinbote's metaphor, he is the one humiliating a cuckolded spouse by sneaking behind her back to be with her husband, but in reality, Kinbote is the one who ought to be embarrassed- - he is just too blind to see it. One step beyond this readerly cognizance of irony is the role of the cuckold imagery in connection to the person and identity of Kinbote — an understanding that influences the reader's overall interpretation of the novel: in Kinbote's story of his past, he is the again the "lean wary

\footnotetext{
${ }^{74}$ Despite the inescapable sexual content of a text like Lolita, for example, in which readers are constantly being reminded that the text they are reading is narrated by a pedophile obsessed with a young girl, Nabokov is almost prudish in his dismissal of actual sexual acts, favoring instead to talk around and through sex to focus on more interesting pursuits, such as playing with puns and other word-games, revealing the absurdities of Freudian sexobsessed psychoanalysis, or presenting the reader with a reflected image of himself as the pervert (especially in that the reader must "pervert" to get at the essence of a text).
} 
lover," cuckolding his wife for whom he feels no sexual attraction. Kinbote's not-so-secret homosexuality, another marker of his seemingly alien presence in the text, becomes an enactment for the actual reader to echo. The reader, like Kinbote, picks apart the novel, taking up a position between the author and the text, and pounces on any and every opportunity for slipping off the novel's coverings to spy on the inner-workings underneath. But all the while, the author (Nabokov) watches, knowing what it is the reader is doing, anticipating her every attempt to pierce through the puzzle he has created.

In the beginning of her performance of Pale Fire, the reader is unambiguously instructed to closely follow Kinbote's script for reading the poem, "Pale Fire." Almost as soon as she begins to obey, the reader becomes aware that with every choice there is another alternative method to reading both the poem and the novel, suggesting that while Kinbote wants readers to read in his prescribed manner and order, the author of Pale Fire - some other entity the reader can't quite put her finger on —intends for the reader to ignore Kinbote's instructions or at least to question them. This awareness of and desire for alternative reading practices is directly connected to a growing sense of distrust experienced by the reader of the eccentric and obsessive Kinbote in which the most damning indication of his untrustworthiness is his misrepresentation of his relationship with Shade: Kinbote tells readers he is a close companion and confidant of Shade — closer to him than Shade's own wife. But Kinbote's narrative gives him away in allowing the reader to see that Kinbote is in fact an unwanted, irritating nuisance who inserts himself into the Shades' lives uninvited. The purpose for such duplicity is revealed to be equally troubling: a close relationship with Shade is a necessary component of Kinbote's argument for why readers should follow his directions for how to read "Pale Fire" in that it allows him to claim that he alone has the authority and ability to provide a right reading of the text as it was 
meant to be understood. Once the reader sees through Kinbote's masquerade of intimacy, this argument begins to splinter. But even if the reader decides to reject Kinbote's scripted reading commands and/or to read the poem without conceding to Kinbote's largely irrelevant interruptions, the unease is not abated - if anything, it increases. If Kinbote is indeed a megalomaniacal, self-deluded narcissist, what is the reader to make of the curious connections between the two sections-particularly the ones Kinbote himself seems not to notice such as connections between poems and girls, suicide and rape, and fatherly and readerly loss? Kinbote and his interpretation of "Pale Fire" must be accounted for, otherwise the reader has missed something. Here Nabokov has the reader by the short hairs in his knowledge that readers who read for the challenge of the text on their intellect and individuality still want to believe they are reading "rightly" - that they are not, in fact, missing something that could change the meaning or outcome of the text entirely. Pale Fire shows readers that to read for a challenge is still to read for approval. In fact, counterintuitively, the author's set script for readerly minds and bodies to perform is the only way in which the reader will embody the challenges of the text; conversely, in reading off script, the reader skips scenes and stage directions for sensory and cognitive enactments of reading entirely.

One of the primary challenges Pale Fire puts to its readers (in fact, the whole novel arguably hangs on this issue) is the question of whether or not Shade was inspired to write "Pale Fire" from Kinbote's Zembla stories. The trajectory of this challenge is unique in that although it is probably the first puzzle to which the reader pins an answer ("no: 'Pale Fire' is not about Kinbote"), it persists in an annoyingly tenacious manner throughout the reader's experience of the novel. Doubt sets in: if "Pale Fire" is unequivocally not about Kinbote, then why does there seem to be so much of Kinbote in it? Is there, perhaps, something to Kinbote's insinuation that 
he was Shade's muse? Best to take a second look, the carefully-performing reader will conclude. Much like Catherine in The Garden of Eden, Kinbote proudly describes how he put himself in a subversive position by priming the author with his story, demanding that the writer write what he, the reader, wants and expects. Kinbote tells readers that months before Shade began what would be his final poem, Kinbote "felt sure at last that he would recreate in a poem the dazzling Zembla burning in my brain. I mesmerized him with it, I saturated him with my vision, I pressed upon him, with a drunkard's wild generosity, all that I was helpless to put into verse" (Pale Fire 80). The sexual overtones of Shade being, in Kinbote's assessment, "ripe with my Zembla, bursting with suitable rhymes, ready to spurt at the brush of an eyelash," pits Shade as the virginal, poem-juiced fruit and Kinbote the greedy gardener (Pale Fire 80). The allusion carries on as Kinbote explains how he was able to encourage the Shadeans to "enjoy [the text] in the full fruit of whatever advice they gave my good-natured poet"- assuring readers that while he inspired the poem, he did not alter it prior to publication (Pale Fire 81). Kinbote's sexual pride in the poem (which he is able to claim as his own so long as he can argue that Shade owes his poem's creation to him) carries on through the Commentary, notably in his note to line 802 when he describes his reaction to believing Shade to be writing his story as summoning "an erection of veined stone and shaggy firs, rose before me in all its power and pride. The splendid news made my heart pound, and I felt that I could now, in my turn, afford to be generous" (Pale Fire 259). As illustrated in this line, Kinbote's feelings for the poet, who he views as the enabler of his Zembla story, and his story itself, as retold to the reader through the Commentary, are linked. Herein lies another challenge for the reader to puzzle over: why does Kinbote plainly state his disappointment in discovering that "Pale Fire" was not about Zembla?; why not revise the poem 
to make his interpretation more convincing?; why take the reader through these contortions of mind and body and then reveal the smoking gun?

Another challenging component of the reader's experience with the novel is that while Kinbote eagerly attempts to take the reader further away from poem, his narration consistently pulls her back to it. Kinbote's readings of the text are revealed to mimic the reader's own in his need to read and re-read to "understand" the nuanced allusions (although the reader believes that she is the one who is seeing the poem for what it really is-Kinbote reads into the poem what he wants to see). In his initial reading, Kinbote is so sure that the poem will be the story of the exiled Zemblan king that the discovery of his miscalculation could not be anything other than extreme bearing a "bitter hot mist of disappointment" (Pale Fire 206). Like the recitation of a lover's discovery of betrayal, Kinbote's reaction of the "horrible disappointment" is painstakingly described:

I started to read the poem. I read faster and faster. I sped through it, snarling, as a furious young heir through an old deceiver's testament... The complex contribution I had been pressing upon him with a hypnotist's patience and a lover's urge was simply not there. Oh, but I cannot express the agony! (Pale Fire 296)

Kinbote's second reading of the poem reveals that he "liked it better when expecting less," and it is in this rereading that Kinbote is able to detect hints and whispers of faithfulness to his Zemblan theme. Here, a reader familiar with Lolita will detect an eerie similarity in which a text is described as a violated young girl:

I now felt a new, pitiful tenderness toward the poem as one has for a fickle young creature who has been stolen and brutally enjoyed by a black giant but now again 
is safe in our hall and park whistling with the stableboys, swimming with the tame seal. The spot still hurts, it must hurt, but with strange gratitude we kiss those heavy wet eyelids and caress that polluted flesh. (Pale Fire 297)

"The spot" in this passage, referring back to the pain of the reader (and not the text-as-victim), describes the disappointment of no longer being able to enjoy a pure, virginal, unmolested textthe "black giant" a depiction of Sybil, of Shade himself, of fate, of Nabokov—a dark body who took in textual purity and returned only "polluted flesh." As a result, the reader (Kinbote and the reader of Pale Fire) must be content with what is left over while still keenly feeling the loss of the original.

It is this sense of loss, mistreated potential, and yet hoarded, precious value that falls to the reader of Pale Fire as Kinbote encourages a desire for the "Solus Rex" that never was—or only is in Kinbote's commentary—a sun of which "Pale Fire" is but a poor lunar reflection. When confronted by the "polluted flesh" passage, only a few pages from the end of the novel, the reader of Pale Fire is presented with a particularly disagreeable model for thinking about "Pale Fire" and for experiencing the novel as a whole. It is also a model that appears patently irreconcilable with the poem itself as "Pale Fire" stands up, despite Kinbote's harshest critique, as legitimately beautiful poetry. In the actual reader's imagination of a "pure" reader and reading of "Pale Fire" (without Kinbote's distorting remarks), the poem does not elicit any of the Zemblan story that Kinbote reads into it—-therefore Kinbote's interpretation is a false one. But of course, the actual reader must acknowledge that the construct of the "pure" reader of "Pale Fire" outside of the context of Pale Fire is an imaginary one: "Pale Fire" does not exist without Kinbote. Thus, Kinbote has no need to revise "Pale Fire" into "Solus Rex"; the one will always exist in the other. 
Kinbote's imagery suggests that reading puts readers in the position of lovers towards texts and towards texts' authors and that, once a lover, the reader can be attracted to, led on, and ultimately let down by the whims of text and author. Shade, on the other hand, offers reading as a loving relationship of the familial kind in his poem which stretches to build the certainty of a family tree between past and present, living and dead, the threads of unknown and unknowable generations (his own dead parents) connected to the cut-short threads of his own unknown and now unknowable progeny (his dead daughter). Both attempts rely on the question of design, of the significance of repetitions, puns, wordplay, jokes, unexpected connections—of tunnels, bridges, paths, movements between known and unknown, dark and light, mystery and knowledge. In these kisses and caresses of text-flesh, readers must be drawn on out of love and delight; Kinbote could only find pleasure in the text of "Pale Fire" when he read it appreciating what it was and not looking for what it was not. Similarly, actual readers of the novel are poised to read to discover, probe, question, and puzzle but are not instructed to read into the text what is not already there: a hopelessness or despair in our human state of curiosity and inquiry. The variety of potential readerly performances expands into a funhouse of potential forms and directions, but to be the dull reader - the reader who reads only to discover the signs and symbols laid out without enjoying the beauty of the experience — is the one image the reader should never see reflected back to her.

\section{Reading as Contact with the Past}

The reader's experience of forged connections and intimacies between author and writer (and poem and commentary) parallels her experience of Pale Fire's forged connections between one individual's past and another's. Despite Kinbote's best attempts to overlay the story of his 
past over the story of Shade's past told in the poem, the reader is allowed to see the seams for what they are: the points of contact between these two dueling histories is not enough to completely obliterate the one under the pressure of the other. In her careful decoupling and enactments of pasts, the reader of Pale Fire is the impeding, impending future, swallowing up both pasts - Shade's love for his wife and daughter, the pain of loss, the pain of hope, Kinbote's grand palaces and political intrigues, a daring escape, the search of Zemblans for their kingeventually the future overtakes them all. At the end of the novel, the reader also comes to realize that both authors (or both characters) are dead: Shade by a murderer's hand, and Kinbote by his own. After embodying competing and overlapping pasts in the frantic flipping forward and behind, repeating and re-reading (re-remembering) particular moments of significance, the reader finds she is left alone in the present with only the traces of those pasts in her memories of vitality and abundance enacted in her reading.

Pale Fire demonstrates to readers that replacing one past with another is in fact a common metafictional activity of reading and of living — especially that of replacing a less satisfying version of the past with a better one. Kinbote is once again the reader's model. At one point in his narration, he reports that while attending a summer school party, he overheard Shade defend a man from the newspaper_—“"a loony,"” according to some-who "“thought he was God and begun redirecting the trains"" (Pale Fire 238). Shade's comment was that "One should not apply it [the word "loony"] to a person who deliberately peels off a drab and unhappy past and replaces it with a brilliant invention. That's merely turning a new leaf with the left hand'" (Pale 
Fire 238). ${ }^{75}$ In claiming this man as one of his own ilk, a fellow poet, Shade speaks to a wishfulfillment common to all: that of undoing and replacing one's past with something better by changing the narrative (Pale Fire 238). If, according to Shade, this is indeed one of the distinctions of a poet, a reader will likewise come to expect such overtures as distinctions of art: art as the unacceptance of the grim parameters of reality. Where else does the reader see such replacements of pasts? In Kinbote's Zembla. In fact, Shade's allusion to one's replacement of the past with "brilliant invention" suggests a reading of Kinbote (a bored or insane man who replaces his unremarkable life with fantastic invention) as well as a reading of Kinbote's reading of "Pale Fire." A reader can understand this reported dialogue as another instance of dramatic irony: Shade's referencing Kinbote without Kinbote's realizing he was the one being described by outsiders as a "looney" but viewed by Shade with pity and acceptance. Although he could not possibly know that Kinbote would attempt to write over his poem in this manner, Shade seems to preemptively forgive him — but of course, only a re-reader will be able to see the extent of Shade's goodwill. Taking a further step back, the reader may come to see in this passage the benevolence of a higher power-Nabokov—-toward the ensnared and enchanted reader looking for a "brilliant invention" to cover over her own life, dull by comparison.

But there is another, less complimentary image of the reader within the novel to be contended with. To bridge the gap between the past narrated by Shade's poem - a past in which his relationship with his wife and daughter and his search for proof of an afterlife after his daughter's death feature heavily_ and the past narrated in Kinbote's commentary—a past of

\footnotetext{
75 The inclusion of "the left hand" in Shade's statement will likely recall to the reader the use of the left hand to make the secret mark of the missing Zemblan king and the king's own left-handedness - a trait historically associated (in our world) with awkwardness, weakness, sinister intentions, and other undesirable traits. Here, Shade's peculiar reference to the left hand could arguably be read as an assertion of Kinbote's into Shade's dialogue, an intentional manipulation of supposed direct quotes from a remembered conversation with Shade.
} 
exotic lands, romantic trysts, secret journeys and societies, international plots, and false identities are the themes_-Kinbote invokes the creeping presence of Gradus. Described by Kinbote as a disgusting, plebian, and shallow character, there are, nevertheless, uncanny connections between the movement of Gradus and of the reader through the text. First alluded to in the Foreword as “the jailed killer," Gradus is introduced by name in Kinbote's first note to Shade's poem as "the would-be regicide Gradus" (Pale Fire 17, 74). Insisting that the reader see along with him the name Gradus in Shade’s words "gradual” (line 17), "gray" (line 29). and later "gradual decay" (line 209), Kinbote traces his movements closer to poet, poem, and reader (Pale Fire 77). Jakob Gradus is of necessity a man of many names and forms: Jack Degree, Jacques de Grey, James de Gray, Ravus, Ravenstone, d’Argus, Vinogradus, and simple Jack Grey — an amorphous, unassuming figure, much like Kinbote's anticipation of the actual reader (Pale Fire 77). The merger of the poem with Gradus (a character also fused with the approach of destiny as well as Kinbote's "secret" past catching up to him) is central to Kinbote's reading - and now to the actual reader's own as, according to Kinbote:

We shall accompany Gradus in constant thought, as he makes his way from distant dim Zembla to green Appalachia, through the entire length of the poem, following the road of its rhythm, riding past in a rhyme, skidding around the corner of a run-on, breathing with the caesura, swinging down to the foot of the page from line to line as from branch to branch, hiding between two words... reappearing on the horizon of a new canto, steadily marching nearer in iambic motion, crossing streets, moving up with his valise on the escalator of the pentameter, stepping off, boarding a new train of thought, entering the hall of a hotel, putting out the bedlight, while Shade blots out a word, and falling asleep as 
the poet lays down his pen for the night. (Pale Fire 78)

The form of the poem, the sound of its words, the time of the poet's writing of it, and the time of the reader's reading of it come together in this moving target: a hitman drawing closer all the while to his goal, a target he only ever achieves in Kinbote's commentary—not Shade's poem which ends with Shade's death by his hand. In this, the Kinbote reveals that Gradus is more than a character: he too is oddly linked with Shade, Kinbote, and the poem. The careful reader will even realize that the three men have the same birthday: July 5, 1959. Significantly, Kinbote also instructs readers to reread his notes on Gradus: particularly his note to line 181 which chronicles the events occurring on their shared birthday including an overview of Shade's progress on the poem followed by a review of Gradus' movements half a world away en route to Copenhagen. Readers are directed to this note from the note to lines 120-121 describing Gradus getting ready to leave Zembla, the note to line 209 in which Gradus has reached Copenhagen, as well as the note to line 347 in reference to Kinbote's birthday present for Shade (Pale Fire 117, 163, 190). Thus Gradus, in the reader's enactment of Kinbote's prescribed method for reading, is made to start out for Europe again and again in parallel to Shade's beginning of Canto Two on his birthday with Kinbote on the prowl — all of which mirrors the reader's directed return to the middle of the story, before the three men finally meet so that the climax of final contact between them can be recreated again and again.

But these repeating instructions to mix and repeats moments in time-Shade's time with Kinbote's time, Gradus' time with the reader's time, Gradus' time with the time of the poem's composition, and Shade's writing time with the reader's time- - becomes difficult for the reader to keep track of. Following Kinbote's instructions to shift from one note or line to another, the obedient reader would change places at least 105 times in the course of reading the Foreword 
through to the Commentary (without including the Index or Kinbote's inclusion of lines without a direct comment to turn to them)! Kinbote does not intend for normative narrative chronology to hold true here, even in comparison to a more-or-less traditional novel with frequent flashbacks or flash-forwards. A new topical chronology is instead held out to replace a linear one in the reading of Pale Fire. And in this new chronology, the reader can only read one thing at a time, but Kinbote, as both reader, interpreter, and creator in his own right, can move in all directions simultaneously. His commentary bears the evidence of such freedoms in his constant instructions for the reader to flip forward or backward to read or reread another section. Strangely at times Kinbote has exact knowledge of other notes he has (and must have) already written; yet, at other times he conveys a lack of knowledge as when he refers to an earlier note without knowing exactly which one it is and later amends it: "I have considered in my earlier note (I see now it is the note to line 171)" (Pale Fire 279). The reader can interpret this as scholastic laziness on the part of an individual who is supposed to serve as a guide and a model of superior reading habits but only if the reader follows along with Kinbote's jumps to observe his lack of follow-through and/or concern with accuracy. This model of rereading both the notes and the poem must then be contended with by the reader. Will the reader reread previously read sections which will effectively prolong his overall time with the novel? Will he read the entire commentary multiple times out of order as suggested by Kinbote, or will he attempt to stick to the traditional novelreading chronology of beginning to end in the order? And if he chooses the latter option, how will his lack of knowledge in the events he is instructed to read about earlier affect his overall understanding of the story in his awareness that by reading linearly he has read out of order?

The reader's choice to follow Kinbote's instructions and modeling or to depart on his own reading timeline strike deep at the heart of a reading experience heavily invested in the idea 
of rereading. And in so doing, the illusion of control by the reader over the text is shown to be just that: illusory. Even a reader who intends to follow along in Kinbote's footsteps is likely to balk at being asked to read the same note over again within a few moments of just having reading it or at interrupting the thread of the narrative for multiple asides in the same sentence. The novel demands time of its readers and, with it, a willingness to reevaluate the parameters of the novel, as when Kinbote informs readers that it was he who chose the footnote from Boswell's Life of Dr. Johnson (included in the novel's front matter) (Pale Fire 154). Rereading and rerereading, on and on, expands the actual time the actual reader must spend with the novel, but it also disrupts normative notions of rereading as failure. For in such rereadings, a diligent reader is made aware that lack of intelligence or attentiveness is not a cruel author's insinuation, but rather that rereading becomes the only method by which a reader is able to pick out and piece together all (or at least most) of the potential meanings running through and around the same phrase or even a single word of the text. An example of an over-abundance of meaning that no reader, however skillful, could pick up in a single reading is in the opening (and, according to Kinbote, closing) lines of the poem:

${ }^{1}$ I was the shadow of the waxwing slain

${ }^{2}$ By the false azure in the windowpane; (Pale Fire 33)

Here a reader will likely first consider the concrete experience the poet is describing: a bird, specifically a waxwing (which the reader may be led to look up for a clarifying image), killing itself by flying into a window reflecting the blue of the sky. But beyond this surface meaning are implications about the speaker himself and central themes to be taken up and expanded further within the poem - meanings only recognizable as the reader reads on, and some, only when the reader reads back: Shade as the author speaking from beyond the grave (in the past tense of 
"was"); the pun between "shadow" and "Shade"; Shade connecting himself to a "waxwing" which is later connected to a particular butterfly, the "Vanessa," in its similar patterns and colorization; Shade invoking his dead father who was an ornithologist; Shade invoking Kinbote and his father within the Zemblan stories as King Alfin the Vague who killed himself in an airplane crash; an allusion to the Icarus and Daedalus myth in which the son, Icarus, in flying too close to the sun, melted his waxwings and fell to his death; an allusion to Stephen Dedalus of James Joyce's Ulysses; the setting up of a repeated rhyme-scheme between slain/pane with the repetition of "pain" signaling, perhaps unconsciously to the reader, the presence and role of loss within the poem; an account of the afterlife with death as a mirror of life; a play on the name, Hazel, in "azure" as an early reference to the role of his daughter's suicide in the poem and the poet's thoughts; and very likely, many others. This accumulation of layers upon layers of meaning and connections asserts the role of rereading within the novel as necessary for getting the most possible out of the experience — rereading as an activity insinuating fullness rather than lack or futility. Counterintuitively, the more the reader reads and rereads, the more these layers of past and meaning pile up, each evoking its own sensory simulations to a final cognitive overload. In order to make up for our human inability to take in an entire book all at once as we can a painting, the reader must spread out her artistic appreciation of it over a series of rereadings; failure to do so risks missing details which make the text what it is. For Nabokov, all novels thus demand more time than they appear to; Pale Fire plays off this compulsion by demanding all that the reader has to give and more. But if Nabokov is right in his belief that all good readers are rereaders, Pale Fire has the potential to turn poor to middling readers into great ones so long as they answer this call to press on, further and farther into the novel's concentric 
and inter-connecting courses to chart the outermost expanses of the great "web of sense" ("Pale Fire" line 810, Pale Fire 63).

In chronicling the death of an author before the completion of his final work, Pale Fire is strangely echoed by Nabokov's own unfinished novel, The Original of Laura (2008), published decades after his death by his son and editor, Dmitri Nabokov, as "A novel in fragments." Much like his metafictional writer John Shade, Nabokov's method of writing out the beginnings of his works on notecards and then arranging them into the order he wants is retained in the 138 photocopied and transcribed cards that make up Laura - the reader even being granted the opportunity to punch out the cards' perforated edges and engage in an individual act of readerly rearrangement and sense-making. Nabokov, despite his deathbed demands that his wife burn the cards of his incomplete novel, would probably find great amusement in his faithful readers' inevitable mimicking of Pale Fire's Charles Kinbote in their manipulation and treasuring of his handwritten cards, their struggles to interpret the crossed out and rewritten variants, and their searches for some secret message of the writer from beyond the grave-some hope or proof or wisdom or connection imparted by a celebrated, departed author to his adoring, departing readers. And indeed the faithful revenant are rewarded by strange and strangely familiar signs in Laura: an overweight, cuckolded neurologist who explores the mysteries of self-evisceration; the resurrection of an old familiar in the form of gropey and pedophilic "Hubert H. Hubert"; a beautiful and evasive woman who finds herself the unwilling subject of a book written by an old lover (another mise en abîme called My Laura); and all throughout, the distinctive Nabokovian turns of phrase, puns, lyrical descriptions, and chilling observations of the lives and thoughts of those we sense to be uncomfortably close to our own. 
For a reader taken in hand and taught to stand on the promises of a Pale Fire reading experience, the death of the author implies only more to discover. Trained to seek out even the softest of connections, a reader of Pale Fire must return to the work and life of the man himself even in the knowledge that any understanding gained is always incomplete. Pale Fire shows readers a way of reveling in such incompleteness - to rejoice in the realization that there is always more to discover. Such curiosity holds at bay the threat of suicide and suicidalidealization, even while suggesting suicide itself to be caught up in the design of our existencea topic and an activity to be explored like any other for the connections it reveals to other aspects of life. From Pale Fire a good reader, now (if not previously) a rereader, is primed to go forward with an expectation and an appetite for continued connections, puzzle-solving, and meaningmaking offered by narratives, laughing at the chance puns of daily life, marveling that so much can be contained in the words chosen by a master-craftsman and that self-imposed restrictions can counterintuitively generate even greater opportunities for cross-referencing. Moreover, an actual-actualized reader of Pale Fire must continue reading and questioning the role of her reading in her life, her expectations for reading, her relationships towards books and authors, and her reading as a direct output of who she in as individual: a seeker after everything the world has to offer — sensory and cognitively_ as opposed to an unfortunately blinded dupe, ignorant of all the potential that surrounds her.

\section{Readerly Revolution, Adverse Possession, and Mountain-climbing; or: to whom should we send flowers?}

By the conclusion of Barthes' monumental "The Death of the Author" essay, the bodies of individual writers of literature have been rendered unidentifiable, their voices silenced as if all 
memory of distinct speech were but a dream; Barthes allows for only the hand of the "scriptor" to remain - the last trace of physicality of the modern writer, detached from both voice and body, wriggling over the pages like an anemic spider. Hailed as the new hero of literature, Barthes' depiction of the reader fares hardly better: he is equally impersonal - "a man without history, without biography, without psychology; he is only that someone who holds gathered into a single field all the paths of which the text is constituted" (6). Such sterility in the description of actual acts conducted by actual people in the material world ironically demands an accounting of Barthes himself, the former high structuralist and later post-structuralist who would by the end of his career declare all theory, ideology, and determinate meaning to be terroristic to the free play of language in The Pleasure of the Text (1973). And yet here, amidst the pseudoscientific stripping of individuality in the name of some collection of "multiplicity," Barthes' commitment to the work of his knife verges on personal betrayal (6). Its logic relies on a shared sense of indignation in response to the tyranny of the Author - that oppressor who must be overthrown in order for the reader to rise up and be heard. In this sense, "The Death of the Author" is a rallying cry against the likes of any author whose work demands a recognition of its writer as an individual. It is time, Barthes implores us, to lay to rest these antiquated views with their antiquated author-myths: Nabokov, with his insistence that great authors be seen as geniuses, and Hemingway, making himself out to be one of the great prize-fighters in competition with other greats authors - readers can be done with that now, as well as with the kinds of readings these extratextual stories perpetuate.

If the reader takes away from this tour de force a sense of the loneliness of modern malaise - that of being disconnected and disconnecting, free-floating and looking back longingly 
for the time when there were still anchors - can he be blamed? Zadie Smith has this to say on the subject of anchors:

Nowadays I know the true reason I read is to feel less alone, to make a connection with a consciousness other than my own. To this end I find myself placing a cautious faith in the difficult partnership between reader and writer, the discrete struggle to reveal an individual's experience of the world through the unstable medium of language. Not a refusal of meaning, then, but a quest for it. (57) In the contest over the authority of authors, the place of readers, and the flexibility of textual meaning, authors such as Hemingway and Nabokov resist severance from their texts by appealing to this readerly desire for challenge, for struggle, and for comraderie - all of which provide both evidence and reason for being alive and for seeking out stories in the first place. But for it to be a true challenge, the author has to have some skin in the game: reputation on the line, vulnerability in the face of possible obliteration — both methods require a great deal of confidence.

According to Hemingway, for a writer to not try for "something that is beyond attainment... something that had never been done or that others have tried and failed" is to lose everything that could have made him great (qtd. in Fleming 128). Something of this questing, challenging spirit, a willingness to be "driven far out past where he can go, out to where no one can help him" persists in the character of Catherine, the "artist who wasn't"—or perhaps, Hemingway's closest personification of the destructive creative forces he could do nothing with (Hemingway qtd. in Fleming 128). At the end of The Garden of Eden, there is the sense that readers have not quite come to the end of Catherine, just as her husband has only just glimpsed what she is capable of and what she really wants. She is beautiful and she is dangerous because 
she is beautiful — that's about as far as David will allow himself to go in understanding her. While seeming to uncomplicate the world by using the surface of physical appearances, (physical bodies were her favorite mediums) to reflect the depths of her true desires, Catherine manages to complicate and invert the images back on themselves like the refractions between two facing mirrors. David sees it but doesn't understand it, and her explanations_ —“'I am you and her. That's what I did it for. I'm everybody"'_-speak to a multiplicity and overlapping of bodies at complete odds with David's desires for oneness with only one other, a united front against the world (GOE 196). Catherine as artist is perhaps the true shadow of Hemingway: a creator who desires an expression only relatable in the inclusion of everyone, a "destructive type" who can't last in the garden but will never be at home anywhere else (GOE 5). Perhaps the problems revealed in this self-reflection is why Hemingway chose for his final female antagonist to be a natural force — the sea — instead of a woman. Catherine leaves, but she doesn't fade, and readers are likely to remember her long after they forget the flat outlines of Marita and even the Africa of David's troubled past. Catherine is a force to be reckoned with - a cult of personality and starpower much like her creator — and like him, we imagine, she would not let anything else take her but her own hand. Always, Hemingway insists, will his stories come back to him.

And what is the purpose of stories? For all their differences, Shade, Kinbote, and Nabokov are in agreement when it comes to the most important aspect of reading being pleasure. "“First of all, dismiss ideas, and social background, and train the freshmen to shiver, to get drunk on the poetry of Hamlet or Lear, to read with his spine and not his skull," Shade says, a line which echoes Nabokov's own lectures to his students (Pale Fire 155). Kinbote too longs for transcendence, for the poetry of Shade to ensure that, "“the stuff will be true, and the people will come alive"” (Pale Fire 214). In the end, Kinbote, speaking here as more a character in a book 
then at any other time, says that he "shall continue to exist" as a result of the reader's reading of the text as a whole; and in turn, the text will exist with his commentary never separable from Shade's poetry because, “without my notes Shade's text simply has no reality at all” (Pale Fire 300, 28). Can we hear Nabokov admitting the same - that in our reading of his novel, the story will continue to exist, but that without him — his mind and his planning and preparing a place for us - the story has no reality at all? A final word from Nabokov on reader/writer relationships:

The art of writing is a very futile business if it does not imply first of all the art of seeing the world as the potentiality of fiction... The writer is the first man to map it and to name the natural objects it contains. Those berries there are edible. That speckled creature that bolted across my path might be tamed. That lake between those trees will be called Lake Opal or, more artistically, Dishwater Lake. That mist is a mountain — and that mountain must be conquered. Up a trackless slope climbs the master artist, and at the top, on a windy ridge, whom do you think he meets? The panting and happy reader, and there they spontaneously embrace and are linked forever if the book lasts forever. ("Good Readers and Good Writers" 2) As for Papa Hemingway, we'll leave him on his own mountain with his meek and adoring shepherdess, having done at last what he had long feared was impossible: writing one last great novel before his end, not The Garden of Eden, but The Old Man and the Sea. He and Nabokov too can rest easy. They both survived their eviscerations on the old Frenchman's slab. 


\section{CHAPTER 4: READING AS PURSUIT}

"The brave things in the old tales and songs, Mr. Frodo: adventures, as I used to call them. I used to think that they were things the wonderful folk of the stories went out and looked for, because they wanted them, because they were exciting and life was a bit dull, a kind of sport, as you might say. But that's not the way of it with the tales that really mattered, or the ones that stay in the mind. Folk seem to have been just landed in them, usually - their paths were laid that way, as you put it. But I expect they had lots of chances, like us, of turning back, only they didn't. And if they had, we shouldn't know, because they'd have been forgotten. We hear about those as just went on..."

— J. R. R. Tolkien, The Two Towers, 320-321

In one of the darkest episodes in one of the greatest epics of recent times, two reluctant travelers charged with a world-altering mission pause for a rare moment to contemplate the nature of their situation and its connection to the adventure stories they both had heard and loved since childhood. Sam reflects that now that he himself has been landed in a story (although both he and Frodo doubt they will survive to its end), he must reevaluate the motives of people who become characters. Sam had always assumed that these "wonderful folk" pursued adventures willingly; now he understands that the adventures had pursued them. But this brief moment of metafictionality (for of course, Sam and Frodo, for actual readers, are characters in an existing story thinking about themselves as characters in a potential story) also speaks beyond their situation to the nature of stories in general and particularly to what stories must contain in order to be told and retold. Characters in stories must go on in pursuit of their end regardless of whether it is a good or a bad one. They must be given opportunities to do things other than continue the pursuit, but continue they must. In this realization, Sam answers his own question of whether he and Frodo shall ever be characters in a tale "put into words" to be told or read to an audience: of course they will because they have chosen to go on and will continue to choose to go on, otherwise we would not be reading about them in the first place (Tolkien 321). The story itself is evidence of pursuit, and pursuit is evidence of mind and body commitment to a cause. My discussion of "Reading as Challenge" in Chapter Three largely focused on the readertext-author relationship as a puzzle or contest in which the reader is pitted in a struggle of wits, 
body, and time against the text/author. The focus of this chapter, "Reading as Pursuit," involves a related overall sense of reading as a quest for consummation, completion, and conclusion—an end-state which the text intentionally withholds from the reader for a period of time, if not indefinitely. The embodied nature of the concept of pursuit reveals itself in the language we use to describe our lives and our bodies_ - a naturalized and universalized language overwhelmingly characterized in terms of movement, progress, and advancement. Such descriptions string together and transcend the cycles and repetitions of the body into a master-narrative event: we are born, we grow old, we die; we seek, we strive, we find an end. Such an inscription of narrative on biology provides structure and meaning to the events of our lives - albeit usually retrospectively. And as the study of everything from childhood development to theories of personality demonstrates, the articulation of phases of development in which the human body and the embodied mind are shown to pass from one stage to the next is a comforting narrative because it allows for a sense - perhaps the illusory sense - of progress and continuous forward motion. As our physical bodies themselves can attest, the object being pursued alters the course (and the traces left behind) of that pursuit. With every scar, callus, tattoo, wrinkle, piercing, blemish, and brow-line, we become a map of our choices and a record of the challenges, detours, and sacrifices of what we pursue. In other words, pursuit is a process of embodiment because it is derived from a need to understand the changes we experience in our bodies and in the world we live in.

Not surprisingly, the use of pursuits to structure narratives has a long and significant role in the Western canon, including the wandering homeward journey of Homer's The Odyssey, the Arthurian search for the Holy Grail, Jason and the Argonauts' search for the Golden Fleece in Argonautica, and the journeys of the Israelites in search of their chosen homeland in the Torah 
and Old Testament. Modern reworkings and adaptations of older questing tales tend to complicate the purpose of the pursuit and/or the object or person being pursued, but they continue to replicate in some manner the quest itself. For many contemporary metafictional works, the traditional narrative pattern of beginning $\rightarrow$ middle $\rightarrow$ end is itself complicated, undermined, and/or reinterpreted as the object of pursuit while continuing to mediate the presentation of the pursuit (even if only as a negative model). In these works, authors play with readerly expectations and desires for narratives that consist of predictable, steady patterns and movements. Metafiction allows authors to question and analyze these expectations partially by allowing metafictional pursuits to follow a process of embodiment in which the object and course of pursuit are inscribed on the body of the whole. As a result of this intense narrative scrutiny and reliance, the reader is fashioned into a map of metafictional pursuit through the reading act: on her body is laid the destination of the narrative, the movement, the distance, and the achievement of an end. Her responses to the text give way to others as her body's sensations are touched and played on by the narrative; her understandings of the text, altered by the revelation of new information and the clarification of faulty perceptions, maps a paralleling cognitive journey of the overall narrative pursuit. Metafictional narratives, thus, render the body "story-shaped" in a manner one step removed from the usual naturalization of story on body. ${ }^{76}$ And as in other guiding metaphors of reading, the metafictional reader becomes the touchstone for how the pursuit of narrative, through narrative, will play out in the body and mind of an actual reader.

\footnotetext{
${ }^{76}$ As we shall see in Chapter Five, narratives' imposition of a "story-shape" to an assortment of events, "facts," and characters can be a powerful action with potentially harmful or anodyne consequences for both the story-teller and his/her audience.
} 
In this chapter, I focus on two metafictional texts characterized by the pursuit of a very particular material object: the physical book. In Italo Calvino's postmodern classic, If on a winter's night a traveler, the main character, a reader, is set on a hopeless quest in pursuit of the missing endings of ten stories in the mode of an amateur detective-all to no avail. This Reader's primary pursuit is largely frustrated, but over the course of one pursuit he is granted success in another: his pursuit of an equally captivating fellow reader. Similarly, J. J. Abrams and Doug Dorst's $S$. tracks the progress of two readers' scouring of a book for answers as to the identity and clandestine background of its author. This pursuit takes the two readers both beyond the physical book and deeper into it, uncovering secret messages embedded in its main text and paratexts. As in Traveler, these metafictional readers' primary pursuit is left unfinished, but their pursuit of each other is fully realized as a result of their collaboration in their textual quest. In both texts, the characters' pursuits for physical texts are the driving force of the plot, but their metafictional reading bodies and minds are the object of the narrative's pursuit.

To formulate a sense of "Reading as Pursuit," these texts rely on the combination of three embodied metaphors: (1) Reading as Journey, (2) Reading as Performance, and (3) Reading as Sexual Intercourse. Together, these metaphors convey the intimate, exhausting, and compulsory sense of what pursuit feels like in the body. The first, Journey, invokes a sense of movement and travel for the reader in that reading through a text is situated as a quest or hunt requiring continuous forward motion. The reader as hunter/quester/seeker/detective, as opposed to a mere passenger, must constantly be on the lookout for traces of her prey (i.e. the end of the narrative, answer to the mystery, etc.) which may take her to strange lands beyond the immediate scope of the story, such as supplemental texts within the main narrative or entirely other texts outside it. Whether the journey is written to feel rushed and inevitable (as a hunter astride a fast horse 
following close behind the braying hounds), plodding and exploratory (as a detective on foot, carefully following behind his giant magnifying-glass), or torturously slow (as a weary traveler longing for the sight of his journey's end, no longer interested in the scenery he passes), the proprioceptive sense of movement is critical to the reader's experience - a sense often indicated by a blending of the modes and speeds of travel utilized by the characters and the overall plot's suggestion of forward motion. As discussed in greater detail below, paratextual and intertextual movement also plays a key role in facilitating a sense of transition and journey in these metafictional novels. The reader's perspective of the text's movement—another item firmly in the author's control - is key to crafting how the narrative will be experienced by the reader, as in the difference between being aboard a train and feeling its speed directly versus watching that same train pull away from the stability of the platform. For this reason, the Reading as Journey metaphor is closely intertwined with the Reading as Performance metaphor.

In following the trail of her prey, the reader strives to keep up with its twists and turns, dismissing false trails and clues, making her way through the word-games and puzzles before her, always with an eye to what else may lie ahead. Just as a ski run will dictate the direction and necessary bodily movements of the skier who must adapt to its fluctuations in pitch, width, and speed, the narrative provides the direction(s) the reader will travel as well as imperatives for the types of reading the text requires. In this sense, the reader must perform the journey of the narrative - a journey which may lead through times of elation, confusion, and sometimes exhaustion. The reader's body performs the results of this narrative journey in close relation to the body's response to undertaking a physical journey: elevated breathing and heart rate at exciting moments, lethargy (a reluctance to turn the page or even to keep reading) at the slower points, anxiety (pressed lips, drumming fingers, itchy scalp) on behalf of the characters' 
encounters with dangers along the way, etc. Quite commonly, the reader receives from the narrative the sense of impulsion, that the pursuit must go on, leading him to stay up late into the night or to ignore other concerns in order to pursue the story to its end. Pursuits, after all, are demanding undertakings, not to be taken up lightly. At times, when the possibilities and directions for the journey are multiplied, such performances may feel to the reader like improvisation - the next step always unknown and unknowable, the reader having to quickly adapt his body to form what he believes to be the correct response. One such version of this reading improv was illustrated in Chapter Three in the many possible jumps of the reader through the various textual junctures in Nabokov's Pale Fire. Conversely, the reader's performance of the narrative journey may come across as steady and unsurprising as when only one option forward is continually offered to the reader as in the traditional detective novel which generally leads the reader to suspect first one character and then another as per the structured revelations of new information. ${ }^{77}$

The final embodied metaphor of Reading as Sexual Intercourse involved in the construct of "Reading as Pursuit" provides further coloring of the reader's sense of the journeyperformance as well as the driving force behind it. The tantalizing promise that answers, endings, and finality are out there, just out of reach, seduces the reader and answers the question of why the reader will continue to devote time, energy, and emotion to a largely fruitless endeavor. In the pursuit-oriented version of Reading as Sex, there is always more to be had, more to be wanted; it is not an encounter of total satisfaction but one that causes the reader to want more of

\footnotetext{
77 According to William V. Spanos, this latter model of narrative performance-journey reflects "the 'form' of the well-made positivistic universe" that is "grounded in the equally comforting certainty that the scientist and/or psychanalyst can solve the immediate problem by the inductive method, a process involving the inference of relationships between discontinuous 'facts' that point to or lead straight to an explanation of the 'mystery,' the 'crime' of contingent existence" (150). The pursuit also mimics the world in which it is contained.
} 
it: an addiction, not the cure. It is desire as deferred and ultimately withheld which underlies this dance give-and-take; like sexual desire, a reader's reaction to the seduction of the text may reveal itself in bodily announcements of both a sensory and cognitive nature, such as: increased heart rate, breathing, and blood pressure; a rise in body temperature; flushing of the skin; pupil dilation; irritability; trouble concentrating on other things; etc. Beyond these general signs and reactions, sexual desire and arousal presents differently on the level of the individual. Male sexuality has been characterized in popular and scholarly understandings as visually-stimulated, single-minded in its pursuit, and capable of existing independently of an emotional relationship with another; meanwhile, female sexuality is typically characterized as relationship-driven and more reliant on at least the perception of an intimate, emotional attachment with another for optimal dopamine release (Ogas and Gaddam). As feminist scholars have noted, the literary characterization of reading desire is never apolitical and the displaced desire of conclusion/consummation has a distinctively masculine tone, according to writers such as Julia Kristeva. If pleasures — including the pleasure of a narrative ending — are created by and in culture, then the desire for the textual pleasure of an ending (characterized as sexual) is never a simple fulfillment, especially when such desire is displaced and fueled by inaccessibility. According to this argument, when reading is posed as sexual encounter, desire, and potential consummation, the reading body's gender is automatically coded as male. As we shall see in both Traveler and S., female readers are portrayed as instinctually desiring deeper, "simpler" (read as primitive, naïve, and/or more opportunistic) pleasure in their reading experiences in comparison to their male counterparts. This textual distinction puts the actual reader (both male and female) in an interesting position regarding whose metafictional reading the text wants the reader to more closely model — the male metafictional reader or the female metafictional reader. 
In both Traveler and $S$., the sensory and cognitive encounters which spell the experience of pursuit for readers are bounded by historically-located metafictionality. Metafictionality, including intertextuality and the incorporation of paratexts, is by no means a new phenomenon in the novel genre (consider the self-conscious textuality of Don Quixote and Tristram Shandy), but its utilization in postmodern and contemporary fiction to upset the totalizing impulses of the realistic novel, in which journeys, performances, and sexual desire/fulfillment are natural, biological, and stable, represents an important turn in fictional embodiment. As I have argued, the combinations of metaphors chosen by authors serve as markers of historical reading experiences. In taking on the abstract metaphor of "Reading as Pursuit," both novels date themselves in the experience of pursuit they require and in the stakes their pursuits involve: Traveler reveals itself to be a postmodern text whose pursuit for a postmodern readerly embodiment is largely caught up in a historically-significant separation of the wheat of the "true" readers from the chaff of the stereotypically-drawn critical readers of the time; comparatively, as a contemporary text that acquires its fifteen minutes of fame via a time-sensitive mystery, $S$. invites readers to participate in a physical pursuit that yields to a virtual one, but ultimately burns through itself and its readers. While the possibility for readerly embodiment lives on in the metaphors employed by these texts—as, after all, these are texts that require readerly experience and participation - the pursuits they sanction stale over time.

\section{Postmodern Paratextuality and Beyond}

Postmodernism, the name given to either the period following modernism or the second half of modernism's twentieth-century reign, is typically described in terms of parody, pastiche, and play $-a$ free-floating disconnection between signs and signifiers, referents and references, 
and creators and receivers of texts. Postmodernism celebrates the disassembly of the previously untouchable gods, overturned by its modernist predecessors, and recommends an embrace of multiplicity and of the power of the uncoupled. In fiction, postmodernism's denaturalizing ${ }^{78}$ impulse towards dominant cultural representations and ideological productions of meaning situates itself around the formalist stronghold of the author as subject and the text as original, creative production. For postmodern critics such as Julia Kristeva, Roland Barthes, and Michael Riffaterre, this attack on the "'founding subject' (alias: the humanist notion of the author) as the original and originating source of fixed and fetishized meaning in the text" largely takes the form of paratextuality, particularly intertextuality, among other features (Hutcheon A Poetics 126). Paratextuality as a phenomenon emphasizes the inherent multi-text status of "the text" as combined and overlaid with other texts which inform readers as to its identity, purpose, and status. For instance, the front and back matter of a literary work typically informs the reader as to the text's fictionality or nonfictionality (i.e. its genre), its historical period, a brief biography of its author, a plot summary, and published praise from trusted or well-known reviewers assuring the reader of the text's worthiness as a read. When made the central focus of a work, paratexts also present a chimera of embodiment in the continuous competing, apprising, and overlapping movements of textual bodies that inform the reader of the nature of its whole. As Hutcheon notes in her study of the postmodern aesthetic, this focus on the plurality of texts within and behind any given work emphasizes the idea of textual productivity and reader-text relationships at the expense of previous eras' critical focus on textual origins and the author-text relationship ( $A$ Poetics 126). But such a shift is inherently paradoxical, she notes. Postmodern fiction both turns inward to reflect and parody the act of writing (and reading) while also turning outward in a

\footnotetext{
${ }^{78}$ Or "de-doxifying" in Linda Hutcheon's terms, in turn derived from Barthes
} 
relationship with the world outside the text in acknowledging that much of our knowledge is textual and thus mediated by the naturalized rules of discourse.

For Roland Barthes, author of the "death of the Author" notion discussed at length in Chapter Three, an even greater paradox exists in the reader's experience of a text and particularly the reader's moments of extreme pleasure with a text: "what I enjoy in a narrative is not directly its content or even its structure, but rather the abrasions I impose upon the fine surface: I read on, I skip, I look up, I dip in again," he says in The Pleasure of the Text (11-12). According to Barthes, these "abrasions" cannot be predicted or even prepared by the author who "cannot choose to write what will not be read"; rather, the pleasure comes at the unpredictable moments in reading when the reader's body "pursues its own ideas" ( $7,11,17$, italics in original). A reader's pursuit of textual pleasure may be direct, but its fleeting achievement is indirect, fractured, and periphery. Such a materiality that fractures, has seams, and embraces gaps and relapses above continuity and sameness, is itself reflected in the art produced according to the poetics of postmodernism. Paratextual complexity, including intertextual references to the world (e.g.. history) and to other texts (e.g. canon), disrupts the assumed linear reading of the obedient reader while revealing the mythical status of the isolated, "original" text. If for the prepostmodern writer, reading was an individual creation "of a coherent, totalizing fictive narrative," postmodern fiction demands a subversion and suspicion of the master narrative even while acknowledging the reader's desire for it (Hutcheon A Politics 81). Postmodern novels can therefore draw attention to and question the formulas, conventions, and history of the novel genre (and its readers) by utilizing those same features to accomplish their critical ends. Italo Calvino's If on a winter's night a traveler demonstrates many of the attributes expected in a work of postmodern fiction: there is an emphasis on the multiplicity of "texts" in 
the form of incipit novels which remain incomplete; there are intertextual allusions to institutions surrounding the production and consumption of texts including a bookstore, a publishing house, literature professors, reading groups, etc.; and the main characters are defined in terms of their relation to books: Reader, Non-Reader, Author, Translator, etc. Not without reason, the novel has been proclaimed as a stereotypical representation of postmodern literature in its supposed celebration of readerly power and freedom to the tune of Barthes' "death of the Author." What makes Traveler a truly postmodern text, however, is its refusal of readerly empowerment: even while the Reader is seemingly permitted to choose his own ending and is provided with breadcrumbs to follow in his quest for a narrative conclusion, the writer, arguable, is the true hero of the novel — even as authors and the Author (that is, Calvino himself) are shown to be caught up in the conventions and productions of novel-writing. No one-reader nor writer-is ever "free" from control and convention — a moral as postmodern as they come. Traveler's emphasis on authorial control over readers' bodies, emotions, cognitions, and desires suggests that although the work appears to follow Barthes' call for the rise of the reader, it resists his celebration of reading "seams" as the true site of readerly pleasure; instead, the pleasure of the author's pursuit of control over the reader's body is the superior textual pleasure.

The question of what comes (and has come) after postmodernism persists despite the popular opinion that literature, criticism, art, philosophy, and the rest of the sociocultural features of any -ism have long moved beyond postmodernism and into something else. This "something else" was correctly predicted to continue in an "intertextual, interactive aesthetic suggested by [postmodernism's] hypertextuality" (Hutcheon A Politics 181). The literary scene of the present day, much like its postmodern forebears, is paradoxical and often antagonistic with its mistrust and avoidance of theory; its interest in an ultra-real which can nevertheless be virtual; its faith in 
the power of narrative to right narrated wrongs while often remaining powerless to effect wider change; its embrace of interactive narratives, reader-writer voices, and non-institution-sanctioned author-celebrity; its depiction of physical texts' offering of a real, individuated experience in a near-instantaneous, digital world of simulacra; its alleged post-humanity of cyborg hybridity; and its quest for originality in its collective nostalgia. While postmodernism is inscribed with its own knowing self-consciousness, its ironic knowledge of itself as compromised and complicit, the twenty-first century's ultra-real, post-human aesthetic is arguable marked by a denial of its contradictory desires. To an audience for whom an infinite amount of texts and narratives abound, the past is always equally accessible; packaging and the appearance of novelty will dictate which one to give our time and attention, but we will always inevitably miss equally worthy ones. And we know this. This is the reality of the contemporary time: a lack of time, a premium on attention, the necessity of hyperattention, and a bonus for any text which elevates our own status in a status-determined reality.

J. J. Abrams and Doug Dorst's $S$. holds such a compromised position as a contemporary text deeply indebted to the explorations of postmodernism's paratextuality while simultaneously seeking to erase any such appearance of indebtedness in service to the illusion of originality. It shares a similarity with other contemporary experimental literary works in its focus on the written word and its stimulation of self-reflexive reading habits. (See Appendix A for a look at S.'s visual aesthetics as well as a visual sampling of other experimental texts.) In the best of contemporary experimental literary aesthetics, the novel is more than it appears: two novels in one masquerading as a used library book. Once opened, the reader discovers that multiple, supplementary texts are included within the main (a decoder, a map scribbled on a napkin, a postcard, a letter, etc.) in a generous bounty of interactive materiality. $S$. presumes the reader's 
total engagement and hyperattention to all its moving parts resulting in a continuous raising of the stakes in the reader's pursuit with more and more either potentially gained or potentially lost. Such participatory genre-bending and blending expansions are increasingly likely to be the norm in this time of adaptation, expansion, and paratextual-intertextual mutations.

From postmodernism's critique of the original text is birthed an explosion of competing texts which allow for a statistically guaranteed original readerly experience-both within a text such as $S$. and within the overall intertextual paratextuality availability to twenty-first century readers. Such generational shifts in metafiction, while successfully altering the appearance of the text's pursuit, nevertheless continue to center around the body of the actual reader for confirmation of its realization. The reader as a map of performed journeys and carefully inspired and deferred desires remains the site of reading understood as a pursuit of an end - a narrative end - which is consciously connected back to its roots in a bodily end. As the following close readings of Traveler and $S$. demonstrate, the reader-particularly the reader's embodiment of the narrative sensations and cognitions - becomes both the object of pursuit and the method of pursuit even in metafiction that ostensibly allows the reader to merely follow along in the pursuit of metafictional readers. A narrative pursuit, like any pursuit, must undergo the process of embodiment in order to be meaningfully experienced by both reader and author.

\section{Trains, Planes, and Couplings in Calvino's If on a winter's night a traveler}

Italo Calvino's If on a winter's night a traveler (1979) is a novel made up of ten incipit novels — stories that begin but never end-alternating with twelve numbered chapters which tell the story of the Reader whose reading holds these incipits together. In his quest to find first one story's ending and then the next, the Reader finds himself falling deeper and deeper into the 
worst pit imaginable for his particular brand of bookworm: a perpetual state of "middleness" in which every attempt to escape into an ending only sends him spiraling down once more into another beginning. "'I am forced to stop reading just when they become most gripping. I can't wait to resume, but when I think I am reopening the book I began, I find a completely different book before me... even more gripping. But I can't manage to finish this one, either. And so on,"” he explains (Traveler 197). Likewise, the actual reader of the novel experiences the confusion, betrayal, and perhaps anger associated with reading a novel in which every other chapter presents a different narrative, with different characters to keep track of, and little hope of unification.

While the twelve numbered chapters constitute a separate narrative from the incipits in their chronicling of the Reader's journey to find the endings, the incipit chapters are curiously related — even foretold—by the Reader's narrative. As Marilyn Orr notes, the discrete incipit novels are especially united in the person of Ludmilla, the female "Other Reader," who continually updates her desire for the book she would most like to read. Ludmilla is a significant character in large part due to her significance to the Reader but also in her identification by the text as an "ideal" reader. She is curious, passionate, intelligent, and sexual—a "real" woman whose tastes and desires change over time. Parroting a central tenet of the novel itself, "“Reading,"” according to Ludmilla, "“is going toward something that is about to be, and no one yet knows what it will be..."' (Traveler 72). Ludmilla as Calvino's ideal reader speaks to the historical period in which the novel was written and published. In the 1970s and 80s, at a time when critics, professors, scholars, and fellow authors had developed a new understanding of "right" reading as necessarily political, reading that emphasized readerly embodiment and experience of a text as its own end was viewed as mockingly old-fashioned. This alternative 
position that everything — including acts of reading and the reader's body—is political and therefore available for politicizing is represented in the novel by Ludmilla's sister, Lotaria, who uses computer algorithms to do her reading for her to save time. Forceful, opinioned, scholarly Lotaria is a thoroughly 1970s trope of an unembodied, postmodern, feminist reader who manages to both repulse the Reader in her reading habits and attract him in the exposure of her out-of-bounds body. The text's treatment of Lotaria is equal to her treatment of Flannery's novel: she is systematically taken apart, peeled back to reveal only further signification-never anything real. Predictably, the Reader must find his way away from the corrupting influence of Lotaria and her brand of clinical reading, and back to Ludmilla's embodied embrace.

While the text's metafictional interest in the experience of the reader is undeniable, the "birth" of the reader's autonomy at the cost of the author's "death" is negligible at best. The novel's opening attack on readerly autonomy is in its subsummation of all readers into the second person "you" as reader - a construct both open and closed to the actual reader. Certainly, the Reader is the nominal protagonist of the novel and is even allowed to dictate his ending of choice (marriage to a beautiful woman), but as a metaphor of total absorption into narrativityof being lost in a good book - the Reader character traps all readers in a supposed representation that intentionally does not fit all readers. Traveler bridges the pursuit of the $\mathrm{r} /$ Reader for autonomy and answers with the pursuit of the author for the embodied reader by dually narrating the journeys and desires of figures on all sides of the text. The pursuit of the reader is for narrative finality and consummation, whereas the pursuit of the text/author is to affect the body of the reader in a desired and desirable way. But to achieve this end, the text must first convince the reader that he is taking a journey, perhaps by train, by horse, on foot, or in the air: "'You realize that it takes considerable heedlessness to entrust yourself to unsure instruments, handled 
with approximation," the narrator tells the Reader, "or perhaps this demonstrates an invincible tendency to passivity, to regression, to infantile dependence. (But are you reflecting on the air journey or on reading?)"” (Traveler 210).

\section{Reading as Performed-Journey}

In Traveler, the metaphor of "Reading as Journey" merges with "Reading as Performance" to form the how of the pursuit, beginning as early as the title and continuing throughout with repetitions of travelers, quests, escapes, pursuits, and journeys. But as opposed to steady progressions, the novel repeatedly portrays journeys that end en medias res and restart again from a new point of departure, both in the form of new narratives the Reader encounters and in the appearance of new clues regarding the mystery of the jumbled manuscripts which he encounters before he is able to fully resolve old questions. These constant interruptions and restarts focus the actual reader's attention on the act of beginning to read a new story — that is, how the author conveys what this journey will feel like, why a reader chooses a particular story to read and not some other one, etc.- - despite the Reader character's primary interest in finishing stories. It is the hope that an ending not only exists but is accessible to the $\mathrm{r} /$ Reader that promotes the sense of journey from one story to another. But even while the theme and experience of journey implies a certain amount of autonomy to the traveler-reader, the convergence of this metaphor with "Reading as Performance" presses on the inevitable passivity involved in these reading journeys. For all that literature is upraised (at least by those of the Barthesian school) for releasing and empowering their readers, both the Reader and the actual reader are shown to be strapped in place within their journeys as opposed to freely choosing direction, pace, and destination. The actual reader is made aware of this reality from the novel's opening in the 
corralling effect of the second person "you" which ostensibly describes what "you" the actual reader is doing at the moment of beginning a new novel while ignoring the likelihood of inaccuracies and dissention. Likewise, it is the author who dictates the reader's sense of travel, movement, and anticipation by funneling the reader's initial sense of textual possibility — a sense which each reader brings to the start of an unknown text. While the Reader and actual readers are kept busy futilely pursuing stories without endings, the author is able to overlay on the readers' body a story about the difficulty and allure of telling stories, about the choices the author must make in order to pressure the reader into the type of response the author desires him or her to experience.

Throughout Traveler, the sensory details and invocations utilized in the ten incipits modify the r/Reader's journey throughout the novel while investigating the means by which a reader experiences a particular narrative's journey, principally its beginning. These sensory details are often connected with metafictional, narratorial asides in which the "I" characternarrator of the various incipits conveys his (and/or the author's) intentions for the reader's sensory experience of the information given. Their existence suggests that the metafictional Reader character reads a different text than the actual reader-a text in which these asides do not exist, just as the Reader never seems to be fully cognizant of his own narrator in the numbered chapters. Thus, it is for the person of the actual reader then, and not the Reader character, that these revealing asides are intended — the Reader and actual reader experiencing an embodiment of the sensory details conveyed in the text, but only the actual reader pressed to consider why and how they are experienced. As the plot of the novel is centered around a search for physical texts, the materiality of novels as objects (of consumption, circulation, and possession) is consistently pitted against their immateriality as the origin of pleasurable, sensory experience. 
This paradox, in the words of Barthes, is that "significance... is meaning, insofar as it is sensually produced" (61, italics in original). The incipits thus become stories about how authors compel their readers to feel in a bodily, sensory manner in order to get readers to feel their stories fully. Traveler not only elicits these embodiments of textual movements but invitescommands - actual readers to realize what is happening while it happens to them.

The novel's ten incipits explore the power of sensory invocation in varying degrees of self-reflexivity. For instance, the opening incipit, "If on a winter's night a traveler," begins with a man getting off a train, holding a mysterious suitcase he is anxious to get rid of. Subterfuge, secret identities, espionage, midnight journeys - these hints of subversion, that all is not what it appears, predict the type of quest on which the r/Reader will unwittingly embark in this narrative and the shady characters he will soon find himself seeking and tracking. And as this narrative's "I" has no qualms in pointing out, the initial obfuscation portrayed by the smoke and steam of the train aptly describes the r/Reader's entrance into this narrative landscape: uncertainty results from the partial erasure and exposure of this narrative voice which covers over the very scene it portrays by calling out its fictionality. But the sensory details that make up the railway station's depiction also order what this narrative journey will feel like: the obfuscation of smoke connected to the steam blown off the customers' hot coffee in the bar; the odor of "waiting" which is made up of the odor of trains, of the platform, of the "wet sawdust in the toilets," of the telephone booth when a frantic call goes unanswered; the sounds of the train whistle, the rain on the platform, the "pling" of the cash register (Traveler 10-11). The "I" digresses into an exposition on the role of these particularly-chosen sensory details in orienting the $\mathrm{r} /$ Reader to the world of the book in terms of time and place as well as the ability of the author to obscure these things by presenting these details from a single point of limited perspective: the "I" who may be 
"nearsighted or irritated," oblivious or secretive (Traveler 12). Bearing this in mind, the actual reader is primed to pay attention to the details used to convey time and place in this story and in the remainder of the novel as well as to notice possibilities for where details hide more than they reveal - a seemingly broad wink from the author to the reader for what to expect. Such direct exposition also positions the actual reader into a "gotcha" moment in that even while describing how the text is able to move and elicit sensations in the reader, the movements and sensations are still happening; the explanatory narration casts an additional layer between the actual reader and the scene being conveyed, but this reflective membrane does not entirely prevent the reader from being touched by the text's dictation for embodiment.

Beyond describing how the text is able to affect and dictate the performed movements of the reader, the narrative "I" begins to gradually unfold the authorial intent of these manipulations and the why behind the actual reader's guinea-pig-like flounderings. In "Looks down in the gathering shadow" the author/text/narrator claims to desire for:

you [the reader] to feel, around the story, a saturation of other stories that I could tell and maybe will tell or who knows may already have told on some other occasion, a space full of stories that perhaps is simply my lifetime, where you move in all directions, as in space, always finding stories that cannot be told until other stories are told first, and so, setting out from any moment or place, you encounter always the same density of material to be told... (Traveler 109) It is in accordance to the author's wishes for the reader to experience a sense of abundance, density, fullness, and saturation that the reader is laid to stretch on the rack that is Traveler-she is pulled first one way and then another in her attempts to feel and think through the piling up of narratives on top of others. She is urged through the contortionist performances of the inevitable 
journey laid out by the novel for the answer to the author's question of how such contortions are possible. Traveler reveals it is in the middle, the direction of the text beyond the hump of potentiality of the beginning, that shows the devices and desires of an author. Traveler is interested in where narratives and their authors/texts go from the opening promise of possibility and abundance and the operations by which they convince readers to go with them of a journey.

What the Reader actually finds once he surpasses the "middleness" and reaches at last the end of his quest — for all quests must end at some point—is heavily contested. Orr submits that both the Reader and the Other Reader learn the lesson that "the book is not all" and that they must, in the end, "put down the book" and live their lives (217). Conversely, Madeleine Sorapure reads the end of the Reader's quest as a revelation that pursuits for unity or consummation are always futile and that readers, like authors, are "forced to exist in fragmentation and disorder" (705). Sorapure does not see the Reader's decision to marry Ludmilla at the end of the novel as anything more than a "semblance of an ending," claiming that "the detective Male Reader, despite his insistent and single-minded pursuit, finds neither end - the resolution to his confusion - nor the origin — the source of his confusion — to the tales that have so intrigued him" (706). Likewise Sorapure notes, attempts at erasure in the novel—-"to simplify and thus gain control over one's life, to escape being in the midst by returning to an ideal condition"-is equally damning in terms of achieving a desired end and only results in the creation of more chaos (708). Mariolina Salvatori, similar to Orr's interpretations, chooses to see Traveler's ending as a personal triumph over the Reader's "obsession" with closure leading him to "becom[e], in many ways, a better reader" more like Ludmilla with a healthy dose of life inserted within and around his readings (197). The novel's final focus on Ludmilla and the anticipation of an intimate relationship with her as the ultimate ending (and possibly as the ultimate answer to 
the Reader's pursuit) speaks to the final guiding metaphor of reading which permeates the reader's experience of the novel. Actual readers, alongside the Reader character, are pushed out of the world of the text with narrators and authors who carefully choose sensations in order to propel readers to a particular sense of movement and location to the "real" world, a chaotic place in which the r/Reader must become his own narrator, his own author, in choosing what to pay attention to in his pursuit of some object. The r/Reader must also choose the source of the motivations behind his pursuit: his raison d'etre, his raison d'aller.

\section{Reading as Sexual Intercourse}

The ambivalent end of journey for the traveling Reader has much to do with the ambivalence of his journey's origins and purpose. What begins as a simple enough desire - to find and read the end of a story — spirals into other desires which may or may not be achieved in the course of his journey to fulfill his initial desire. Early on, the novel introduces the idea of a desired woman — just out of sight or just out of reach — who draws the r/Reader's interest and provides a secondary object around which the quest can center (book + woman). But the combination (and conflation) of the book with an actual woman complicates matters for the Reader. The narrator of the numbed chapters describes the Reader's desire for Ludmilla, a fleshand-blood woman, as:

... an apprehensive curiosity not unlike that which binds you [the Reader] to Zwida Ozkart, in the novel whose continuation you are hunting for, and also to Madame Marne in the novel you had begun to read the day before and have temporarily put aside, and here you are in pursuit of all these shadows together, those of the imagination and those of life. (Traveler 51) 
The actual woman thus becomes conflated with desirable fictional women and so appears and reappears in many guises - sometimes more than once in a single incipit — as: Armida, Brigd, Zwida, Irina, Bernadette, Marjorie, Elfida, Lorna, Makiko, Corinna-Gertrude-Ingrid-AlfonsinaSheila-Alexandra-Lotaria, Amaranta, Jacinta, and Franziska. In this alphabetic conglomeration of the ideal woman, Ludmilla's body is used and reused as a site for female sexuality and male desire each time the Reader takes up a new story. As opposed to being herself and only herself, Ludmilla stands as an Everywoman for the Reader's Everyman; her transformations (unbeknownst to the real Ludmilla) also serve as a provocation for the Reader's continued journey and purpose. As the metafictional author, Silas Flannery, writes, “To be sure, without a female character, the Reader's journey would lose liveliness: he must encounter some other woman on his way" (Traveler 198). Ironically, in his knowledge and desire for the female characters of the incipits, the Reader feels that he is getting closer to the real Ludmilla, even while they take him physically further away from her and even into the arms of another. From the Reader's perspective (according to his narrator), the pursuit is the means by which he expects to be able to draw closer to the living and breathing Ludmilla: "This hunt excites you because you're pursuing it with her, because the two of you can experience it together and discuss it as you are experiencing it" (Traveler 93).

Ludmilla also indirectly generates a third object of pursuit for the Reader - a role hinted at in her original designation as the Other Reader and in the obvious differences in reading habits and desires between the two readers. Ludmilla retains well the memory of what she reads; the Reader does not. Ludmilla reads many books simultaneously; the Reader does not. Ludmilla has very strong preferences for the particular type of book she wants to read at any given moment; the Reader does not. Although both readers are initially inspired to seek out the ending of the 
first incipit — a desire that leads to their first encounter in the bookshop_Ludmilla is more curious than frustrated by the mix-up. It does not become an obsession. For a time, Ludmilla goes along with the Reader as a co-pursuer of the ends of the narratives, but she shows reluctance to participating as his constant companion in the pursuit. As a method of achieving intimacy with someone, forming a partnership in pursuit of a common objective is a respectable choice, but Ludmilla herself puts a damper on this promising collaboration in her unwillingness to go as far as the Reader is willing to go for answers. For her, there is a boundary line: "on one side are those who make books, on the other those who read them. I want to remain one of those who reads them, so I take care always to remain on my side of the line,"' she tells him (Traveler 93). ${ }^{79}$ But here the Reader's dual quest of (1) finding the ends of the narratives and (2) winning over Ludmilla fractures to include a third desire: that of "rediscovering a condition of natural reading, innocent, primitive" (Traveler 92). After his experience in the publishing house, the Reader wonders if perhaps he has crossed Ludmilla's "boundary line" and had "lost that privileged relationship with books which is peculiar to the reader: the ability to consider what is written as something finished and definitive, to which there is nothing to be added, from which there is nothing to be removed" - a relationship he connects with Ludmilla: a reader who is able to separate the physical person of the author from the person of the author who exists independently within his works (Traveler 115). In order for the Reader to rediscover this state of "innocent reading," he must find the endings and then immediately back away from what he has witnessed of the assembly and disassembly of books in general—he must return to a "normal" reading life beyond the pursuit which so consumes him. The novel as a whole, however, hints at the impossibility of such an endeavor as well as the nonexistence of an "innocent reading" in the

\footnotetext{
79 The Reader and actual reader later finds that this isn't exactly the truth; Ludmilla had herself instigated a relationship with the author Silas Flannery.
} 
first place as readers are shown to be irrevocably complicit in the creation and production of books. Ludmilla's boundary line between readers and authors is a self-deluding fiction.

All told, the figure of Ludmilla is the key to the Reader's quest for answers to the mystery of the missing endings; she provides a blueprint for an alternative relationship between a reader and text; and she provides an opportunity for his desired physical intimacy to culminatenot in their sexual intercourse, but in a marital relationship. The woman as the answer and ending to the man's quest may be traditional, but its use in Traveler has become an issue of debate in the text's critical history. By beginning with a universal second person, "you," which is only later revealed to be male, a female reader of the novel who initially assumed (as would a male reader) that the "you" referred to her, would be understandably unsettled upon discovering she is in fact bypassed by the Reader's male sex and has instead been relegated to the position of the Other Reader - a "she," not a "you." As Salvatori notes, in the original Italian, "Lettore" and "Lettrice" do denote gender where the English translations uses the gender-neutral "Reader" and "Other Reader" (186). The delayed realization that "you, the reader" is a male character is likely not as abrupt in the original Italian with the male form "lettore" used as early as the first incipit—albeit, a general, lowercase "lettore" and not the specific "Lettore" used later. But even setting aside the male Reader/female Other Reader concerns, the positioning of the female Ludmilla as the object of the sexualized hunt - the prized quarry of a male Reader protagonist, a male author, a male translator, and a male Non-reader (Irnerio) — equates the female figure to a narrative and/or a book and male desire to reading, knowing, and possessing that narrative. Where, then, does this equation leave female desire and female reading? Ludmilla's relationship with the metafictional author, Silas Flannery, perhaps holds the key to the text's treatment of Ludmilla as a reader. While the figure of the unknown woman reader is an abstract inspiration and puzzle to Flannery, 
Ludmilla as the "ideal reader" is particularly troubling to him after he realizes she sees the "real him," the man, as "nothing but an impersonal graphic energy, ready to shift from the unexpressed into writing an imaginary world that exists independently of me" (Traveler 186, 190). It is Ludmilla's lack of desire for the author that is so alarming, especially after she rebukes him for making a pass at her. Ludmilla is a reader whose desires constantly change, who reads whatever strikes her fancy, and who cares nothing for the living-and-breathing author-a reader both faithful and faithless to author and text. Her status as Flannery's "ideal" reader must finally falter; she has read all his books but has no real loyalty to the man himself-something Flannery cannot accept. As her punishment, he attempts to break up the happy coupling of readers, echoing Marana's attempts to break up the coupling between reader and author.

There is, of course, another female reader in Traveler: Ludmilla's sister Lotaria who is notably never designated as a "Reader" by the text, even though she is writing a thesis on Flannery's works and belongs to a series of reading groups and workshops. Lotaria is an acknowledgement that not all female readers read as Ludmilla does, but instead of portraying a healthy reading alternative, Lotaria's reading is depicted as noxious and corrupt. In fact, her theory and statistics obsessed "reading," according to the text, is clearly not real reading at all. She reads narratives "only to find in them what she has already convinced of before reading them"; still worse, instead of fully immersing herself in a text, Lotaria allows machines to do her reading for her by turning narratives into lists (Traveler 185). Where Ludmilla allows the narrative full control to embody itself on and in her, Lotaria imposes her own control over the text by making it a foreign body unto itself, saying: "What is the reading of a text, in fact, except the recording of certain thematic recurrences, certain insistences of forms and meanings? An electronic reading supplies me with a list of frequencies, which I have only to glance at to 
form an idea of the problems the book suggests to my critical study'" (Traveler 186). Lotaria's electronic reading frightens the author Flannery (at least as much as Ludmilla's disinterest in him sexually) and compels him to picture his every word "spun around by the electronic brain, ranked according to its frequency" — an image which drastically differs from his prior imagining of reading in the woman whose responsive, reading body perfectly reenacts his every word (Traveler 188-188).

But while Lotaria causes Flannery to think of an electronic brain instead of a sensory body, she is not unsexed - in fact, the Reader's sexual desire for a woman he believes is Lotaria in disguise is repeatedly highlighted as subversive and disloyal to Ludmilla. But despite her sexual appeal, Lotaria's body is unlike Ludmilla's body in its prohibition of narrative embodiment. Instead, the Lotaria-identified woman claims: "The body is a uniform! The body is armed militia! The body is violent action! The body claims power! The body's at war! The body declares itself subject! The body is an end and not a means! The body signifies! Communicates! Shouts! Protests! Subverts!'” (Traveler 219). Lotaria is chastised by the text as "two-faced"she is portrayed as opinionated and diligent, but too ideological and head-focused (Traveler 219). As both her scholarship and her reading is depicted as deeply flawed and superficial, in the end, Lotaria is just another obstacle for the Reader to overcome in order to get back to Ludmilla. Her body is dismissed, just as her reading is.

With Lotaria neatly out of the way, the actual reader is left to determine whose reading is preferable: that of the male Reader or of the female Other Reader. For many critics, Traveler holds a mirror up to readers who, like the Reader, are too invested in endings; Ludmilla's reading is argued to be superior to that of the Reader because the lack of an ending does not devastate her. Instead, Ludmilla is willing to let go of a narrative when necessary and enjoy her life. She is, 
according to Sorapure, "the epitome of the interested reader" in her involved attentiveness to the stories she reads which contrasts sharply with the Reader's efforts to "remain suspended above" stories (707). She also makes for a very unconventional "prize," coolly informing the Reader he will never have the right to "“a jealous scene"” around her, casting aside Flannery's advances despite her admiration for his books, and defeating Marana's best efforts to come between her and her books with her "always curious, always insatiable reading that managed to uncover truths hidden in the most barefaced fake" (Traveler 153, 191, 239). She is exasperated and intrigued by the missing endings to the incipits, but they do not cause her to question herself or her reading as they do the Reader. Ludmilla continues to remain open to more narratives and to the juxtaposition of narratives over other narratives which she sees not as a problem but as a desired state given the great number of in-progress books the Reader finds strewn around her house. But does it matter that Ludmilla is a, even the female reader? Traveler neatly sidesteps the issue with the presence of Lotaria as the counter-balance of Ludmilla's reading and ignores the discrepancies between what Ludmilla says about herself as a reader and how she actually reads. Her insistence that those who consume books are separate from those who produce them is shown to be an impossibility in the journal entries of the metafictional author who cannot stop thinking about readers and their reading of his works. The reader is already there, specifically the ideal female reader, presupposed in the act of writing and of reading.

Traveler demonstrates the powers of the author to lay out a story into the receptive reader's body, but it also contains a surrender, poised in the words of the book-hating Marana“"'In reading, something happens over which I have no power"”"; here, Traveler acknowledges the power of reading to do something beyond what the author intends, something only the individual reader can determine (Traveler 240). Because reading occurs at the level of the 
reader's own body — the most personally-controlled object we possess — the author/text must rely on the reader to grant him power over it. Here at least, Barthes and Calvino are in agreement: reading is run-through with seams - it is patchwork, not whole-cloth - a medley of sensations, desires, arousals, and perceptions to which the reader, text, and author together give form.

At the end of Traveler, the Reader comes to the great library and enjoys a moment of delighted relief in thinking he will finally be able to finish the ten novels he had begun over the course of the narrative. As luck would have it, although the novels exist in the library's catalog, none of them are available to be checked out. The Reader, instead of reading, finds himself drawn into a conversation about reading that functions stylistically as a catch-all for various views on reading not yet portrayed in the novel. ${ }^{80}$ The seven unnamed readers he meets each share a different perspective of what reading means to them: (1) the tangential reader who breaks off his reading after a few lines to pursue other thoughts evoked by the text, (2) the digger who latches onto "clumps of meaning" in a text and digs like a miner in search of gold veins, (3) the re-reader who finds a new book at every rereading of an old text, (4) the unifier who views all books as the continuation of a single story, (5) the nostalgic who is forever seeking the lost ideal book from his childhood, (6) the pre-reader who values highest the promise of reading prior to the start of each book, and (7) the post-reader who sees the goal and value of the book as something beyond its ending (Traveler 254-256). The Reader admits that his reading preferences do not match those of any of the seven readers: what he cares most about is for each reading,

\footnotetext{
${ }^{80}$ In a 1984 interview with Gregory L. Lucente, Calvino explains how this final section came to be: "At a certain point I still had a great many questions left in regard to reading, to various types of reading, so I massed them all together in the chapter set in the library, in which I made up a kind of encyclopedia on the art of reading" (248).
} 
each book, to be definitive and distinct from any other with a clear beginning and end. But instead he has found that " "there now exist only stories that remain suspended or get lost along the way" (Traveler 257). In this moment, the Reader is most clearly himself a trope of reading: he has become so fully absorbed into the idea of narrativity, so lost in his book, that he embodies, instead of acts of reading, the abstract pursuit of reading. He has become the man on the train with the mysterious package, and the package is the book that he had been looking for all along. The Reader and the actual reader cannot be left in such a state.

The pursuit is finally allowed to end when one of the library readers, seeing the list of book titles the Reader is looking for, mistakenly reads them together as the opening line of a single story: the story of a traveler, passing by a town and spying an empty grave, wondering what the story is behind it. This reader remarks that "'once upon a time they all began like that, all novels. There was somebody who went along a lonely street and saw something that attracted his attention, something that seemed to conceal a mystery, a premonition; then he asked for explanations and they told him a long story..." (Traveler 258). These stories were not about the traveler, however; the traveler merely provided the necessary context for the stories to spring forth. In this novel about a traveling reader - a reader who must become a traveler to become a reader - the Reader is the pretext for the stories to be told (the ten incipits as well as the other stories of Flannery, of Marana, of the Sultana, of the tortured reader, of Irnerio the book-artist, of Lotaria and her academic reading group, etc.), the subject of his own narrative, and the medium on which the story is played out. In the figure of the Reader, the stories told come together to form an "ultimate meaning"" for his life as two sides of a coin: "“the continuity of life, the inevitability of death"' (Traveler 259). But it is in the figure of the actual reader where the purpose of Traveler's mad-scientist "reading experiment" comes together. The actual reader is 
granted an up-close view of the necessity of the Reader to undergo the trials of his journey to find the missing endings in order for him to realize that living his life while he has is it more important than the hopeless quest - that life is always lived in the middle and the possibility of a life with Ludmilla is more appealing that a self-sacrifice to narrative endings. And miraculously in giving up his quest, the Reader is somehow allowed to finish at least one of the books on his list, the one he had reenacted without realizing-Italo Calvino's If on a winter's night a traveler. But the novel also intimately demonstrates the journeys and desires of the author: a quest to write books that readers will read feelingly, to unify and to divide, to enthrall, and to relegate the hum of the everyday to the background while simultaneously providing a background noise for the present moment. ${ }^{81}$ For this reason, readers have found it difficult to write about Traveler beyond acknowledging its postmodernness. The primary traveler is not the reader, but the author-the reader is the willing roadmap on which the author's journeys and desires are laid out. The reader must look down and ask to be told a story.

\section{“Falling" In and For J.J. Abrams and Doug Dorst's $S$.}

S. (2013) tells the story of two present day readers, Jen Heyward and Eric Husch, who together tackle one of the most perplexing mysteries of their reality's literary history: the identity of the author and international conspirator, V. M. Straka. Their collaborative research and relationship begins accidentally but soon flourishes in obsessive proliferation as their notes steadily fill the margins of nearly every page of Straka's final novel, Ship of Theseus (which I will abbreviate as SOT, like the readers do). Due to the extreme competition in their scholarly world to uncover irrefutable proof as to the identity of Straka, which by the time the readers take

\footnotetext{
${ }^{81}$ These final two items are echoes of Calvino's list of definitions of "the Classics" from his essay, "Why Read the Classics?" (Why Read the Classics).
} 
the case has become a decades old mystery, they continue to use the book as their primary means of communication by which point it has become a "scrapbook" of their relationship (S. 293). Thanks to Jen's research skills and Eric's expertise on Straka lore and history, the two readers are able to determine that the bizarre footnotes contain a series of secret messages planted by Caldeira-whose real first name, they also discover, is Filomena not Francisco or Filip. The messages once decoded consist of declarations of love and devotion from Calderia to Straka. The readers also determine that the novel's main text is an allegorical confession from Straka to Calderia depicting both his enduring love for her and why he was unable to give up his life of intrigue to be with her. Thus, SOT itself, even prior to the "contemporary" marginalia of Jen and Eric, functions as a two-way medium of communication between two separated lovers. Jen and Eric eventually conclude from the uncovered love story of Caldeira and Straka that they ought not to take their relationship and their ability to be together for granted. After Jen graduates, the two take off for Prague to continue the hunt for evidence to prove their theory of Straka's identity. The physical book, precious for its scholarly notes and insights but more so for its record of the couple's early days and growing intimacy, is finally rendered superfluous.

As the product of a particular time and place, $S$. is a text necessarily caught up in its own moment in history: its production and its termination. As a result, the fan community, discussions boards, and digital paratexts — authenticated and otherwise — surrounding the novel are similarly affixed to the mid-2010s. In true Hollywood style, the reveal of J. J. Abrams and Doug Dorst's $S$. was an event long before the text was made available to readers. The hype began with an April 2011 article in the New York Times citing the announcement of publisher Little, Brown \& Company that the famous film producer and director was collaborating with author Doug Dorst on a hush-hush, unnamed novel with a planned 2012 release (Itzkoff). The 
year 2012 came and went with no further word of the novel's status or subject and with no plans for a delayed publication. In April of 2013, Mulholland Books (an imprint of Little, Brown \& Company) announced that the collaboration, now with the title of "S.," would be published in October of that year; the announcement also included the first information regarding the subject of the novel which they proclaimed would be "a literary event... a love letter to the printed word," according to editorial director, Josh Kendall (Mulholland Books “JJ Abrams"). Mulholland Books also announced that “Abrams' production company, Bad Robot, will be promoting the book leading up to and at publication time" (Mulholland Books "JJ Abrams"). Despite these statements made and circulated in the book world, many fans of Abrams' film and TV productions were understandably baffled by the novel's promotions which took the form of teaser trailers, guessing that J. J. Abrams' new mystery project was a film or possibly a video game. ${ }^{82}$ Instead the project was something of both worlds - a hyper-interactive reading experience which many fans are fond of calling "book-ception" (referring to the Christopher Nolan film, Inception): a book inside a book, with layers of readers/writers overlaid on other readers/writers, and with no clear indication of where the world of the book ends and the "real" world begins.

Following the much-anticipated publication of $S$., a fan-world exploded into existence on various platforms including Reddit discussions of the novel among readers, personal blogs and

\footnotetext{
82 The original one-minute long teaser trailer from August 19, 2013, titled "Stranger," portrays an enactment of the opening scene of SOT with a voice-over narration from actual lines of the book (Bad Robot Productions). Given the prominence of the Bad Robot icon in the title reel and the lack of any reference to the project being a book, fans such as Brendon Connelly admit to initially thinking "Stranger" was the first announcement of a videogame collaboration with Bad Robot's partners at Valve (Connelly). It is not until the second teaser trailer, released on September 9, 2013, that the project is given the name $S$. and is unequivocally revealed to be a book to viewers unaware of the earlier text-based announcements (Movieclips Trailer). The website listed at the end of this second trailer, soonyouwillknow.com, takes viewers to a single page website listing the novel's release date as October $29^{\text {th }}$ along with book availability information for the U.S./Canada and the U.K.
} 
websites dedicated to solving the novel's unanswered mysteries, and fervent calls for interviews and responses from the authors. For many readers of $S$., the novel simply demanded a response: it facilitated a sense of the text as enveloping reality and bypassing the traditional boundaries between fiction and nonfiction. Abrams and Dorst met this call by releasing further clues regarding the novel's ending (although many such clues remain unauthenticated) and inviting readers over a year later to continue the quest with the release of a video announcing the existence of five signed copies of $S$. hidden throughout the U.S. ${ }^{83}$ The website eotvoswheel.com is perhaps the most surprising find in the online fan-world of $S$. . first launched in 2009 , years before the book's publication, both the site's credibility (and vicariously the novel's) is confirmed by its preexistence and continuation after the text's publication. On this site, the mysterious and self-proclaimed faux-Straka scholar, J. W. Dominguez (who is not a character in the book), is shown to have been compiling research on the same question that haunts the two main characters of $S$. : who is V. M. Straka? The site contains photos alluded to by the characters of $S$. but not included in the book as well as further background information on the various "candidates" for the identity of Straka beyond what Eric tells Jen (and of course, actual readers) on the pages of SOT. The authenticity of this site (as opposed to the unconfirmed albeit convincing tweets between characters Jen and Eric via Twitter ${ }^{84}$ and the unauthenticated Straka ending of Ship of Theseus which appeared on jenheyward.tumblr.com) has been further

\footnotetext{
${ }^{83}$ This video invitation, titled "S.earch," was released on December 16, 2014 (Bad Robot Productions). Viewers/readers are further invited to follow @DougDorst on Twitter for clues to the search. According to the careful chronicling of fan sites, all five of these copies were found within a matter of days in specially-selected bookstores, Little Free Library boxes, and literary watering-holes across America (sfiles22.blogspot.com).

${ }^{84}$ The users @EricHusch and @ JenTheUndergrad take to Twitter to communicate, supposedly after Eric's phone breaks and the readers are forced to separate once again when Eric travels to New York City at the bidding of the mysterious Serin Institute - a wealthy organization interested in the Straka question whose intentions and backers are never revealed in the novel (Mystimus). The author of these tweets, if not Dorst and/or Abrams, takes pains to make them especially convincing by writing in the by now familiar styles of Jen and Eric, providing a reason for them to communicate via Twitter, and having the two only talk to one another.
} 
confirmed by none other than Mulholland Books who in April 2014 announced the availability of free "S. Reading Group Kits" for U.S. readers (Mulholland Books "Request"). These kits included a letter from "J. W. Dominguez" who they designate as their "marketing consultant on S.” as well as further puzzles and S.-related memorabilia specifically designed for groups of readers to tackle together (Mulholland Books "Request"). These additions to the Straka saga quickly made their way online so that even readers unable to receive a kit themselves could benefit from its clues and hints (“(S)pecial Delivery”).

All of these highly visible and complex interactions between readers of $S$. with each other, between readers with the text, between characters with each other, between readers with characters, and between $S$.'s readers and authors, perpetuate the view of $S$. as a "found object"that is, a physical artifact of "real world" interactions between living people. Clearly, the necessary suspension of disbelief required for this understanding of the text is much less daunting when the reader is able to join in with a collective of fellow readers bent on uncovering further evidence of its "reality" in the world external to the text. Once the slipcover referencing Abrams, Dorst, and the novel's plot synopsis is removed, the reader is invited to experience $S$. for what it appears to be: an actual novel belonging to two actual readers that somehow fell into another reader's (the real actual reader's) hands. Mulholland Books even provides further evidence for this view outside the immediate boundary of the text by authenticating $\mathrm{J}$. W. Dominguez as a contemporary of Jen and Eric and by having Dominguez allude to the mystery of how Mulholland Books got ahold of Jen and Eric's annotated copy of SOT which, he says, has "been a tremendous boon to Straka scholarship"—an insinuation of S.'s dual existence as both a novel written by Abrams and Dorst and a crucial component of a long-standing literary mystery (“(S)pecial Delivery”). 
This is not to say that every reader of $S$. will be inclined to follow its clues and puzzles into the online continuation of the $S$. world. One such reader on the subreddit discussion, “whoisstraka," even admitted to finding the massive online content off-putting, saying, "My hope when I purchased the book was that I could read the book multiple times, work through the mysteries and come to a full resolution (maybe with some help from the internet if I get stuck). What I don't want is an ongoing string of mystery that just goes deeper with more and more web content" (Vigeous). One respondent to this reader assures him/her, "you certainly don't NEED to follow the internet rabbit trail. For the most part, I just read the book(s?) and felt satisfied" (Vigeous). This issue is an important one: must the physical lead to the virtual? The authors themselves are quite clear about their intention that the book be a physical book (and not an online book, a movie, or a video game): "it's intended to be a celebration of the analog, of the physical object... We wanted to include things you can actually hold in your hand," says Abrams in an interview with The New Yorker's Joshua Rothman ("The Story”). Abrams also frequently tells the story of how the idea for $S$. began with a book he found on a bench with a note that the reader read it and then leave it for someone else to find; after the initial idea was shared, inspiration, the authors claim, further came from other books in the tradition of found objects such as epistolary novels and the 1930s "crime dossier" books of Dennis Wheatley ("The Story"). Prior to the amassment of online ephemera, discussion forums, videos, and tweets, the voyeuristic sense that actual readers are spying on something extremely intimate and private between metafictional readers is what makes the novel feel "real" in the sense that the reader alongside these metafictional readers is able to pursue questions with meaningful answers among the presence and absence proffered in the interactive materiality of $S$.'s orts, scraps, and 
fragments. ${ }^{85}$ The resulting experience, performed and mediated by the availability of readerly choices contained in the novel which lead to still other choices, is a journey, an intimate encounter with another human, and a performance of both scripted and unscripted interactions. The reader must press on to uncover the answers of multiple mysteries and codes and to discover whether Jen and Eric will choose each other over their obsession with the story of an author. Whether the reader will herself press on further to journey into a virtual map —and to, in so doing, embody a virtual map of reading — is an individual choice, but one that is highly encouraged by the text's authorities.

\section{Reading as Performed-Journey}

The journey inscribed in $S$., while a love story, is one of revolution, paranoia, and violence. The initiation of all readings of a new copy of $S$. are marked by the reader's own hand with an act of physical violence: the breaking of a paper seal bearing a stylized "S." inside the dial of a compass. Even for a reader not keen on symbolism in her reading practices, the breaking of a seal is memorable because it is unusual; likewise, the compass imagery might prepare the reader from the beginning of her experience for a journey. But a journey inside of a compass suggests a futility from the start or even a return to the place from which one starts. If the reader is further inclined to consider her textual history, the presence of a physical seal will recall antiquated symbols of authenticity and confidentiality in transmitted written documents; it signifies the presence of a specific sender and a specific receiver. Furthermore, it binds the slipcover of $S$., the outer book with a named publisher, publication date, authors' bios, synopsis, UPC code, and recommended prices to the inner book, Ship of Theseus which is in appearance, a

\footnotetext{
${ }^{85}$ As Woolf would say.
} 
library book. It is only a thin membrane between the reality of the book as a consumable, material object and the fictional world it contains, but it is a boundary nonetheless. The careful reader will further note the seal is already perforated and has a removable backing - perhaps the novel's invitation that the reader retain its memory and its represented external world by attaching it to the side of SOT. If the reader chooses to do so, the broken seal remains a present reminder of the journey the reader takes through the novel and that the reader, like the seal, has been broken open so that the story may take life in the reader's body.

This necessary violence to the text marks the first of many choices in how a particular reader will experience his or her journey through the novel. Beyond this point, there seems to be no right or wrong way to read $S$., and readers_-some frustrated, some awed-have frequently commented on online forums regarding the various methods and order by which the text can/should be read. A highly disciplined and methodical reader could read the novel in chronological layers (mimicking the chronology in which the text was written according to its authors) beginning with (1) the full text of $S O T$, proceeding to (2) Caldeira's footnotes, moving to (3) Eric's earliest notes in pencil, to (4) Jen and Eric's first notes (in blue and black, respectively), and proceeding through the subsequent layers of annotations and ephemera by color/iteration (5) (6) (7?) until the final set (8) in which Jen and Eric write in the same black pen, further emphasizing that they are now together physically. ${ }^{86} \mathrm{~A}$ less orderly, more spontaneous reader might read each page as she comes to it, consuming all layers of the text and its chronological levels of annotations indiscriminately. This method could also combine with

\footnotetext{
${ }^{86}$ It should be noted that in order to perform this chronology-focused order of reading from the beginning, the reader would need to have knowledge that such a chronology exists ahead of time, either because he/she read it before or because he/she was provided with some information about the novel by fellow readers. It is, of course, quite possible that a reader might shift over to a chronology-ordered reading of the novel upon discovering that a chronology exists, but this shift would likely only occur once the reader is already several pages in.
} 
the previous in which the reader reads each chapter in chronological layers before proceeding onto the next. A purely "instinctual" reader might reject all of these methods and choose to read in whatever order she pleases as it suits her at any given point: reading ahead, doubling back, pausing to read up on references to ciphers and bird calls, skipping to the ephemera that jumps out and away from the pages which struggle to contain them-effectively reading at will. ${ }^{87}$

All told, whatever method and order the reader chooses to conduct his reading will always result in fragmentation and fragmented attention. The realization that there will always be something missing characterizes not only the metafictional readings within the text but also the contained journeys and relationships of "real-world" Jen and Eric, Filomena and Straka, and SOT's characters, S. and Sola. The journey will always falter due to lack of knowledge but also due to a strong sense of repeated exhaustion, confusion, exasperation, and fear in these three pairs who at various times each wonder if their pursuit is worth the trouble. Likewise, the actual reader's journey through $S$. will likely evoke at least a momentary question of whether the timeconsuming reading demanded by the novel is worth it. On this question hinges the entire novel and all layers of stories it contains. Is pursuit — of pleasure, of knowledge, of escape, of hope, of a challenge, of an answer, of a story, of someone else-worth the effort and time and faith we put into it? The fact that Jen and Eric are allowed to learn from the past mistakes of others suggests that $S$.'s answer is indeed: yes. Pursuits of stories (and pursuits in general) are valuable in that if nothing else they can touch and teach us through embodied example. But at the same time, $S$. offers actual readers a careful consideration of the dangers of giving oneself wholeheartedly to a (narrative) pursuit at the expense of throwing away relationships with other

\footnotetext{
${ }^{87}$ The potential loss and/or misplacement of the ephemera is very much a part of the reading experience of $S$. The reader must ask herself: how important is it to retain the authenticity of the ephemera's original locationsespecially once the reader realizes that their original placements in the text do not always align with where the readers mention them, the readers having perhaps moved them around or themselves misplaced them.
} 
people. In eerie similarity to Calvino's Traveler, $S$. ends with the female reader calling to the male reader to "put the book down. Come in here + stay" $(S .457) .{ }^{88}$ Eventually, $S$. seems to be saying, priorities must be realigned so that the real world is more important than any book world — even a world as compelling as Straka's — and even a world as compelling as Abrams' and Dorst's. Notably, in both $S$. and SOT, the book world leads readers back to the "real" world, although, for many readers of $S$., that "real" world is a digital one. This moral lesson is, of course, confused by the role of the authors in keeping their readers out of the "real" world and ensconced in the world(s) of $S$.

Reading in $S$. is dangerous, addicting, misleading, and frustrating. The readers are intellectually and emotionally endangered in the commitment required by the text—with bodily and cognitive fatigue their constant companion-but also physically endangered when suspicious behavior, threatening messages, and unknown spies insinuate that someone may be willing to kill for the information. But the risk involved also offers a baptismal journey that makes Jen and Eric better readers, and arguably, better people. At the beginning of $S$., Jen characterizes herself as an escapist reader, saying that she "Loved all the mystery — the book, Straka, all of it, I really needed an escape, I think" (S. i). While Eric immediately takes her to task for thinking reading SOT could ever be an escape, the actual reader soon discovers that either Jen sells herself short or she has a different definition of "escape." As Eric is repeatedly amazed to discover, Jen has made insightful and valuable notes to various parts of SOT in her initial reading, marking herself as a reflective, engaged, and curious reader as well as one who is able to take delight in the language and sensory evocation of a text. Her accusation that Eric has "totally missed something important about FX. Caldeira" intrigues him enough to read her notes; ultimately he has to admit that she

\footnotetext{
${ }^{88}$ Cf. the final lines of Traveler: "Ludmilla closes her book, turns off her light, puts her head back against the pillow, and says, 'Turn off your light, too. Aren't you tired of reading?"' (260).
} 
was right: her particular brand of "escapist" reading allowed her to dive deeper into the subtext of SOT than anyone had before (or at least, more so than any scholar had before) (S. i). Eric, a longtime fan of Straka and former Ph.D. student, is a very different type of reader, a more stereotypical scholar-reader who reads a text for a particular purpose: to uncover clues as to the identity of Straka. Even Eric's earliest comments to SOT, which he claims date back twelve years ago to when he was sixteen, speak to his interest in research, intertextuality, authority, and interactions between author biography and text as well as a deep suspicion of Caldeira who claims authority/primacy in Straka knowledge. This early distrust in scholarly authority foreshadows Eric's falling out with other Straka scholars after their betrayal and theft of his work. But under Jen's prompting, Eric begins to see SOT and Straka in a new light, revealing himself to be capable of true scholarship in admitting he had it wrong and demonstrating a willingness to change his thinking. Jen's reading of SOT pushes Eric to rethink his old assumptions and to go deeper-literally reading between and around the lines for the hidden codes she is so confident are there. More than anything though, Jen's reading presses Eric to accept the possibility that SOT has a non-academic (or what he considers non-academic) subject and purpose: love between two people, an author and a reader.

Both SOT and Eric's reading of it push Jen as a reader as well. Her tendency to read the plot, the characters, and details as based in real life incidents, people, and sensory descriptions of the real world is put sharply in check by Eric who repeatedly reminds her that authors are not absolutely beholden to the real world when creating their narratives. Her research skills are also heightened as a result of the opportunities and incentives (i.e. to impress Eric) laid out in the couple's reading of SOT. Jen finds evidence of the existence of The Archer's Tales, cypher solutions, and other documents overlooked by serious Straka scholars including Eric. 
Bailey 220

Significantly, the most common comments from both readers are expressions of awe and reconsideration, of "never thought of it that way" in response to the other's insights $(S$. 179). For both readers, the direction of their lives, their reading, and their identity changed as a result of their reading experience of SOT as a journey they had to follow down to its end. But their reading was also altered as a result of having another reader's reading to compare it to. The pages of $S$. bare the traces of turning points, readerly choices, and performances of reading that the two readers create for themselves and in turn for the actual readers who follow in their metafictional footsteps.

\section{Reading as Sexual Intercourse}

$S$. also portrays reading in the language and patterns of sexual intercourse, particularly focusing on the sexual/textual binary of obfuscation and revelation. The final answers to the novel's mysteries are continually withheld from both metafictional and actual readers while just enough of them are revealed to keep readers interested; thus, reading in and of $S$. becomes the textual equivalent of a strip tease: a phenomenon designed to induce immediate, albeit simulated, intimacy and desire by utilizing the razor-sharp intersection between revelation and obfuscation, exposure/disclosure and mystification. Interestingly, what information is revealed and what is obscured is not always the same for both sets of readers of and in $S$. : at times the metafictional readers know more than actual readers (e.g. when Jen and Eric refer to photos, other Straka novels, and documents actual readers are not privy to) and sometimes actual readers know more than metafictional ones (e.g. in actual readers' ability to see the future of Jen and Eric's 
relationship from the beginning of the novel as a result of the ink-colored layers of time) ${ }^{89}$ But both types of readers experience authorial limits on what they can know and discover. The plainest example of this is in the novel's refusal to authenticate the metafictional readers' theory on the question of Straka's identity. The accuracy of their theory remains unanswered and unanswerable since the novel ends before Jen and Eric complete their research. At other times Jen and Eric frustratingly come to conclusions without taking readers through the steps in their thinking or allude to in-person conversations not included in full in their marginalia. But as many readers of $S$. can attest, the fact that the whole story (complete with definitive answers) is not revealed by the novel's end keeps readers longing for more-perhaps even returning to its beginning in search of overlooked clues and hidden messages, now with a better understanding of how to go about finding them.

Just as Jen and Eric feel an obsessive, magnetic connection to SOT and, to a lesser extent, other Straka novels, $S$. will likely attract actual readers who are curious, book-loving, and willing to commit whatever time and attention is required of them - these are easy marks for a novel like $S$. To fall deeper under its spell and allow oneself permission to pursue the addiction of the story, the reader must also accept that her initial expectations for what the novel will be and feel like are likely to be confounded. $S$. is designed to overflow the reader's mind with parallels, mysteries, and connections to our world, both large and small—with rabbit trails and false turnings all along the way; the novel also overflows the reader's senses with its requirement of

\footnotetext{
${ }^{89}$ Here the connection between $S$. and the crime dossier mystery novels of Dennis Wheatley (in the tradition of the "master" detective narratives in which the detective sees more than the reader and figures out "whodunit" prior to the reader) is apparent in the already-cracked state of many of SOT"s hidden ciphers and coded messages. The actual reader at times is provided with answers to ciphers and codes almost as soon as she is aware that there is a code to solve. However, as Dorst comments in an interview with Noah Charney of The Daily Beast who mistakenly believes that Jen and Eric solve all of the codes in the novel: "It seemed unsporting to write a novel in which codes and ciphers play a big role without giving readers something [sic] a way to participate on their own. So there are other pleasures to be found there for readers who are inclined to go looking" (Dorst).
} 
hyper-interactivity between the text, the footnotes, the marginalia, the ephemera, and the allusions to texts before the book. $S$. is very much a story about the tactile nature of reading and of doing research: setting up a comparison between itself and the assorted collection of passedon objects that derive and develop from a relationship with another person. It should come as no surprise then that some actual readers become so entranced by the strip-tease "reality" offered by the novel as to question whether Straka was a "real" author and SOT a "real" book. ${ }^{90}$ But as readers must ultimately come to accept, $S$. is fiction-moreover it is a fake old book that is "based on an illusion" of digitally-worked, nostalgic artificiality (Tanderup 53). The yellowed pages, the library stamps, the extensive annotations - are all intended to lure the reader into a particular understanding of the object in their hands. (Regrettably, the most obvious flaw in the illusion cast by $S$. is the lack of "old book smell"— a detail unable to be overlooked by a reader whose nose knows.) The differences in tactility between the pages of the book, the heavy cardstock of the postcards, the rough newspaper clippings, the fabric lightness of the napkin, the smoothness of the expensive stationary, the coffee stained edges of the yellow notebook paperall evoke sense memories of the actual reader's past interactions with different types of textual materials in their added combination to the text's felt authenticity. The tactile experience of reading $S$. is a messy and jumbled, much like a new and covert sexual encounter. $S$. demands the reader's intimate and dedicated involvement with reading; it demands that the reader surrender to the illusion of its subversive, voyeuristic encounter with other readers' intimacies. The question then becomes whether the actual reader of $S$. feels cheated in any way by the deceptiveness of the intimacy when at last the lights come on and her time with the book is up. Given the continued online pursuit of $S$.'s layered mysteries, it seems that many readers are so charmed by

\footnotetext{
90 S.'s Straka is regularly connected by Caldeira's footnotes and Jen and Eric's marginalia to real-world authors such as Hemingway, Dos Passos, and Stein for added authenticity.
} 
the idea of $S$. as a book-lover's wet dream that they choose to see the illusion as real, all the while knowing and understanding the ploy for what it is. Reading $S$. is frustrating, overwhelming, and exhausting, but it is also intensely and haptically pleasurable in the hands and eyes of the reader.

The physicality of the text in the form of a book filled with additional textual treasures is intended to be seductive, but the narrative curiously contains many pointed warnings to readers centered around the form of the physical book: (1) the book as a facilitator of unwarranted intimacies, (2) the book as the incubator of obsession, (3) the book as architect of readerly vulnerability, and (4) the book as an encourager of separation between fiction and reality. The metafictional readers remain somewhat aware of these dangers, but nevertheless, let their obsession for the book consume them. Ironically, while the actual reader may share in this obsession, it eventually peters out along with the mystery. Jen and Eric meanwhile, live on forever in the physical and virtual worlds of $S$. as forever seeking after its answers and drawing closer to each other. Abrams and Dorst have both at various times emphasized their intention for $S$. to demonstrate the development of intimacy between two people that comes about from sharing a book ("The Story of ' $S$."'; Dorst). While they have not overtly suggested that the novel also speaks to the dark side of obsessions (including obsessions with books), $S$. traces a series of pitfalls, some of which are not resolved by the novel's end, on the intersections of intimacy, love, books, and reading. Seemingly induced by the strip tease styled enticements of SOT and the Straka mystery, Jen and Eric's relationship resembles nothing so much as an illicit love affair. The readers are intensely secretive and protective of their relationship from outside forces whose intentions are unclear but threatening. As their relationship grows, Jen especially begins to drift away from her friends, roommates, and family who she now sees as shallow and wanting to 
control and infantilize her. Both readers are aware of the obsessive nature of their involvement, but neither is able to tell where the obsession with Straka ends and their interest in the other begins: the two are in many ways the same thing. While critics such as Sara Tanderup posit this textual communication as more closely aligned to an email conversation, Eric defends their textbased relationship against Jen's grumbles: “There was a time when people relied on letters to get to know each other" (S. 51, underline in original). But even here, it seems that the reader doth protest too much.

While this reliance on textual documents and text-based communications to get to know one's lover is quaint, even ideal (to some), and closely parallels the modern online dating world of today, at some point, the actual reader will realize that Jen and Eric's note-exchanging been taken to the level of manic obsession. As opposed to responding to notes in a chronological order, each reader scans through the entire text of SOT searching for new notes. That this occurs multiple times per day creates a situation in which each and every page of the text is fully known by the readers; the patterns between text, footnotes, and marginalia are familiar to the extent that the slightest alternation — or lack thereof—stands out like a child's dirty handprints in a white kitchen. Jen jokes that Eric is so obsessive over their comments that he would know if she "put one dot on any page in this book"- which she of course then does and he of course then finds $(S$. 87, underline in original). Of the two of them, Eric is the more overtly concerned about keeping records of their comments as evidenced by his various accountings: "You wrote 112 notes today. Average of 28 per pass"; "New record for you, 118 notes. That's 39.25 per" $(S .16 ; 56) .{ }^{91}$ The readers' marginalia also bears witness to their frequent rereading of old notes as they both

\footnotetext{
${ }^{91}$ Such helpful details also enable the actual reader to do the math and discover that the readers complete roughly three to four "passes" a day except for the times when Eric is out of the country on research trips and when Jen is sick or upset with him [e.g. "I noticed you didn’t pick up the book again..." (S. 97)].
} 
habitually look back and understand the other's older comments in a different light: Eric: “...Oh, wait-you were talking about me there, weren't you..."; Jen: "Remember when you thought this wasn't about LOVE?" $(S .17 ; 184)$. As a result of these unusual conditions, the two readers are constantly engaged in dozens of specialized conversations which sometimes overlap, sometimes trail off into ephemera, and sometimes (although rarely) end abruptly when one reader refuses to respond. This situation is workable in "margin world" as the readers call it, but not so much in the real world. Eric breaks off multiple arrangements to meet with Jen-always apologizing later. The two also take to the book to say things they apparently cannot say in person-one again, perhaps accelerating the gradual development of intimacy in a "normal" (i.e. non-bookbased) relationship. Eric occasionally voices this very fear: that their relationship has moved forward too fast, that they are exchanging confidences too early. Despite the readers' recognition that this state of affairs in indeed a problem, they continue. Upon the actual reader's realization of the dangers inherent in the frequency and obsessive thoroughness of Jen and Eric's noteexchanging practices, the fact that good-girl Jen is in danger of failing out of college is not so surprising: SOT, the Straka mystery, and the other reader takes up nearly every waking second of Jen and Eric's time.

Besides its potential impediment to their growing relationship, use of the book as the metafictional readers' primary means of communication sets up an additional vulnerability if the book were to fall into the wrong hands. While it initially serves as the only safe way to pass information without linking them to each other (no "paper trail" via email or library room log-in records) Jen and Eric come to spend an increasing amount of time discussing the safety of the book's "drop" spot (S. 149). Originally in the library, they decide to change locations once it becomes apparent that there are unknown players lurking about and attempting to connect Jen 
and Eric to each other. Even more frightening is the evidence that someone else is reading through the book when they uncover new and threatening marginalia for which neither reader claims responsibility ( $S$. xiii, 168). Although the danger of exposure is very real, Eric assures Jen that he will never get rid of the book—-Ever." - suggesting that its status as a memento of their earlier selves and relationship is worth the risk of keeping it to him (S. 153). As in the plot of SOT and in the story of Caldeira/Straka, writing is sometimes the only way to keep pursuing what matters - even when the revelation of that writing to unsanctioned readers spells certain danger to the writer and his/her reader or choice. S. writes as a way to connect to Sola, hoping to "find her there" on the margins just as Straka writes to connect to Caldeira just as Eric and Jen write to connect to each other $(S .380)$. Because the messages sent and received are so intimate, reading is always potentially dangerous depending on whose hands the texts fall into.

Another final concern is that Jen and Eric's obsession with SOT and the Straka mystery is separate from the "real" world — an all-consuming fantasy that takes them away from other people and concerns in their separate lives. Jen's parents become incredibly worried at the news of Jen's secret, older boyfriend and attempt to bring her back home to get her away from him. Ironically, Jen mentions earlier in the text that after her breakup with her previous boyfriend, Jacob, she was able to see that her friends' concerns about him were legitimate. Her relationship with Eric, if anything, is even more concerning because she keeps him and the source of their attraction a secret. At the end of $S$., Jen and Eric must leave everyone and everything behind in order to be together and continue to pursue Straka. Conveniently, they both by this point have already damaged ties with everyone else in their lives, so this necessary final severance is not overwhelmingly painful. While the love between the two readers seems genuine and their decision to travel to conduct research is arguably romantic (in a book-nerd kind of way), the fact 
that their personal burned bridges no longer bother either reader gives pause. The readers choose "love" as it were and end up with each other, but where does that leave actual readers? The equivalent of a Jen or an Eric, according to the publishers at least, is to read $S$. with a group of friends - a financially-savvy answer on their part to the intimacy questions posed by the novel.

In her recent article on memory and "media nostalgia" in contemporary experimental literature, Sara Tanderup notes that there is a tendency in contemporary texts to "transition from the book as a space for intimacy, privacy — towards reading as a collective process" (54). Such a claim insinuates the existence of a before and an after: a prior state in which the reader sought out reading as an independent, private activity in which intimacy was to be had with the text and/or its author in opposition to a current state of reading in which the reader reads as a communal activity offering intimacy with other readers. The long existence and popularity of book clubs, literary lectures, reading groups, and mass literary subscriptions to organizations such as Reader's Digest, problematizes this strict dichotomy, but Tanderup's point is well-taken. S. and other experimental contemporary literary works such as Steven Hall's The Raw Shark Texts and Mark Z. Danielewski's House of Leaves do emphasize an awareness of other readers and have something of a cult online presence consisting of readers collaborating with other readers (who they likely do not know outside of these forums and sites) to deliberate, decode, and generally love on the text itself. Jen and Eric both initially read SOT straight through on their own and then reread (and re-reread) it together. Actual readers are invited by the novel's authors and publishers to adopt similar reading practices in first reading the text for themselves followed by exchanging observations and insights with other readers, a strategy that facilitates rereadings 
and other forms of continued involvement with the text. These text-based incentives to read, reread, and share align nicely with the aims of community reading websites, such as the Amazon-owned Goodreads, which for the past decade has been encouraging readers to follow up their readings with an online response, whether a simple "star" review or an extended write-up, which is then viewable by other reader-users, perpetuating the notion of communal readership. What does this push toward interactivity and collaboration mean for the future of fiction and its readers? Do readers, as Tanderup suggests, in their view of reading as a "collective process" now disdain a private reading that does not eventually allow them to reconnect with the thoughts and opinions of others? It's largely unclear if these highly communal reading practices are the new norm or merely a passing trend mediated under the auspices of experimental contemporary literature. But while $S$. clearly celebrates collaborative reading and demonstrates its potential in fostering intimacy, connection, and partnerships with other readers, it also portrays collaborative reading as demanding, overwhelming, obsessive, and dangerous. Jen and Eric do come to represent a level of embodied reading to strive for - they are curious, insightful, research-oriented, and heavily invested, allowing the narrative free rein in their embodied encounters with it - but they are also written into a practically unattainable ending in being allowed to escape the demands of everyday life to devote their lives to each other and to the pursuit of Straka - essentially, more of the same as what they did in the book, but indefinitely. While the actual reader is ostensibly invited to follow the metafictional readers' ending by entering the online world of $S$. in which the pursuit continues and intimacies with other readers are to be had, because there is no Straka, because the literary mystery at its heart can only go as deep as its authors and collaborators have decided to go, at some point, the actual reader has to give up the quest and move on. The online world of $S$. is both eternally continuous (saving the 
total collapse of the internet in worldwide apocalyptic doom) and invariably static; it requires new blood, new bodies, to continue the pursuit. Based on the most recent updates on $S$. blogs, sites, and discussion forums, readerly interest in the novel largely died out in late 2014, early 2015 following the recovery of the five hidden autographed copies. New readers can of course discover $S$. on their own and recover the information and discussions left behind by the initial 2013-2014 frenzy of readerly delight and labor, but the connections will be largely one-sided unless a new burst of interest in the novel takes place sometime in the future. Despite the lessons contained within $S$. regarding the drawbacks of readerly obsession and passion, it seems that $S$.mania died out, not because readers saw the novel as a reading morality tale, but because, finally, there was nothing more to discover. The contemporary reading pursuit dies, not in cries of triumph, but in chatroom silence.

\section{Pursuant Readings: Concluding Thoughts}

Pursuits, tests, quests, and journeys have a tendency of leading to still other pursuits, tests, quests, and journeys. Just ask Hercules. Similarly, the stories we tell ourselves about progress, evolution, pursuits, and endings assure us that there is always more of these things to come. In the fleeting sense that the reader is pursuing a narrative end-even an unsatisfying one - she might be able to find peace, comfort, stillness, and rest from the relentless grind of her own pursuits. But more importantly, the story saves the reader from the necessity of acknowledging that the end of her pursuit, which we call life, is in fact death. In the world of the story, the ending is something: it is a white space after the end of the words, it is the difference between the story that is and the story that isn't, it is a physical and so graspable end whether the text be made up of print and paper or pixels and code. In the stories that continue on to find form 
in embodied places beyond the text, in the readers who take them in and hold them there in their minds and bodies, the end is both eternal and finite, the way humans feel themselves to be, even while our own final journey is into the unknown - perhaps into nothing. Some say we make stories simply to stave off the eternal darkness we know comes for all of us.

Like everything else we create, we make stories in our own image. We read into them ourselves and how we wish we could be and how we wish the world could be. Unlike us though, "Stories want to end. They don't care what happens next..." assuming, as always, there is a next to happen (Pratchett 267). That's why there needs to be more than one story. The pursuit carries on in search of the new, the next, and the beyond; it carries on and through the terminal end and into less final, in-between narrative ends that we can imagine represent true finality - a kind of temporary, everlasting life from the word incarnate. The stories are familiar to us and strange at the same time. And when we read, the pursuit makes us eternal, for a time, like a journey that never ends or a cycle that's ending is also its beginning.

What begins at the water shall end there and what ends there shall once more begin. $-S$. 


\section{CHAPTER 5: READING AS ESCAPE}

A great many people want to go there [to Elfland], without knowing what it is they're looking for, driven by a vague hunger for something real... But the point about Elfland is that you are not at home there. It's not Poughkeepsie. It's different.

-Ursula K. Le Guin (From Elfland to Poughkeepsie, 4)

As seen in the previous chapter, understanding "Reading as Pursuit" lays out both cognitive and sensory implications for the reader as quester, puzzler, and traveler in search of completeness and consummation. This reader is driven forward through the narrative out a desire to know and/or to possess - with the sexual undertones of such desires fully available to authors in their characterizations of these particular pursuers and pursuits of narrative. But a variation on this popular understanding of reading and readers as moving through a narrative (much in the same way as we understand ourselves as moving "through" our lives) shifts the emphasis to the movement itself over the thing being pursued; this variation can be summed up in the broad metaphor of "Reading as Escape." In this version of reading as movement and journey, the impetus for reading is to gain access to the "otherworldliness" of fiction while simultaneously getting out of this world - a nuanced shift of emphasis from "through" to "in." Significantly, since this sense of escape comes from entering the world of the narrative via reading, the reader is compelled to keep reading in order to keep escaping; just as a physical journey into a strange country takes travelers further from their places of origin, the further "in" a reader goes in a narrative world, the further she can feel from her native reality - and the closer she can feel to a "realer" one. ${ }^{92}$

The idea that readers read fiction to escape from the mundane, "nonfiction" world around them is by many accounts the most popular as well as most contentious reason for reading - a

\footnotetext{
${ }^{92}$ In "From Elfland to Poughkeepie," from which the epigraph to this chapter is taken, Ursula K. Le Guin notes that "when fantasy is the real thing, nothing after all, is realer" (28).
} 
duality to which I will pay especial attention in this chapter. Notably, looking down on self- or other-identified escapist reading habits and genres associated with escapist reading is perceived as an easy way to gain literary highbrow cred. After all, if fiction is intended to show readers a deeper element of reality, then reading to escape reality has no real place in the habits of "right" readers. Perceptions of readers, their chosen texts, and their reading practices and motivations become extremely important for the critic of escapist reading. If a reader's escape is viewed as a much-needed respite from the harsh demands of the reader's life in the real world or as an outlet for the reader's frustrations and feelings of powerlessness, we are back to an understood and moderately acceptable practice — catharsis — which rides the fence between acceptable and unacceptable depending on the critic's perspective. ${ }^{93}$ Similarly, if reading as escape is seen to arise from the desire for wish-fulfilment in terms of the reader being able to experience adventure and excitement through situations impossible or implausible in real life or as an opportunity for a sense of empathetic identification with a significant individual (a.k.a. a main character), the critic of escapist reading could easily view such fiction-reading practices as detrimentally setting up a false reality which will only serve to harm the reader greater in the wake of her reality's inability to measure up. ${ }^{94}$ To criticize escapist reading, in this instance, is seemingly motivated out of concern for the reader's welfare; nevertheless, I would argue that more often the critic of escapist reading looks down on these practices out of a sense that to do so is intellectually superior, as opposed to any real interest in the reader as an individual.

\footnotetext{
${ }^{93}$ For a good introduction to the Early-Modern reconceptualization of the Greek concept of catharsis (which plays into our contemporary understanding of catharsis as both a good explanatory model for certain behaviors as well as an outdated therapeutic activity), see Katherine Craik and Tanya Pollard's Shakespearean Sensations: Experiencing Literature in Early Modern England.

${ }^{94}$ Both this motivation for reading and others' disdain for it are considered in Janice A. Radway's Reading the Romance: Women, Patriarchy, and Popular Literature, a thorough and thoroughly delightful study of a genre which has endured overwhelming critique in Western society.
} 
In one sense escape is almost too broad a category to be applied to fiction-reading. Linda Hutcheon goes so far as to claim that "in fact, all reading (whether of novels, history or science) is a kind of 'escape' in that it involves a temporary transfer of consciousness from the reader's empirical surroundings to things imagined rather than perceived" (76-77). From this observation, it is easy to conclude that every activity of sustained attention is an "escape" from realityincluding the act of critiquing escapist reading - if by reality we mean an awareness of the passage of time. In Hutcheon's view the derogatory implications of escapist reading come from the critical opinion that the reader's choice of a textual world over the "empirical world" is equally a choice of disorderly behavior over some more desirable activity (77). Once again, we are back to escape as a matter of perspective: of whether reading truly does take the reader out of the real world and far afield from any applicable human experience or if the experience of reading fiction somehow informs the reader about the world in a way only accessible by "leaving" it momentarily. Perspective implies a viewpoint, a certain distance and angle for considering a phenomenon. Escape implies a movement, a particular trajectory for achieving that distance. Together, it would seem that escape and escapist reading can offer a different type of perspective on the world, and perspective, as the world's evolutionary and social histories have taught us, can mean all the difference in everything from mere survival to true transcendence. Authors of some of the choicest texts for escapist reading practices imply that this is the end they are going for, both in their writings about reading and in the narratives themselves. I am speaking, of course, of authors of fantasy, its sister-genre of science fiction, and the more adultsounding magical realism - the genres whose very existence seems to imply that reading for escape is the only way to read. Coupled with these "fantastic" genres' celebration of escape is their tendency towards self-awareness and subsequent metafictionality - arguably caused by the 
intense social scrutiny under which these genres struggle. ${ }^{95}$ Such metafictionality can serve as a venue for authors to speak to their readers about the very acts of reading in which they are engaged - especially reading as escape — in surprisingly didactic ways, demonstrating to readers the consequences of their reading as well as authors' hopes for what such acts will enable in the readers" "real" lives.

Fantasy fiction by definition celebrates otherworldly scenes and feats such as magic, passages into new worlds, and/or the discovery of new worlds within seemingly familiar onesand as many authors note, these fantastic experiences are much like the experience of reading itself, allowing for such metafictionality to speak beyond their immediate text and genre for all of fiction and all acts of reading. Lev Grossman, author of the best-selling Magicians trilogy, views the "portal" passage of his favorite childhood fantasy book, The Lion, the Witch, and the Wardrobe (from C.S. Lewis' The Chronicles of Narnia), as "a magnificent metaphor for reading itself": "when she opens the doors to the wardrobe, it's like Lucy's opening the covers of a book and passing through it to somewhere else-which is just the same experience you're having at the moment you're reading the passage," Grossman explains in an interview with The Atlantic. Such a metaphorical interpretation suggests at least one reason for why the fantasy genre also so easily lends itself to metafictionality. In creating portals to new worlds, fantasy authors are free to explore what it means to be a reader and to lose oneself in order to enter a new world: a practice necessary to transported readers. But while there is an undeniable freedom and power in this self-loss, there is also a danger: that of not wanting to come back. This reluctance to return to the real world is a central conflict in C.S. Lewis' The Chronicles of Narnia as well as Grossman's Magicians trilogy, both of which contain protagonists who question whether they

\footnotetext{
${ }^{95}$ For simplicity, I will refer to this assortment of subgenres and sister-genres which depict non-realist narratives as "fantasy" or "fantasy fiction."
} 
want to return or even should return to the real world after experiencing the fantasy worlds of Narnia and Fillory, respectively. The Neverending Story (1979), while perhaps better known by its lighter movie adaptation, also contains strict consequences for those individuals who enter the fantasy world of Fantastica and refuse to return home: they become dumb, illiterate, and always preoccupied "Know-Nothings," trapped forever in the world of the book.

That the necessity of returning to the real world has been critically and artistic dealt with within many of the very fantasy works which celebrate leaving it suggests fantasy authors have had to anticipate the potential dangers within the practices of escapism and sustained transportation which draw their readers to them in the first place. Yet, fantasy's inherent metafictionality also allows authors the opportunity to guide readers in their understanding of the journey-experience of fiction, and in so doing, offer a defense for reading's necessary function despite its potential dangers. Grossman explains what this dual message could hypothetically look like in a fantasy work: "when you pass through the portal, you re-encounter in the fantasy world the problems you thought you left behind in the real world... Fantasy takes all those things from deep inside and puts them where you can see them, and then deal with them." This is the tenor of many fantasy authors on the subject of their work's purpose- - or, to put it a different way, the journey they have laid out for their readers - including the authors of three texts I will examine in greater detail in this chapter: Neil Gaiman and Haruki Murakami. In addition to supplementary, extra-textual authorial commentary in the form of essays, lectures, and interviews, these authors' fictional narratives become declarations about the act of reading: what it feels like, what it looks like, what it does, and what it means for readers. As in many works of metafictional fantasy, the metaphors of "Reading as Journey" and "Reading as an Encounter with Nature" work together to facilitate portrayals of reading and readers navigating between at least 
two worlds: (1) the world the reader enters into through reading the book (Ursula K. Le Guin's "Elfland") and (2) the "real" world from which the reader exits to go into the book and into which she returns when the reading is over-which is not, perhaps, the same world as it was before she left.

"Reading as Journey" is a fundamental reading metaphor in contemporary articulations of the experience of reading because it so closely parallels the way we understand our lives: linearly. The sense of movement, transportation, orientation, and balance is so crucial to the Western model of existence that to live a "little life" in the few hours or days spent reading a narrative becomes a miniature model of the larger thing. If life, as journey, is locked in eternal opposition to its destination, death, then the enemy of reading, according to this metaphor, is the end of the book (or the inability to start a new one). Movement and progress is the purpose (as opposed to reaching the destination), and a reader progressing through a narrative is transformed to a traveler of constant movement into that narrative. The act of reading thus has a necessary impact on the reader's body in that she must of necessity forget (or forget to respond to) the world around her. With her senses cued to the world of the narrative and away from the real world, the effects of this journey are enacted sensorily in nuanced ways such as the sense that time has passed, that space has become time, and that the text (and perhaps the reader to an extent) controls the speed of movement. What form such journeys take is often suggested by the metafictional journeys of travelling characters: for example, how can we read Pilgrim's Progress as anything but ploddingly, on foot. Same with J.R.R. Tolkien's Lord of the Rings trilogy whose characters and readers inch slowly along through the dense but variable world of Middle Earth. In Gaiman's The Ocean at the End of the Lane, the reader quickly arrives with all the speed of an automobile licking up the easy miles into the adult narrator's past, and then slows to match the 
steps of him as a small child playing in the yard or inching down a drainpipe, marveling at the world around him with its rush of sensory detail. In Murakami’s Kafka on the Shore the reader similarly wizzes past miles via train and bus, while at other times, methodically treads through the deep woods of consciousness. This sense of speed and of transportation (trains, planes, automobiles, or our own two feet) gives concrete sensations to a more lucid process: that of being already-present in the world of the book through reading while also continuing to "get there"- to fill in the outlines and the colors of that world by continuing to read; that of passing over some details along the way, while devoting vast attention to others we cannot pull ourselves away from. Journey gives readers a way to think about the sense that they straddle two worlds when entering into a narrative different from their own; it provides a way to think about the balance necessary to move from one to the other. Journey also implies a noticeable change in location, hence its connection to the secondary metaphor of "Reading as an Encounter with Nature."

While reading through and into a narrative implies journey and constant movement, there is also a sense of arrival — of presence — in the world of the text. This world, whether friendly or hostile, feels accessible to the reader in that her presence there is "natural" regardless of how unnatural its components may seem. Flying monkeys, talking trees, cunning dragons, magicworkers - the landscape of the world of the fantastic narrative can be whatever it is, whatever it can be, and the reader will feel and interact with it (at least initially) just as she would with the more realistic world of a naturalist novel: as an explorer and adventurer, on the look-out for clues about the natural of this reality, expecting both strangeness and familiarity-but not too much familiarity. Le Guin reminds us that "fantasy is nearer to poetry, to mysticism, and to insanity than naturalistic fiction is. It is a real wilderness, and those who go there should not feel too safe" 
(5). According to the "Reading as an Encounter with Nature" metaphor, the natural world comes to signal the reader's location in the world of the narrative as well as how she should respond to it (with fear, wonder, confusion, awe, delight?). Through smelling, seeing, hearing, tasting, and touching the indigenous plants, animals, and vistas as well as experiencing characters' relationships with their settings, readers are shown what living in this particular world is like and what is required to survive and thrive in it. Harry Potter is a good example of this phenomenon in that, following along with Harry's gradual passage into the "other" world where magic and wizards exist, the reader too gradually encounters the richness of the arcane just under the surface of the mundane once she is allowed to perceive its having been there all along. And significantly it is Harry's reaction to this magical undercurrent which prompts the reader's varied responses, usually wonder and awe, but occasionally superior amusement, apprehension, or horror. Reminiscent of Nabokov's author-constructed mountain and Zadie Smith's readerpossessed book-house discussed in Chapter 3, the perfect equilibrium is when the reader feels herself to be something of both a tourist and a resident within the world of the narrative, a perfect mix of familiarity (with recognizable patterns and a sense of belonging) with strangeness (the surprises, complexity, and intensity of things beyond and/or underneath the familiar patterns). As in The Ocean at the End of the Lane, encounters with aspects of the natural world(s) signal movements from present to past, reality to fantasy, and vice versa. Similarly in Kafka on the Shore and The Strange Library, sensory experiences with one's environment provide characters (and readers) with necessary information about where (and when) they are as well as clues for how to get to where (and when) they want to be.

Fantasy fiction which metafictionally examines the journeys and worlds it creates typically contains characters who are not the same at the end as they were in the beginning. 
Readers are likewise offered an opportunity for self-evaluation, reflection, and even confrontation of their selves and their pasts. Metafictional fantasy tends to ask deep questions about the role of one's past in one's present and allows for surprising revelations on these grounds, including the idea that one's future can be altered through a reevaluation of the role of one's past. As a result of utilizing the "Reading as Journey" combined with the "Reading as an Encounter with Nature" metaphors, fantasy authors are able to transport their readers to worlds where they have the opportunity to gain meaningful insights from the experience of reading fantasy - an experience which is significant in equal measure to its ability to convince readers that they are indeed taking such a journey. And in taking on the subject of reading as escape, journey, and an entrance into an other world —-without having to bend to the pesky rules of naturalist fiction - fantasy fiction is able take readers on unexpected journeys in understanding the nature of the activity in which they are at that moment engaged and invested. Interestingly, in all three of the texts examined below, the protagonists must come back out of their respective fantastical worlds at the end of their journeys, as signaled by the fading of their settings' "unnatural" details and events at the end of the narratives. Essentially each of these texts follows a series of shifts from a realistic world to a fantastical world and back again to a realistic world at their close. Likewise, readers are forced to return to the "naturalness" of their own world, though perhaps one which still retains a shadow of the fantastic. But to gain a clearer sense of the context for such didactic and moralizing movements in metafictional works of fantasy, a brief overview of the fantasy genre and its hidden-heart of metafictionality is necessary.

\section{Metafictional Readers in the Worlds of Fantasy}


In showing readers themselves, books and their authors wield a power as strong and compelling as the magic and magical worlds they contain. Metafictional readers and reading in fantasy works are reflective of their actual readers doing the thing they are at that moment doing: entering a new world and seeing themselves differently in that world. Such metafictionality tends to focus around a prominent and persistent theme: that of a journey which includes (eventually) a return to the world of humans, to one's home, to one's past, and/or to one's true self. No matter how comfortable or peaceful the fantasy interlude may be, metafictional protagonists must go back to where they came from - this is where the textual journey diverges from our image of the life journey: not all of us get or want to go home.

But returning home in fantasy works never means returning unchanged. True to the prototypical Hero's Journey, reading-protagonists within fantasy have a tendency to return home equipped or at least prepared to deal with their problems thanks to their fantastic adventures and experiences. Joseph Campbell, in his classic text, Hero with a Thousand Faces, describes this necessary return as "the full round" which "requires that the hero shall now begin the labor of bringing the runes of wisdom, the Golden Fleece, or his sleeping princess back into the kingdom of humanity, where the boon may rebound to the renewing of the community, the nation, the planet, or the ten thousand worlds" (167). While fantasy's protagonists are not always cast in epic tales of community, nation, planet, or world-saving, salvation and transformation —at least on a personal level—are often the result of returning home. Portrayals of metafictional reading, readers, and books can play a prominent role in guiding the reader to this place, but they leave the final responsibility of making amends, taking charge, or completing some task that needs closure on the reader. Neil Gaiman sums up this process while simultaneously responding to the negative insinuations of escapist reading, in a line from his 2013 lecture to the Reading Agency: 
... escapist fiction is just that: fiction that opens a door, shows the sunlight outside, gives you a place to go where you are in control, are with people you want to be with... and more importantly, during your escape, books can also give you knowledge about the world and your predicament, give you weapons, give you armor: real things you can take back into your prison. Skills and knowledge and tools you can use to escape for real. ("Why Our Future Depends on Libraries, Reading, and Daydreaming" 9)

As Gaiman rightly notes in his lecture, this opportunity for tool-making and knowledge-finding is strangely at odds with the inherent subversiveness of the fantasy genre, in that writers of fantasy must be aware that they are participating in the supply of what is seen by many as socially-subversive material, and that fantasy readers can come to constitute a select group of counter-cultural seekers. There is a danger that such perceptions will do real harm to readers either by hedging off would-be readers in the first place or convincing "escapist" readers that the world no longer wants them and instigating their reluctance to return to the world outside of stories - a self-fulfilling prophecy of sorts. As such, metafictional fantasy works tend to portray complex entanglements of both potential benefits and potential harms involved in acts of reading—and particularly, reading for escape.

A basic framework of the alleged pros and cons of reading exhibited within and by metafictional fantasy fiction is provided in Amie A. Doughty's consideration of "Books as Artifacts of Power" within her study of Children's and Young Adult's fantasy (27-49). On the affirmative side, she provides examples of narratives metafictionally demonstrating how books can: (1) provide comfort and a place of retreat for readers; (2) function as a touchstone for home and family; (3) guide readers by providing essential knowledge and information about the world; 
(4) help readers understand their place/role in that world; (5) instill a sense of confidence in readers; (6) encourage a greater awareness of the world; (7) play with the balance between reality and fiction in meaningful ways; (8) provide prophecies and/or orderings for the future; and (9) can even lead to a questioning of adult authority. ${ }^{96}$ On the negative side, however, metafictional fantasy fiction can demonstrate that: (1) books are a poor substitute for actual people; (2) the help they provide is usually limited; (3) they cannot replace actual experience in the world; (4) they can be dangerous (due to their content and/or a ban on reading which the reader must risk in order to pursue the experience); (5) they can be dangerous in the wrong hands - perhaps because they contain "too much" knowledge; (6) they can set up unfortunate boundaries between the identities of readers and non-readers; (7) they can bring about mockery or attack on their readers/possessors; (8) they can be used to control and/or distract readers; and finally, (9) they can represent adult authority (especially over a child-reader). All told, Doughty locates successful metafictional readers within her study of fantasy texts as negotiating the complex territory between books and first-hand experience; mature readers, she claims, will move away from books in favor of experience, and even the most avid of readers must force books to be only secondary to their identities so that they can fully realize the ultimate goal of self-sufficiency (167-168). This claim that reading teaching readers to value experience over texts is an important one to consider in the context of adult fantasy fiction as well. While I whole-heartedly accept Doughty's summation of this trend within metafictional fantasy (indeed, I trace this same trend within The Ocean at the End of the Lane in the section below), I propose that opposed to compelling readers to go "off books," metafictional fantasy encourages the

\footnotetext{
${ }^{96}$ Doughty interestingly does not fully speak to this apparent contradiction in that books can both represent adult authority for young readers and simultaneously encourage these readers to question adult authority, only to say that "the results are not always positive" (43).
} 
cultivation of healthy reading practices beginning with readers' identification with metafictional characters and ultimately resolving in a reconsideration of one's self as a reader and as a whole individual — perhaps going so far as to result in the reader's reevaluation of her past, her present identity, and/or her future. Particularly, as the reader is brought into the fantastical space within the narrative and back out again — where the fantasy world comes to represent a place for the examination of memory and the past - a turn inward and away from the narrative is encouraged by that experience. I hold with Le Guin's intimation of fantasy as a high-stakes game for readers to play: "It is a different approach to reality, an alternate technique for apprehending and coping with existence" (5). And while metafictional books and reading may be understood as representational of the press of others' opinions and ideas on one's own, the metafictional fantasy book in the hands of the reader is quite the opposite of what Doughty's analysis suggests it would be: modeling, instead of a distrust of others' dictations, an ultimate acceptance of the journey and experience offered by fantasy narratives and fiction in general.

Beyond its most common themes of exploring new worlds and encountering magical/unexplained passages, powers, and creatures, the fantasy genre as a whole has other attributes which equip the writer of fantasy in his or her considerations of reading and readers. The immense popularity of fantasy fiction is in and of itself a primary motivation for thinking about fantasy works in the context of readerly concerns: for instance, the "value" of reading fantasy in connection to its popular affirmation of reading as escape. Fantasy's popularity with young readers is an especial cause for its scrutiny, with mixed reactions from teachers, parents, and librarians who on one hand praise the power of fantasy works to turn formerly non-reading children and teens into voracious readers of impressively lengthy texts, while on the other, 
question whether the texts themselves are properly edifying and/or challenging (Withers and Ross; Renaissance Learning; "The Nation's Report Card”).

Perhaps due to its increasing popularity, fantasy works also have a tendency towards authorial and fan-written serialization which encourages metafictional considerations especially among their readers. Such continuations of favorite storylines allow more space for readerly engagement with beloved characters and worlds, and later, can lead to nostalgia among older readers looking back on their early favorites. This nostalgia seems to be largely responsible for fantasy works' popularity in fanfiction, in which readers are allowed the opportunity to continue their favorite stories even further and, if desired, insert themselves (or characters closely resembling themselves) within existing narratives to explore future interactions and plotlines. Such serialization (and popularity) is also connected to fantasy works' frequent adaptations into film and TV shows, noticeably highlighted by Peter Jackson's The Lord of the Rings blockbusters in 2001-2003 and continuing with Disney's Harry Potter movies (2001-2011), The Hunger Games franchise (2012-2015), and many others. Such an arrangement appears to be mutually beneficial to both the print and film industries as readers turn into viewers and viewers into readers.

All of these factors suggest there are more readers of fantasy for authors to potentially reach and a deeper connection between readers of fantasy and those works/authors than is typically enjoyed by other genres: readers expect longer journeys through storylines (and will take it upon themselves to lengthen stories if necessary) and anticipate the retellings of their favorite stories across multiple medias whether they be print, film, or interactive online platforms such as blogs and communities. Such fan communities maintain connections with fantasy authors as well through interviews, conventions, book-signings and readings, cosplay, and other 
outlets in a predominantly unique way from writers of realist fiction. Clearly, the invitation to be a part of the author's created world exerts a powerful pull on the fully-transported reader of fantasy.

There is also the inherent connection between the use and power of magic in works of fantasy and the use and power of everyday language in the world of the reader which compliments metafictional elements in works of fantasy. Traditionally, magic has been evoked in fantasy works through characters speaking or reading aloud spells, perhaps in combination with hand motions and/or the use of magical artifacts and ingredients. This augmented speech act is then able to act on the world around it, changing some element of either the speaker-subject or an object such as another person, a physical item, the weather, or some other feature of the speaker's environment. The main attribute of most fictional magic is a one-to-one correlation between the words spoken/read and the change desired and caused by the speaker/reader. Because of the supreme significance of words, most fantasy works also require that magic spells be spoken in a certain order and manner with an emphasis on consistency and precision. In Christopher Paolini's Eragon series, for example, the language of magic, gradually learned by the protagonist and subsequently by the reader, is discovered to be the first Ancient Language, once used by all beings, in which it is impossible to tell a direct lie. The words themselves are always unquestionably true because they are themselves the nature of reality; thus, speaking the words alters the reality. As in the magical languages of other fantasy works, names spoken in the Ancient Language of Eragon's world are those things' "true names." Naming as a way to influence the named is an especially prevalent feature of magic and of fantasy works in general. This explanation for magic with an emphasis on naming as an act of dominance also appears in the Neil Gaiman text analyzed below. 
While the "magic words" of the real world are usually translated by parents as the everyday manners a child will need to get by as an adult among other adults, language use in our world acts in ways similar to magic use in fantasy worlds. There are indeed very precise orderings of words and emphases on inflection and pronunciations which impart meaning — even in a language as generally forgiving as English. Getting the words right increases the likelihood that the speaker/writer's desired outcome will come to pass. Getting the words wrong can lead to misunderstandings, delays, and outright rejections. Words are given great power by their speakers to transfer an infinite amount of meanings, carefully selected and manipulated by the individual speaker to fit the time, place, and audience of the speech act. Thus, the workings of magic in works of fantasy are not nearly as outlandish as they might appear. Readers are familiar with the workings of linguistic power and control over physical and mental phenomena. Writing a work of fantasy therefore allows the writer a unique space for experimenting with the impact of language on the world. Readers are put into the position of being acted upon as if themselves under a magic spell, commanded to see and hear and smell and taste and touch an immaterial world, the world of the book. And for so many readers eager to leave their own world behind, the magic works times and time again.

Neil Gaiman's The Ocean at the End of the Lane (2013), which I will turn to first, tells the story of an early childhood trauma, but it also tells the story of growing up, of journeying through bizarre lands and situations, of being brave in the face of danger, and of enduring the loss a friend. Like so many other fantasy protagonists, Gaiman's unnamed narrator is a reader who "lived in books more than [he] lived anywhere else" (Ocean 13), but even his prior experience of entering new worlds while reading is not enough to prepare him for the imposition of an other, dangerous world in his own reality. The actual reader, along with the narrator, is 
taken on a journey initiated by sensory cues which allow for his remembrance of previously forgotten memories of his past and the other world. The trick Gaiman plays with the reader is in introducing doubt as to whether the narrator's memories of the other world (and all the fantasy elements of the novel) are "true" or are instead a series of intricate, self-protecting inventions to cover over a childhood trauma he is unable to face head-on. Ironically, even if the other world is viewed as a vivid, hallucinogenic defense mechanism, its detailed remembrances still bring the narrator closer to acceptance and healing in his real life, and what begins as an escape from his life ends up becoming a shockingly close encounter with its most hidden parts. The reader is likewise shown how journeys to fantastic places can also be journeys to one's past and self, and moreover that these journeys - viewed outwardly as "counterfeit" because they are read and not lived - are sometimes necessary to making the journey forward to one's future.

\section{Journeys and (Un)natural Encounters in The Ocean at the End of the Lane}

In the introduction to Neil Gaiman's recent short-story collection, Trigger Warning (2015), Gaiman questions whether fictions are "safe places" before proceeding to ask the reader if they "should... be safe places?" (xvii, italics in original). According to the "Reading as Journey" metaphor, fiction does indeed possess the power to take its readers to different placesplaces which may or may not be characterized as "safe"-regardless of the reader's personal desire for safety or even surety in his fiction. The Ocean at the End of the Lane explores this juxtaposition: on the one hand, reading provides a comfortable, even necessary escape for the metafictional reader-narrator within the novel, while on the other the reading experiences contained within and encouraged by the novel suggest that reading can be dangerous in its uncanny tendency to return readers to a place and time of the gravest danger: the reader's own 
past and past self. This contradiction was earlier acknowledged by Le Guin in her 1973 comparison of fantasy to psychoanalysis, both of which, she claims, can be understood as "a journey into the subconscious mind... it can be dangerous; and it will change you" (24, italics in original). The undertaking of such a journey, illustrated within Ocean by its protagonist and subsequently offered to the reader of the novel if she be willing to take it, is largely promoted as a worthwhile trip, though not, it is a true, a "safe" one.

While the "Journey" metaphor in Ocean is most overtly utilized to explore complex parallels between the narrator's and the reader's journeys from reality to fantasy, the novel is in fact rife with journeys to and from physical locations, times, people, and states of awareness which the reader is welcome to travel. Early on we find that the narrator has a childhood love of reading focused around the idea of "Reading as Escape": he travels into books because they are safe places and because they provide a relief from his real, more messy seven-year-old life. Beautifully observant and poignant accounts of reading during childhood usher in a readerly identification with the narrator as a fellow reader - both as an adult and as a child with whom actual readers likely share similar experiences in libraries and in bedrooms under covers with flashlights. Such rapport prepares the actual reader to identify with other journeys taken by the narrator, including: (1) the narrator's journey from a funeral to his old childhood neighborhood, (2) the narrator's journey from the present moment (as an adult sitting by a pond) to the past (as a child by the same pond), (3) the narrator's journey from childhood to adulthood over the course of the narrative, and (4) the narrator's journey from childhood pain in the form of loss, betrayal, and fear, to a post-trauma acceptance and hopefulness. ${ }^{97}$ Ocean can ultimately be read as the

\footnotetext{
${ }^{97}$ As I explore later, even if reading this novel as an allegory in which the frightening fantastical events did not actually happen, the narrator still experiences traumatic events in: his beloved kitten being run over, seeing the dead body of his family's tenant, witnessing his father's affair with the nanny, experiencing his father's rage and violence, and almost being drowned by his father.
} 
story of an attempted journey home — a journey to a home that no longer exists — taking the narrator from the place where his childhood home once stood, to the "new" house of his teenage years, down the half-paved lane to the Hempstocks' farm, and finally to the "Ocean" where it all started and ended. This homeward-bound journey of the adult-narrator mimics the original steps the narrator took as a seven-year-old child as well as, we discover, the steps he had taken twice before as an adult in (later-forgotten) times of crisis. In response to the narrator's question of why he is there this time, Old Mrs. Hempstock tells him, “'You wanted to get away from everyone and be on your own. So first of all you drove back to the place you'd lived in as a boy, and when that didn't give you what you missed, you drove to the end of the lane and you came here, like you always do"' (Ocean 173). Although she doesn't say so, the narrative hints that Mrs. Hempstock is equally aware of the return of the narrator's jarring memories of the fantastic other world and the unintended consequences of his trespassing there. A search for home, for the narrator, is a search for comfort but a confrontation with repressed memory.

The most pivotal journey scene of the novel occurs when the narrator first enters the other world through the magic of the Hempstocks' seemingly normal dairy farm. What begins as two children playing a scavenger-hunt game in the yard gives way to a journey much further than either realized they would go:

We pushed our way into a clump of trees, and through the clump of trees into a wood, and squeezed our way through the trees too close together, their foliage a thick canopy above our heads. We found a clearing in the wood, and walked along the clearing, in a world made of green. (Ocean 37) [... 
A gust of wind threw leaves and dirt up into our faces. In the distance I could hear something rumble, like a train. It was getting harder to see, and the sky that I could make out above the canopy of leaves was dark, as if huge storm-clouds had moved above our heads, or as if it had gone from morning directly to twilight. (Ocean 38)

$[\ldots]$

I did not know where we were, but I could not believe we were still on the Hempstocks' land, no more than I believed we were in the world I had grown up in. The sky of this place was the dull orange of a warning light; the plants, which were spiky, like huge, ragged aloes, were a dark, silvery green, and looked as if they had been beaten from gunmetal. (Ocean 40)

In these few pages, Lettie and the narrator travel from a pleasant land of abundant greenery, still clearly on the farm, into a dark and foreboding place of margins and monsters. The color details in these passages indicate the narrator's growing sense of fear: the "world made of green" giving way to a "twilight" which in turn gives way to a sky the color of "a warning light." In a sense, Gaiman's careful persistence in describing his characters' progression into a fantasy world stands as a direct challenge to his reader: the reader may or may not have anticipated this complete immersion into the fantasy genre, but the sensory details highlighting shifts in colors and impressions of plants and sky urge the reader into an acceptance of these events. Whereas prior to this "passage" passage, the novel had only hinted at magical/fantastical elements (namely in the Hempstocks' uncanny ability to know what people were thinking and to predict future outcomes), this is the first instance of unmistakable fantasy in a novel that is also very much invested in the sensations and perceptions of a child's real world. 
This shift from reality to fantasy in the above scene serves as an illumination of the experience of reading itself: the book-world invading the reader's world as the two become forever simultaneously codependent in the reader's experience and memory of that experience. The journey of the reader of Ocean — and of books in general — is both gradual and immediate once the choice is made to undertake the journey, and in order for an immersive reading experience to occur, readers must allow for their own immediate worlds to fade to the background. In direct connection with these physical and mental journeys, the "Reading as an Encounter with Nature" metaphor stimulates the reader's sense of the worlds the narrator is journeying to, from, and between. The very sensuality of the childhood memories the narrator relates bring them closer to the reader in an association of childhood with richness of detail. The Hemstocks' farm, the narrator's house, the yard, the garden, the bedrooms, the food, the fieldsall are convincingly available for the reader's encounter, and the narrator's past dictates their present presence. Similarly, when the natural world of the typical British farm gives way to a distinctly unnatural world of orange sky, frightening creatures of flapping fabric, and black cats pulled out of ponds by their cat-tails, the fantasy elements of a completely other world invade the realistic elements of the one the reader has grown accustomed to-a world which itself has invaded the reader's world. And at the novel's end, just as the natural world's phantasmagoric alterations signaled an entrance into the other world (or signaled that the other world had now entered the real one), its recession signals the narrator's (and the reader's) return to reality: the impossible ocean once again becomes a pond, the two moons in the sky revert to one, and the second Mrs. Hemstock in the yard disappears leaving only an old woman; both the narrator and the reader are left with the decision of which story to believe, cued by the natural and the unnatural sensory details of these opposing worlds. 
Foremost of these sensory cues of the natural and unnatural worlds are those involving food and eating. Ocean is almost overwhelmingly a gustatory-focused novel, likely to pique the appetites of the most satiated reader, and its descriptions of food are noteworthy in their ability to situate and naturalize the sensations of the narrator with his world. The novel's first depiction of food and eating begins with a birthday cake topped with a book in icing - a cake which symbolically sets the narrator apart from other boys his age by highlighting his preference for reading over physical activity. The cake is mostly uneaten because no one comes his party, and the narrator himself is more interested in the actual books he receives as presents than the bookcake. Food as foreshadowing occurs most noticeably in the dichotomy between the food provided at the narrator's own home- - beginning with the burnt toast with peanut butter served to him by his father, and the rich, delicious country food given to him by the Hempstocks. Both types of food, even food that the narrator refuses to eat, are connected to his sense of the past. Although his memories of the more significant events have faded, the narrator reassures us that certain visceral, sensual memories remained "after I had forgotten everything else" (Ocean 20). It is to these that the narrator, and the reader, cling for clarity and sense of place-so much so that these specific, detailed memories of food largely come to stand in for childhood and childhood memory in general. At one point, the narrator claims to "not miss childhood," but goes on to say that he misses "the way I took pleasure in small things, even as greater things crumbled... I found joy in the things that made me happy" (Ocean 149). And in eating his first meal at the Hempstocks' farm, the narrator claims to have been "as happy as I have ever been about anything. It tasted perfect" (Ocean 20). From this simple detail, the reader is assured that the Hempstocks are good and trustworthy, and the rich descriptions of the food they provide for the narrator never wavers from this conviction. 
The food the narrator enjoys at the Hempstocks' comes both before and after traumatic events in the narrator's life and gradually increases in substance as the story progresses. His first meal there follows his first major shock — that of seeing a dead body in his father's mini, parked down the lane, outside the Hempstocks' farm, As dairy-farmers, naturally the first item the narrator is given there is from Old Mrs. Hempstock: "a cup of creamy milk from Bessie the cow, the fresh milk before it had gone through the cooler. Nothing I had drunk had ever tasted like that before: rich and warm and perfectly happy in my mouth" (Ocean 20). Next is "warm porridge from the stovetop, with a lump of homemade blackberry jam" (Ocean 20). After his next major shock of waking up with a coin stuck in his throat, the narrator returns to the farm where Lettie makes him "paper-thin” pancakes with lemon and plum jam, and Old Mrs. Hempstock feeds him a lump of honeycomb with cream: "I ate it with a spoon, chewing the wax like gum, letting the honey flow into my mouth, sweet and sticky with an aftertaste of wildflowers" (Ocean 31, 34). After the narrator's near-drowning at the hands of his father and narrow escape from the clutches of Ursula, he is given the most substantial food yet following a hot bath and hot soup: "a joint of beef, with roast potatoes, golden-crisp on the outside and white inside, buttered greens I did not recognize, although I think now that they might have been nettles, roasted carrots all blackened and sweet... For dessert there was the pie, stuffed with apples and with swollen raisins and crushed nuts, all topped with a thick yellow custard, creamier and richer than anything I had ever tasted at school or at home" (Ocean 93). The generous fare provided to the narrator at the Hempstocks' farm seemed to be determined by the narrator's needs but is thoroughly rooted in the farm's location and self-sufficiency; this is no conjured Turkish Delight, but real food which has a real, wholesome effect on the narrator. The farm has its own beehive, its own milk churns and cooler, a chicken yard, a vegetable garden, 
and fruit trees. Ironically though, the Hempstocks themselves are guardians of the other world, and their farm, while completely homey and established within the natural world, is also the entrance to the other world. "'It's in the Domesday Book,"” Mrs. Hempstock says proudly of their farm - a detail which in and of itself becomes suspect as the narrator discovers that it's not just the farm that had been there since William the Conqueror, but its current inhabitants.

The pleasant and fulfilling tastes of the food served at the Hempstocks' directly contrasts to the dangerous, frightening food served at the narrator's home, made by Ursula. Ursula's presence in the real world (and particularly in the narrator's house) has made the narrator's home frightening. Meanwhile, the Hempstocks' farmhouse kitchen is "a friendly place" filled with pure, honest colors of yellow daffodils, a red floor, gray flagstones, and whitewashed walls (Ocean 31, 34). Later the purring of cats and a warm fire complete the comfortable and homey feeling of the kitchen, and the narrator says that, "It was if the essence of grandmotherliness had been condensed into that one place, that one time" (Ocean 92). The presence of wholesome, delicious food made and provided by the mysterious Hempstock women in a safe, familial setting undoes the narrator's normal experience of being "scared of eating food outside my home, scared that I might want to leave food I did not like and by told off," since "the food at the Hempstocks' was always perfect. It did not scare me" (Ocean 147). It is here in this place of shelter and protection that the narrator feels truly safe, in direct contrast to his actual home where he is locked in his room and served food he dare not touch for fear Ursula had poisoned it. "I was starving," the narrator comments, watching his sister eat food Ursula had made; "I wondered whether the sandwiches were dangerous or not. I did not know. I was scared that I would eat one and it would turn into worms in my stomach, and that they would wriggle through me, colonizing my body, until they pushed out of my skin" (Ocean 55). Later, the narrator's refusal 
to eat Ursula's food causes a devastating rift between the narrator and his father. After first claiming to not be hungry — even though he was "so hungry it hurt" - the narrator finally confesses that he "“won't eat anything she made,"” using Old Mrs. Hempstock's name for Ursula's kind: a flea (Ocean 69-70). The narrator's near-drowning at his father's hands as a result of this insult is a scene filled with intense sensory details which also has a direct parallel to descriptions of the narrator's warm and fortifying bath at the Hempstocks' farm (Ocean 71-73; 92-93).$^{98}$ While both scenes contain a sense of "wrongness" for the narrator (in one, his father breaking open the locked bathroom door and holding him under cold water, and in the other, the Hempstocks having him undress and bathe right there in the kitchen), it is only at the Hempstocks' that this sense of wrongness is cast aside by their indifference to his nakedness. The narrator's vulnerability is not taken advantage of here in this homey, wholesome place the way it is at his actual home by Ursula and his father: the former locking him in his room and threatening to keep him in the attic and do worse, the latter bullying him, belittling him, and physically hurting him. In "Not at Home: Examining the Uncanny," Yaeri Kim sums up this inversion in the narrator's experience as "the commonsensical world of the everyday [...] portrayed as incomprehensible and unsettling, while fantastic creatures and events are often depicted as familiar and reassuring" (154). But it is the narration's sensory details of these scenes - particularly the directly conflicting details of safe and unsafe food — that allow the reader to experience this shift on a visceral level as a distinction between safety/abundance and danger/starvation.

\footnotetext{
${ }^{98}$ Being held under the cold water with his clothes on by his father is "wrong. The bathwater was cold, so cold and so wrong" (Ocean 72). Although initially modified at having to get undressed in front of "people I didn't know," the narrator's bath at the Hempstocks' kitchen in water of "the perfect temperature" while drinking rich, hot soup was "a perfectly new experience" that leaves the narrator with feelings of safety and a revised appetite for their delicious dinner (Ocean 91-93).
} 
Beyond mimicking and signaling shifts in the reader's experience of the novel, the dual availability of both sets of sensory details - those of the familiar, real world and those of the strange, other world — offers a series of choices for the reader of Ocean: most immediate, is the choice of whether to read this story literally in acceptance of its fantastical and magical elements or to read the story allegorically as a retelling of childhood trauma in "story-shape." 99 Since the novel supports both readings and allows for multiple interpretations of the veracity of its events given the narrator's own layers of remembering, misremembering, and forgetting, the reader is drawn to consider a middle region of mutual acceptance of both the reality and the fantasy (i.e. the details of childhood memories alongside the mythic unveiling of the universe's fantastical underpinnings). But as a result of its metafictionality and emphasis on the role of journeys, Ocean can also be read as a story about the value of momentary escapes from the real world (such as those achieved through reading); it can be a fantasy tale that becomes mythic, standing between childhood tales and adult books; and it can be a conformation that stories are a way to simultaneously relive childhood and honor its role in who we are now. ${ }^{100}$ Regardless of whether the reader chooses to accept the fantasy alongside the realistic and the past alongside the present, the novel implicitly recognizes that the reader will ultimately have to put the book down and return to a life which perhaps has the illusion of a second moon, but is still comprised of the everyday demands that makes up the reader's normative experiences. As such the novel holds up

\footnotetext{
${ }^{99}$ In Gaiman's short-story “The Flints of Memory Lane," a similarly-unnamed, adult narrator struggles to put a frightening encounter from his childhood into something that makes sense and provides a sense of closure. In failing to do so, the narrator proclaims that "like all eruptions of the odd and strange into my world, the event sits there, unexplained. It is not story-shaped" (68).

${ }^{100}$ Critics, reviewers, and readers of this novel have been fascinated by its deep well of autobiographical details and imagery, as confirmed by Gaiman in numerous readings and interviews. While clarifying that the novel is indeed fiction, Gaiman also adds that "I had to plunder my memories... everything is grabbed and smashed and moved... because I'm enjoying the power of fiction." (quoted from book unveiling and reading event in NYC, July 2013)
} 
the possibility that the reader can take stories with him—stories that make his life better and more significant — even if those stories are not entirely at place in a rational universe. That the narrator himself has forgotten his most significant story - that of how he got to where he is and what his life is worth to someone who loves him - is demonstrative of what a life without stories could stoop to: loneliness, loss, and emptiness. The reader wants the narrator to remember this time, even after realizing that this cycle of memory and forgetfulness has happened so many times before, or, at the very least, the reader wants the narrator to be able to hold onto the hope his story brought him. Significantly, it is only the reader who has been fully transported to and in the world of the novel who will be able to accept this final lesson of the narrator's journey: escapes from the real world are not weakness; sometimes they can even provide us with our greatest strengths; but the escape will always lead us back to the world we came from - though hopefully all the better for having experienced and lived in an other world. While the reader has to go back to his own world at the end of the story, he doesn't have to go emptyhanded.

The importance of understanding the truth about fictional and metafictional journeys between world, and back to our world of origin, is equally significant within Murakami's Kafka on the Shore. The title character's journey begins as an attempted escape from a horrific, Oedipus-like prophecy which he fears will always order his life. Unfortunately, like Oedipus himself, Kafka's attempt to escape from his prophecy ends up bringing about the very events which fulfill it — of sorts. While Kafka remains an avid reader and even seeks refuge in a library, the end of the novel sees him facing his fears about himself as he decides to "grab [the prophecy] by the horns and fulfill the program that's been laid out for [him]" (Kafka 370). His journey home in the final chapter brings this Hero's Journey to a close with Kafka hopefully anticipating being "part of a brand-new world" (Kafka 467). 


\section{Journeys and (Un)natural Encounters in Kafka on the Shore}

It would be difficult to find an author more absorbed in the philosophy of motion and mobility than Haruki Murakami, also known as "the Running Novelist." In his memoir, What I Talk About When I Talk About Running (2007), Murakami has even claimed that "most of what I know about writing I've learned through running every day. These are practical, physical lessons" (What I Talk About 81-82). The frequency with which Murakami's works are imbued with layered utilizations of the "Reading as Journey" metaphor confirm the centrality of movement and travel in the author's conceptualizations of reading - a centrality which is translated to the reader of his work who will likely come to see herself as a traveler, or at least, a person always on the brink of traveling. ${ }^{101}$

Kafka on the Shore begins and ends with a journey and its reverse, a trip from Tokyo to

Takamatsu and back again, undertaken by the fifteen-year-old protagonist. This initial movement through space and time is nothing less than a hoped-for escape — both physically, as a son escaping from an abusive father, and metaphysically, as a young man escaping his destiny (or at least, attempting to). But such a journey invites other journeys-journeys that are less straightforward in taking characters not only to other places but to other worlds. As in Gaiman's The Ocean at the End of the Lane, "Reading as an Encounter with Nature," as a secondary

\footnotetext{
${ }^{101}$ Matthew Carl Strecher's careful analysis in The Forbidden Worlds of Haruki Murakami emphasizes the movements of characters of Murakami fiction as a whole into other metafictional worlds. Strecher's analysis suggests these worlds are always simultaneously characters' own deepest reaches of consciousness and memory as well as a kind of collective unconsciousness, what Strecher refers to as "the Narrative" (19, italics in original). [Incidentally, it is these movements that make Murakami so hard to quantify as a writer with "magical-realism," "fantasy," "surrealism," and "dream-fantasy" all used to describe his works.] Such world-travelling is largely prompted by the risk of characters' individual narratives being "threatened with being subsumed into a group narrative (but not the Narrative)," and can take all manner of appearances, such as falling asleep, walking into the woods, or climbing down a well (Strecher 19, italics in original). Strecher also points out that both worlds are completely necessary "to the overall development and well-bring of the individual" as well as the universe of the story itself (105). Kafka proves no exception to these trends.
} 
metaphor, structures these journeys between reality and fantasy (or the "real" and the "unreal") via sensory-rich descriptions of the opposing worlds of the novel and characters' interactions with these worlds. As the reader gradually discovers, characters' encounters with nature in the real world are complicated in their unexpected unreality: physical (i.e. definite, certain) encounters with the natural world are no longer dependable as an alarming number of unnatural, inexplicable events occur without cause-some in front of large crowds of witnesses so that the reader cannot easily resort to explaining the unnatural events as mere hallucinations. Fish and leeches fall from the sky, blood mysteriously appears hundreds of miles away from its source, a group of schoolchildren simultaneously fall to the ground unconscious while picking mushrooms in the woods, missing soldiers from a lifetime ago appear without having aged a day — these events suggest, instead of psychosis on the part of a single character, that the fantastical, other world's presence is increasingly upsetting the order of the natural world within the novel. And while only a few characters gain access to the other, fantastical world, its effects on the natural world are felt by many. In conjunction with these impositions, the traditional hierarchy of physical over nonphysical in determining the true nature of reality is flipped in that the intangible encounters experienced by the characters become more real and more sure than the natural ones. For the natural world to "make sense," the characters (and readers with them) must look to an alternate "natural" order at home in the unnatural world - a world which redirects the nature of the "real" world to suit its own, othered reality.

For many readers - especially those already familiar with Murakami’s work, the journeys demanded by Kafka ask too much and offer too little as a reward. Reminiscent of Nabokov's famed call for "re-readers," Murakami himself suggests a second reading—a second journey—is necessary, saying: 
Things should be clearer the second time around. I've read it, of course, dozens of times as I rewrote it, and each time I did, slowly but surely the whole started to come into sharper focus. Kafka on the Shore contains several riddles, but there aren't any solutions provided. Instead several of these riddles combine, and through their interaction the possibility of a solution takes shape. And the form this solution takes will be different for each reader. To put it another way, the riddles function as part of the solution. It's hard to explain, but that's the kind of novel I set out to write. (Murakami "Questions")

Throughout the novel, Murakami carefully crafts together the idea that stories construct a path which, once travelled, help us understand ourselves and the way we think about the world in the stories we are told, the stories we read, and the stories we tell about ourselves. Murakamitranslator and biographer, Jay Rubin, sums up the message of Murakami's writing as: "A life is what you make it. There's nothing exterior; there's nothing outside the brain. It's all inside $[\ldots]$ All of reality is in your synapses. The best thing you can do is just keep learning about the world, and whatever meaning it has is meaning that you assign to it" (Haruki Murakami). With this insight in mind, the physical journeys and interactions undertaken by characters acquire a greater significance in that all physical encounters are usurped by the metaphysical, other world of the text. Nothing — not Kafka's secret desires, philosophical musings, genetics, chosen pseudonym, or wet dreams - is sacred from the imposition of the other reality, all of which, of course, takes 
readers further into a world seemingly constructed of consciousness, memory, desire, and stories as opposed to physical matter. ${ }^{102}$

Similar to the readerly experience of Ocean, the fantastical elements of Kafka's other world do not occur all at once. Instead, the reader is gradually awakened to the realization of the other world's presence in the "real" world through a series of increasingly difficult events to reason away. In the novel's opening, a section titled "The Boy Named Crow," the reader must first come to terms with the presence of Kafka's alter-ego who (the reader realizes later) only speaks to him, much like a child's imaginary friend. But the reader's understandable impulse to conclude that Kafka is talking to himself (or a mental construct in his head) is complicated by the information that the boy named Crow has a "sluggish voice," is able to "smirk[] and look[] around" the room, "shakes his head," and can even "toy[] with a bee-shaped glass paperweight" from Kafka's father's desk — activities that do not easily befit the abilities of an imaginary person (Kafka 3-4). The next "fantastical" event the reader encounters in her narrative journey, arrives in the form of declassified Top Secret U.S. documents which tell about the strange events surrounding "the Rice Bowl Hill Incident" in 1944. But as these events are acknowledged by their primary teller as bizarre and inexplicable, the reader is likely able to accept them as exactly that: a perplexing mystery of things that happened long ago (perhaps attributable to a foreign military operation) as opposed to a jarring venture into fantasy (although, that's exactly what it is). Continuing without blatant fantastical eruptions for some chapters, the reader is next confronted by the seeming impossibility of an old man, Nakata, who can talk to cats. The reader

\footnotetext{
102 Kafka, the reader discovers, is not actual the protagonist's real name, but an assumed one. Betiel Wasihun's “The Name 'Kafka': Evocation and Resistance in Haruki Murakami's Kafka on the Shore" provides a fascinating analysis of the uses of "Kafka" in the novel. Wasihun's conclusion concerning the painting passage is that "Kafka' has become a general icon of modern literature, or to be more precise, an icon of modern world literature... One need not even read Kafka... in order to live in a world that recognizably presents itself as 'Kafkaesque'... At the very least 'Kafka' has come to represent some aspects of our perceptible reality_regardless of what 'the real' might bethat we are not able to articulate but that strikes us with its familiar and disconcerting strangeness..." (1205).
} 
could possibly read this latest occurrence as the ravings of an eccentric old man, but it is more likely that this fantastical event will also be finally accepted by the reader due to the character's own fumbling admittance of shock that he was able to speak to cats in connection to a childhood "accident" that made him dumb in every other way — an individual abnormality as opposed to presenting this ability as normal or natural. Also, the narration's depiction of the cats' side of the conversation with Nakata likely has an ameliorating effect on the reader's acceptance; while cats do not speak overtly in the reader's world, the cats of Kafka speak, move, reason, and act in ways consistent with our imaginings of what cats would sound like if they could talk: they doze in the sun, enjoy tuna and other fishy treats, bask in (solicited) belly-rubs, don't worry about remembering dates and names, keep to set routines, are naturally suspicious of new things, and only a few choose to communicate with Nakata - many can't be bothered or are too scared of humans to listen. Essentially, they are still cats as the reader recognizes them. So far, so good; the natural world of Kafka has proven strange, but not entirely incompatible with our own world or internally inconsistent to the extent that the reader will call foul. That is until the shrine scene.

Even if the reader thus far has been able to accept the gradual appearances of the fantastic in the novel's initially realistic world, Kafka's unexplained memory lapse and bloodied appearance at a shrine in the middle of the night should cue the reader's need for a reevaluation of the novel's status as "realistic with dashes of fantasy." Much like the "passage" scene of Ocean in which the narrator is taken into the fantasy world which will dominate the rest of his experience until the end of the novel, Kafka's bizarre, vicariously-enacted murder of his own father is the point of no return. This is the first instance of an impossible physical journey (how could Kafka have gotten to Tokyo to kill his father and awake at a shrine hundreds of miles away?) which signals a central theme of the novel: namely, that body and self/soul are not 
always linked together in the physical realm. From here, the reader encounters other impossible "natural" phenomenon in the form of metaphysical beings taking on the appearance of American icons of consumerism (Johnnie Walker and Colonel Sanders); a flute made of cat souls; a dangerous forest that can lose armies; blood disappearing and reappearing somewhere else; mackerel, sardines, and leeches falling from the sky; a ghost-girl who is the preserved memory of a living woman; and an entrance stone which is the key to all of it, opening and closing the pathway between worlds. The point at which the reader finally decides to shift her impression of $K a f k a$, as a novel, from natural/realistic to fantasy, is the moment she will begin to seek elsewhere for answers not found in the natural world of the novel. This shift necessarily requires an embrace of Kafka's (and Kafka's) journey into the other world in which inexplicable events and relationship have some explanation it that world's othered logic.

Where Kafka largely differs from Ocean is in its need for balance between the two worlds themselves and characters' journeys between them. While the narrators of both Ocean and Kafka must leave their responsive other worlds to return to their respective real worlds, in Ocean the portal to the other world is essentially left open forever, guarded by the Hempstocks who were there for the Big Bang and will be there until the end of the world. In Kafka, the entrance to the other world must be closed in order for things to return to their proper order and place; there must be a balance of energy between these two worlds that prevents the dominance of the metaphysical over the physical and vice versa. For instance, when Miss Saeki opened the entrance stone to prevent her "“perfect, private world from collapsing," it caused distortions in ways she could never imagine (Kafka 392). Although a full description of the various consequences are not given, the reader does discover that the opening of the entrance stone is the reason Nakata had to take Kafka's place in murdering his father; it is also the reason for Nakata's 
missing memories and half a shadow which, not coincidentally, parallels Miss Saeki who also has only half a shadow and has been doomed to live in her past instead of in the present; finally, Miss Saeki's opening of the entrance stone forty years ago is the reason that Nakata must now open and close it again - to "'restore what's here now to the way it should be"” (Kafka 390). This is not to say that the other world is bad or evil, only that it has a dangerous, unpredictable effect on the real world, and as such, must be held in check. Although Kafka himself is not the one to accomplish this task, his final decision to return to the real world and to his place in it is the necessary, parallel journey to his initial metaphysical escape from his identity and destiny in the novel's beginning. In Kafka, as in Murakami's fiction in general, there must also be a balance in physical movements and journeys which possess great significance for individual lives as well as for a global sense of fate or destiny: sometimes these movements are cyclically balanced, as in Kafka's life at the library in which every day follows the same routine; sometimes they are linear and balanced by their inverse as in Kafka's return to his home at the end of the novel to begin his life again. Human lives, and Murakami’s human characters, require both types of symmetry just as Murakami’s worlds require equilibrium.

Looking at Kafka from a metafictional perspective, characters' interactions with eruptions of the other world in their real world can simultaneously be depictions of the reader's interactions with the other world of the narrative - and any narrative in which she accepts the proffered journey to another fiction-wrapped world. The prickling of unreality in the reader's reality occurs beneath the surface of the observable world: the reader seeing new connections between physically disconnected things as a result of the bridge of the narrative. Simply put, narratives allow readers to break the rules of forging present, personal connections between sensation and cognitive. Similarly, the form of the other world in Kafka does not follow the rules 
of the natural world - and why should it? Just like narratives, because it doesn't exist in the physical world, the other world of Kafka can take as many forms and appearances as there are people wanting to enter it. For Miss Saeki, the woman looking back on her opening of the entrance into the other world as a young girl, the other world is just a room, much like the room Kafka is housed in at the Komura Library. The purpose of Miss Saeki's other world (that is, the form that the other world takes for her) is to preserve forever the most important memories of her past: her long-dead childhood lover at the time before the two were separated. "'All I wanted was to go off to some other world, a place beyond anybody's reach. A place beyond the flow of time... Because I knew that I would never be happier than I was then," she tells Kafka who has actually seen the "ghost" of her fifteen-year-old self preserved in such a room (Kafka 250-251). Although she is reticent to admit it, Miss Saeki opened the entrance stone and anchored her memories and desires to the room previously occupied by him and now filled with mementos of their childhood together, forming a lacuna in time (although the novel never uses this term) which overlaps with the physical room. Unfortunately, using the other world for this purpose results in a great deal of pain. As Miss Saeki discovers, people are not meant to lock away their memories in this fashion because it dooms us to a life that is "merely a series of endless reminiscences, a dark winding corridor leading nowhere"' (Kafka 392). It is significant to note that in her opening of the entrance stone, Miss Saeki did not create the other world; it is bigger and older than her and her desires for total stasis; it is world open to everyone who seeks it and able to change to meet the needs of its seekers.

For other characters, including Oshima and Kafka, the entrance to the other world takes the form of a journey in the woods. Unlike Miss Saeki's other world, the entrance is not a simple, open door but a frightening venture into the unknown; the journeyer has a choice of how 
far and how deep into the other world he or she wants to go. Before Kafka's furthest and final trip into the other world, Oshima warns him about this journey: “"There's another world that parallels our own, and to a certain degree you're able to step into that other world and come back safely. As long as you're careful. But go past a certain point and you'll lose the path out. It's a labyrinth"' (Kafka 352). Significantly, Oshima tells him, it is a labyrinth that parallels the one inside you: “Things outside you are projections of what's inside you, and what's inside you is a projection of what's outside. So when you step into the labyrinth outside you, at the same time you're stepping into the labyrinth inside. Most definitely a risky business" (Kafka 352, italics in original). But Kafka, unable to help himself, decides to go in anyway. In preparation for the journey, he first outfits himself with normal hiking tools befitting a journey in the physical world: a poncho, compass, knife, canteen, food, gloves, spray paint, hatchet. And initially the journey is much like his other, briefer journeys into these woods; he is able to maintain his general direction, make good time, and mark an obvious trail to follow to get back out again. But the forest soon broaches into the uncanny once he goes beyond familiar territory. There are weird, out-of-place sounds: "a thud like something hitting the ground, a creak like floorboards, groaning under weight, and others I can't even describe" (Kafka 383). Every sound he himself makes seems to echo. The feeling of the woods becomes oppressive, like he is being watched. Finally, Kafka reaches "a dead end in the maze" (Kafka 387). He finds himself seriously considering suicide, his blood and DNA "rotting among the weeds," and his "battle" with the prophecy finally over (Kafka 388). In this moment of intense personal struggle, Kafka attempts to "find [his] center" which suddenly appears to him as "a break in the dark clouds, like looking out the window to see the leaves of the dogwood gleaming like a thousand blades in the moonlight"; once he reaches this moment, he unthinkingly drops his supplies-the equipment 
that ensured his safe return from this journey — and travels on completely vulnerable to the forest (Kafka 288).

In a strange combination of sensory detail, Kafka finds that, while continuing to walk in the woods, he is also "walking by the shores of consciousness... try[ing] to quickly read what's written there, between one wave and the next" as his mind puzzles through the familiar questions of his past, his family, and of why his mother abandoned him. The ocean-side imagery hearkens back to other familiar images from earlier in the novel in which the shore represents the pastparticularly Kafka's only happy memory of his actual past—but also the past in which he is actually the childhood sweetheart of Miss Saeki — the past captured by the painter of "Kafka on the Shore." This combination of the deep woods with the open shore suggests that one metaphor is not enough to capture the intricacies of consciousness: even while fully immersed in the "labyrinth" metaphor of mind, Kafka's thoughts strike out for more ways connections, more nuance in his quest for self. In casting down his physical tools, Kafka has finally let down all physical and mental guards in his willingness to accept whatever answers-whatever imagery, symbols, metaphors, signs - the other world can give him regardless of whether they make sense in the real world. It is only after this pivotal moment that Kafka finally finds the two soldiers who guard the entrance to the town hidden deep in the mountains. Although they warn him that “"once you're in, it isn't easy to turn back," Kafka decides he needs the answers more than he needs a definite way back to the real world. He presses on.

At the end of this trial, both mental and physical, is the town—although Kafka isn't sure it can be called a town. There are roads and small buildings, but no shops, signs, bulletin boards, gardens, or trees - or people, for that matter. The town has electricity though and even old TVs, which according to the soldiers, were provided more recently for the newer residents who 
wanted such things. Later Kafka discovers that the town's residents, including the fifteen-yearold Miss Saeki - the same girl he saw in the library, exist outside time, but are still connected, albeit tenuously, to the real world. The soldiers eventually explain that even this place is not as far in as its possible to go into the other world: "'We're not cut off from the world here. There is a somewhere else"” (Kafka 218, italics in original). For a moment, Kafka has a vision of the town as "a space where emptiness and substance neatly overlap, where past and future form a continuous, endless loop" (Kafka 416). He understands that he is in a threshold between the worlds, which explains how the recently dead are able to momentarily be present there. And this version of the other world, like Miss Saeki's room was to her, is perfectly suited to Kafka's individual needs: he has to physically exert himself to reach it, he gets to see for the last time the girl he has fallen in love with, and, most importantly, he is able to question the woman he believes to be his mother about why he was abandoned as a child, and to forgive her in place of his mother and in place of the person she abandoned.

The pseudo-permanent town discovered by Kafka balanced on the edge between worlds hints at the other world's broader designation as the afterlife. After all, it is the final destination of Miss Saeki - and possibly Nakata — after death. But the fact that the other world can manipulate its nature to suit the needs of individual seekers makes it impossible to ignore its connection to consciousness, desire, and memory on an individual level. The other world remains throughout the novel a mysterious place outside of time and space, primarily utilized by characters for the storage of memory and the creation of necessary connections via metaphors for relationships that, for whatever reason, do not exist in the real world. In this way, the other world is strongly connected to the library—both the particular Komura Library where Miss Saeki first opened the entrance stone and to the idea of a library in general. The library as an overarching 
metaphor for the other world works on various levels. It is a place where information, memories, and lives are stored and able to be accessed and re-accessed by readers. It is also a place of personal memory: a "“little room where we store those memories. A room like the stacks... and to understand the workings of our own heart we have to keep on making new reference cards"' (Kafka 463-464). As Oshima suggests here, each reader will gradually build up his or her own library: a place to store narratives, memories, and connections, accessible to the reader as needed to provide support for dealing with the real world. Kafka teaches readers that regardless of whether they think about why they choose what they choose to read, the stories they take in become part of their journey and come to inform the way they interpret and understand the world around them. Consciousness as " "your own private library"” also stresses personal choice and agency: if you choose, your mind can be a beautiful and useful place to live, but you can also choose to neglect it, resulting in dust, stale air, dead flowers, and outdated reference cards. Reader be warned!

The actual benefits of viewing one's readings as forming a personal library of the mind are frequently demonstrated by the characters of the novel, especially Kafka. Miraculously (or not), Kafka continuously finds that the books he chooses at random to read come to have meaning in his life beyond what he could have anticipated. ${ }^{103}$ Over and over, the stories he reads come to dictate the way he sees and understands the world. For instance, in his reading of The Arabian Nights, Kafka discovers a sense of reality he feels is lacking from the hectic, everyday

\footnotetext{
${ }^{103}$ Beyond the books that Kafka himself reads over the course of the novel are the stories and concepts that are repeated and contemplated in conversations with other characters: Aristophanes in Plato's Symposium (Kafka 3940); Franz Kafka's "In the Penal Colony" (Kafka 58); Schubert (Kafka 110-112); Cassandra the Greek Diviner (Kafka 153-154); Sophocles' Electra (Kafka 178); T.S. Eliot's “hollow” people (Kafka 181); Sophocles' Oedipus Rex (Kafka 199-202); Yeats (Kafka 204); The Tale of Genji by Murasaki Shikibu (Kafka 225); Ueda Akinari’s Tales of Moonlight and Rain (Kafka 226-227, 284); Henri Bergson’s Matter and Memory (Kafka 273); Hegel (Kafka 274); Chekhov (Kafka 287-288); Haydn (Kafka 297, 328); Rousseau (Kafka 315-316); Beethoven (Kafka 325-327, 356359, 376-379); François Truffaut's The 400 Blows (Kafka 327-329, 420); the "labyrinth" of ancient Mesopotamians (Kafka 352, 396-397); Berlioz (Kafka 379); and The Sound of Music (Kafka 419).
} 
world around him in that the deepest desires of humanity — sex, violence, freedom, and life — are given haptic vitality on the pages. In Soseki's The Miner, Kafka is presented with the idea that passivity and a reluctance or inability to change is closer to how people are in real life - a truer explanation, he feels, than the typical bildungsroman tale of growing up and overcoming difficulties through change, and a good depiction of Kafka himself. Kafka also mentions the lack of certainty at this novel's end as being the reason why the story is able to impact its readers: “"It's like not really knowing what he's getting at is the part that stays with you"” (Kafka 106) perhaps Murakami's nod to current readers of Kafka and a warning of what's to come. The question of responsibility deriving from his reading of a book on Adolf Eichmann speaks to Kafka's questioning of his own sense of responsibility in the Oedipal curse he is caught up in. And his reading of the deadly and exhausting journey of the soldiers in Napoleon's doomed advance returns to Kafka's mind in his own uncertain march through the forest he had been warned could absorb him whole (Kafka 367, 385).

When reading truly absorbs, transports, and moves readers, they are in a sense torn apart and rebuilt again from the inside out, only with something new added: the story itself. Some gaps are filled that were empty before, not with words alone, but with doubled sensation (both immediate and vicariously experienced) and with a sense of meaning. Kafka pushes readers to see stories as both a way to understand their own existence a little better and as a guide into developing a more discerning scale of meaning in their lives. But readers shouldn't be surprised if there's no easy way to talk about their reading experience of Kafka just as Kafka finds that even to someone who has had a similar life-changing experience in the mysterious forest, it isn't something that can be talked about: "'It's not something you can get across in words. The real response is something words can’t express"” (Kafka 459). Sada agrees: "'Better not to try to 
explain it, even to yourself"' (Kafka 459). These lessons show why reading and storiesespecially stories about and for the need to escape — matter, and why readers can take so much away from reading without exactly being able to explain how reading "makes them a better person," etc. It's not a simple action-response relationship. Reading is, according to Kafka, a metaphor whose interpretation we each get to decide for ourselves. And as Kafka says to Miss Saeki, “"Metaphors help eliminate what separates you and me”" (Kafka 294).

\section{Journeys and (Un)natural Encounter in The Strange Library}

Murakami's The Strange Library makes for an interesting counterpoint to Kafka on the Shore, to say the least. Its more recent picture-book edition is slightly modified from its original short-story version, "Toshokan Kidan" (Jap: "The Strange Story of the Library"), published in 1983 and never translated into English. Significantly, the picture-book version, Fushigina Toshokan (Jap: "The Strange Library") was published in Japan in 2005, the same year the English translation of Kafka on the Shore was released. ${ }^{104}$ In 2014, The Strange Library was reformatted with a different font and images—-some of which could be mistaken for 3D Optical Illusions Art—-before being published in English.

The close relationship between The Strange Library and Kafka on the Shore, initially suggested by the proximity of their publication dates, goes beyond similarities in characters and locations, of which there are: libraries, librarians, reading rooms, readers, mysterious "ghost" girls, big black dogs, birds to-the-rescue, and other corresponding images. As in Kafka, there are multiple overlapping worlds which in turn affect and balance each other in The Strange Library. Characters' journeys between these worlds unsettle and resettle this balance further, and, as in

${ }^{104}$ Umibe no Kafuka (Kafka on the Shore) was originally published in Japanese in 2002. 
Kafka, the protagonist of The Strange Library must overcome bizarre obstacles in order to survive these journeys, but is still left with an enduring sense of guilt, trauma, and loneliness that must be dealt with beyond the end of the storyline. Life and its events are seemingly random, and the protagonist is without a logical framework to make sense of his life and the conflicting sensory details of the "real world" and the world created when he reads. In fact, as is the case for many readers, these created reading worlds, which exist in a metaphysical realm, seem to make more sense than his life in the physical one. Unfortunately for the narrator of The Strange Library, the imagined world created through reading is not one that ultimately provides any lasting peace or growth or even self-knowledge. While the reading-narrator is exposed to a new world of sensory encounter and escape in his reading, nothing significant results from this experience, and overall, reading and books becomes aligned with trauma and darkness. Such an alignment is suggestive of a similar danger for real life readers: that of the reader's and reading's potential separation from meaningful interactions in the real world - and worse, the loss of reading's magic to provide a journey for the reader when utilized for the wrong reasons.

The story begins with the narrator-protagonist entering a public library (as opposed to Kafka's private library) to return two books, How to Build a Submarine and Memoirs of a Shepherd. The very first line of the story, "The library was even more hushed than usual," sets up the possibility for an unusual event to unfold, but one that hardly any reader could conceivably predict, for this is no ordinary library. (Or rather, as the narrator discovers, libraries as a general rule are not as ordinary as we have come to believe.) Readers are also quick to discover something of the oddity of the narrator-protagonist himself: he has broad and unusual reading habits, first detectable from the titles of the books he returns, and then later in the topic of books he requests from the old librarian: "I want to learn how taxes were collected in the 
Ottoman Empire,"” he says (Strange Library 9). The narrator is made uncomfortable, however, by the librarian's agreement that tax collection in the Ottoman Empire is "“a fascinating subject if there ever was one!'” (Strange Library 9). He confesses to the reader that:

I wasn't all that eager to learn about Ottoman tax collection- the topic had just popped into my head on my way home from school. As in, I wonder, how did the Ottomans collect taxes? Like that. And ever since I was little my mother had told me, if you don't know something, go to the library and look it up. (Strange Library 10).

Reading is thus set up as a kind of duty in that the narrator is compelled to read about whatever accidental topic pops into his head out of a sense of obligation to her mother's commands and not out of a personal desire for enlightenment or pleasure. It would also seem that the narrator's journey into books is not one of sensory encounter or engagement — at least not at first—nor is it sought out of a desire to escape or journey into the self and the inner-workings of the world around one's self. Instead, reading is about fact-finding — and seemingly, the more academic and impractical, the better - a task which the narrator performs fairly well, considering that his reading of Memoirs of a Shepherd provide him with the incidental knowledge that shepherds must "stick to their schedule" for the sake of their sheep's sanity (The Strange Library 3). (He does not, incidentally, mention or use information from his submarine-building book.) Interestingly, these early thoughts concerning the purpose of reading come to directly contradict the narrator's intratextual experiences of reading while locked in the dungeon underneath the library. This text does indeed come to tell the story of "reading to escape," but instead of the book providing a necessary escape from the horrors of the reader's world, reading is the tool for 
the reader to escape from his mandate to read and from the library he is trapped in, even while he simultaneously experiences fiction in a radically new and pleasurable way.

From the old librarian's office, the protagonist's plight goes swiftly downhill as he is led through the library's labyrinth-like basement to a "Reading Room," which he finds is actually a jail cell. There he is commanded to read and memorize his books (The Ottoman Tax System, The Diary of an Ottoman Tax Collector, and Tax Revolts and Their Suppression in the OttomanTurkish Empire) in order to be let out in one month's time. The sheep man, a prisoner himself and servant of the old man, confesses that the librarian will never really let the narrator out and that the narrator is being forced to read "because brains packed with knowledge are yummy," and the old man eats brains (Strange Library 37). The narrator naturally concludes that he'll have to escape and decides that reading the books he has been provided with is the best way to put his enemy off his guard. This pretense is, of course, a matter of doing exactly what the old librarian wants him to do: reading books, memorizing their contents, and flavoring his brain with the experience of that reading.

The narrator is praised for his reading efforts and is described by the sheep man and the librarian as an impressive boy for making such headway in his task despite his youthsuggesting that other, less fortunate reading-prisoners have not been so industrious. However, this praise seems to be only partially earned as once the narrator makes the decision to start reading, he seems to have no power over when he stops, putting the book down only when he is interrupted for a meal. Other strange aspects of his reading also emerge with no indication of whether they are caused by some power of the "Reading Room," the mysterious girl who visits him, or the old librarian himself. For instance, the narrator is surprised to find that although The Diary of an Ottoman Tax Collector is written in Turkish, he can understand it easily. 
Furthermore, the narrator finds that as he reads, "each page stuck in [his] memory, word for word. For some reason or other, [his] brain was sopping up everything that [he] read" (Strange Library 47-48). But most surprising of all is that the narrator actually becomes the character of the book he reads: the Turkish tax collector Ibn Armut Hasir. At first these accounts of reading seem to describe the normal reading experience of readers "becoming" the characters in a book, living their lives vicariously through the words on the page. But the narrator of The Strange Library seems to be able to affect and change the world of the book he reads just as it affects him, especially after he discovers that the mysterious, mute girl who has been bringing him food in the cell is actually one of the characters in his book. This unique readerly experience of "becoming" a character in a book is also, significantly, filled with deeply sensual imagery and sensation for the narrator:

The air was filled with the scent of fruit and chickens, tobacco and coffee; it hung heavily over the city, like a stagnant river. Hawkers squatted along the streets, shouting out their wares: dates, Turkish oranges, and the like. (The Strange Library 48)

I walked the streets of Istanbul during the day, collecting taxes, but when evening came, I returned home to feed my parakeet. A razor-thin crescent of white moon floated in the night sky. I could hear someone playing a flute in the distance. Have lit the incense for my room, my African servant moved about, chasing away mosquitos with something that resembled a flyswatter. (The Strange Library 60). The narrator, while Ibn Armut Hasir, sees, smells, hears, tastes, and touches the other world that he enters while reading, in the same way the original Hasir writes of doing in his diary. These 
pleasurable experiences wandering around the streets of Istanbul in another man's body and returning home to that man's luxurious life, directly contradict the narrator's experience in his own body locked inside a cell deep in the bowels of a library, chained to his bed, forced to read and memorize three thick books, meeting strange, otherworldly people, all while facing imminent death.

Vicariously, the reader of The Strange Library is also pulled into the alternating pleasant and unpleasant depths of the story as the sparsity of the text and the tactility of the adjacent images compete for the reader's attention. While the images can be seen as tangentially illustrating the text of The Strange Library, they also present their own interpretation of the reading experience, independent of the text. For instance, page two's drawing of a man's black dress shoe overlaid with Japanese characters, compliments the previous page's mention of the narrator's "new leather shoes" which "clacked against the gray linoleum" making a "hard, dry sound," but it also foreshadows the narrator's later anxiety about having to leave behind his shoes, given to him by his mother as a birthday present, because he fears their loud squeaking will foil his escape attempt (The Strange Library 1-2; 70-72). The close-up image of a monstrous green eye surrounded by dark animal fur is another instance where an image both corresponds to the immediately adjacent text (this time, the narrator's account of getting bit by a big black dog as a child), while also anticipating a later event in the book (The Strange Library 54-55). In this example, however, an identical picture of the earlier image of the green eye is used later, coinciding with the appearance of the librarian's big black dog in their final showdown — leading the reader to wonder whether it was the same dog all along (The Strange Library 81). Altered versions of the image repeat three more times while the dog's eye is gradually covered by an origami-square image of a white bird (The Strange Library 83, 85, 87). By the fourth time, the 
entire image of the eye is blocked out as the bird comes to take up two facing pages without any text, representing both the dead bird's actual swelling in the jaws of the dog (described in the text) and the bird's defeat of the dog and the librarian (The Strange Library 88-89). In only one other instance are two facing pages completely taken up by images in a juxtaposition of half a full-moon and half a doughnut (The Strange Library 62-63). Both of these images appear elsewhere in the text, the half doughnut corresponding to the sheep man's tray of homemade doughnuts which the narrator declares to be "'the best doughnut I've ever eaten,"” and the half of a full-moon corresponding to the appearance of the new moon which "will shape our destinies," according to the girl (The Strange Library 58; 61). Together these two halves make up a whole which symbolizes the hoped-for escape of all three characters: the light of the new moon reputedly lulling the librarian into a deeper sleep than usual; the narrator's promise to the sheep man to help him open up a doughnut shop; and the trio's hope for companionship, fullness, and escape.

These images, which alternatively portray recognizably Japanese "retro" art, modified photographs, cartoonish drawings, Mandela-like figures, and geometric patterns with a combination of Japanese and English words occasionally overlaying then, continually remind the reader to consider what is seen while reading while simultaneously shaping that experience by supplementing the reader with representational but not totally illustrative images. ${ }^{105}$ For instance, the law of the library — that internal texts not be removed from the library — premises the narrator's imprisonment in the Reading Room and also appears on the spine of the text itself. If

\footnotetext{
${ }^{105}$ Interestingly, the Japanese version of The Strange Library (Fushigina Toshokan) contains an entirely different set of images in the style of cartoon drawings which directly illustrate the textual scenes on their surrounding pages. These illustrations also include two images of the book world within the story and the narrator as Ibn Armut Hasir surrounded by the textual world of the Ottoman Empire brought to life with fruit, monkeys, and his beloved, parakeet.
} 
The Strange Library is a book that is "for internal use only," then the reader's experience can be seen to parallel the narrator's in that the knowledge of the story will stick with the reader, making his brains "yummy" and more palatable for old librarians — or even authors— to slurp down.

Overall, the reader's encounters with the diverse images of The Strange Library in combination with the text itself creates varied overlapping interactions with the narrative as a whole. Like the narrator's reading of The Diary of an Ottoman Tax Collector, the images encourage a reliance on multiple senses (and therefore interpretations) by the reader, especially in their hapticity: the purple-black of the hairs surrounding the green eye, the illuminated sugarcoating of the half a doughnut, the pock-marks on the half a moon, the blurred moiré patterns of images juxtaposed with sharp textboxes, the mazes and maze-like repetitions which draw the eye to follow them, etc. As a result, a combination of sight and touch are almost overwhelmingly demanded of the reader of The Strange Library. But there is also a pull on the senses of taste and smells (the illuminated sugar of the surface of a doughnut; the pixelated nose and mouth on the slip-cover), and the sense of hearing (the clock striking the next hour; the close-up drawing of a child's cheek and ear). These overlapping combinations and competitions for sensory engagement suggest a full-bodied reading of the story is essential to its experience, in direct parallel to the narrator's reading of his own book. Whereas prior to his imprisonment in the library, the narrator does not appear to have a sensory encounter with the books he read, now he has the ability to truly enter into a story, allowing for fully embodied encounters with the sensory-rich natural world within the book. This is the type of reading which makes brains "yummy," in that the knowledge and memories of the stories are soaked up into the reading mind. 
Although the narrator does escape from the library at the end of the story, it is not the successful venture it had seemed to be when he, the beautiful girl, and the sheep man were planning their futures. The narrator has apparently lost more than his shoes and his starling in his escape - he has also lost most of his memories of those three nights to the extent that he wonders if his friends really existed. The narrator's question of "How much of what I remember really happened?" leaves the door open for readers to interpret the entire story as "all in his head," but as opposed to the missing memories of the narrator of Ocean, these jumbled memories seem to do more harm than good (The Strange Library 82). Regardless of what really happened, readers are told that the narrator "never visited the city library again," and that "the mere sight of the library building at dusk was enough to stop [him] in [his] tracks" (The Strange Library 82). Readers are not told if his memories of reading, which in the cell were so infallible, had also left him after his escape. At the end of the story, the only memories the narrator is truly able to relive are that of feeling alone in the cell and of the "darkness as pitch black as the night of the new moon" (The Strange Library 84). The corresponding final images of wide, cartoonish eyes on a red background seem whimsical but also suggest that the story/narrator is now looking out to the reader of The Strange Library and his/her reading of the text. The narrator's reading experiences offer no balm or refuge but are instead a source of trauma. Since he never returns to the library, it would seem that the narrator is now no longer a reader at all. It would also seem that the narrator has not actually changed or grown as a result of this harrowing experience, but can only look back with mingled longing (for his friends, for knowledge of the truth) and regret (for being revealed to himself, alone, in the dark). In short, Murakami paints a character who is almost completely without a self to discover, an inner void much like Nakata in Kafka on the Shore who also has no books inside him. Perhaps, as the plot seems to indicate, the narrator does not read 
for pleasure because he has been damaged too far for books to help him as even the metafictional accounts of him reading and enjoying the experience of reading are at last aligned with trauma and damage to the self at the end of the book.

\section{Escaping in Books: Conclusion}

Despite its reputation for encouraging plebian superficiality among readers, reading to escape one's reality is, according to many fantasy authors, more than just an acceptable practice - it is an act necessary for a full and rich life. Neil Gaiman goes so far as to claim that "reading for pleasure, is one of the most important things one can do," adding that "we have an obligation to read for pleasure in private and in public places" where we will be seen by others who may see our reading as an impetus for their own ("Why Our Future" 5, 13). Most fantasy authors also claim that the reader, beyond gaining a momentary reprieve in narrative from the real world, is granted the opportunity to learn, grow, and gain what she needs to better face the struggles once she returns to her reality. Thus, works of fiction-especially works of fantasyshould not be a "total" escape in the sense that a reader's experience in them has nothing whatsoever to do with her life in the "real" world, and to see reading in this way overlooks the fact that the narratives, characters, challenges, and lessons in fiction are derived from someone's experience in the "real" world - that's why they have the power to strike us as so desirable and so meaningful in the first place.

In readers' journeys in fiction, the simplicity of movement and gained sense of progress - a progress which can turn into inertia - may sometimes be the most significant part of the experience. Nothing counters a sense of stagnation quite like experiencing stories that suggest there is always more to learn, always more worlds to experience, and that everything will 
come together in the end. These journeys keep readers moving and show them new worlds they can move to and in; they also teach readers how to see their lives as journeys, but moreover what it takes to be a traveler beyond movement, namely awareness. Gaiman's travel-heavy metaphors in "Make Good Art" reveal the lessons art has taught him which he passes on to his readers: "let go and enjoy the ride, because the ride takes you to some remarkable and unexpected places" (458).

This is not to say the darker side of a reader's need to escape is ignored by these authors. As both Gaiman and Murakami remark in their nonfiction as well as their fiction, many readers come to stories out of a need to escape from a real pain, loss, or loneliness experienced in their lives. As someone who requires solitude despite its pain, Murakami insists that the experience of loneliness and solitude — an experience he seeks out in his running as well as his writing — is necessary for the creation of his fiction. For many readers, this combination of need and fulfillment equally describes what happens during the act of reading: a loneliness, a hurt, even a boredom is healed and put into perspective as the reader gains access to a world removed from her personal hurts despite being derived from the struggles of another. Although reading can take readers to whole worlds populated to an inch by fascinating characters and engaging storylines, to read, a reader much be independent, and to be independent, Murakami asserts, is to be hurt. The best of these narratives will acknowledge the paradox of the reader's strange existence between two worlds, and show the reader something worth finding — perhaps even a new way to understand her life outside the narrative world.

Finally, when a reader opens himself to a narrative that takes him on a journey out of his natural world, he must also anticipate the possibility of an unflattering mirror or a formidable challenge waiting for him in the world of the narrative. Fantasy authors such as Gaiman and 
Murakami allow their readers the escape they desire (a fix, a drug, a high — as some have called it), but they also press for more in their imperative for the reader to undertake an internal, selfreflective journey as well. The potential responses by readers to this imperative range from choosing to go on to read other books that stretch, perplex, and inspire as well as amuse and divert; readers might further seek out similarly moving experiences in art, music, film, and other "non-essential" human creation; but maybe, more immediately, readers will also choose to reconsider the role of stories, metaphors, language, and self-knowledge in their own lives. When this happens, the escape sought by the reader may just be the journey that changes his life since, after all, "“That's how stories happen—with a turning point, an unexpected twist..." (Kafka 157). 


\section{Coda: The future of embodied reading}

Our fledgling twenty-first century has witnessed pronounced changes to what reading looks and feels like for both readers and authors. The rise of e-books and e-readers — Kindles, Nooks, tablets, and smartphones — have shifted the paper pages of a book to a touchscreen, printed ink to layers of written code, and hands holding, thumbing, and turning over pages to the directed point of a single fingertip. Such technological innovations in the production and accessibility of texts have also transformed the language used to talk about acts of reading, with "scroll" transformed from a noun to a verb and "reader" from a person to a machine. As a result of these recent innovations, human readers are exposed to new methods of reading and possible responses to texts, including: algorithmic “distant reading” (foretold in Calvino’s Lotaria), "hyper reading" and the increased cognitive load of electronic reading in comparison to print reading, the web-based and network-inspired genres of Digital Humanities and Electronic Literature, and communal websites dedicated to the sharing and reviewing of texts-many of which exist only as e-books. ${ }^{106}$

The modern e-book and e-reader have altered the multisensory experience of reading in a way similar to the digitalization of other media, such as music and art, which also met early resistance. Over the past few decades, e-reading in general has been largely normalized in Western culture with a percentage of readers even declaring themselves to be entirely print-free. Although many analysts predict that print books will eventually become a niche market as ebooks continue to consume a greater percentage of overall book sales, e-reader users continue to

\footnotetext{
106 See Stephen Ramsay's Reading Machines (2011) and Franco Moretti's Distant Reading (2013) for examples of the controversial turn to computer-based text analysis in literary criticism (paralleling similarities in the literature of Digital Humanities). See N. Katherine Hayles’ How We Think: Digital Media and Contemporary Technogenesis (2012) for comparisons between digital and print media, traditions, and readings.
} 
report both pros and cons in the e-reading experience in comparison to traditional print reading. ${ }^{107,108}$ The convenience of the e-reader has long been their biggest selling point. Users have in one, easy-to-carry device, quick and relatively cheap or free access to more texts than they could read in a lifetime - a feature that is especially useful for travel and transport or for voracious readers with small apartments. Many users report that their e-readers have led to a willingness on their part to purchase e-book versions of "mindless" or déclassé texts for which they would not otherwise have paid "full price" (i.e. print price). The instant gratification, so common to members of the Internet age, is another advantage offered to the owner of an ereader: as opposed to having to wait for a print book's delivery or needing to physically travel to a library or bookstore to acquire a book, e-books are immediately downloadable and accessible. This ease of access along with augmented navigation tools can be a boon for scholarly users of ereaders for checking a quote or locating instances of a particular word or phrase in a text. Ereader users have also reported that when learning a new language, using an e-reader in combination with a print book is a convenient method for easily looking up unknown words, checking translations, and other tedious activities that are accelerated via e-book software and web-searches. But how does this increased accessibility and speed as compared to print books stack up in regards to the physical experience of e-reading?

\footnotetext{
${ }^{107}$ While in 2015, the "Big Five" general trade publishers in the UK reported the first drop in e-book sales, many remain skeptical that this trend will continue and point instead to the overall drop in traditional publishing book sales as the explanation (Tivnan; Ingram). Fortune's Matthew Ingram claims that the increase in Amazon and other self-publishing services has encouraged authors to cut out the middle-man and sell directly to the consumer. Meanwhile, the Codex Group's recent survey has suggested an alternative explanation for the drop in the experience of "digital fatigue" among e-reader users, who make the largest percentage of e-book readers, with $25 \%$ of surveyed book buyers saying they want to spend less time on digital devices (Milliot).

${ }^{108}$ The observations offered in the next few paragraphs largely derive from the useful feedback of my Dissertation Writing Support Group (February 14, 2017).
} 
One of the most common issues reported by users of e-readers is a difficulty in flipping pages and orienting oneself in relative location to the text's beginning and end. This includes a greater difficulty in finding a certain passage especially given that page numbers on many ebooks do not consistently align with the page numbers of their print counterparts or may be nonexistent - replaced with a percentage that informs the reader he is $55 \%$ through a book, with $45 \%$ to go. Other common complaints against the sensory experience of e-reading concern the negative effects of lighted screens on the eyes, a phenomenon that has led to recommendations not to use e-readers or any electronic device before bed so as not to disrupt sleep cycles as well as the new recognition of Computer Vision Syndrome (also known as Digital Eye Strain) by the American Optometric Association and a subsequent industry set on resolving such screen-related issues with special backlighting and even glasses that counteract adverse effects.

Another sensory difference between e-reading and print reading has to do with smell; ereaders do not (or at least, not yet) allow readers to judge a book's age and origin by the smell of its paper, ink, binding materials, and glue. While print books are individual objects with their own histories, outer distinguishing features, weight, and smell, e-books do not alter the physical experience of the reader with the physical device — be it a tablet, smartphone, or laptop-from one text to another. An individual book smell is one sensory dynamic that is completely erased from the e-reader experience of texts along with the presence of the physical thickness and weight of the print book which haptically informs the reader of secondary reading perceptions based on her prior experience with other print books. In beginning a new book, a print reader is able to estimate the length and estimated reading time by the relative number of pages, size of the pages, size of the font, and width of the margins. Once she begins reading, she is able to determine how far in she has read at any given point based on the feel of the edges of the pages 
and by visually perceiving how far through the text she has gone already and how much more of the text remains. The print reader is also easily able to flip back to check a previously-read word or sentence, flip ahead to decide whether or not she wants to read one more chapter that night given its length, see at what point a dreary expository section will end to get to the dialogue, look ahead to pictures to get a clue as to what will happen next (I admit doing this with my Nancy Drew books), and other related activities which provide information about space, time, and experience in print reading. Many of these options are simply not available to readers of e-books or are more cumbersome to achieve and therefore no longer an automatic auxiliary activity to reading. But perhaps the most significant difference between e-reading and print reading has to do with memory and readers' attitudes toward the text.

Particularly for students and scholars, the increased difficulty of physically altering a text via underlining, highlighting, or adding marginalia is a major drawback of the e-reader — tasks that directly relate to memory retention and sophisticated interaction with a text. Many recently released e-reader brands have attempted to make such interactions easier, but users continue to complain that notes are too hard to find once they are written or are difficult to view in concert with the original text being annotated. Worst of all is the accusation that e-reading makes texts harder to remember in general. Some studies have supported feedback regarding e-reading's negative effect on memory retention, paying especial attention to college students' interactions with e-textbooks as opposed to traditional print textbooks. ${ }^{109}$ Some researchers look to the tactile

\footnotetext{
${ }^{109}$ Scientific America's Ferris Jabr provides a succinct overview of research directions pertaining to the study of ereading in "The Reading Brain in the Digital Age: The Science of Paper versus Screens." Regarding students' performance and preferences with e-textbooks, researchers David B. Daniel, William Douglass Woody, and Crystal A. Baker have found that students tend to take significantly longer to read an electronic text as opposed to a print text and that despite greater technological savvy than any previous cohort, students today are not more likely to prefer e-books over print textbooks. Related to the e-textbook vs. print textbook debate, Pam A. Mueller and Daniel M. Oppenheimer found that students who take longhand notes as opposed to typing notes perform better on answering conceptual questions - a finding the authors attribute to the necessity of reframing and processing the information in longhand note-taking as opposed to transcribing lectures verbatim which typing notes facilitates.
} 
disruption in e-reading as the culprit: the device feels the same regardless of what page the reader is on, how far into the text she has gotten, with subtle shifts in weight no longer markers of location and progress. The reliance of medieval mnemonic techniques on the physical appearance of the page - color, font, marginalia, etc.-is suggestive of the likelihood that even when not actively trying to remember a text verbatim, readers routinely use such details to orient themselves much like trail-blazes and landmarks in strange terrain. Other theories as to the negative effects of e-reading on memory look to the phenomenon of hyper reading, a modern manner of reading characterized by multitasking due to interruptions to the text by ads, hyperlinks, and competing texts — all of which add to the reader's cognitive load and prime her to skim through any electronically portrayed text, even ones without those interruptions. A lack of inclination to engage in metacognitive learning regulation (such as setting goals, rereading difficult sections, checking comprehension) and a tendency to take shortcuts when e-reading by scanning and hunting for keywords as opposed to reading every word, suggests that "subconsciously, many people may think of reading on a computer or tablet as a less serious affair than reading on paper" (Jabr). This is likely the reason many users claim to only use their e-readers to read books which they don't particularly care to remember-fluff, popular books to pass the time on the bus to work or while on a vacation, or to skim through a text they will read in greater detail later in print.

By and large, owners of e-readers have individually constructed categories of texts they don't mind reading as e-books and others, particularly texts that require close-reading for study, analysis, and/or memory, that they refuse to read in an electronic format. This combinational use of e-readers alongside traditional print books speaks to the historical period we find ourselves: ereaders are relatively cheap (many now are under \$100), offer a wide variety of free and cheap 
texts (including libraries' e-lending of books), and allow users access to a variety of time-saving tools such as the ability to quickly search a text, look up a word, post a review, and download a sequel or related text. However, print technology continues to offer advantages that electronic technology still cannot, particularly regarding the promotion of an individual and memorable sensory experience related to the book as object, including activities such as: lending or giving a book to a friend; selling or buying a book in used bookstores; using certain books as physical marker of identity, intelligence, and/or sophistication by displaying it prominently in one's home or office; and physically altering a book to make it a personal copy—a possession—with inscriptions, notes, messages to a future self, etc. It is likely that e-reading and print reading will continue to exist side by side for some time with the reader as the primary determiner of what form of reading will work best for encountering which text.

While these changes in the forms and platforms of reading and texts have shaken the contemporary publishing world to its core, from a historical perspective, they are predictable manifestations of the nature of fiction. Fiction never has and never will be stable; its forms and its effects are inherently linked to the information technologies of their time. From oral narrative telling and performances, to scrolls, folios, and quartos, to cheap paperbacks, to the electronic books we know today, the changing forms of texts necessitate a corresponding change in their manner of approach. Thus, the methods, habits, and preferences that make up the literary activities of a contemporary reader must be seen as historically grounded and open to continuous change alongside political, social, and technological trends. What is of equal if not greater significance than the physical $\rightarrow$ digital alterations of textual forms, however, are the profound changes that have reconstructed the landscape of many literary communities, including reader/author relationships. 
Today's reader has options in fostering contact with an author. True, a reader can choose to maintain a distance between herself and the author of a text she has just read, but she may be curious to see what other readers have had to say about the text or about the author's body of work. This would likely take her online. An author or title name search will usually bring up some combination of Amazon shopping pages and author-sourced webpages. Many contemporary authors have personal websites with book lists, biographical information, choice reviews, updates about forthcoming projects, and, depending on how open the author is willing to be, journals, videos, and links to social media pages. All of this means that a notinconsiderable amount of contact between reader and author is available outside of the text as opposed to being predominantly mediated by and within the text. The reader may start here at the author's webpage or social media profile or enter by way of fan sites and reviews to this level of contact with the author. Some authors, such as John Conroe, author of the e-book urban fantasy series, The Demon Accords, regularly update readers via social media on the progress of their writing down to a weekly wordcount. These updates can be peppered with various conversational comments such as TV and film recommendations, interesting news articles, and personal health information - all of which encourage further communication from readers, some of whom maintain the stereotypical "fanboy/girl" stance but many of whom respond to the author as they would a friend. For the reader who chooses the latter, a complex relationship may have the opportunity to unfold in which the support and desires of readers indirectly or directly begin to influence what the author writers. Kevin Hearne, author of The Iron Druid Chronicles which is available in traditional paperback, on Audible, and as e-books, claims that interactions with his readers have had a largely positive effect on his writing, particularly emails that speak to "how much my novels helped readers who were going through a rough time in their life and Atticus \& 
Oberon [characters in his books] cheered them up. Soldiers deployed overseas, for example, who are obviously experiencing horrors and need an escape. And in several cases, episodes of terminal cancer where the son/daughter read my books to their mother/father and eased a very painful time. Those emails mean a lot to me" (Hearne). Of course, relationships between readers and authors are not new-letter-writing especially has a long existence among literary producers and their patrons, but the flurry of immediate, chummy accessibility in a virtual world of authors and readers is quite unique to the twenty-first century.

What do these technological and relational changes mean for the future of embodied reading and understandings of reading? Despite the luddite fears of contemporary technology's erosion of the reading experience as sensory, the embodied metaphors that dictate what reading feels like to readers are recycled in each new literary epoch—not abolished. Fiction overlays human experience of the world with narrative and overlays narrative with human experience embodied by the reader; in this sense, reading already is and always has been a "virtual" experience. One credible prediction for the future of reading comes to us from the earlytwentieth-century theories of Virginia Woolf discussed in Chapter 2. Although her contemporary readers read physical books, most of which were hand-printed by Hogarth Press and illustrated with her sister's distinctive cover designs, Woolf's preferred metaphors of reading closely match those used by authors and readers today as reading is reconfirmed as a site of contact and connection. While Woolf theorized connections between readers that came about through shared embodied acts of reading, her descriptions nevertheless speak to the more literal connections between readers today as mediated through fansites, discussions boards, amateur reviews, and favorited book lists on social media profiles. The sense of "Reading as an Encounter with Sensory Bodies," the embodied metaphor that most informs her view of Reading as Connection, 
persists — even flourishes — in these contemporary acts of reading. For many readers, a digital body, an avatar for the reading self, is sent into direct contact with fellow readers, so that the almost spiritual connections between readers that Woolf writes about occur in a virtual plane of existence. The concept of the posthuman (a reconceiving of human nature in the wake of posthumanist philosophy, machine augmentations, and cyborg theory) speaks to this projection of the self/consciousness into a virtual space, but it is typically coupled with an emphasis on disembodiment in its reformation of subjectivity. Scholars such as N. Katherine Hayles have argued for an "embodied virtuality" in the posthuman in recognition that posthumanity still consists of "embodied creatures living within and through embodied worlds and embodied words," situated in biological structures and behaviors that have developed as a result of a shared evolutionary history (Hayles, How We Became Posthuman 24). I argue a similar position in the context of reading and readers: the cyborg reader of the twenty-first century encounters the sensory bodies of authors and fellow readers in her readings because virtual projections of the self are still grounded in sensory perceptions and behaviors. Readers still haptically encounter their texts even if the haptics have changed from the touch of paper to the touch of a screen. And readers still connect with other readers through a shared experience of embodying narrative through their individual but mutual acts of reading.

The abstract metaphor of Reading as Challenge, discussed in Chapter 3, also survives in a modified state in contemporary acts of reading. Vladimir Nabokov and Ernest Hemingway tested the boundaries between author and reader and challenged readers to spar with them via textual puzzles and confrontational, metafictional narratives in response to critical movements to elevate the reader's experience over authorial intentions. Here in our time, there are new challenges issued, new relationships forged between authors and readers-especially given the narrow line 
between reader/writer roles when anyone can become a self-published writer or even "borrow" an author's characters, worlds, and plots to create and circulate fanfiction. The embodied metaphors employed by Nabokov and Hemingway_-"Reading as Performance," "Reading as Sexual Intercourse," and "Reading as Contact with the Past"-are similarly adapted to the needs of contemporary times as they were to the twentieth century's needs to express new opportunities for intimacies, puzzles, relationships, and memories shared between authors and readers. All three bodily activities have been altered as a result of the abundant accessibility opened up by the internet and complementary technologies that bring the internet into people's lives, minds, and bodies. According to neuroscientists Ogi Ogas and Sai Gaddam, the Internet also makes human activity and desire easier to observe and catalog largely because we feel our online avatars to be anonymous. This sense of freedom through anonymity can accelerate the fractured sense of self - the divergence between our public personas and our private ones; similarly, individual experiences of performance, sex, and memories of the past, can be perceived as separate in the material world as opposed to the virtual world. Performances of unacceptable sexual desires (whether socially unacceptable or unacceptable to one's partner) can be granted free rein, individuals can take on a new self, a new past, in their online personas-all with the anticipation of maintaining control over the disconnect between their "real" selves and their online selves. This means that the contemporary reader is more readily accepting of narrative's imperative to put her "full" self on hold in order to become, first and foremost, a reading self. Metafictional texts about the challenges of reading require a careful compartmentalization of the self in which the reader is simultaneously a passive, immersed reader and a higher-level, analytical reader. Contemporary texts have found new ways to challenge the author/reader/text dynamic by 
expecting this multilevel splintering of readerly desires and habits and then pushing on readerly expectation of disembodiment or fracture.

The abstract metaphor of "Reading as Pursuit," explored in Chapter 4, endures in the digitally-reworked creation of twenty-first century pursuits, such as in J. J. Abrams and Doug Dorst's $S$. in which the reader's continued pursuit of the text's mysteries transition from the physical world of the book to the digital world of fansites, discussion boards, and digital paratexts. Today, the embodied metaphor of "Reading as Journey" utilized by authors to facilitate a sense of "Reading as Pursuit," can speak to traditional journeys as well as digital ones that take the form of clicking through webpages, scrolling through documents, following hyperlinks to supplemental texts, viewing videos, and listening to audio files - all of which are possible without altering one's physical position in relation to one's environment. For contemporary readers, overlap between physical and virtual pursuits are acceptable and even expected. The surprise success of Pokémon GO, which allows players to experience an overlay of the game's virtual world on the physical world, requires bodily movement to advance through digital pursuits and related gameplay. Similarly, the much older phenomenon of Geocaching takes users on pursuits for hidden treasures navigated via the technology of GPS maps and tracker-tags. Such pursuits anticipate the microchip implantation many assume is coming when virtual projections of information, entertainment, and functional applications will be continuously overlaid on the physical world of implanted humans. Such superimposition of digital enhancements on physical journeys suggests that for twenty-first century humanity, information is the new landscape of the world. For readers directed by authors, journeys into this new natural world can be just as threatening as physical journeys in the possibility that they change the mental landscape of the reader forever. 
In Discognition (2015), Steven Shaviro takes as his premise the idea that science fiction provides a unique method for working out the impact of technological innovations on human identity, society, the environment, and consciousness using narrative to create an alternative "what if?" world. Metafictional narratives offer an analogous space for working out the impact of innovations in textual transmission technologies and bodily experiences in the contemporary world on reading and readers: the "what if?" world of potential, metafictional readers that is finally embodied by actual readers. In Chapter 5: Reading as Escape, the worlds that Neil Gaiman and Haruki Murakami's metafictional texts create are shown to be temporary escapes from the real world that also signal the inherent dangers of the reader's continued reliance on them. This motivation for reading has taken hold of the virgin, fertile ground offered by the internet's multifaceted brand of escapism, uniting in the production of further opportunities for post-narrative escapes in the form of fan-worlds. Fanfiction, fanart, cosplay, conventions, interactions with authors, book review sites - these contemporary literary activities open up a new world that transfers the "natural" world of the narrative into digital spaces. The primary sensations are, as expected, facilitated by sight and hearing, and secondary senses are greatly dampened if not ignored outright. But the contemporary expectation of availability and abundance —of information, experiences, sensations, etc.—is especially significant in this transmutation from a physical to a virtual body. While not as immediate as the LAN-speeds of the Internet, an east-coaster no longer has to travel to New Orleans to enjoy authentic jambalaya and live jazz; a literary scholar no longer has to physically gain access to the British Library to study the original images of Beowulf; a hobbyist no longer needs to scour individual stores and warehouses to find the elusive missing piece to his collection. Today's world is one of nearinstant gratification with next-day deliveries and single-day TV season releases that includes an 
availability of novel sensations - if the individual is so inclined. In this immersive, interactive, superimposed virtual world, the warnings of metafiction against obsession and submersion sound themselves otherworldly. But, as I argue, if reading is and always has been a virtual activity, then perhaps readers would be wise to heed fiction's imperatives for balance.

In order to create the experience of reading, narratives allow for readers to access and make use of a variety of sensations and cognitions, combining them into associations that are either encouraged or abandoned, dredging up sensory memories of the reader's past, incorporating the reader's knowledge of her world in the goal of coming to understand or at least fathom a narrative world peopled with narrated bodies and minds. In order to fulfill these obligations, the reader must see narratives as approachable, absorbable, and embodiable — and then act on these invitations to do so. The metaphors that inform a given historical period of what reading feels like, looks like, smells like, tastes like, and sounds like, come and go in ascendency, but they remain the defining methods by which we can best approximate the complex swirl of emotions, sensations, cognitions, memories, and epiphanies that we experience when reading. 


\section{WORKS CITED}

\section{Primary Sources:}

Abrams, J.J. and Doug Dorst. S. New York: Mulholland Books, 2013. Print.

---. “The Story of ' $S$ ': Talking with J. J. Abrams and Doug Dorst.” Interview by Joshua Rothman. The New Yorker. The New Yorker, 23 Nov. 2013. Web. 3 Jan. 2017.

Austen, Jane. Northanger Abbey. 1818. New York: Penguin Classics, 2003. Print.

Bad Robot Productions. “S.earch.” YouTube. YouTube, 16 Dec, 2014. Web. 26 Feb 2017.

---. "Stranger.” YouTube. YouTube, 19 Aug. 2013. Web. 26 Feb. 2017.

Calvino, Italo. “An Interview with Italo Calvino.” Interview by Gregory L. Lucente. Contemporary Literature 26.3 (1985): 245-253. Academic Search Complete. Web. 17 Dec. 2016.

---. If on a winter's night a traveler. Trans. William Weaver. New York: A Harvest Book, 1979. Print.

---. "Why Read the Classics?” Why Read the Classics? Trans. Martin McLaughlin. New York: Mariner Books, 1991. 3-9. Print.

Conroe, John. "The Demon Accords." Facebook. Facebook, Feb. 2010. Web. 24 Feb. 2017.

Danielewski, Mark Z. House of Leaves. New York: Pantheon Books, 2000. Print.

---. Only Revolutions. New York: Pantheon Books, 2006. Print.

Dorst, Doug. “How I Write: Doug Dorst.” Interview by Noah Charney. The Daily Beast. The Daily Beast, 26 Feb, 2014. Web. 3 Jan. 2017.

Ende, Michael. The Neverending Story. 1979. Trans. Ralph Manheim. New York: Penguin Group, 2005. Print.

Eotvoswheel.com. J. W. Dominguez, 2009. Web. 26 Feb. 2017. 
Gaiman, Neil. The Ocean at the End of the Lane. New York: HarperCollins Publishers, 2013. Print.

---. "Make Good Art." The View from the Cheap Seats: Selected Nonfiction. New York: William Morrow, 2016. 451-459. Print.

---. “The Flints of Memory Lane.” Fragile Things. New York: Harper Perennial, 2006. Print.

---. Trigger Warning: Short Fictions and Disturbances. New York: HarperCollins Publishers, 2015. Print.

---. "Why Our Future Depends on Libraries, Reading and Daydreaming: The Reading Agency Lecture, 2013." The View from the Cheap Seats: Selected Nonfiction. New York: William Morrow, 2016. 5-15. Print.

Galaxy Quest. Dir. Dean Parisot. Perf. Tim Allen, Sigourney Weaver, Alan Rickman, Tony Shalhoub, Sam Rockwell, and Daryl Mitchell. DreamWorks Pictures, 1999. Film. Grossman, Lev. Interview by Fassler, Joe. "Confronting Reality by Reading Fantasy.” TheAtlantic.com. The Atlantic, 5 Aug. 2014. Web. 23 Dec. 2015.

---. The Magicians. New York: Plume, 2009. Print.

Hall, Steven. The Raw Shark Texts. New York: Canongate, 2007. Print.

Hearne, Kevin. Online author survey response, May 29, 2016.

Hemingway, Ernest. A Moveable Feast. 1964. New York: Scribner, 2003. Print.

---. “An Africa Story.” The Complete Short Stories of Ernest Hemingway: The Finca Vigía Edition. 1987. New York: Scribner, 2003. 605-650. Print.

---. "Big Two-Hearted River." The Complete Short Stories of Ernest Hemingway: The Finca Vigía Edition. 1987. New York: Scribner, 2003. 161-180. Print.

---. The Garden of Eden. New York: Charles Scribners' Sons, 1986. Print. 
---. The Letters of Ernest Hemingway, Vol. 2, 1923-1925. Eds. Sandra Spanier, Albert J. Defazio III, \& Robert W. Trogdon. New York: Cambridge UP, 2013. Print.

---. The Old Man and the Sea. 1952. New York: Scribner, 1995. Print.

---. "The Strange Country." The Complete Short Stories of Ernest Hemingway: The Finca Vigía Edition. 1987. New York: Scribner, 2003. 605-650. Print.

Jenheyward.tumblr.com. Tumblr, n.d. Web. 26 Feb. 2017.

Lewis, C. S. The Lion, the Witch and the Wardrobe. 1950. New York: HarperCollins, 1994. Print.

McEwan, Ian. Atonement. New York: Anchor Books, 2001. Print.

Movieclips Trailer. “S. Trailer \#1 (2013) - J.J. Abrams 'Mystery' Project HD.” YouTube.

YouTube, 9 Sept. 2013. Web. 26 Feb. 2017.

Mulholland Books. "J.J. Abrams' Next Project, a Novel, to be Published by Mulholland Books." Mulholland Books.com. Mulholland Books, 29 Apr. 2013. Web. 3 Jan. 2017.

---. "Request an S. Reading Group Kit." Mullholland Books.com/s.-bookclub. Mulholland Books, n.d. Web. 3 Jan. 2017.

Murakami, Haruki. Kafka on the Shore. Trans. Philip Gabriel. New York: Vintage International, 2005. Print.

---. "Questions for Murakami about Kafka on the Shore." Harukimurakami.com/resources. Alfred A Knopf, n.d. Web. 30 Jan. 2016.

---. The Strange Library. Trans. Ted Goossen. New York: Alfred A. Knopf, 2014. Print.

---. What I Talk About When I Talk About Running: A Memoir. Trans. Philip Gabriel. New York: Vintage Books, 2008. Print. 
Mystimus. "Eric and Jen Discuss NYC on April 28." Storify.com. Storify, 2014. Web. 26 Feb. 2017.

Nabokov, Vladimir. “Good Readers and Good Writers.” Lectures on Literature. New York: Harcourt Brace Jovanovich, 1980. 1-7. Print.

---. Lolita. 1955. New York: Second Vintage International, 1997. Print.

---. Pale Fire. 1962. New York: Vintage International, 1989. Print.

---. Speak, Memory: An Autobiography Revisited. 1967. New York: Vintage International, 1989. Print.

---. The Original of Laura. Ed. Dmitri Nabokov. New York: Alfred A. Knopf, 2009. Print.

Naylor, Gloria. Mama Day. New York: Vintage Contemporaries, 1988. Print.

Paolini, Christopher. The Inheritance Cycle: Books \#1-\#4. New York: Alfred A. Knopf, 20022011. Print.

Pratchett, Terry. Witches Abroad. London: Corgi Books, 1991. Print.

Rowling, J. K. Harry Potter and the Sorcerer's Stone. New York: Scholastic, Inc., 1997. Print. Scalzi, John. Redshirts. New York: A Tom Doherty Associates Book, 2012. Print.

Shelley, Mary. "Intro to Frankenstein, Third Edition.” 1831. Frankenstein: A Norton Critical Edition. Ed. J. Paul Hunter. New York: W. W. Norton \& Company, Inc., 1996. Print.

Soonyouwillknow.com. n.d. Web. 3 Jan. 2017.

“(S)pecial Delivery.” Sfiles22.blogspot.com. Sfiles22, 22 Apr. 2014. Web. 3 Jan. 2017.

Tolkien, J. R. R. The Two Towers: Being the Second Part of The Lord of the Rings. 1954. $2^{\text {nd }}$ ed. Boston: Houghton Mifflin Co, 1965. Print.

Vigeous. "Does the S. Experience Resolve?” Subreddit: “whoisstraka.” Reddit, 2016. Web. 3 Jan. 2017. 
Ware, Chris. Building Stories. New York: Pantheon, 2012. Print.

Woolf, Virginia. “Anon [and] The Reader.” The Essays of Virginia Woolf. Vol. VI. 1933-1941. London: The Hogarth Press, 2011. Print.

---. Between the Acts. 1941. San Diego: Harcourt, Inc., 1969. Print.

---. “Character in Fiction.” The Essays of Virginia Woolf. Vol. III. 1919-1924. San Diego:

Harcourt Brace Jovanovich, Publishers, 1988. Print.

---. “On Re-reading Novels.” The Essays of Virginia Woolf. Vol. III. 1919-1924. San Diego:

Harcourt Brace Jovanovich, Publishers, 1988. Print.

---. Orlando: A Biography. 1928. Orlando, FL: Harcourt, Inc., 1956. Print.

---. Pointz Hall: The Earlier and Later Typescripts of Between the Acts. Ed. Mitchell A. Leaska. New York: University Publications, 1983. Print.

---. "Reading.” The Essays of Virginia Woolf. Vol. III. 1919-1924. San Diego: Harcourt Brace Jovanovich, Publishers, 1988. Print.

---. A Room of One’s Own. 1929. Mansfield Centre, CT: Martino Publishing, 2012. Print.

---. The Common Reader: First Series. 1925. Orlando, FL: Harcourt, Inc., 1984. Print.

---. The Diary of Virginia Woolf. Vol. III. 1925-1930. San Diego: Harcourt Brace Jovanovich Publishers, 1980. Print.

---. The Second Common Reader. 1932. San Diego, Harcourt, Inc., 1986. Print.

\section{Secondary Sources:}

Alter, Robert. Partial Magic: The Novel as Self-Conscious Genre. Berkeley: U of California P, 1975. Print. 
Altick, Richard D. The English Common Reader: A Social History of the Mass Reading Public, 1800-1900. $2^{\text {nd }}$ ed. Columbus: Ohio State UP, 1957. Print.

Arons, Rachel. "Book News: Reading Fiction May Boost Empathy, and Other Stories from the Week." The New Yorker. Condé Nast, 4 Oct. 2013. Web. 24 Feb. 2017.

Barsalou, Lawrence W. “Grounded Cognition.” Annual Review of Psychology 59 (2008): 617645. GoogleScholar. 14 Mar. 2016.

Barthes, Roland. "The Death of the Author." 1967. 1-6. http://www.tbook.constantvzw.org/wpcontent/death_authorbarthes.pdf. Pdf file.

---. The Pleasure of the Text. Trans. Richard Miller. New York: Hill and Wang, 1975. Print.

Belluck, Pam. "For Better Social Skills, Scientists Recommend a Little Chekhov." The New York Times. The New York Times, 3 Oct. 2013. Web. 24 Feb. 2017.

Bendycki DaSilva, Liz. "Empathy and Fiction Reading... Revisited.” Sociallymindful.com. Socially Mindful, 8 Oct. 2013. Web. 24 Feb. 2017.

Boehm, Beth A. "Fact, Fiction, and Metafiction: Blurred Gen(d)res in 'Orlando' and 'A Room of One's Own."' The Journal of Narrative Technique 22.3 (1992): 191-204. JSTOR. Web. 3 July 2015.

Booth, Wayne C. The Rhetoric of Fiction. $2^{\text {nd }}$ ed. Chicago: U of Chicago P, 1983. Print. Boulenger, Véronique, Alice C. Roy, Yves Paulignan, Viviane Deprez, Marc Jeannerod, and Tatjana A. Nazir. "Cross-talk between Language Processes and Overt Motor Behavior in the First 200 msec of Processing." Journal of Cognitive Neuroscience 18.10 (2006): 1607-1615. Academic Search Complete. 14 Mar. 2016.

Boyd, Brian. Nabokov's Pale Fire: The Magic of Artistic Discovery. Princeton: Princeton UP, 1999. Print. 
---. On the Origin of Stories: Evolution, Cognition, and Fiction. Cambridge, MA: Harvard UP, 2010. Print.

Brennan, Summer. "On the Heartbreaking Difficulty of Getting Rid of Books." Literary Hub. Grove Atlantic and Electronic Literature, 26 Apr. 2016. Web. 24 May 2016.

Briggs, Julia. Virginia Woolf: An Inner Life. Orlando, FL: Harcourt, Inc., 2005. Print.

Brooks, Peter. "Narrative Desire." Narrative Dynamics: Essays on Time, Plot, Closure, and Frames. Ed. Brian Richardson. Columbus: The Ohio State UP, 2002. 130-137. Print.

Bury, Liz. "Reading literary fiction improves empathy, study finds." The Guardian. The Guardian, 8 Oct. 2013. Web, 24 Feb. 2017.

Campbell, Joseph. The Hero with a Thousand Faces. 1949. $3^{\text {rd }}$ ed. Novato, CA: New World Library, 2008. Print.

Carey, John. The Intellectuals and the Masses: Pride and Prejudice Among the Literary Intelligensia, 1880-1939. London: Faber and Faber, 1992. Print.

Carruthers, Mary. The Book of Memory: A Study of Memory in Medieval Culture. $2^{\text {nd }}$ ed. Cambridge, UK: Cambridge UP, 2008. Print.

Chamovitz, Daniel. What A Plant Knows: A Field Guide to the Senses. New York: Scientific American/ Farrar, Straus and Giroux, 2012. Print.

Chemero, Anthony. Radical Embodied Cognitive Science. Cambridge, MA: MIT Press, 2009. Print.

Chiaet, Julianne. "Novel Finding: Reading Literary Fiction Improves Empathy.” Scientific American. Scientific American, 4 Oct. 2013. Web. 24 Feb. 2017.

Classen, Constance. The Deepest Sense: A Cultural History of Touch. Champaign, IL: U of Illinois P, 2012. Print. 
Collier, Patrick. "Virginia Woolf in the Pay of Booksellers: Commerce, Privacy, Professionalism, Orlando." Twentieth Century Literature 48.4 (2002): 363-392. JSTOR. Web. 3 July 2015.

Connelly, Brendon. “The Bad Robot Mystery Trailer Is For S., A New Novel Devised By JJ Abrams, Written By Doug Dorst.” Bleedingcool.com. Bleeding Cool.com, 19, Aug. 2013. Web. 3 Jan. 2017.

Craik, Katarine A. and Tanya Pollard, eds. Shakespearean Sensations: Experiencing Literature in Early Modern England. New York: Cambridge UP, 2013. Print.

Craik, Katarine. A. Reading Sensations in Early Modern England. New York: Palgrave Macmillan, 2007. Print.

Cuddy, Amy. "Your Body Language Shapes Who You Are.” TED.com. TED Conferences, LLC., June 2012. Web. 24 Feb. 2017.

Cuddy-Keane, Melba. Virginia Woolf, the Intellectual, and the Public Sphere. New York: Cambridge UP, 2003. Print.

Daniel, David B. and William Douglas Woody. "E-textbooks at what cost? Performance and use of electronic v. print texts." Computers \& Education 62 (2013): 18-23. Science Direct. Web. 20 Feb. 2017.

Daugherty, Beth. "Face to Face with 'Ourselves' in Virginia Woolf's Between the Acts." Virginia Woolf: Themes and Variations: Selected Papers from the Second Annual Conference on Virginia Woolf. Ed. Vera Neverow. New Haven: Connecticut State U, 1993. Print. 
Djikic, Maja, Keith Oatley and Mihnea C. Moldoveanu. "Reading Other Minds: Effects of Literature on Empathy." Scientific Study of Literature 3.1 (2013): 28-47. Academic Search Complete. 14 Mar. 2016.

Djikic, Maja, Keith Oatley, Sara Soeterman, and Jordan B. Peterson. "On Being Moved by Art: How Reading Fiction Transforms the Self." Creativity Research Journal 21.1 (2009): 2429. Academic Search Complete. 14 Mar. 2016.

Donaldson, Scott. "Introduction: Hemingway and Fame." The Cambridge Companion to Ernest Hemingway. Ed. Scott Donaldson. Cambridge: Cambridge UP, 1996. 128-149. Print.

Doughty, Amie A. "Throw the Book Away": Reading versus Experience in Children's Fantasy. Jefferson, NC: McFarland \& Co, Inc., Publishers, 2013. Print.

Dusinberre, Juliet. Virginia Woolf's Renaissance: Woman reader or common reader?. Iowa City: U of Iowa P, 1997. Print.

Eagleton, Terry. Literary Theory: An Introduction. Minneapolis: U of Minnesota P, 1983. Print. Fauconnier, Gilles and Mark Turner. The Way We Think: Conceptual Blending and the Mind's Hidden Complexities. New York: Basic Books, 2002. Print.

Field, Andrew. Nabokov: His Life in Art. Boston: Little, Brown and Company, 1967. Print. Fleming, Robert E. "Hemingway's Late Fiction: Breaking New Ground.” The Cambridge Companion to Ernest Hemingway. Ed. Scott Donaldson. Cambridge: Cambridge UP, 1996. 128-149. Print.

Garrington, Abbie. Haptic Modernism: Touch and the Tactile in Modernist Writing. Edinburgh: Edinburgh UP, 2015. Print.

Gerrig, Richard J. Experiencing Narrative Worlds: On the Psychological Activities of Reading. New Haven: Yale UP, 1993. Print. 
González, Julio, Alfonso Barros-Loscertales, Friedemann Pulvermüller, Vanessa Meseguer, Ana Sanjuán, Vicente Belloch, and César Ávila. "Reading Cinnamon Activates Olfactory Brain Regions.” NeuroImage 32 (2006): 906-912. Academic Search Complete. 14 Mar. 2016.

Green, Melanie C. and Timothy C. Brock. "The Role of Transportation in the Persuasiveness of Public Narratives.” Journal of Personality and Social Psychology 79.5 (2000): 701-721. Academic Search Complete. 29 Mar. 2016.

Haruki Murakami: In Search of This Elusive Writer. Perf. Alan Yentob. BBC.

Hauk, Olaf, Ingrid Johnsrude, and Friedemann Pulvermüller. "Somatotopic Respresentation of Action Words in Human Motor and Premotor Cortex.” Neuron 41 (2004): 301-307. Academic Search Complete. 14 Mar. 2016.

Hayles, N. Katherine. How We Became Posthuman: Virtual Bodies in Cybernetics, Literature, and Informatics. Chicago: U of Chicago P, 1999. Print.

---. How We Think: Digital Media and Contemporary Technogenesis. Chicago: U of Chicago P, 2012. Print.

Howes, David, ed. Empire of the Senses: The Sensual Culture Reader. New York: Bloomsbury Academic P, 2005. Print.

Hutcheon, Linda. A Poetics of Postmodernism: History, Theory, Fiction. New York: Routledge, 1988. Print.

---. Narcissistic Narrative: The Metafictional Paradox. $2^{\text {nd }}$ Ed. Waterloo, Ontario: Wilfrid Laurier UP, 2013. Print.

---. The Politics of Postmodernism. $2^{\text {nd }}$ ed. New York: Routledge, 1989. Print. 
Ingram, Matthew. "No, e-book sales are not falling, despite what publishers say." Fortune. Time, Inc., 24 Sept. 2015. Web. 20 Feb. 2017.

Iser, Wolfgang. The Implied Reader: Patterns of Communication in Prose Fiction from Bunyan to Beckett. Baltimore: Johns Hopkins UP, 1974. Print.

Itzkoff, David. “J. J. Abrams Collaborating on Novel for Little, Brown.” Artsbeat.blogs.nytimes. The New York Times, 6 Apr. 2011. Web. 3 Jan. 2017.

Jabr, Ferris. "The Reading Brain in the Digital Age: The Screen of Paper versus Screen.” Scientific America. Scientific America, 11 Apr. 2013. Web. 20 Feb. 2017.

Johnson, D. Barton. Worlds in Regression: Some Novels of Vladimir Nabokov. New York: Ardis, 1985. Print.

Jütte, Robert. A History of the Senses: From Antiquity to Cyberspace. Boston: Polity, 2004. Print.

Keen, Suzanne. Empathy and the Novel. New York: Oxford UP, 2007. Print.

Kidd, David Comer, and Emanuele Castano. "Reading Literary Fiction Improves Theory of Mind." Science 342.6156 (2013): 377-80. Academic Search Complete. Web. 29 Mar. 2016.

Kittler, Frederick A. Discourse Networks 1800/1900. 1985. Trans. Michael Metteer. Redwood City, CA: Stanford UP, 1992. Print.

Koutsantoni, Katerina. Virginia Woolf's Common Reader. Burlington, VT: Ashgate Publishing Company, 2009. Print.

Kövecses, Zoltán. Metaphor and Emotion: Language, Culture, and Body in Human Feeling. New York: Cambridge UP, 2003. Print. 
Lacey, Simon, Randall Stilla, and K. Sathian. "Metaphorically Feeling: Comprehending Textual Metaphors Activates Somatosensory Cortex.” Brain \& Language 120 (2012): 416-421. Academic Search Complete. 14 Mar. 2016.

Lakoff, George and Mark Johnson. Metaphors We Live By. Chicago: U of Chicago P, 1980. Print.

Le Guin, Ursula K. From Elfland to Poughkeepsie. 1973. Portland, OR: Pendragon P, 1975. Print.

Lee, Hermione. Virginia Woolf. New York: Vintage Books, 1996. Print.

Leung, A.K., S. Kim, E. Polman, L.S. Ong, L. Qiu, J.A. Goncalo, and J. Sanchez-Burks. "Embodied Metaphors and Creative 'Acts.'" Psychological Science. 23.5 (2012): 502-9. Academic Search Complete. Web. 27 August 2016.

Mar, Raymond A., Keith Oatley, Maja Djikic, and Justin Mullin. "Emotion and Narrative Fiction: Interactive Influences Before, During, and After Reading.” Cognition and Emotion 25.5 (2011): 818-833. Academic Search Complete. 14 Mar. 2016.

Marks, Laura U. The Skin of the Film: Intercultural Cinema, Embodiment, and the Senses. Durham: Duke UP, 2000. Print.

McHale, Brian. Postmodernist Fiction. 1987. New York: Routledge, 2001. Print.

Mellow, James R. Hemingway: A Life without Consequences. Reading, MA: Addison-Wesley Publishing Company, 1992. Print.

Mendelsund, Peter. What We See When We Read: A Phenomenology with Illustrations. New York: Vintage Books, 2014. Print.

"meta-, prefix." OED Online. Oxford University Press, June 2016. Web. 27 August 2016.

"metaphor, n." OED Online. Oxford University Press, June 2016. Web. 27 August 2016. 
Milliot, Jim. “As E-book Sales Decline, Digital Fatigue Grows.” Publishers Weekly. Publishers Weekly, 17 Jun. 2016. Web. 20 Feb. 2017.

Moretti, Franco. Distant Reading. New York: Verso, 2013. Print.

Mueller, Pam A. and Daniel M. Oppenheimer. "The Pen is Mightier Than the Keyboard: Advantages of Longhand Over Laptop Note Taking.” Psychological Science 25.6 (2014): 1159-1168. Google. Web. 20 Feb. 2017.

Myers, David G. Psychology. $7^{\text {th }}$ ed. New York: Worth Publishers, 2004. Print NAEP. “The Nation's Report Card.” The Nation's Report Card. NAEP, 2013. Web. Jan. 7, 2016. Nesmith, Chris L. “'The Law of an Ancient God' and the Editing of Hemingway's The Garden of Eden: The Final Corrected Typescript and Galleys.” The Hemingway Review 20.2 (2001): 16-36. Project MUSE. 20 November 2016.

O’Connell, Mark. “10 Novels to a Better You.” Slate. Slate, 28 Oct. 2013. Web. 24 Feb. 2017. Ogas, Ogi and Sai Gaddam. A Billion Wicked Thoughts: What the Internet Tells Us About Sexual Relationships. New York: Plume, 2012. Print.

Orr, Marilyn. "Beginning in the Middle: The Story of Reading in Calvino's If on winter's night a traveler." Paper on Language and Literature 21.2 (1985): 210-219. Academic Search Complete. Web. 17 Dec. 2016.

Pifer, Ellen. Nabokov and the Novel. Cambridge, MA: Harvard UP, 1980. Print. Pinker, Steven. The Better Angels of Our Nature: Why Violence Has Declined. New York: Penguin, 2011. Print.

Rabinowitz, Peter J. "Truth in Fiction: A Reexamination of Audiences." Critical Inquiry 4.1 (1977): 121-41. JSTOR. Web. 26 Feb. 2017. 
Radway, Janice. Reading the Romance: Women, Patriarchy, and Popular Literature. Chapel Hill: U of North Carolina P, 1984. Print.

Ramsay, Stephen. Reading Machines: Towards an Algorithmic Criticism. Urbana: U of Illinois P, 2011. Print.

Rayner, Keith, Alexander Pollatsek, Jane Ashby, and Charles Clifton, Jr. Psychology of Reading. $2^{\text {nd }}$ ed. New York: Psychology Press/ Taylor \& Francis Group, 2012. Print.

Renaissance Learning. "What Kids Are Reading And the Path to College and Careers." Renaissance Learning. Renaissance Learning, Inc., 2015. Pdf.

Ricoeur, Paul. The Rule of Metaphor: The Creation of Meaning in Language. 1975. New York: Routledge Classics, 2003. Print.

Rose, Jonathan. The Intellectual Life of the British Working Class. New Haven: Yale UP, 2001. Print.

Ross, Lillian. Portrait of Hemingway. New York: Simon and Schuster, 1961. Print.

Salvatori, Mariolina. “Italo Calvino's If on a winter's night a traveler: Writer's Authority, Reader's Autonomy.” Contemporary Literature 27.2 (1986): 182-212. Academic Search Complete. Web. 17 Dec. 2016.

Sanderson, Rena, "Hemingway and Gender History." The Cambridge Companion to Ernest Hemingway. Ed. Scott Donaldson. Cambridge: Cambridge UP, 1996. 170-196. Print. Scafella, Frank. "Clippings from The Garden of Eden.” The Hemingway Review 7.1 (1987): 2029. Academic Search Complete. Web. 27 Feb. 2013.

Scholes, Robert. Fabulation and Metafiction. Urbana: U of Illinois P, 1979. Print. Seals, Marc. "Trauma Theory and Hemingway’s Lost Paris Manuscripts.” The Hemingway Review 2.4 (2005): 62-72. Academic Search Complete. Web. 27 Feb. 2013. 
Shaviro, Steven. Discognition. London: Repeater Books, 2015. Print.

Smith, Mark M. Sensing the Past: Seeing, Hearing, Smelling, Tasting, and Touching in History. Berkeley, CA: U of California P, 2008. Print.

Smith, Zadie. "Rereading Barthes and Nabokov." Changing My Mind: Occasional Essays. New York: Penguin Books, 2009. 42-57. Print.

Sorapure, Madeleine. "Being in the Midst: Italo Calvino's If on a winter's night a traveler." Modern Fiction Studies 31.4 (1985): 702-710. Academic Search Complete. Web. 17 Dec. 2016.

Spanos, William V. "The Detective and the Boundary: Some Notes on the Postmodern Literary Imagination.” Boundary 21.1 (1972): 1147-168. Academic Search Complete. Web. 18 Dec. 2016.

Stegner, Page. Escape into Aesthetics: The Art of Vladimir Nabokov. New York, The Dial P, 1966. Print.

Strecher, Matthew Carl. The Forbidden Worlds of Haruki Murakami. Minneapolis: U of Minnesota P, 2014. Print.

Tivnan, Tom. "E-book sales abate for Big Five.” The Bookseller. Bookseller Media, Ltd., 29 Jan. 2016. Web. 20 Feb. 2017.

Tyson, Lois. "Reader-response criticism." Critical Theory Today. $2^{\text {nd }}$ Ed. New York: Routledge, 2006. Print.

Wasihun, Betiel. “The Name 'Kafka': Evocation and Resistance in Haruki Murakami’s Kafka on the Shore.” MLN 129 (2014): 1199-1216. Academic Search Complete. Web. 31 Jan. 2016. 
Watts, Melissa. "Reinscribing a Dead Author in If on a Winter's Night a Traveler." Modern Fiction Studies 37.4 (1991): 705-716. Academic Search Complete. Web. 17 Dec. 2016.

Whittier-Ferguson, John, “The Burden of Drafts: Woolf’s Revisions of Between the Acts." Text 10 (1997): 297-319. JSTOR. Web. 3 July 2015.

Wierzbicka, Anna. Experience, Evidence, and Sense: The Hidden Cultural Legacy of English. New York: Oxford UP, 2010. Print.

Willingham, Kathy. "Hemingway's The Garden of Eden: Writing with the Body." The Hemingway Review 12.2 (1993): 46-61. Academic Search Complete. Web. 27 Feb. 2013.

Winans, Robert B. "The Growth of a Novel-Reading Public in Late-Eighteenth-Century America." Early American Literature 9.3 (1975): 267-75. JSTOR. Web. 27 Aug 2016.

Winnett, Susan. "Coming Unstrung: Women, Men, Narrative, and Principles of Pleasure.” Narrative Dynamics: Essays on Time, Plot, Closure, and Frames. Ed. Brian Richardson. Columbus: The Ohio State UP, 2002. 138-158. Print.

Withers, Hannah and Lauren Ross. "Young People Are Reading More Than You." McSweeneys.net. McSweeney’s, 8 Feb. 2011. Web. 16 Feb. 2016.

Woody, William Douglas, David B. Daniel, and Crystal A. Baker. "E-books or textbooks: Students prefer textbooks." Computers \& Education 55 (2010): 945-948. Science Direct. Web. 20 Feb. 2017.

Yao, Bo, Pascal Belin, and Christoph Scheepers. "Silent Reading of Direct versus Indirect Speech Activates Voice-selective Areas in the Auditory Cortex." Journal of Cognitive Neuroscience 23.10 (2011): 3146-3152. Academic Search Complete. 14 Mar. 2016. Zarkadakis, George. In Our Own Image: Will Artificial Intelligence Save or Destroy Us? London: Rider/Penguin Random House group, 2015. Print. 
Bailey 312

Zunshine, Lisa. Why We Read Fiction: Theory of Mind and the Novel. Columbus, OH: Ohio State UP, 2006. Print. 


\section{Appendix A: A sampling of contemporary experimental literature's visual aesthetics}

J. J. Abrams and Doug Dorst's S. (2014)
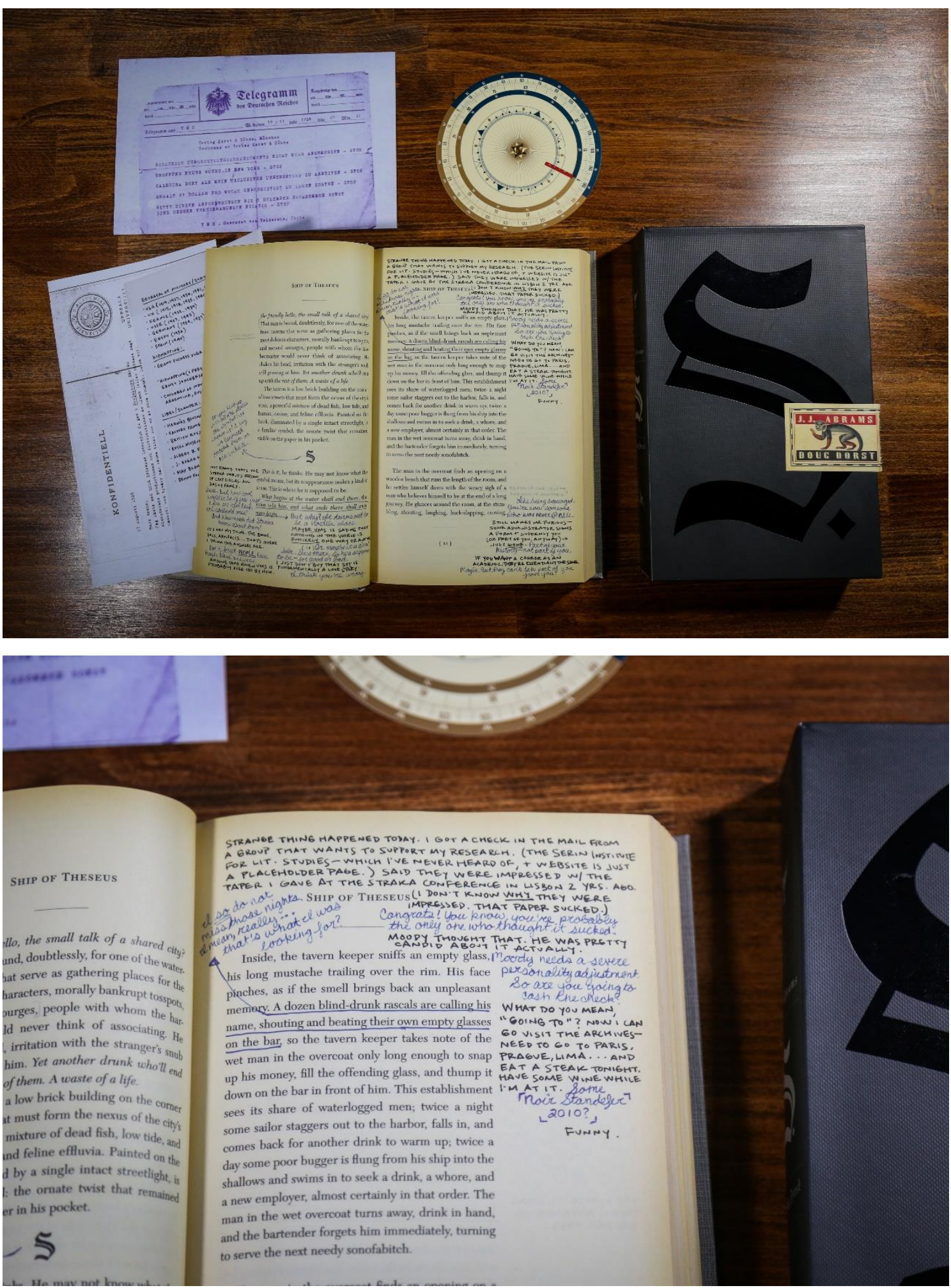
Bailey 314

Chris Ware's Building Stories (2012)
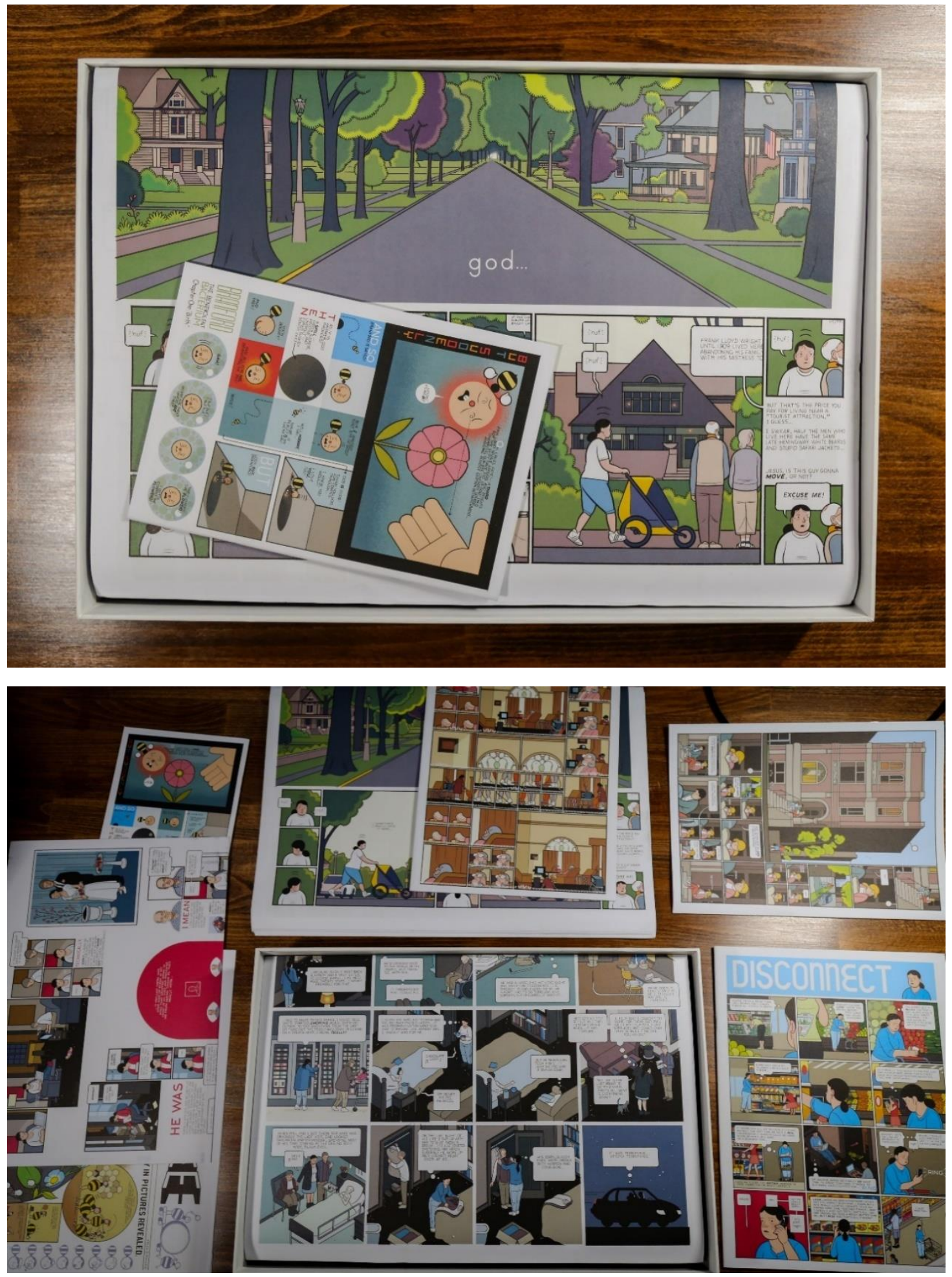
Steven Hall's The Raw Shark Texts (2007)

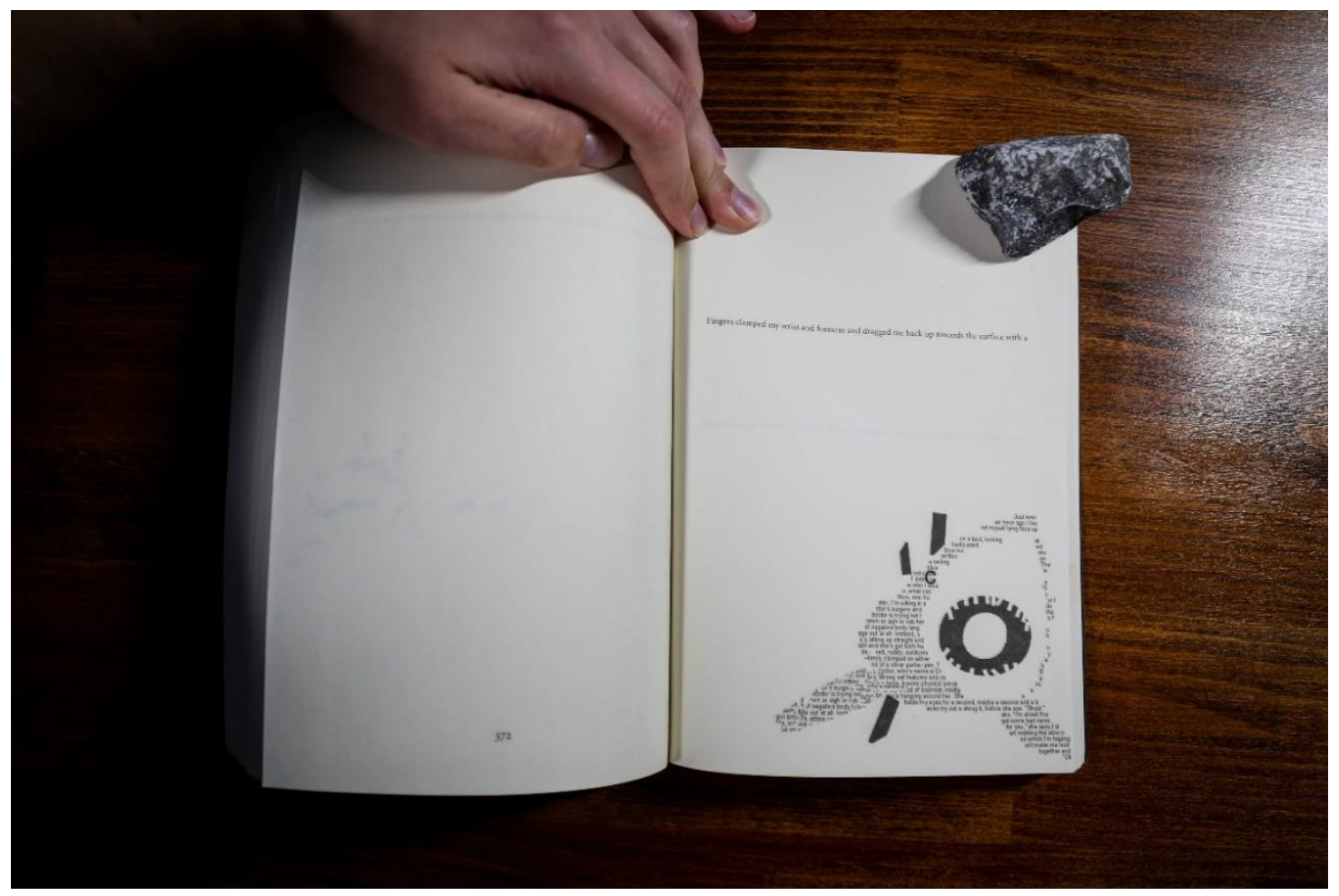

Mark Z. Danielewski’s Only Revolutions (2006)

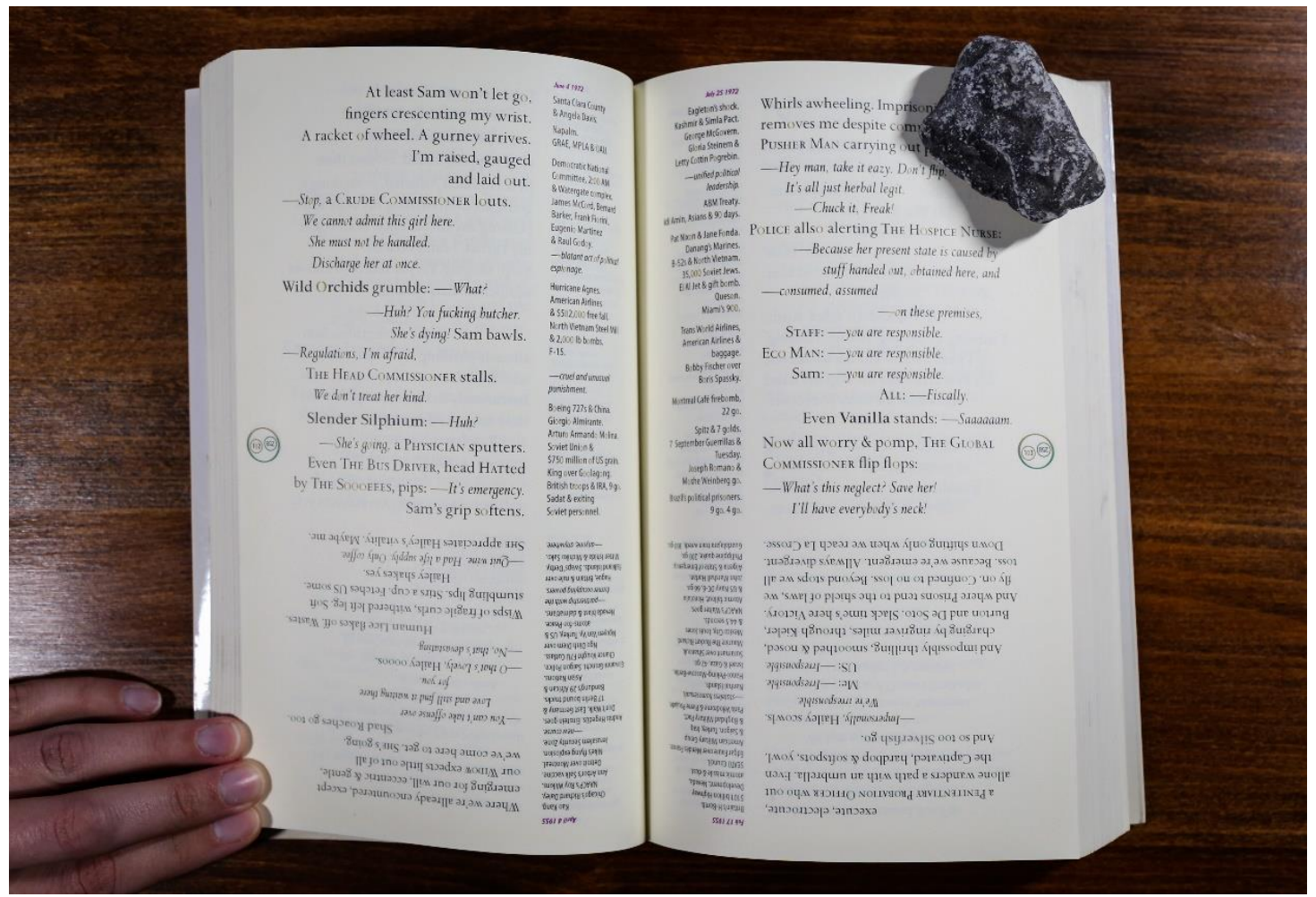

